\author{
Universidade de São Paulo \\ Instituto de Física
}

\title{
Construção e Caracterização de um Laser Contínuo de Titânio-Safira
}

\author{
Flávio Campopiano Dias de Moraes
}

Orientador: Prof. Dr. Paulo A. Nussenzveig

Dissertação de mestrado apresentada ao Instituto de Física para a obtenção do título de Mestre em Ciências

Banca Examinadora:

Prof. Dr. Paulo Alberto Nussenzveig (USP)

Prof. Dr. Adilson Jose da Silva (USP)

Prof. Dr. Reinaldo Luiz Cavasso Filho (UFABC) 



\section{Resumo}

Durante este trabalho construímos e caracterizamos um laser de titânio-safira para ser utilizado em experimentos de ótica quântica e ótica não linear, no Laboratório de Manipulação Coerente de Átomos e Luz (LMCAL).

Constatamos que, operando em 780nm, o laser construído têm eficiência de $51 \%$, atingindo uma potência de saída de $832 \mathrm{~mW}$ para uma potência de bombeio de $5 \mathrm{~W}$, e sua largura de linha é da ordem de $0,6 \mathrm{MHz}$.

Analisamos também o espectro de ruído do laser e concluímos que, para frequências de análise a partir de $10 \mathrm{MHz}$, a luz emitida corresponde a um estado coerente, com ruído quântico muito inferior ao dos lasers de diodo que vêm sendo utilizados no laboratório. 



\section{Abstract}

We built and characterized a titanium-sapphire laser to be used in quantum optics and non linear optics experiments in the Laboratory for Coherent Manipulation of Atoms and Light - LMCAL (Laboratório de Manipulação Coerente de Átomos e Luz).

We verified that the laser has $51 \%$ efficiency when operating at $780 \mathrm{~nm}$, reaching $832 \mathrm{~mW}$ output power for a pump power of $5 \mathrm{~W}$, and its linewidth is approximately $0.6 \mathrm{MHz}$.

We also analyzed the laser noise spectrum and found that, for analysis frequencies above $10 \mathrm{MHz}$, the laser output is in a coherent state, with much lower quantum noise than the diode lasers that have been used in our laboratory. 

Agradeço ao meu orientador, Paulo A. Nussenzveig, e ao professor Marcelo Martinelli, aos colegas de laboratório, Felippe Barbosa, Hans Marin, Antônio Coelho, Paula Meireles, Carlos Gonzalez, Rayssa Bruzaca, Klara Theophilo, Igor Konieczniak, Renato Domeneguetti e Renné Medeiros de Araújo, ao ex-colega Marcio Miranda, ao Luiz, nosso técnico de laboratório, às secretárias Edi e Juliane, à minha namorada Emiliana, aos meus pais Sueli e Didier, ao meu irmão Marcelo e aos meus amigos e familiares. 



\section{Tabela de conteúdos}

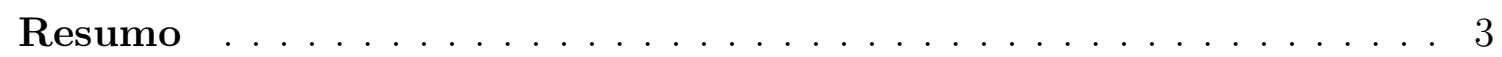

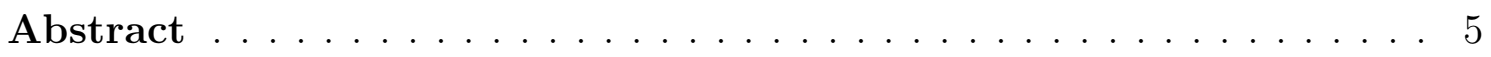

1 Introdução $\ldots \ldots \ldots \ldots \ldots \ldots \ldots \ldots \ldots \ldots \ldots \ldots \ldots \ldots \ldots \ldots$

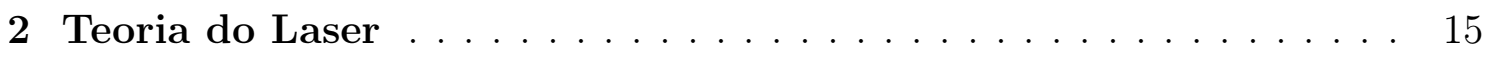

2.1 Emissão de radiação por decaimento estimulado . . . . . . . . . . . 16

2.2 Cavidades óticas . . . . . . . . . . . . . . . . . . . . 16

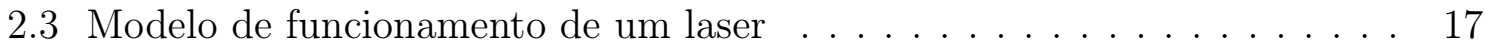

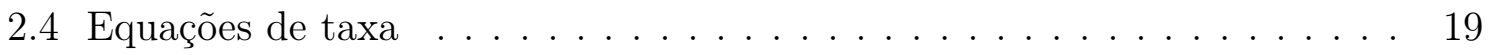

2.5 Laser de 4 níveis . . . . . . . . . . . . . . . . . . . . . 21

2.6 Acoplamento átomo-campo . . . . . . . . . . . . . . . . . . . 24

2.7 Polarização e Susceptibilidade . . . . . . . . . . . . . . . . . . 30

2.8 Colisões e perdas de coerência $\ldots \ldots \ldots \ldots \ldots \ldots \ldots \ldots \ldots$

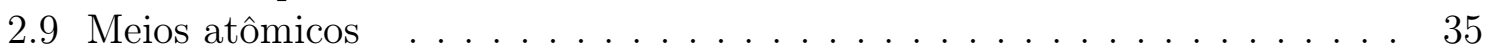

2.10 Laser de Titânio-Safira . . . . . . . . . . . . . . . . . 37

3 Engenharia da Cavidade $\ldots \ldots \ldots \ldots \ldots \ldots \ldots \ldots \ldots$

3.1 Cavidade de Fabry-Perot $\ldots \ldots \ldots \ldots \ldots \ldots \ldots \ldots \ldots$

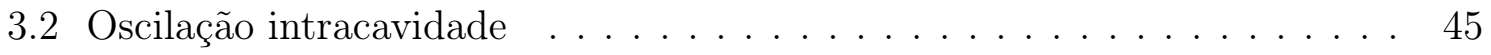

3.2 .1 Limiar de oscilação . . . . . . . . . . . . . . . . . . . 46

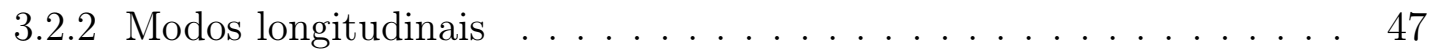

3.3 Propagação do campo intracavidade $\ldots \ldots \ldots \ldots \ldots \ldots \ldots \ldots . . \ldots$

3.3 .1 Onda não plana . . . . . . . . . . . . . . . . . . . 48

3.3 .2 Feixes gaussianos $\ldots \ldots \ldots \ldots \ldots \ldots \ldots \ldots \ldots \ldots$

3.3 .3 Outros modos transversos $\ldots \ldots \ldots \ldots \ldots \ldots \ldots \ldots \ldots$

3.3 .4 Matrizes ABCD . . . . . . . . . . . . . . . . . 54

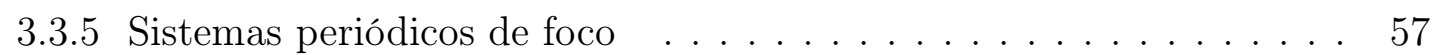

3.4 Cavidade do Titânio Safira $\ldots \ldots \ldots \ldots \ldots \ldots \ldots$

3.4 .1 Astigmatismo da cavidade . . . . . . . . . . . . . 61

3.4.1.1 Astigmatismo provocado pelo cristal em ângulo de Brewster . 61

Plano tangencial: . . . . . . . . . . . . . . . 62

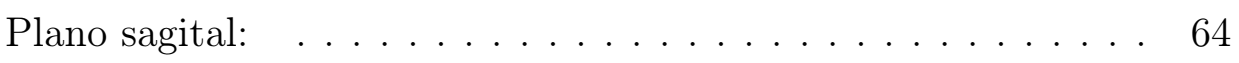

3.4.1.2 Astigmatismo provocado pelo espelho curvo fora do eixo ótico 65

Plano tangencial: . . . . . . . . . . . . . . . . . . 65

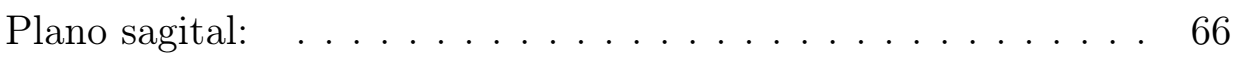

3.4 .2 Geometria e cálculo da cavidade $\ldots \ldots \ldots \ldots \ldots \ldots \ldots$ 
3.5 Birrefringência e Efeito Faraday . . . . . . . . . . . . . . . . 70

3.5.1 Lâminas de onda . . . . . . . . . . . . . . . . . . 73

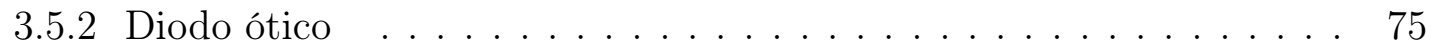

3.5 .3 Isolador ótico . . . . . . . . . . . . . . . . . . 76

3.6 Seleção e travamento de frequência . . . . . . . . . . . . . . 77

3.6 .1 Filtro de Lyot . . . . . . . . . . . . . . . . . 78

3.6 .2 Sistema de travamento do etalon . . . . . . . . . . . . . . . 81

3.6.3 Sistema de travamento da cavidade . . . . . . . . . . . . . . 83

4 Caracterização e Medidas . . . . . . . . . . . . . . . . . 87

4.1 Potência de Saída . . . . . . . . . . . . . . . . . . . . . . . 87

4.2 Perfil transverso do laser . . . . . . . . . . . . . . . . . . . . . . 92

4.3 Estabilidade de Frequência . . . . . . . . . . . . . . . . . . . . . 94

4.3.1 Resposta e limitações do travamento do etalon . . . . . . . . . . . 95

4.3.2 Sinal de Erro do Travamento da Cavidade de Referência . . . . . . . 96

4.3 .3 Espectroscopia de Absorção Saturada . . . . . . . . . . . . . . . . . . . 99

4.4 Flutuação de Frequência . . . . . . . . . . . . . . . . . . . . . . . . . . . 102

4.5 Flutuações de Potência . . . . . . . . . . . . . . . . . . . . . 104

5 Ruídos Quânticos . . . . . . . . . . . . . . . . . . 107

5.1 Estado Coerente . . . . . . . . . . . . . . . . . . . . . 107

5.2 Ruído Quântico de um Laser . . . . . . . . . . . . . . . . . . . . . . . . . . 109

5.3 Excesso de Ruído . . . . . . . . . . . . . . . . . . . . . . . . . . 111

5.4 Estatística de Fótons . . . . . . . . . . . . . . . . . . . . . . . . . 112

5.5 Ruído de Amplitude . . . . . . . . . . . . . . . . . . . . . . . . 113

5.6 Ruído de Fase . . . . . . . . . . . . . . . . . . . . . . . . . 115

5.7 Medidas de Ruído . . . . . . . . . . . . . . . . . . . . . . 118

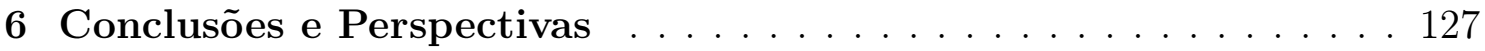

Bibliografia . . . . . . . . . . . . . . . . . . . . . . . 129 


\section{Capítulo 1 Introdução}

Este trabalho faz parte de um conjunto de trabalhos realizados no Laboratório de Manipulação Coerente de Átomos e Luz (LMCAL), que têm como objetivo central o desenvolvimento de conhecimento científico que possa ser aplicado na área de Informação Quântica, seja para armazenamento e manipulação de informação, seja para comunicação.

Atualmente as pesquisas realizadas pelo nosso grupo se dividem em experimentos com átomos (vapor de rubídio) e sobre ótica não linear.

As pesquisas com átomos estão voltadas para o desenvolvimento de memórias quânticas, já que átomos podem armazenar informações quânticas contidas em um campo, por um determinado tempo.

Para essas pesquisas o LMCAL possui uma MOT [1], sigla em inglês para armadilha magneto-ótica, que combina campos magnéticos e lasers com frequência próxima à da ressonância atômica, para desacelerar os átomos de vapor de rubídio dentro de uma câmara de vácuo de baixíssima pressão, até pará-los quase que completamente.

Os átomos aprisionados, por terem baixa velocidade e estarem espacialmente confinados, podem ser mais facilmente manipulados. Eles estão em estados de baixa energia e livres de efeito Doppler, o que simplifica as teorias que descrevem os experimentos nos quais são utilizados, além de estarem sujeitos a poucas perturbações, o que lhes permite armazenar informação por um período maior de tempo.

Para armazenamento e leitura de informações em átomos de uma MOT é possível utilizar um sistema de bombeio e prova, em que um primeiro feixe de um laser (bombeio) atravessa os átomos aprisionados excitando-os. Após algum tempo um segundo feixe (prova) estimula uma transição atômica, emitindo um campo com característica semelhante ao bombeio.

As pesquisas sobre ótica não linear estão voltadas para o estudo de feixes emaranhados em um OPO (oscilador paramétrico ótico) [2], [3], [4], [5], [6], [7], [8], [9].

Um OPO consiste em uma cavidade e um cristal que, ao ser bombeado por um laser, gera dois feixes correlacionados entre si, chamados de feixes gêmeos (sinal e complementar). A correlação entre esses feixes permite comunicação a longa distância, que pode ser aplicada, por exemplo, em criptografia e teletransporte quânticos.

Uma das características do OPO, que é de extrema importância para a ótica quântica, é que, quando bombeado por um feixe em estado coerente, ele é capaz de produzir feixes em estado comprimido.

O estado coerente é um estado de mínima incerteza, ou seja, um estado para o qual o produto entre as incertezas de quadraturas conjugadas (por exemplo amplitude e fase) corresponde ao limite quântico. Além disso, o estado coerente possui incerteza igualmente distribuida nas quadraturas. 
Já o estado comprimido, embora seja também um estado de mínima incerteza, possui incerteza de uma dessas grandezas abaixo do limite quântico, a custo de um excesso de incerteza da grandeza conjugada.

Os feixes em estado comprimido gerados pelo OPO têm uma correlação extremamente forte e por isso são tão importantes para a ótica quântica. No LMCAL, estamos explorando essa correlação com o intuito de comunicar sistemas físicos diferentes.

Contruímos um OPO para o qual mostramos que os feixes de sinal e complementar eram emaranhados não apenas entre si, mas também com o feixe de bombeio [6], [7], ou seja, um emaranhamento tripartite. Estes feixes têm frequências distintas, e pretendemos utilizá-los para comunicar a armadilha de rubídio (780nm) com outro sistema que opere em uma frequência diferente.

Atualmente, estamos construindo um OPO cujo laser utilizado para o bombeio opera em torno de $780 \mathrm{~nm}$. Os feixes de sinal e complementar poderão ser transmitidos, em fibras óticas, com poucas perdas, comunicando os átomos da MOT com outro sistema quântico, o que possibilita a criação de uma rede quântica híbrida.

Para a sincronização entre o OPO e a MOT precisávamos de um laser que operasse em $780 \mathrm{~nm}$ e gerasse um campo em estado coerente, sem excesso de ruído quântico.

O objetivo específico deste trabalho foi o desenvolvimento e a caracterização de um laser contínuo de titânio-safira que atendesse a essas demandas, inspirado no projeto de 2001 da UNICAMP [10]. O laser já está sendo utilizado para bombear o novo OPO.

Como demosntramos, o laser construído gera um campo com ruído de amplitude e fase igual ao shot-noise para frequências de análise superiores a $10 \mathrm{MHz}$. Ele é bombeado por um Verdi-V18 da Coherent e opera entre $730 \mathrm{~nm}$ e $800 \mathrm{~nm}$, podendo ser extendido. Operando em $780 \mathrm{~nm}$, sua eficiência quântica é $\eta_{Q}=51 \%$, sua potência de saída chega a $832 \mathrm{~mW}$ para um bombeio de $5 W$ e sua largura de linha da ordem de $0,6 \mathrm{MHz}$.

Verificamos também que o perfil transverso do laser corresponde a um perfil gaussiano livre de astigmatismo e que ele sofre uma variação média de frequência de $10,35(81) \mathrm{MHz} /$ minuto.

Além das aplicações para a qual foi construído, o titânio-safira abre diversas possibilidades de pesquisa em qualquer laboratório de ótica, pois pode variar sobre uma vasta gama de frequência, sendo muito útil para espectroscopia em infravermelho, e, com algumas alterações, pode operar em modo pulsado, produzindo pulsos ultracurtos e extremamente intensos, com alta taxa de repetição, sendo muito útil para experimentos de ótica não linear.

No segundo capítulo desta monografia exporemos a teoria dos processos relevantes que ocorrem em um laser, partindo da discussão de como um campo perturba um meio material ao se propagar através dele, e discutiremos as consequências dessas perturbações para o próprio campo; em seguida, introduziremos os conceitos de perda e amplificação do campo e finalizaremos com um breve resumo sobre os diferentes tipos de meios de ganho utilizados para a construção de lasers. 
No terceiro capítulo, discutiremos os diferentes tipos de cavidade, a propagação da luz dentro delas e as matrizes ABCD, como ferramenta para calcular o efeito dos elementos óticos paraxiais sobre o caminho percorrido por um feixe. Explicaremos as componentes do laser de titânio-safira e o funcionamento do sistema de estabilização de frequência.

No quarto capítulo, apresentaremos os métodos utilizados para a caracterização do laser e as propriedades clássicas do laser construído.

No quinto capítulo, descreveremos os processos de flutuações quânticas e os métodos utilizados para as medições dos ruídos de amplitude e fase, bem como o espectro de ruído do laser.

No último capítulo, exporemos nossas conclusões e as perspectivas de uso do laser construído. 



\section{Capítulo 2}

\section{Teoria do Laser}

Um laser é um dispositivo de geração ou amplificação de luz, que funciona a partir da combinação de um amplificador (um meio de ganho que, através do processo de emissão estimulada de radiação, emite luz com aproximadamente a mesma frequência, as mesmas direções de propagação e polarização, e em fase com o campo a ser amplificado) e um ressoador (uma cavidade que aprisiona o campo gerado, fazendo com que ele passe mais de uma vez pelo meio de ganho, imprimindo aos fótons, por consequência, uma distribuição estatística bastante particular, que distingue o laser de outras fontes de luz).

Dependendo das características da cavidade e do meio de ganho, um laser pode ser bem definido em frequência (laser monomodo, ou monocromático), ou, no caso de um laser pulsado, bem definido temporalmente. Como a relação entre a precisão em frequência e a precisão no tempo é dada por uma transformada de Fourier, quanto mais curto for o pulso de um laser, mais largo será o seu espectro, enquanto um laser monomodo será necessariamente contínuo.

Lasers pulsados têm a vantagem de produzir um feixe de pulsos que, apesar de terem potência média semelhante à de lasers contínuos, têm potência de pico muito mais alta, e, por isso, podem ser utilizados, por exemplo, para pesquisa em ótica não linear, ou, em indústrias, para ablação.

Um laser pulsado de Ti:Safira extremo pode emitir pulsos da ordem de 50 femtosegundos, com potência de píco de 1 Terawatt e taxa de repetição de 100MHz[11]. Como consequência, a largura de linha desses feixes é da ordem de Gigahertz.

Aplicações que demandam potências extremamente altas requerem pulsos extremamente curtos, e para gerá-los é preciso garantir uma operação simultânea em múltiplos modos longitudinais.

Já para espectroscopia, por exemplo, é desejável um laser que seja o mais monocromático possível, mas que possa ter sua frequência alterada. Entretanto, garantir que um laser capaz de oscilar dentro de um largo espectro de frequências opere em regime monomodo não é algo trivial.

Para aprendermos como controlar as propriedades do feixe de saída de um laser, precisamos, primeiramente, conhecer com detalhes o processo de amplificação da luz.

Começaremos esse capítulo com uma explicação sobre os processos de emissão de radiação e como eles podem ser matematicamente descritos através de equações de taxa. Mais informações a respeito podem ser encontradas com bastante detalhes em livros-textos sobre lasers como [12],[13] e [14] ou de forma sintetizada em [15].

Em seguida, para explicar melhor a dinâmica dos níveis energéticos do meio de ganho, durante o processo de amplificação, apresentaremos um modelo de quatro níveis, que se aplica muito bem para o cristal de titânio-safira. O mesmo modelo está também descrito em [12]. 
$\mathrm{Na}$ continuação explicaremos como se alteram os níveis de energia de um meio atômico, que é polarizado devido às interações com o campo eletromagnético [16], [17], [18], e como, por consequência, o meio polarizado atua na amplificação do campo [12], [19].

Para concluir, apresentaremos alguns dos diferentes meios atômicos utilizados para a construção de diversos tipos de lasers e, em mais detalhe, as propriedades do laser sintonizável de titânio-safira, que podem ser encontradas em [19] ou nos primeiros artigos sobre seus estudos [20], [21], [22], [23] e [24].

\subsection{Emissão de radiação por decaimento estimulado}

A amplificação de um campo em um laser é decorrente da emissão, pelo meio de ganho, de radiação com as mesmas propriedades do campo incidente.

Esse processo ocorre a partir do chamado decaimento estimulado, que é fruto da interação entre o campo eletromagnético e um meio atômico, que será descrita mais adiante.

Por ora, iremos considerar um modelo clássico em que átomos, com níveis de energia definidos e que podem ser excitados ou decair emitindo radiação, se comportam como pequenas antenas oscilantes, onde os núcleos podem oscilar ao redor do centro de uma casca de elétrons.

Um átomo em um estado excitado vibra, em princípio, de maneira aleatória, sem nenhuma relação com outros átomos ao seu redor, e tem uma probabilidade de decair espotaneamente para um estado de menor energia, emitindo radiação com qualquer direção de propagação, polarização e fase. A frequência da radiação emitida está logicamente relacionada com a diferença de energia entre os níveis do átomo, mas pode variar aleatoriamente dentro de uma largura de linha.

No processo de decaimento estimulado, a presença de um campo externo induz os átomos a oscilarem todos em fase e a decaírem emitindo radiação com aproximadamente as mesmas características (inclusive frequência) que ele, somando-se a ele e, portanto, amplificando-o.

Dentro de um laser, os átomos são mantidos no estado excitado por algum mecanismo de bombeio e o ressoador faz com que o campo amplificado passe mais de uma vez pelo meio de ganho, realimentando o processo de emissão estimulada, e fazendo com que cada vez mais átomos oscilem em fase e maior seja o efeito da amplificação, até que se estabeleça um equilíbrio em que o número médio de átomos no estado excitado disponíveis para sofrer decaimento estimulado não se altere.

\subsection{Cavidades óticas}

Cavidade ótica, ou ressoador ótico, é um arranjo de componentes óticos no qual um campo eletromagnético é confinado, circulando em um caminho fechado.

Se esse caminho é tal que a luz, ao ser refletida por um espelho "final", volte exatamente sobreposta por onde veio, a cavidade é dita linear, e nela, devido à superposição da luz se propagando em ambas as direções, há uma interferência que gera uma onda estacionária. 
Já em uma cavidade de onda propagante, na qual a luz percorre um caminho "cíclico", é possível fazer com que as ondas aprisionadas viajem em uma única direção.
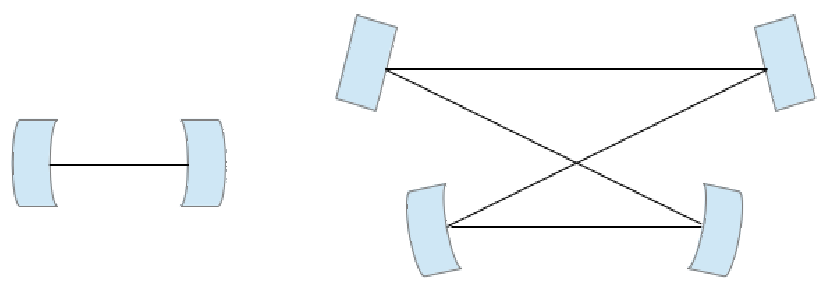

Figura 2.1. Cavidade linear (esquerda), onde a luz é refletida entre dois espelhos no começo e no fim da cavidade, e cavidade de onda propagante (direita), na qual a luz circula sem atingir um fim.

Cavidades ou ressoadores lasers são cavidades que contêm um meio de ganho. Elas são responsáveis não apenas por garantir a realimentação do processo de amplificação, mas também por determinar algumas características do feixe de saída do laser, tais como potência, polarização e frequência.

O campo de saída de um ressoador laser só será intenso se, após uma volta completa na cavidade, ele tiver a mesma fase que no início. Isso porque a variação de fase, a cada volta, faz com que o campo interfira destrutivamente com ele mesmo.

O casamento de fase exige, entretanto, que o comprimento ótico da cavidade seja um múltiplo do comprimento de onda da luz. Dessa forma, o tamanho da cavidade seleciona as frequências dos campos que podem oscilar em seu interior. Os campos que, após uma volta completa na cavidade, permanecem igual ao que eram são chamados de modos do ressoador.

Com a introdução de elementos óticos, além de espelhos, no interior das cavidades, é possível refinar ainda mais o controle sobre as propriedades do campo de saída do laser e, no caso de cavidades de onda propagante, é possível definir também o sentido de propagação do campo, o que nos permite eliminar a criação de ondas estacionárias.

Em ressoadores lasers, ondas estacionárias são normalmente indesejadas, pois dentro do meio de ganho, nos pontos onde o campo é zero, não existe amplificação. Embora isso nem sempre seja um problema, muitos lasers utilizam cavidades de onda propagante. Entretanto, para construir essas cavidades, é necessário que haja reflexão da luz fora do eixo de simetria dos espelhos, o que causa efeitos de astigmatismo.

As cavidades lineares, por estarem normalmente livres de deformações astigmáticas, são mais comuns para a análise do espectro de um feixe.

\subsection{Modelo de funcionamento de um laser}

Para o funcionamento de um laser, são necessários três componentes essenciais: um meio de ganho, um ressoador e um mecanismo de bombeio. 
O meio de ganho é responsável pela amplificação do campo, através do processo de decaimento estimulado, mas para isso é preciso que seus átomos se encontrem em um estado excitado e que exista um campo que estimule o decaimento.

O ressoador é quem realimenta a amplificação e mantém o campo eletromagnético circulando e provocando decaimento estimulado. É claro que, para que exista um feixe de saída do laser, um dos espelhos da cavidade ótica precisa refletir parcialmente o feixe, permitindo que parte dele escape.

O bombeio é responsável pela excitação do meio de ganho. Existem, evidentemente, diversos mecanismos de excitação de um meio de ganho, como a aplicação de correntes elétricas, reações químicas, ou até mesmo a incidência de um outro laser, e a eficiência de cada um desses mecanismos é determinada unicamente pelo meio de ganho em questão.

Com o meio de ganho inserido na cavidade e sendo excitado pelo bombeio, dáse início ao processo de decaimento espontâneo. Em pouco tempo alguns fótons são emitidos em direção aos espelhos da cavidade e são aprisionados, gerando um campo que provoca o decaimento estimulado.

Para que a realimentação seja garantida, é necessário que, após uma volta na cavidade, a perda que o campo sofre seja inferior ao ganho proporcionado pelo meio amplificador. Em perdas estão incluídas a transmissão de luz pelo espelho de saída do ressoador, reflexões indesejadas na superfície dos elementos intracavidades, ou mesmo a absorção de fótons por átomos que estão no estado de menor energia.

Quando é possível atingir uma condição em que a amplificação do campo supera as perdas, a cada volta do campo na cavidade mais átomos emitem radiação por decaimento estimulado e mais fótons se somam ao campo, até que o número de fótons é tanto que o processo de absorção de fótons se iguala ao processo de emissão estimulada, e o laser atinge um equilíbrio em que as perdas igualam os ganhos.

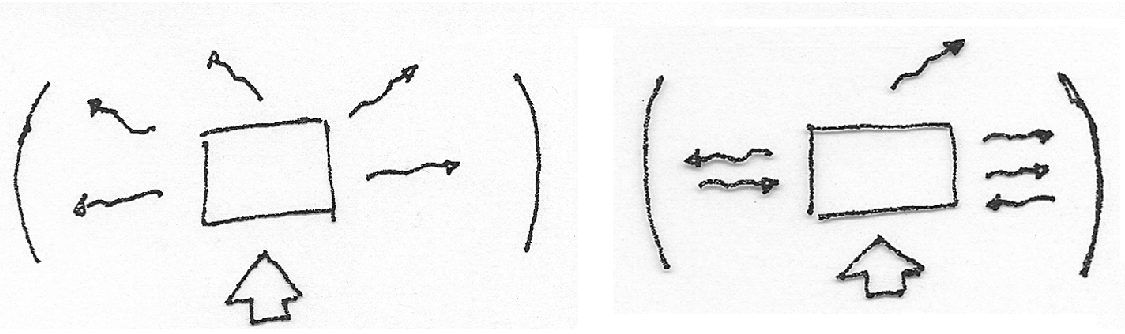

Figura 2.2. Na figura à esquerda, um meio de ganho é excitado por um bombeio e começa a emitir fótons por decaimento espotâneo até que alguns fótons sejam emitidos na direção de aprisionamento da cavidade. Na figura à direita, os fótons aprisionados pela cavidade atravessam o meio de ganho promovendo o decaimento estimulado.

O processo de absorção acontece, como será demonstrado na seção seguinte, com a mesma probabilidade que o decaimento estimulado. Por isso, uma condição necessária para que haja amplificação laser é que existam mais átomos no estado excitado do que no estado fundamental. Caso contrário, haverá mais fótons sendo absorvidos do que sendo emitidos e em poucas voltas o campo será totalmente extinto.

A quantidade de átomos no estado excitado também diminui devido a decaimentos espontâneos e decaimentos não radioativos. 
A dinâmica da população atômica do meio de ganho até atingir o equilíbrio pode ser melhor compreendida através de um tratamento quantitativo. Para isso iremos utilizar equações de taxa que descrevem a variação da população dos átomos em cada estado, em função das taxas de absorção e emissão de fótons, da quantidade de fótons na cavidade e da taxa de bombeio.

\subsection{Equações de taxa}

O sistema atômico mais simples para o qual se podem escrever equações de taxa é um sistema de dois níveis de energia.

Nesse caso, a variação dos átomos no estado excitado, devido apenas ao decaimento espontâneo, é proporcional à quantidade de átomos nesse estado $N_{2}(t)$ e à probabilidade de ocorrer o decaimento espontâneo $\gamma_{\text {esp }}$ :

$$
\left(\frac{\mathrm{d} N_{2}(t)}{\mathrm{dt}}\right)_{\mathrm{esp}}=-N_{2}(t) \gamma_{\text {esp }}
$$

O sinal de menos indica que o número de átomos no estado excitado diminui quando ocorre o decaimento. Já o número de átomos no estado fundamental aumenta na mesma proporção, e, portanto:

$$
\left(\frac{\mathrm{d} N_{2}(t)}{\mathrm{dt}}\right)_{\text {esp }}=-\left(\frac{\mathrm{d} N_{1}(t)}{\mathrm{dt}}\right)_{\mathrm{esp}} .
$$

A variação dos átomos no estado excitado devido ao decaimento estimulado depende, além do número de átomos no estado excitado $N_{2}(t)$ e da probabilidade de ocorrer o decaimento estimulado $K_{21}$, também do número de fótons aprisionados na cavidade $n(t)$. A variação do número de átomos excitados devido à absorção depende probabilidade de excitação $K_{12}$, da quantidade de átomos no estado fundamental $N_{1}(t)$ e também de $n(t)$ :

$$
\left(\frac{\mathrm{d} N_{2}(t)}{\mathrm{dt}}\right)_{\text {est }}=-N_{2}(t) K_{21} n(t)+N_{1}(t) K_{12} n(t)=-\left(\frac{\mathrm{d} N_{1}(t)}{\mathrm{dt}}\right)_{\mathrm{est}} .
$$

Assim, a variação total de átomos no estado excitado pode ser descrita como:

$$
\frac{\mathrm{d} N_{2}(t)}{\mathrm{dt}}=\left(\frac{\mathrm{d} N_{2}(t)}{\mathrm{dt}}\right)_{\text {esp }}+\left(\frac{\mathrm{d} N_{2}(t)}{\mathrm{dt}}\right)_{\text {est }}=-N_{2}(t) \gamma_{\text {esp }}-N_{2}(t) K_{21} n(t)+N_{1}(t) K_{12} n(t)
$$

A cada decaimento, o átomo perde um pacote de energia de $\hbar \omega_{a}$ para o campo, onde $\omega_{a}$ é a frequência de transição atômica. Podemos escrever o fluxo de energia do átomo para o campo como:

$$
\frac{\mathrm{dU} a}{\mathrm{dt}}=A N_{2}(t)+B_{21} N_{2}(t) n(t)-B_{12} N_{1}(t) n(t)=-\hbar w_{a} \frac{\mathrm{d} N_{2}(t)}{\mathrm{dt}},
$$

onde $A=\hbar \omega_{a} \gamma_{\text {esp }}, B_{12}=\hbar \omega_{a} K_{12}$ e $B_{21}=\hbar \omega_{a} K_{21}$.

Essa é uma equação genérica e deve ser válida para qualquer sistema de dois níveis. Em particular, ela deve ser válida para um sistema muito bem conhecido, que é um átomo de dois níveis em equilíbrio térmico, aprisionado em uma cavidade perfeitamente refletora, ainda que este seja um meio ideal. 
O equilíbrio térmico implica que não há troca de energia entre o campo e o meio atômico e, portanto, em média, não há variação da população atômica em cada estado, sendo então $\left\langle\frac{\mathrm{dU_{a }}}{\mathrm{dt}}\right\rangle=0$.

Também ocorre que a distribuição da população atômica em cada estado deve obedecer ao princípio de Boltzmann da termodinâmica, que diz que em equilíbrio térmico:

$$
\frac{N_{2}}{N_{1}}=e^{-\frac{\left(E_{2}-E_{1}\right)}{\mathrm{kT}}}
$$

O confinamento do átomo em uma cavidade ideal de paredes perfeitamente refletoras garante que a quantidade de fótons na cavidade com frequência $\nu$ corresponde à equação de distribuição escrita por Planck para a radiação de corpo negro:

$$
n(t) \rightarrow \rho\left(\nu_{21}\right)=\frac{8 \pi h \nu_{21}^{3}}{c^{3}} \frac{1}{e^{h \nu_{21} / \mathrm{kT}}-1},
$$

pois $\rho(\nu)$ é a densidade de probabilidade de encontrar um fóton com frequência entre $\nu$ e $\nu+d \nu$, e $\nu_{21}=\frac{\omega_{a}}{2 \pi}$ é a frequência dos fótons emitidos após um decaimento atômico do nível excitado para o fundamental.

A equação de fluxo de energia átomo-campo para o sistema confinado na cavidade ideal fica então:

e, portanto,

$$
\left\langle\frac{\mathrm{dU} a}{\mathrm{dt}}\right\rangle=0=A N_{1} e^{-\frac{h \nu_{21}}{\mathrm{kT}}}+n(t) N_{1}\left(B_{21} e^{-\frac{h \nu_{21}}{\mathrm{kT}}}-B_{12}\right)
$$

$$
n(t)=\frac{A}{B_{12} e^{-\frac{h \nu_{21}}{\mathrm{kT}}}-B_{21}},
$$

que, comparada com a equação de radiação de corpo negro, revela que $B_{12}=B_{21}=B$ e

$$
\frac{A}{B}=\frac{8 \pi h \nu_{21}^{3}}{c^{3}}
$$

Esse tratamento fenomenológico para os processos de emissão e absorção de radiação foi proposto por Einstein em 1916[25] e por isso os coeficientes A e B são conhecidos como coeficientes de Einstein.

A proposta de Einstein nos diz que, ao acoplar um campo com um meio atômico, os átomos irão absorver ou emitir fótons por decaimento estimulado, com a mesma probabilidade, o que nos impõe a necessidade de inversão de população para funcionamento do laser.

Matematicamente, a necessidade da inversão de população pode ser simplesmente demonstrada pelas equações de taxa, em um regime em que o número de fótons na cavidade é intenso o bastante para que o decaimento espontâneo possa ser desprezado. Nesse regime a variação de energia do campo é igual apenas à energia dos fótons emitidos pelo decaimento estimulado, menos a energia dos fótons absorvidos:

$$
\frac{\mathrm{d} \mathrm{U}_{c}}{\mathrm{dt}}=\hbar \omega N_{2} K n(t)-\hbar \omega N_{1} K n(t)=K\left(N_{2}-N_{1}\right) \hbar \omega n(t)
$$


onde $K=K_{12}=K 21$. Mas $\hbar \omega n(t)$ é justamente a energia do campo oscilante na cavidade. Assim:

$$
\frac{\mathrm{d} \mathrm{U}_{c}}{\mathrm{dt}}=K\left(N_{2}-N_{1}\right) U_{c}
$$

Se $N_{2}>N_{1}$, a variação de $U_{c}$ é positiva, o que significa que o campo é amplificado; se $N_{2}<N_{1}$ a variação de $U_{c}$ é negativa, indicando que o campo é absorvido.

Em equilíbrio térmico o princípio de Boltzmann da termodinâmica diz que

$$
\frac{N_{2}}{N_{1}}=e^{-\frac{\left(E_{2}-E_{1}\right)}{k T}},
$$

e, portanto, $N_{2}$ é menor do que $N_{1}$.

Mesmo fora do equilíbrio térmico, para um sistema de dois níveis, nenhum sistema de bombeio que possa provocar decaimento estimulado com a mesma probabilidade que a excitação dos átomos irá inverter a população, e, portanto, fazse necessário trabalhar com sistemas mais complexos, de três ou quatro níveis, pelo menos.

\subsection{Laser de 4 níveis}

Existem diversas configurações atômicas diferentes para sistemas de $\mathrm{n}$ níveis, com $n>2$, que permitem que haja a inversão de população necessária para a construção de um laser.

O sistema apresentado nessa seção é um sistema de interesse particular por ser uma boa descrição do laser de titânio-safira, como será explicitado mais adiante.

O sistema consiste em um átomo de quatro níveis, no qual o campo oscilante é sintonizado com a diferença de energia entre os níveis $|3\rangle$ e $|2\rangle$, e que é bombeado por um outro laser, como mostra a figura a seguir:

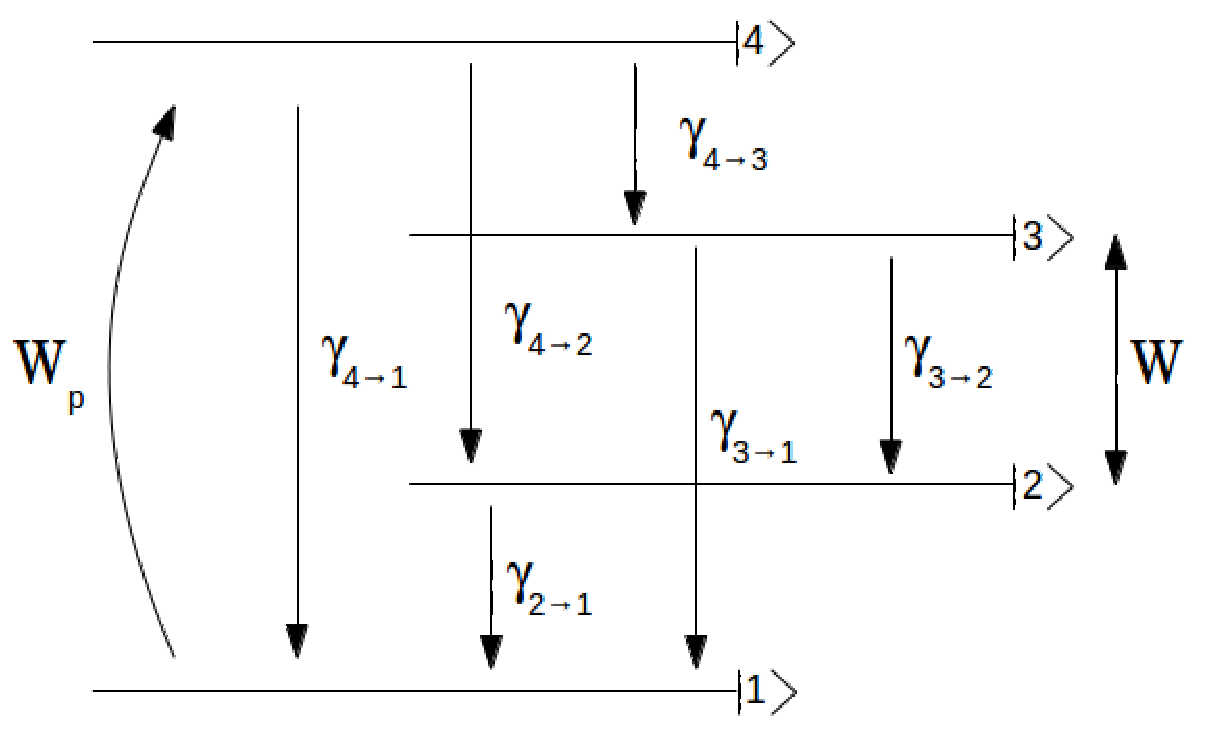

Figura 2.3. Esquema energético de um sistema de 4 níveis com acoplamento do nível 3 para o 2 e bombeio do nível 1 para o 4. 
$W_{p}=K_{14} n_{p}$ é a taxa de bombeamento ou decaimento estimulado entre os níveis $|1\rangle$ e $|4\rangle$, que depende tanto da probabilidade de absorção ou emissão estimulada de um fóton entre esses níveis como do número de fótons do feixe de bombeio $n_{p}$; $W=K_{32} n(t)$ é a potência do feixe produzido por decaimento estimulado entre os níveis $|3\rangle$ e $|2\rangle$, que depende da probabilidade de absorção ou emissão estimulada entre esses estados e da quantidade de fótons aprisionados na cavidade $n(t)$; e $\gamma_{m \rightarrow n}$ é a probabilidade do átomo decair espontaneamente de um estado $|m\rangle$ para um estado $|n\rangle$.

Para esse sistema, a população do estado $|4\rangle$ varia devido ao bombeio, que tanto excita átomos no estado $|1\rangle$ como provoca o decaimento estimulado para este estado, e ao decaimento espontâneo para todos os estados:

$$
\frac{d N_{4}(t)}{\mathrm{dt}}=W_{p}\left(N_{1}(t)-N_{4}(t)\right)-\gamma_{4} N_{4}(t)
$$

onde $\gamma_{4}=\gamma_{4 \rightarrow 1}+\gamma_{4 \rightarrow 2}+\gamma_{4 \rightarrow 3}$.

As equações de taxa dos outros estados são escritas seguindo a mesma lógica:

$$
\begin{gathered}
\frac{d N_{3}(t)}{\mathrm{dt}}=\gamma_{4 \rightarrow 3} N_{4}(t)-\gamma_{3} N_{3}(t)-W\left(N_{3}(t)-N_{2}(t)\right) \\
\frac{d N_{2}(t)}{\mathrm{dt}}=\gamma_{4 \rightarrow 2} N_{4}(t)+\gamma_{3 \rightarrow 2} N_{3}(t)-\gamma_{2 \rightarrow 1} N_{2}(t)+W\left(N_{3}(t)-N_{2}(t)\right)
\end{gathered}
$$

É desnecessário escrever a equação para a variação da população no estado $|1\rangle$ pois toda a informação do sistema já está contida nas outras equações já que:

$$
N_{1}(t)+N_{2}(t)+N_{3}(t)+N_{4}(t)=\text { cte }
$$

e, portanto:

$$
\frac{d N_{1}(t)}{\mathrm{dt}}=-\left(\frac{d N_{2}(t)}{\mathrm{dt}}+\frac{d N_{3}(t)}{\mathrm{dt}}+\frac{d N_{4}(t)}{\mathrm{dt}}\right)
$$

Nesse sistema a inversão de população desejada deve ocorrer entre os níveis $|3\rangle$ e $|2\rangle$ e, para que isso ocorra, é necessário, embora não suficiente, que o tempo de decaimento espontâneo do estado $|4\rangle$ para o estado $|3\rangle$ seja muito curto comparado ao tempo de decaimento espontâneo para os outros estados. O que significa que $\gamma_{4 \rightarrow 3} \gg \gamma_{4 \rightarrow 2}, \gamma_{4 \rightarrow 1}$ e consequentemente $\gamma_{4} \approx \gamma_{4 \rightarrow 3}$.

Quanto maior a taxa de decaimento $\gamma_{4 \rightarrow 3}$, mais rápido o estado $|3\rangle$ será populado, esvaziando o estado $|4\rangle$ e reduzindo o decaimento estimulado produzido pelo bombeio. Por esse motivo, um sistema eficiente para um laser funciona como se os átomos do estado $|1\rangle$ fossem diretamente bombeados para o estado $|3\rangle$, por uma taxa de bombeio $R_{p}$, sem estarem sujeitos a um decaimento estimulado no sentido contrário; e o sistema de quatro níveis pode ser reduzido a um sistema de apenas três níveis. 


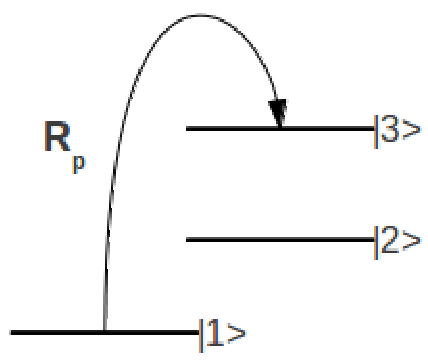

Figura 2.4. Simplificação do sistema de 4 níveis por um sistema de 3 níveis com uma taxa de bombeamento direto $R_{p}$.

Supondo $N_{4} \ll N_{1}$, em um regime de equilíbrio onde $\frac{d N_{i}(t)}{\mathrm{dt}}=0$, a equação $(2.1)$ nos dá:

$$
W_{p} N_{1}=\gamma_{4} N_{4}=R_{p}
$$

Assim, podemos reescrever as equações de taxa do sistema de quatro níveis para o sistema simplificado:

$$
\begin{gathered}
\frac{d N_{3}(t)}{\mathrm{dt}}=R_{p}-\gamma_{3} N_{3}-W\left(N_{3}(t)-N_{2}(t)\right) \\
\frac{d N_{2}(t)}{\mathrm{dt}}=\gamma_{3 \rightarrow 2} N_{3}(t)-\gamma_{2} N_{2}(t)+W\left(N_{3}(t)-N_{2}(t)\right) .
\end{gathered}
$$

No regime de equilíbrio, podemos calcular a diferença de população entre os estados $|3\rangle$ e $|2\rangle, \Delta N=N_{3}-N_{2}$, em função da taxa de bombeamento:

$$
\Delta N=\frac{1}{1+W\left(\frac{\gamma_{2}+\gamma_{3 \rightarrow 1}}{\gamma_{3} \gamma_{2}}\right)} \frac{\gamma_{2}-\gamma_{3 \rightarrow 2}}{\gamma_{3} \gamma_{2}} R_{p}
$$

que pode ser convenientemente reescrita como

$$
\Delta N=\frac{\Delta N_{0}}{1+\frac{W}{W_{\mathrm{sat}}}}=\frac{\Delta N_{0}}{1+\frac{I}{I_{\mathrm{sat}}}},
$$

onde $\Delta N_{0}=\frac{\gamma_{2}-\gamma_{3 \rightarrow 2}}{\gamma_{3} \gamma_{2}} R_{p}$ é a diferença de população não saturada, ou seja, a inversão de população quando não há fótons oscilando na cavidade; e a potência de saturação $W_{\text {sat }}$, que é o valor de $W$ para o qual $\Delta N$ cai pela metade, vale

$$
W_{\text {sat }}=\frac{\gamma_{3} \gamma_{2}}{\gamma_{2}+\gamma_{3 \rightarrow 1}}
$$

A equação (2.4) revela que a inversão de população para o sistema é possível, com a condição de que a taxa de decaimento do estado $|3\rangle$ para o estado $|2\rangle$ seja menor do que a taxa de decaimento do estado $|2\rangle$ para o estado $|1\rangle$, pois assim os átomos que decaem do estado $|2\rangle$ podem ser rapidamente rebombeados para o estado $|3\rangle$.

No caso em que não existem fótons na cavidade, $n=0, W=0, N_{3} \approx 0$ e a diferença de população não saturada $\Delta N_{0}$ é igual à diferença de população $\Delta N$ e vale:

$$
\Delta N_{0}=\frac{R_{p}}{\gamma_{3}}
$$


É importante chamar a atenção também para o fato de que a taxa de bombeio não pode ser aumentada indefinidamente pelo aumento da potência de bombeio. Para uma potência de bombeio bastante elevada a taxa de bombeio deixa de ser desprezível com relação à taxa de decaimento $\gamma_{4 \rightarrow 3}$ e a diferença entre o número de átomos nos estados $|1\rangle$ e $|4\rangle$ diminui, de forma que a taxa de bombeio passa a ser escrita como $R_{p}=W_{p}\left(N_{1}-N_{4}\right)$, que atinge um equilíbrio.

\subsection{Acoplamento átomo-campo}

As equações de taxa nos permitiram calcular a inversão de população em função da taxa de bombeio e a potência para a qual o laser satura. Entretanto, essas informações não são suficientes para determinarmos a amplificação do campo ao atravessar um meio de ganho. Para que possamos fazer isso, precisamos de um modelo mais sofisticado, que explique o que acontece com o meio atômico, na presença de um campo eletromagnético, que faz com que ele emita luz em coerência com o campo.

Trataremos o problema de interação entre o átomo e o campo através de um método perturbativo no qual a hamiltoniana do sistema é descrita como a soma de uma hamiltoniana para o átomo, uma para o campo e um termo de interação entre o átomo e o campo

$$
\mathcal{H}=H_{a}+I_{\mathrm{al}}+H_{c}
$$

onde $H_{a}$ é a hamiltoniana para o átomo livre de campo, independente do tempo, cujos autovalores são $E_{j}=\hbar \omega_{j}, H_{c}$ é a hamiltoniana para o campo e $I_{\text {al }}$ é o termo de interação entre o átomo e o campo.

Esse tratamento semiclássico, porém, não é capaz de explicar o decaimento espontâneo, que não é intrínseco ao átomo, mas resultado da interação entre o átomo e as flutuações de campo do vácuo, como proposto pela teoria de WignerWeisskopf, e exige um tratamento quântico para os campos do vácuo, que pode ser encontrado em [16] ou em livros de mecânica quântica, como [26].

Para o sistema no qual estamos interessados é suficiente conhecer o resultado para a taxa de decaimento espontâneo

$$
\gamma=\frac{\omega_{a}^{3} \mu^{2}}{3 \pi \epsilon_{0} \hbar c^{3}}
$$

onde $\mu$ e $\epsilon_{0}$ são, respectivamente, o momento de dipolo e a permissividade do vácuo, que pode ser introduzida ad hoc ao tratamento semiclássico ao fazermos

$$
\left(\frac{\mathrm{d}}{\mathrm{dt}} C_{2}(t)\right)_{\mathrm{esp}}=-\frac{\gamma}{2} C_{2}(t)
$$

onde $\left|C_{2}(t)\right|^{2}$ é a densidade de probabilidade de encontrarmos o átomo no estado excitado, num determinado instante $t$.

Outra consideração que iremos fazer é que a interação entre o átomo e o campo eletromagnético, relevante para a amplificação do campo, só ocorre entre dois níveis específicos do sistema (no caso do sistema de quatro níveis descrito na seção anterior, ela ocorre entre os níveis 2 e 3). Por isso não há a necessidade de trabalharmos com sistemas mais complexos do que um átomo de dois estados: excitado e fundamental. 
Voltando para o tratamento semiclássico, na presença de um potencial vetor $\vec{A}(\vec{r}, t)$, podemos obter o termo de interação entre o átomo e o campo pela simples substituição do momento pelo momento canônico

$$
\vec{p} \rightarrow \vec{p}-\frac{e}{c} \vec{A}(\vec{r}, t)
$$

onde e é a carga do elétron, $c$ é a velocidade da luz, na hamiltoniana total do sistema

$$
\mathcal{H}(t)=\frac{1}{2 m} p^{2}=H_{a}+I_{\mathrm{al}}+H_{c}
$$

Considerando o calibre de Coulomb, teremos $\vec{\nabla} \cdot \vec{A}=0$, e, portanto, $(\vec{p} \cdot \vec{A}) \psi=$ $\left(\left(\frac{\hbar}{i} \vec{\nabla}\right) \cdot \vec{A}\right) \psi=(\vec{A} \cdot \vec{p}) \psi$. Se assumirmos que não existem cargas livres, o campo eletromagnético é derivado do vetor potencial pela relação $\overrightarrow{\mathcal{E}}=-\frac{1}{c} \frac{\partial \vec{A}}{\partial t}$, o que nos permite escrever o vetor potencial para uma onda eletromagnética plana se propagando na direção $\vec{k}$ como sendo simplesmente

$$
\vec{A}(\vec{r}, t)=\left(A_{o} e^{i(\vec{k} \cdot \vec{r}-\omega t)}+A_{0}^{*} e^{-i(\vec{k} \cdot \vec{r}-\omega t)}\right) \hat{\epsilon},
$$

onde $\omega$ é a frequência de oscilação do campo e $\hat{\epsilon}$ a sua direção da polarização.

A exponencial $e^{i \vec{k} \cdot \vec{r}}$ pode ser expandida em Taylor e, considerando que o átomo é muito menor do que o comprimento de onda da luz, $\vec{k} \cdot \vec{r} \ll 1$, pode ser truncada no primeiro termo, nos levando à aproximação de dipolo elétrico:

$$
\vec{A}(\vec{r}, t) \approx\left(A_{o} e^{-i \omega t}+A_{0}^{*} e^{i \omega t}\right) \hat{\epsilon}
$$

O termo com $\vec{A}^{2}(\vec{r}, t)$ está relacionado com $H_{\mathrm{cv}}$ e é transparente aos autoestados do átomo, de forma que o único termo responsável pela interação átomo-campo é

$$
I_{\mathrm{ac}}=-\frac{e}{\mathrm{mc}} \vec{p} \cdot \vec{A}(\vec{r}, t)
$$

O momento $\vec{p}$ pode ser escrito como $\vec{p}=i \hbar \vec{\nabla}=m \frac{d \vec{r}}{d t}$, sendo que $\frac{d \vec{r}}{d t}=\frac{\partial \vec{r}}{\partial t}-\frac{i}{\hbar}[H$, $\vec{r}]=-\frac{i}{\hbar}[H, \vec{r}]$. Assim chegamos à equação para a hamiltoniana de interação:

que tem valor médio

$$
I_{\mathrm{ac}}=\frac{e}{c} \frac{i}{\hbar}\left(A_{o} e^{-i \omega t}+A_{0}^{*} e^{i \omega t}\right) \hat{\epsilon} \cdot[H, \vec{r}]
$$

$$
\begin{gathered}
\left\langle I_{\mathrm{ac}}\right\rangle=\frac{e}{c} \frac{i}{\hbar}\left(A_{o} e^{-i \omega t}+A_{0}^{*} e^{i \omega t}\right) \hat{\epsilon} \cdot\left\langle\varphi_{j}|H \vec{r}-\vec{r} H| \varphi_{k}\right\rangle= \\
=\frac{e}{c} \frac{i}{\hbar}\left(A_{o} e^{-i \omega t}+A_{0}^{*} e^{i \omega t}\right)\left(E_{k}-E_{j}\right) \hat{\epsilon} \cdot\left\langle\varphi_{j}|\vec{r}| \varphi_{k}\right\rangle= \\
=i \frac{1}{c}\left(A_{o} e^{-i \omega t}+A_{0}^{*} e^{i \omega t}\right)\left(\omega_{k}-\omega_{j}\right) \hat{\epsilon} \cdot \overrightarrow{\mu_{j k}}
\end{gathered}
$$


onde $\overrightarrow{\mu_{j k}}=e\left\langle\varphi_{j}|\vec{r}| \varphi_{k}\right\rangle$ é o momento de dipolo.

Podemos reescrever a equação em função do campo elétromagnético, uma vez que

$$
\overrightarrow{\mathcal{E}}=-\frac{1}{c} \frac{\partial \vec{A}}{\partial t}=i \frac{\omega}{c}\left(A_{o} e^{-i \omega t}-A_{0}^{*} e^{i \omega t}\right) \hat{\epsilon}=\left(\mathcal{E}_{o} e^{-i \omega t}+\mathcal{E}_{o}^{*} e^{i \omega t}\right) \hat{\epsilon}
$$

e, consequentemente, $i \frac{1}{c}\left(A_{o} e^{-i \omega t}+A_{0}^{*} e^{i \omega t}\right)=\frac{1}{\omega}\left(\mathcal{E}_{o} e^{-i \omega t}-\mathcal{E}_{o}^{*} e^{i \omega t}\right) \equiv \frac{1}{\omega} E_{0} \cos (\omega t)$

Assim sendo:

$$
\left\langle I_{\mathrm{ac}}\right\rangle=\frac{1}{\omega} E_{o} \cos (\omega t)\left(\omega_{k}-\omega_{j}\right) \mu_{j k} \cos \theta,
$$

onde $\theta$ é o ângulo entre a polarização do campo e o vetor momento de dipolo. Como o átomo deverá ser polarizado no sentido de polarização do campo, iremos desprezar o fator $\cos \theta$

Como $\vec{r}$ é uma função de simetria ímpar, o momento de dipolo só existe para estados atômicos sem simetria definida. Isso faz com que a hamiltoniana de interação átomo-campo seja antidiagonal:

$$
I_{\mathrm{al}} \approx E_{o} \cos (\omega t)\left(\begin{array}{cc}
0 & \mu_{12} \\
\mu_{21} & 0
\end{array}\right) \equiv \hbar \cos (\omega t)\left(\begin{array}{cc}
0 & \Omega \\
\Omega^{*} & 0
\end{array}\right),
$$

onde se considerou $\frac{\omega_{a}}{\omega} \approx 1$, e $\Omega$ é a frequencia de Rabi, definida como:

$$
\Omega \equiv \frac{e E_{0}}{\hbar}\langle 1|r| 2\rangle \text {. }
$$

Os autovetores para a hamiltoniana serão da forma:

$$
|\Psi(\vec{r}, t)\rangle=\left(C_{1}(t) e^{-i \omega_{1} t}, C_{2}(t) e^{-i \omega_{2} t}\right)\left(\begin{array}{l}
\left|\Phi_{1}(\vec{r})\right\rangle \\
\left|\Phi_{2}(\vec{r})\right\rangle
\end{array}\right)
$$

nos quais, ao aplicarmos a hamiltoniana total, obtemos:

$\mathcal{H}|\Psi(\vec{r}, t)\rangle=\left(\hbar \omega_{1} C_{1}(t) e^{-i \omega_{1} t}+\hbar \Omega e^{i \omega t} C_{2}(t) e^{-i \omega_{2} t}\right)\left|\Phi_{1}(\vec{r})\right\rangle+\left(\hbar \omega_{2} C_{2}(t) e^{-i \omega_{2} t}+\right.$ $\left.\hbar \Omega e^{i \omega t} C_{1}(t) e^{-i \omega_{1} t}\right)\left|\Phi_{2}(\vec{r})\right\rangle$.

Por outro lado,

$i \hbar \frac{\partial}{\partial t}|\Psi(t)\rangle=\left(i \hbar \dot{C}_{1}(t)+\hbar \omega_{1} C_{1}(t)\right) e^{-i \omega_{1} t}\left|\Phi_{1}(\vec{r})\right\rangle+\left(i \hbar \dot{C}_{2}(t)+\hbar \omega_{2} C_{2}(t)\right) e^{-i \omega_{2} t}\left|\Phi_{2}(\vec{r})\right\rangle$.

Igualando ambas, chegamos a um sistema de equações para a evolução dos coeficientes $C_{1}$ e $C_{2}$ :

$$
\begin{aligned}
\frac{\mathrm{d}}{\mathrm{dt}} C_{1}(t) & =-i \frac{\Omega^{*}}{2}\left(e^{i\left(\omega-\omega_{a}\right) t}+e^{-i\left(\omega+\omega_{a}\right) t}\right) C_{2}(t) \\
\frac{\mathrm{d}}{\mathrm{dt}} C_{2}(t) & =-i \frac{\Omega}{2}\left(e^{i\left(\omega+\omega_{a}\right) t}+e^{-i\left(\omega-\omega_{a}\right) t}\right) C_{1}(t)
\end{aligned}
$$

onde foi feita a expansão do cosseno em termos das exponencias. 
As exponenciais do termo $\left(\omega+\omega_{a}\right)$ fazem com que os estados oscilem rapidamente, mas seu efeito médio é nulo ao longo de um intervalo longo de tempo. Já as exponenciais que contêm o termo $\left(\omega-\omega_{a}\right)$ fazem os estados oscilarem lentamente pois $\omega$ é muito próximo a $\omega_{a}$. Por isso, o termo rápido pode ser desprezado. Essa aproximação é chamada de aproximação da onda girante, ou, em inglês, Rotating Wave Aproximation (RWA):

$$
\begin{gathered}
\frac{\mathrm{d}}{\mathrm{dt}} C_{1}(t)=-i \frac{\Omega^{*}}{2} e^{i \delta t} C_{2}(t) \\
\frac{\mathrm{d}}{\mathrm{dt}} C_{2}(t)=-i \frac{\Omega}{2} e^{-i \delta t} C_{1}(t)-\frac{\gamma}{2} C_{2}(t),
\end{gathered}
$$

onde $\delta=\omega-\omega_{a}$. Nessa equação foi adicionado artificialmente o termo de emissão espontânea obtido na equação (2.9).

O passo seguinte é escrever o operador de densidade

e a matriz de densidade

$$
\hat{\rho}=|\Psi\rangle\left\langle\Psi\left|=\sum_{j, k} \rho_{\mathrm{jk}}\right| j\right\rangle\langle k|
$$

$$
\rho(t)=\left(\begin{array}{cc}
\rho_{11} & \rho_{12} \\
\rho_{21} & \rho_{22}
\end{array}\right)=\left(\begin{array}{cc}
C_{1}(t) C_{1}^{*}(t) & C_{1}(t) C_{2}^{*}(t) e^{-i \delta t} \\
C_{2}(t) C_{1}^{*}(t) e^{i \delta t} & C_{2}(t) C_{2}^{*}(t)
\end{array}\right) .
$$

A derivada temporal da matriz de densidade leva a quatro equações, que são chamadas de equações de Bloch.

A diagonal da matriz dá a população nos estados excitado e fundamental, enquanto os termos cruzados dão a polarização do átomo.

A equação para o estado excitado é:

$$
\frac{d}{\mathrm{dt}} \rho_{22}(t)=\left(\frac{d}{\mathrm{dt}} C_{2}(t)\right) C_{2}^{*}(t)+C_{2}(t)\left(\frac{d}{\mathrm{dt}} C_{2}^{*}(t)\right)=-i \frac{\Omega}{2} \rho_{12}(t)+i \frac{\Omega^{*}}{2} \rho_{21}(t)-\gamma \rho_{22}(t) .
$$

A normalização de $\rho_{\mathrm{jk}}$ implica que $\rho_{22}(t)+\rho_{11}(t)=1$ e, portanto, $\frac{d}{\mathrm{dt}} \rho_{22}(t)=$ $-\frac{d}{\mathrm{dt}} \rho_{11}(t)$.

Assim, as quatro equações de Bloch são:

$$
\begin{gathered}
\frac{d}{\mathrm{dt}} \rho_{22}(t)=-i\left(\frac{\Omega}{2} \rho_{12}(t)-\frac{\Omega^{*}}{2} \rho_{21}(t)\right)-\gamma \rho_{22}(t) \\
\frac{d}{\mathrm{dt}} \rho_{11}(t)=i\left(\frac{\Omega}{2} \rho_{12}(t)-\frac{\Omega^{*}}{2} \rho_{21}(t)\right)+\gamma \rho_{22}(t) \\
\frac{d}{\mathrm{dt}} \rho_{12}(t)=-i \frac{\Omega^{*}}{2}\left(\rho_{22}(t)-\rho_{11}(t)\right)-\frac{\gamma}{2} \rho_{12}(t)-i \delta \rho_{12}(t) \\
\frac{d}{\mathrm{dt}} \rho_{21}(t)=-i \frac{\Omega}{2}\left(\rho_{22}(t)-\rho_{11}(t)\right)-\frac{\gamma}{2} \rho_{12}(t)-i \delta \rho_{12}(t) .
\end{gathered}
$$

Sem o decaimento espontâneo, as equações têm solução exata, e descrevem uma oscilação do sistema entre os níveis excitado e fundamental. Nesse caso, $\rho_{22}(t)=$ $\left(\frac{\Omega}{\sqrt{\Omega^{2}+\delta^{2}}}\right)^{2} \operatorname{sen}^{2}\left(\frac{\Omega}{2} t\right)$ : 


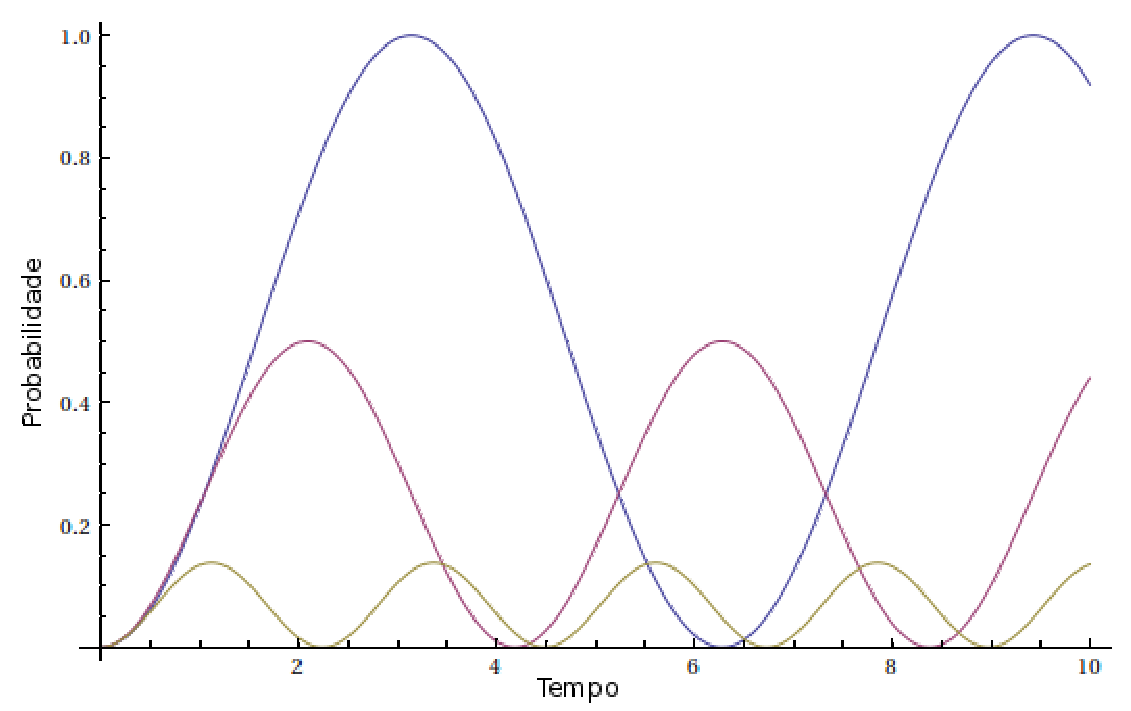

Figura 2.5. Gráfico de $\rho_{22}(t)$ para $\gamma=0$ para alguns valores de $\Omega$ e $\delta$.

Com o termo decaimento espontâneo podemos fazer uma integral númerica para resolver o sistema e obter um gráfico da probabilidade de excitação do átomo:

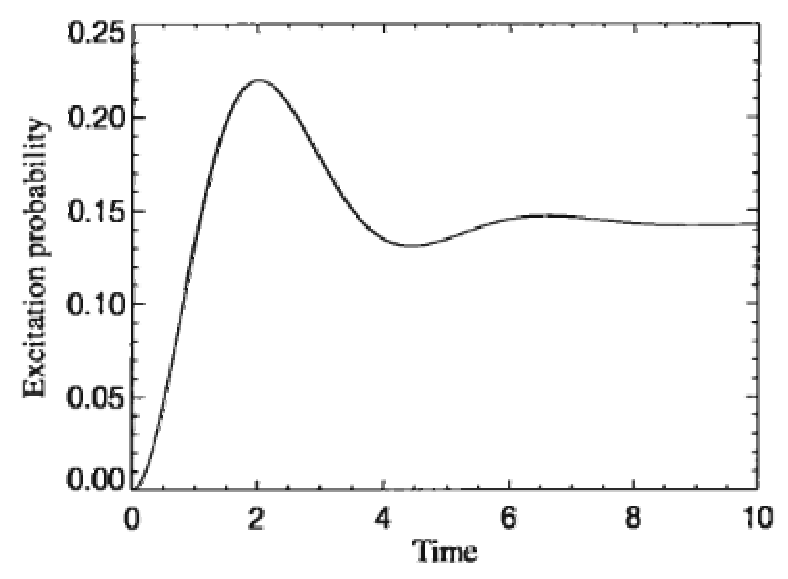

Figura 2.6. Probabilidade de excitação para $\delta=-\gamma$ e para $\Omega=\gamma$, com o tempo em escala de $1 / \gamma$.

Retirado de [16, Metcalf, p.24].

O decaimento espontâneo amortece a oscilação, e o sistema evolui para um equilíbrio quando $t \rightarrow \infty$. O equilíbrio pode ser encontrado fazendo-se $\dot{\rho}_{\mathrm{ss}} \rightarrow 0$, onde o índice $s s$ se refere ao estado estacionário.

Para facilitar a notação, definiremos uma variável $w \equiv \rho_{22 \mathrm{ss}}-\rho_{11 \text { ss }}$ para a diferença de população entre os estados excitado e fundamental no estado estacionário.

Subtraindo a equação (2.16) da equação (2.17), obtemos:

$$
\operatorname{Im}\left\{\rho_{12 \mathrm{ss}} \Omega\right\}=\frac{\gamma(w+1)}{2} .
$$


A soma das equações (2.18) e (2.19) nos dá

$$
\gamma \operatorname{Re}\left\{\rho_{21 \mathrm{ss}} \Omega\right\}=2 \delta \operatorname{Im}\left\{\rho_{12 \mathrm{ss}} \Omega\right\} .
$$

Já ao subtrairmos a equação (2.19) da equação (2.18), temos

$$
i|\Omega|^{2} W+i \gamma \operatorname{Im}\left\{\rho_{12 \mathrm{ss}} \Omega\right\}+2 i \operatorname{Re}\left\{\rho_{12 \mathrm{ss}} \Omega\right\}=0 .
$$

Essas três equações juntas nos permitem resolver a matriz de densidade para o estado estacionário:

$$
\begin{gathered}
\rho_{22 \mathrm{ss}}=\frac{|\Omega|^{2}}{4} \frac{1}{\frac{|\Omega|^{2}}{2}+\left(\frac{\gamma}{2}\right)^{2}+\delta^{2}} \\
\rho_{12 \mathrm{ss}}=\frac{-\frac{\Omega^{*}}{2}\left(\delta+i \frac{\gamma}{2}\right)}{\frac{|\Omega|^{2}}{2}+\left(\frac{\gamma}{2}\right)^{2}+\delta^{2}},
\end{gathered}
$$

sendo que a população do estado fundamental pode ser facilmente encontrada fazendo-se $\rho_{11 s s}=1-\rho_{22 s s}$, e o outro termo de correlação pode ser obtido por $\rho_{21}=\rho_{12}^{*}$.

A dependência da população do estado excitado com $\delta$ revela que, quanto menor for a diferença entre a frequência do laser $\omega$ e a frequência da transição atômica $\omega_{a}$, maior será a população no estado excitado, isso porque a absorção do laser pelos átomos será maior. Além disso $\rho_{22 \text { ss }}$ cai pela metade quando $\delta^{2}=\frac{|\Omega|^{2}}{2}+\left(\frac{\gamma}{2}\right)^{2}$. Assim, a largura de linha da absorção é

$$
\Delta \delta=2 \sqrt{\frac{|\Omega|^{2}}{2}+\left(\frac{\gamma}{2}\right)^{2}}
$$

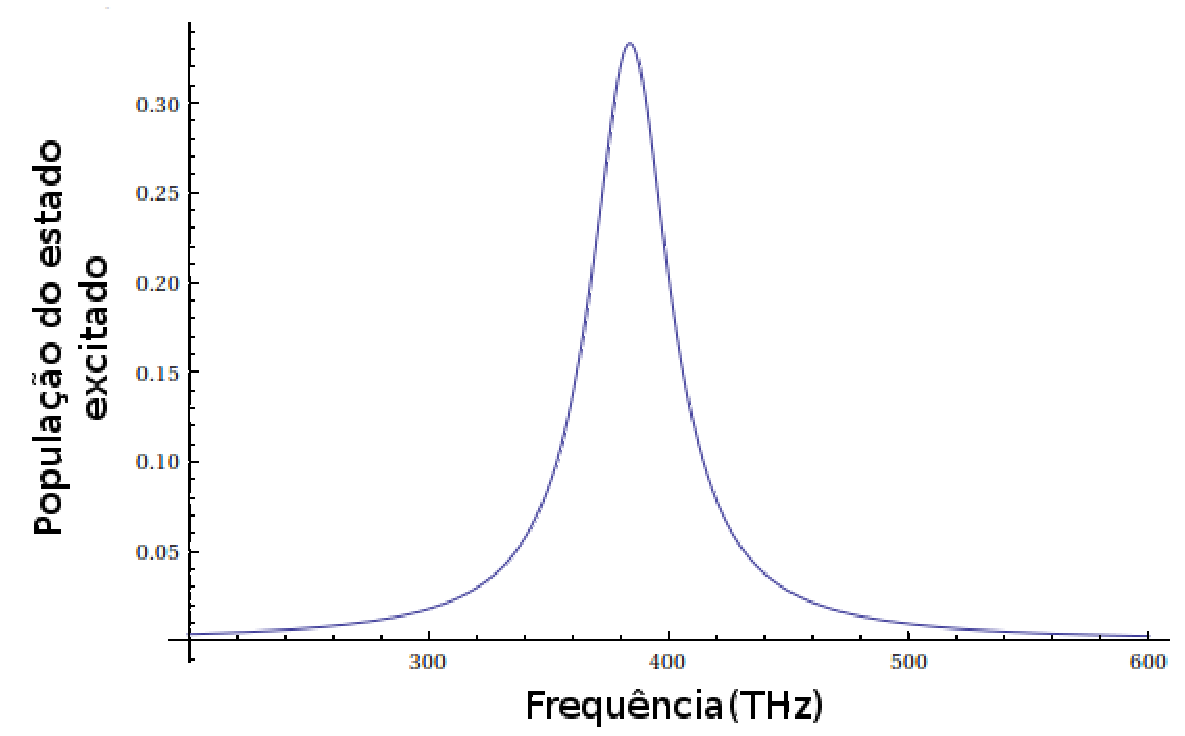

Figura 2.7. Dependência de $\rho_{22 \mathrm{ss}} \operatorname{com} \omega$ para $\Delta \delta=40 \mathrm{THz},|\Omega|=\gamma$ e $\omega_{a}=384 \mathrm{THz}$. 
Como a frequência de Rabi é proporcional ao campo elétrico, o termo $\frac{|\Omega|^{2}}{2}$, da largura de linha da absorção, está relacionado diretamente à intensidade do campo oscilante na cavidade. Por esse motivo, dizemos que este é um fator de alargamento por potência.

\subsection{Polarização e Susceptibilidade}

Na seção anterior, vimos o que acontece com um meio atômico de dois níveis, na presença de um campo eletromagnético. Nesta seção iremos falar sobre a resposta do meio ao campo, ou seja, como o meio polarizado altera as propriedades do campo que o atravessa. Essa resposta é dada através da susceptibilidade do meio atômico, que se relaciona com a sua polarização através da equação:

$$
\tilde{P}(\omega)=\tilde{\chi}(\omega) \epsilon_{0} \tilde{E}(\omega)
$$

onde $\epsilon_{0}$ é a permissividade do vácuo, $\tilde{E}(\omega)$ é o campo eletromagnético que atravessa o meio, e $\omega$ sua frequência de oscilação.

O campo elétrico e a polarização, em um meio linear, estão relacionados pelo vetor deslocamento $\vec{D}$ definido da teoria do eletromagnetismo como:

$$
\tilde{D}(\omega)=\epsilon_{0} \tilde{E}(\omega)+\tilde{P}(\omega)=\epsilon_{0}(1+\tilde{\chi}(\omega)) \tilde{E}(\omega) .
$$

A equação de onda em um meio polarizado pode ser obtida através das equações de Maxwell partindo-se da relação:

$$
\vec{\nabla} \times \vec{\nabla} \times \vec{E}=\nabla(\vec{\nabla} \cdot \vec{E})-\nabla^{2} \vec{E}
$$

onde $\vec{\nabla} \cdot \vec{E}=0$, pois a densidade de cargas é nula e, como sabemos pelas equações de Maxwell que $\vec{\nabla} \times \vec{E}=-\frac{\partial \vec{B}}{\partial t}$, podemos reescrever (2.24) como

$$
-\vec{\nabla} \times\left(\frac{\partial \vec{B}}{\partial t}\right)=-\frac{\partial}{\partial t}(\vec{\nabla} \times \mu \vec{H})=-i \omega \mu \vec{\nabla} \times \vec{H}=-i \omega \mu(\vec{J}+i \omega \vec{D})=-\nabla^{2} \vec{E}
$$

Se o campo eletromagnético viaja em um meio dielétrico linear, com constante dielétrica $\epsilon$ e que contém perda ohmica, então temos que:

$$
\nabla^{2} \tilde{E}=i \omega \mu[\sigma-i \omega \epsilon(1+\tilde{\chi})] \tilde{E}
$$

que nos leva à equação de onda nesse meio:

$$
\left[\nabla^{2}+\omega^{2} \mu \epsilon\left(1+\tilde{\chi}+\frac{i \sigma}{\omega \epsilon}\right)\right] \tilde{E}=0 .
$$


Comparando (2.25) com a equação de onda plana $\left(\nabla^{2}+k^{2}\right) \tilde{E}=0$, obtemos a variação do número de onda $k$ devido à polarização do meio:

$$
k_{T}^{2}=k^{2}\left(1+\chi^{\prime}+i \chi^{\prime \prime}+\frac{i \sigma}{\omega \epsilon}\right)
$$

onde expandimos a susceptibilidade em uma parte real e outra imaginária: $\tilde{\chi}=$ $\chi^{\prime}+i \chi^{\prime \prime}$.

Considerando que a variação de $k$ é pequena, podemos aproximar (2.26) por:

$$
k_{T} \approx k\left(1+\frac{\chi^{\prime}}{2}+i \frac{\chi^{\prime \prime}}{2}+\frac{i \sigma}{2 \omega \epsilon}\right)=k+\Delta k-i \alpha_{m}+i \alpha_{0}
$$

onde $\Delta k=\frac{k \chi^{\prime}}{2}$ é a variação real de $k$ ao atravessar o meio, $\alpha_{m}=-\frac{k \chi^{\prime \prime}}{2}$ é a amplificação do campo e $\alpha_{0}=\frac{k \sigma}{2 \omega \epsilon}$ é a perda por espalhamento ou absorção.

A susceptibilidade pode ser obtida através da polarização descrita em (2.19), para o vetor $|\Psi(\vec{r}, t)\rangle$ definido em $(2.10)$

$$
\langle\vec{\mu}\rangle=e\langle\Psi(\vec{r}, t)|\vec{r}| \Psi(\vec{r}, t)\rangle=e\left\langle\varphi_{1}|\vec{r}| \varphi_{2}\right\rangle C_{1}^{*} C_{2} e^{-i \omega_{a} t}+e\left\langle\varphi_{2}|\vec{r}| \varphi_{1}\right\rangle C_{2}^{*} C_{1} e^{i \omega_{a} t},
$$

que, pela equação (2.15), pode ser simplificado para:

$$
\langle\vec{\mu}\rangle=e r_{12} \rho_{21} e^{-i \omega t}+e r_{21} \rho_{12} e^{i \omega t}
$$

Como existe liberdade para a definição de uma fase global de $r_{12}$, não existe nenhuma perda de generalidade em considerá-lo real, e, portanto:

$$
\langle\vec{\mu}\rangle=e r_{12}\left(\rho_{12} e^{-i \omega t}+\rho_{21} e^{i \omega t}\right)=2 e r_{12}\left(\operatorname{Re}\left\{\rho_{12}\right\} \cos (\omega t)+\operatorname{Im}\left\{\rho_{12}\right\} \operatorname{sen}(\omega t)\right) .
$$

Substituindo em (2.28) o valor de $\rho_{21}$ para o regime estacionário, obtido em (2.21), chegamos a:

$$
\langle\vec{\mu}\rangle=-e r_{12} \Omega \frac{\delta \cos (\omega t)+\frac{\gamma}{2} \operatorname{sen}(\omega t)}{\frac{|\Omega|^{2}}{2}+\left(\frac{\gamma}{2}\right)^{2}+\delta^{2}} .
$$

Novamente podemos considerar a polarização $\vec{\mu}$ como sendo real, sem nenhuma perda de generalidade, e, portanto, pela equação (2.23):

$$
N \vec{\mu}=\operatorname{Re}\{\tilde{P}\}=\operatorname{Re}\left\{\tilde{\chi} \epsilon E_{0} e^{i \omega t}\right\}=\epsilon E_{0}\left(\chi^{\prime} \cos (\omega t)+\chi^{\prime \prime} \operatorname{sen}(\omega t)\right),
$$

onde $N$ é o número de átomos, por unidade de volume, com polarização $\vec{\mu}$.

Comparando (2.30) com (2.29), podemos ver que:

$$
\begin{aligned}
& -\chi^{\prime}=N \frac{e r_{12} \Omega}{\epsilon E_{0}} \frac{\delta}{\frac{|\Omega|^{2}}{2}+\left(\frac{\gamma}{2}\right)^{2}+\delta^{2}} \\
& -\chi^{\prime \prime}=N \frac{e r_{12} \Omega}{2 \epsilon E_{0}} \frac{\gamma}{\frac{|\Omega|^{2}}{2}+\left(\frac{\gamma}{2}\right)^{2}+\delta^{2}} .
\end{aligned}
$$




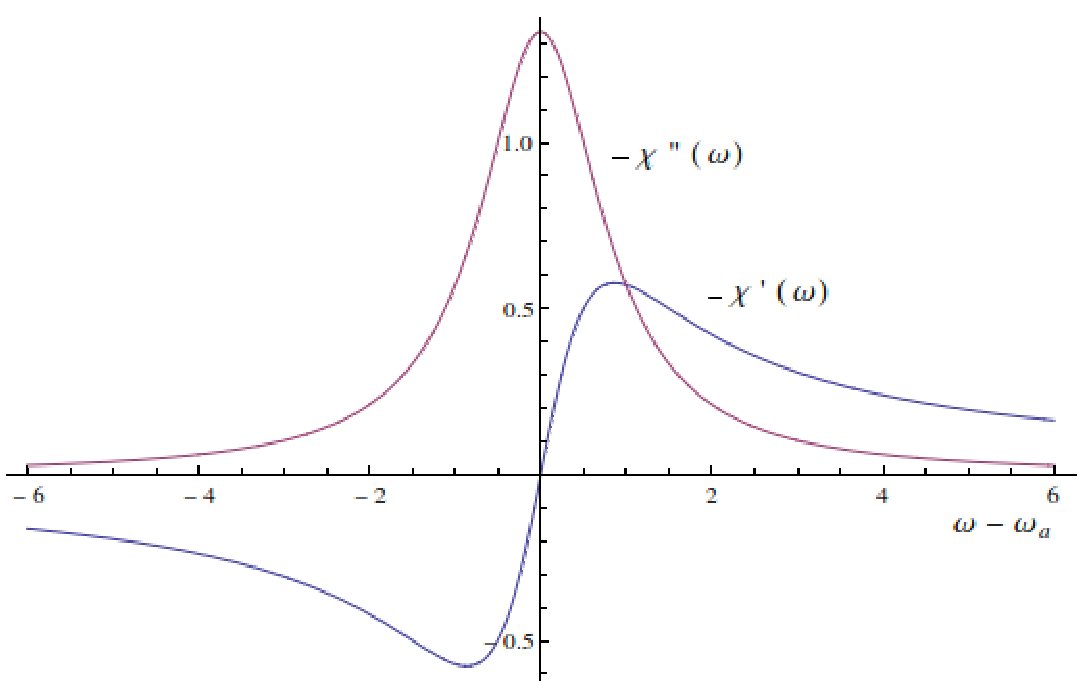

Figura 2.8. Dependência de $-\chi^{\prime}$ e $-\chi^{\prime \prime}$ em função de $\omega$.

Um campo $E(z)=E_{0} e^{\left(\alpha_{m}-\alpha_{0}\right) z} e^{i(k+\Delta k) z}$, que atravessa o meio atômico, é amplificado pelo fator $\left(\alpha_{m}-\alpha_{0}\right)$, e o ganho é definido como

$$
|G(\omega)| \equiv \frac{I(L)}{I(0)}=\left|\frac{E(L)}{E(0)}\right|^{2}=e^{2 \alpha_{m} L-2 \alpha_{0} L}
$$

onde $L$ é o comprimento do meio atômico e $I(L)$ é a intensidade do campo após atravessar o meio.

Em uma situação em que os ganhos superam muito as perdas, $\alpha_{0} \ll \alpha_{m}$, temos:

$$
\ln \left(\cdot \frac{I(L)}{I(0)}\right)=2 \alpha_{m} L
$$

de onde podemos tirar que:

$$
\frac{1}{I} \frac{d I}{d z}=2 \alpha_{m}=\Delta N \frac{e r_{12} \Omega}{2 \epsilon E_{0}} \frac{\gamma}{\frac{|\Omega|^{2}}{2}+\left(\frac{\gamma}{2}\right)^{2}+\delta^{2}} k .
$$

Substituindo aqui o resultado de (2.4) para a inversão de população $\Delta N$, chegamos a:

$$
\frac{1}{I} \frac{d I}{d z}=2 \alpha_{m}=\frac{2 \alpha_{m 0}}{1+\frac{I}{I_{\mathrm{sat}}}}
$$

onde:

$$
2 \alpha_{m 0}=\Delta N_{0} \frac{e r_{12} \Omega}{2 \epsilon E_{0}} \frac{\gamma}{\frac{|\Omega|^{2}}{2}+\left(\frac{\gamma}{2}\right)^{2}+\delta^{2}} k .
$$


Quando a intensidade é pequena, sua dependência com z é exponencial e o laser se torna mais intenso conforme penetra no cristal, mas, à medida que a intensidade cresce, o ganho decresce. No limite em que $I \rightarrow I_{\text {sat }}$ a intensidade passa a crescer linearmente, sendo $\frac{d I}{d z}=2 \alpha_{m 0} I_{\text {sat }}$ o coeficiente angular do crescimento.

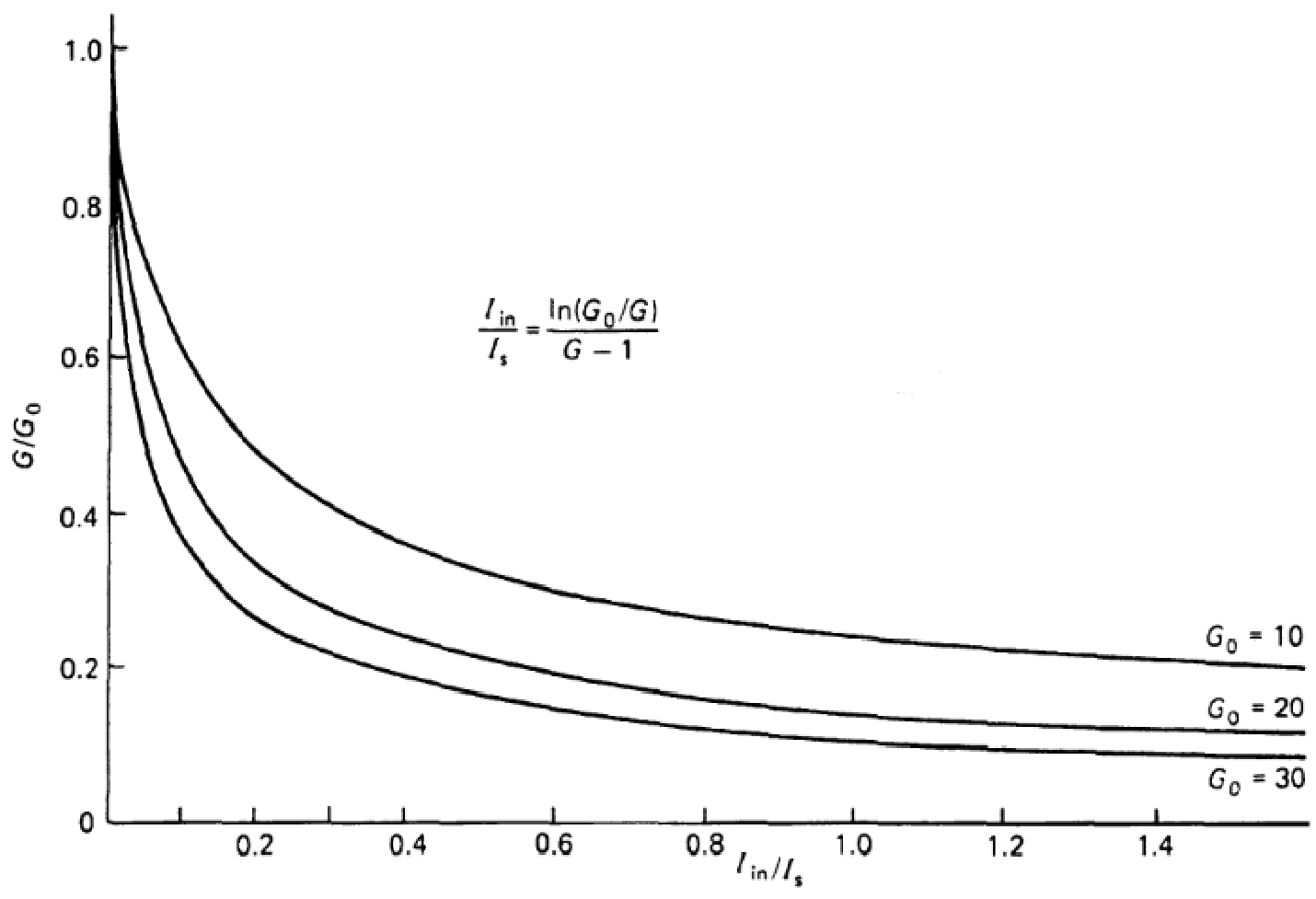

Figura 2.9. Gráfico do ganho efetivo $G=\frac{I(L)}{I(0)}$ no estado estacionário, em função da intensidade do campo amplificado, para o qual estão definidos os parâmetros $G_{0}=e^{\alpha_{m 0} L}$, $I_{\text {in }}=I(0)$ e $I_{s}=I_{\text {sat }}$.

Retirado de [27, Koechner, p.189].

\subsection{Colisões e perdas de coerência}

Na seção 2.6 falamos a respeito da largura de linha de absorção de um único átomo. Na seção 2.7, mostramos a dependência do ganho com relação ao número de átomos acoplados ao campo oscilante da cavidade. Em um meio atômico, efeitos de interação entre os átomos, principalmente colisões, vão interferir na largura de absorção do meio e fazer com que, eventualmente, mesmo em casos de emissão estimulada, os átomos não emitam os fótons em fase com o campo incidente [13], [12]. Tais efeitos dependem sobretudo do meio atômico, que pode ser um líquido, um sólido ou um gás. 
Efeitos de colisão são mais frequentes em gases. Ao colidir, um dipolo que está oscilando na frequência do campo perde a informação de fase, deixando de contribuir para a polarização total do meio.

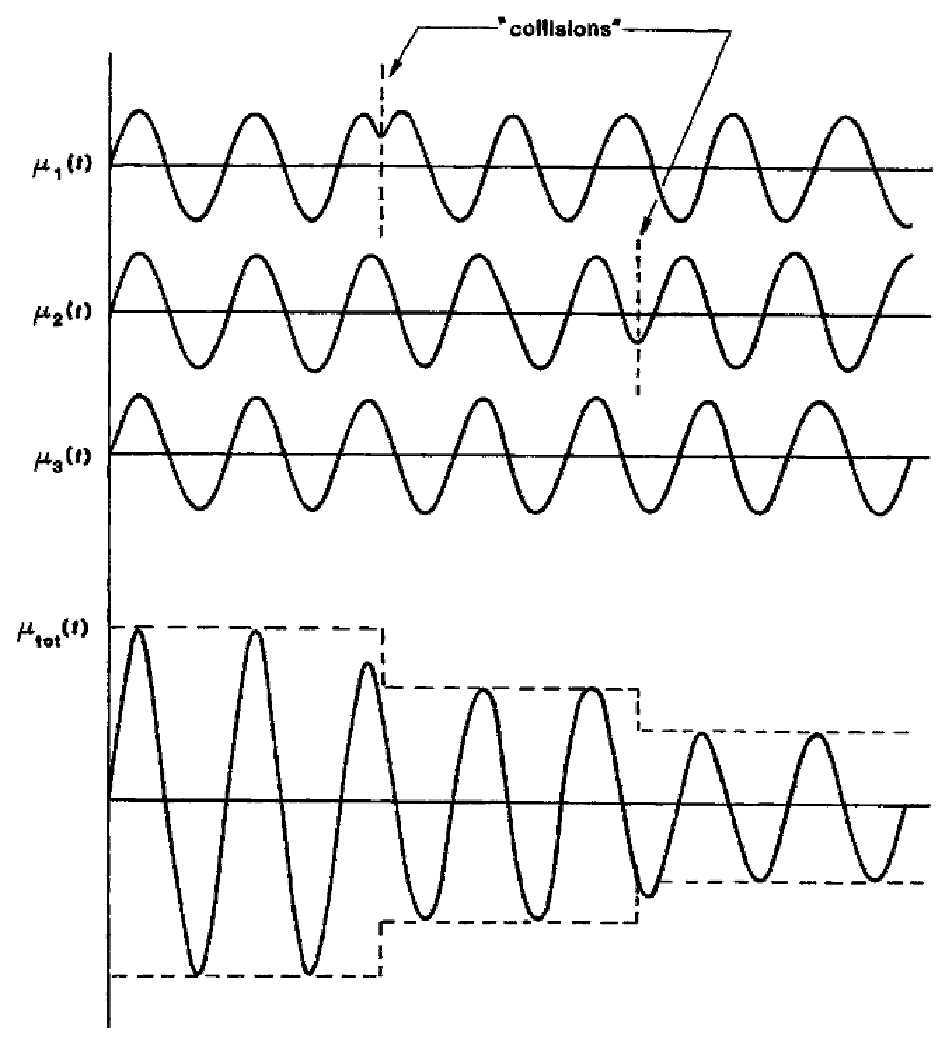

Figura 2.10. Esquema da queda da polarização total dos átomos quando um átomo perde a relação de fase com relação aos outros átomos.

Retirado de [12, Siegman, p.91].

A probabilidade de um dipolo, oscilando em fase com o campo, colidir é proporcional ao número de dipolos oscilando em fase, $N$, e à taxa de colisão, que é o inverso do tempo de colisão $\frac{1}{T_{2}}$. Assim, a variação de $N$ devido a colisões é $\frac{\mathrm{d} N}{\mathrm{dt}}=\frac{N}{T_{2}}$, e, portanto:

$$
N=N_{0} e^{-\frac{t}{T_{2}}}
$$

Como a parte real da polarização total vale:

$$
\operatorname{Re}\{\tilde{P}\}=N(t) \vec{\mu}=N_{0} \vec{\mu} e^{-\frac{t}{T_{2}}}
$$

a taxa de colisão também deve ser acrescentada ao decaimento não coerente

$$
\gamma \rightarrow \gamma+\frac{1}{T_{2}}
$$

provocando um alargamento da linha de absorção do meio. 
Outro efeito que provoca um alargamento da linha de absorção, que é forte em gases, é o efeito Doppler. Como mostrado pelas equações (2.34) e (2.22), a amplificação do meio, assim como a largura de absorção, é proporcional à frequência do campo. Entretanto a frequência observada pelos átomos depende da velocidade do átomo, e a distribuição de velocidades de um átomo em um gás é gaussiana.

Em sólidos, um efeito equivalente é a emissão de fônons em vez de fótons, que fazem com que a rede cristalina vibre, provocando uma variação da frequência.

Assim, tanto para sólidos como para gases, a largura de linha do laser produzido é limitada não apenas pela largura natural de absorção do átomo, mas também por efeitos de decoerência. Esses efeitos, assim como outras características fundamentais dos lasers, estão diretamente relacionados com os meios de ganho usados na amplificação.

\subsection{Meios atômicos}

Muitas características de um laser são determinadas pelo seu meio de ganho, desde os níveis de energia, que determinam a frequência do laser, até o formato do meio, que determina o seu tamanho. Meios de ganho podem ser divididos basicamente em três tipos: sólidos, gases ou líquidos.

Lasers que utilizam meios de ganho sólidos podem ser divididos ainda em dois tipos, que são os lasers de estado sólido e lasers de semicondutores.

O primeiro laser funcional, criado em 1960, era um laser de estado sólido. Mais precisamente, um laser de cristal de rubi.

Os cristais lasers podem ser feitos de vários materiais de base, como óxidos, e cristais e vidros de fluoreto, dopados com íons que fornecem os níveis de energia necessários e que determinam as propriedades fundamentais do laser. Essa combinação pode operar como um sistema de três ou quatro níveis, ou como lasers vibrônicos, como o caso do titânio-safira, que será explicado mais adiante.

Uma das principais vantagens de se utilizar cristais é que estes são meios robustos e compactos e de fácil manipulação.

Lasers de semicondutores, por sua vez, podem ser ainda mais compactos e normalmente utilizam a reflexão na parede do próprio cristal como cavidade.

A maior parte dos lasers de semicondutores são diodos, eletricamente bombeados, e são contínuos, uma vez que não são capazes de armazenar muita energia sem serem danificados.

Sua vantagem é que podem ser encontrados em diversas faixas diferentes de frequência, têm uma alta eficiência de conversão eletro-ótica (entre 50\% a 70\%) e, devido à facilidade de integrá-los a circuitos elétricos, são muito aplicados comercialmente em armazenamento de dados (leitores e gravadores de CDs, DVDs e BluRay), em telecomunicações, laser pointers, leitores de código de barra, etc., o que os torna mais baratos.

Lasers de diodo também são frequentemente utilizados para bombear lasers de estado sólido. 
Lasers de gás podem ser lasers de átomos neutros, íons ou moleculares. São normalmente bombeados por descargas elétricas, mas também podem ser bombeados oticamente ou, diferentemente de qualquer outro tipo de laser, por reações químicas.

Ao contrário de sólidos, gases não são danificados pelo bombeio, e podem recompor suas estruturas rapidamente, o que permite que sejam bombeados por lasers de alta potência. Além disso, como gases provocam pouca distorção ótica, lasers de gás podem produzir feixes extremamente colimados.

A principal vantagem de lasers de gás, entretanto, é que eles podem ser encontrados em faixas de frequências para as quais não existem lasers de estado sólido, desde o infravermelho até o ultravioleta, tendo muita importância para a espectroscopia. O laser químico de gás de fluoreto de deutério, por exemplo, tem cerca de 3500nm de comprimento de onda, e pode chegar a megawatts de potência, já tendo sido utilizado em testes para abater foguetes. Já lasers de exímeros (dímeros excitados), normalmente compostos por um gás nobre e um halógeno (com exceção do hélio e do neônio), operam desde $157 \mathrm{~nm}\left(\mathrm{~F}_{2}\right)$ até $351 \mathrm{~nm}(\mathrm{XeF})$ e têm aplicações em cirurgias óticas, entre outros usos.

Outra característica de lasers de gás é que não possuem uma dependência tão forte entre potência de saída e preço (lasers de gás de alta potência não são muito mais caros do que os mesmos lasers com menor potência).

Lasers de corante são lasers cujo meio de ganho é, normalmente, um composto colorido dissolvido em um solvente líquido, mas existem também estudos com meios de ganho sólidos.

A diversidade de corantes existentes permite atingir praticamente qualquer faixa de frequência. Além disso, cada corante tem, normalmente, uma larga banda de ganho, podendo ser utilizado para lasers pulsados.

Assim como meios gasosos, os corantes têm a vantagem de não serem localmente danificados, mas corantes se degradam quimicamente, precisando ser trocados após algum tempo de uso. Essa degradação acontece mais rapidamente no regime pulsado e, por isso, e pelo fato de que corantes são normalmente substâncias nocivas, os lasers de corantes pulsados já não são muito utilizados.

Por outro lado, lasers de corante contínuos ainda são muito empregados para espectroscopia devido à possibilidade de se trocar o corante utilizado como meio de ganho por outro com um ganho em uma frequência distinta, mudando assim a frequência do laser, sem que seja necessário um grande realinhamento.

Outro tipo importante de laser são os lasers de fibra ótica. São lasers cujo meio de ganho é uma fibra ótica dopada.

A vantagem desse tipo de laser é que a fibra guia tanto o laser produzido como o bombeio, de forma que o feixe de bombeio age sobre um meio de ganho durante um percurso bastante extenso, tendo alta eficiência. Isso permite que se trabalhe com bombeios pouco potentes, ou que, com um bombeio potente, se opere em transições de pouco ganho.

Lasers de fibra podem ser bastante compactos, produzem feixes extremamente colimados e possuem uma largura de linha de ganho ampla, o que permite que se selecione sobre um vasto espectro de frequências, ou que se opere no modo pulsado, com pulsos ultracurtos. Entretanto fibras estão sujeitas a serem danificadas por pulsos muito intensos. 
Existem ainda muitos outros tipos de lasers, que são classificados, não pelo seu meio atômico, mas por suas características especiais, como lasers randômicos, lasers naturais, ou até mesmo lasers que não necessitam de inversão de população atômica [28], [29].

\subsection{Laser de Titânio-Safira}

O laser de titânio-safira é um laser de estado sólido que funciona como um sistema vibrônico. Seu cristal é uma safira de $\mathrm{Al}_{2} \mathrm{O}_{3}$ dopada com cerca de $1 \%$ de $\mathrm{TiO}_{3}$, e os átomos de titânio substituem o alumínio em alguns pontos da estrutura cristalina, ficando triplamente ionizados $\left(\mathrm{Ti}^{3+}\right)$.

A estrutura do $\mathrm{Ti}^{3+}$ é uma casca fechada com um único elétron na camada 3d. Cada um desses íons é cercado por seis íons de oxigênio $\mathrm{O}^{2-}$, que produzem um campo sobre o titânio que pode ser visto como a soma de uma componente de simetria trigonal e uma componente de simetria cúbica, sendo esta última que domina e abre os níveis de energia do titânio em um estado triplamente degenerado, nomeado como ${ }^{2} \mathrm{~T}_{2}$, e outro duplamente degenerado, nomeado como ${ }^{2} \mathrm{E}$.

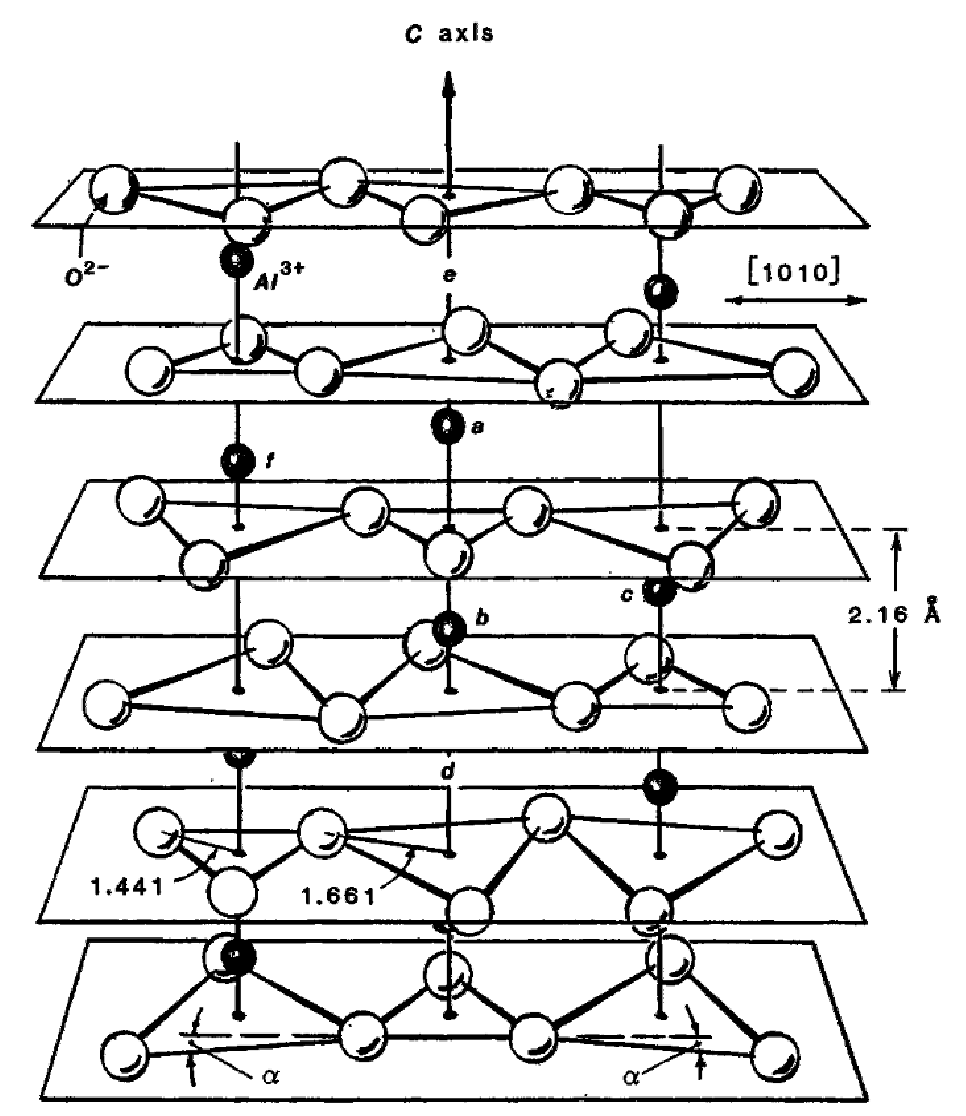

Figura 2.11. Estrutura atômica do cristal de Ti:Saf Retirado de [12, Siegman, p.12]. 
A estrutura atômica permite que os íons de titânio possam vibrar, o que abre os níveis de energia do $\mathrm{Ti}^{3+}$ em um vasto número de níveis vibracionais, que dependem da separação entre o titânio e o oxigênio, como mostrado no esquema da figura 2.12.

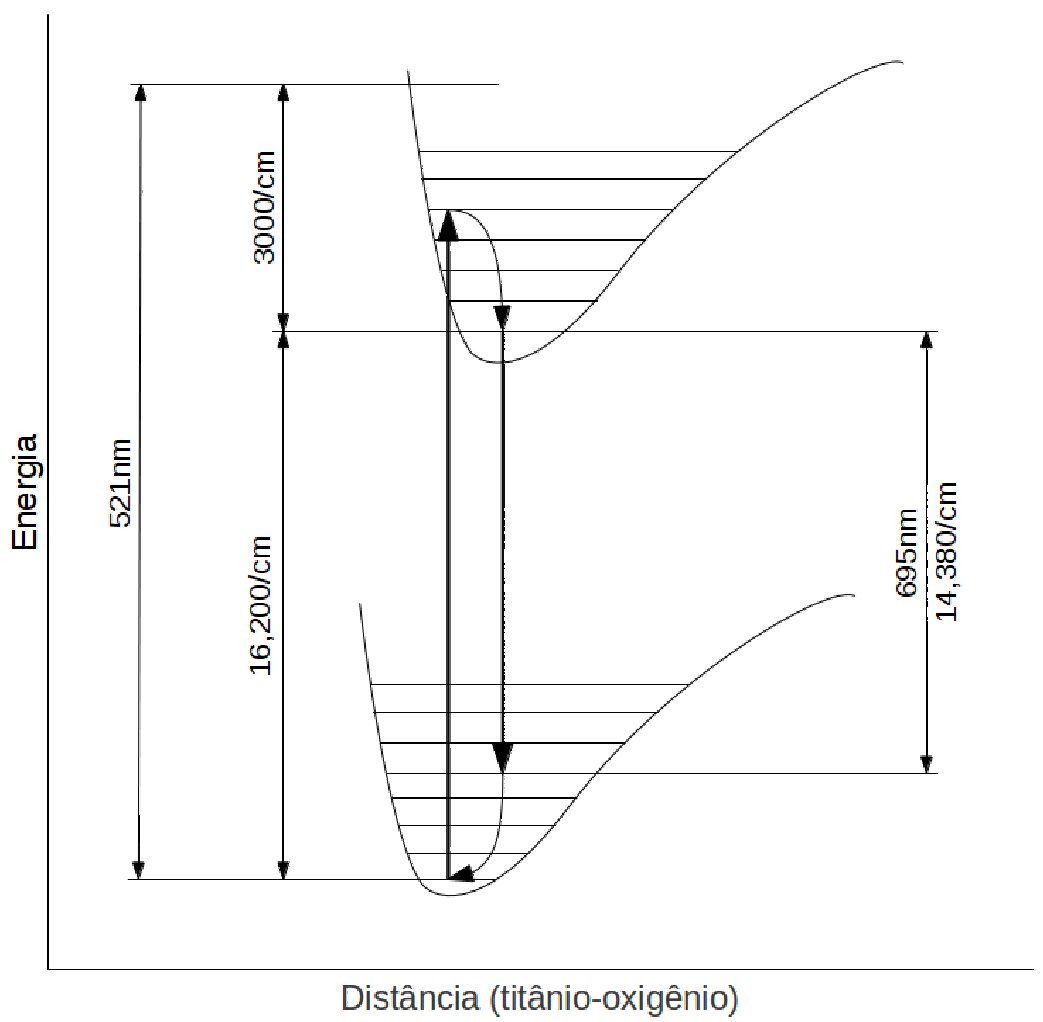

Figura 2.12. Estrutura energética do ion de $\mathrm{Ti}^{3+}$ no cristal de safira.

O íon do titânio pode ser excitado para qualquer um dos desdobramentos do nível ${ }^{2} \mathrm{E}$, o que faz com que a banda de absorção do titânio-safira seja muito larga, com máximo em torno de $521 \mathrm{~nm}$. Uma vez no estado ${ }^{2} \mathrm{E}$, o íon do titânio termaliza, emitindo fônons, e pode decair para qualquer um dos desdobramentos do nível ${ }^{2} \mathrm{~T}_{2}$ e emitir novamente fônons, voltando para o estado inicial, o que faz com que o laser de titânio-safira também tenha uma larga banda de fluorescência.

Apesar dos níveis de energia vibracionais serem discretos, os espectros de emissão e absorção do titânio-safira, representados na figura 2.13, são contínuos, pois a largura de linha da transição ótica é maior do que a diferença de energia de dois níveis vibracionais de forma que os espectros de ambas as transições se sobrepõem formando uma curva contínua.

O laser de titânio-safira opera entre 650nm a 1100nm, com eficiência máxima em torno de 800nm. 


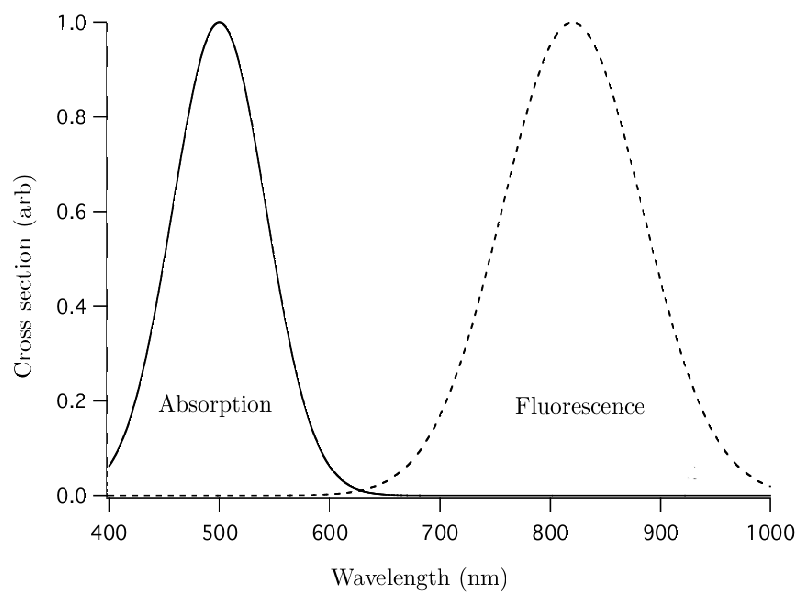

Figura 2.13. Gráfico de absorção e fluorescência do cristal de titânio-safira. Retirado de [19, Nagourney, p.131].

O tempo de termalização do $\mathrm{Ti}^{3+}$ é da ordem de picossegundos, muito curto comparado com o tempo de vida do estado excitado, da ordem de microssegundos. Isso e a separação entre os estados ${ }^{2} \mathrm{~T}_{2}$ e ${ }^{2} \mathrm{E}$ permitem que o laser de titânio-safira possa ser descrito pelo sistema de quatro níveis da seção 2.5. 



\section{Capítulo 3 \\ Engenharia da Cavidade}

No capítulo anterior foi apresentada a parte da teoria básica necessária para a compreensão do funcionamento de um laser. Para seguirmos com sua construção, entretanto, é preciso ir mais além e conhecer em detalhes como se dá a propagação da luz dentro de uma cavidade.

A cavidade é fundamental não apenas no processo de realimentação do amplificador ótico, mas também na determinação das características do feixe de saída, tais como polarização, modo transverso, frequência e cintura do feixe. Além disso, também pode ser utilizada para análise de espectro ou como referência para o travamento de frequência de um laser CW.

Nesse capítulo serão abordados dois tipos diferentes de cavidade: a cavidade de Fabry-Perot [30], utilizada para análise e travamento de frequência do laser [19], e em anel [27], que é a do laser de titânio-safira. Além disso, será discutido o regime de realimentação do amplificador, as condições de circulação do campo dentro de um ressoador, e seus modos longitudinais [27], [31] e [12]. Em seguida, veremos os modos transversos do laser e o método matricial para descrever uma cavidade [32], [12]. Por fim apresentaremos a cavidade completa utilizada para a construção do laser de titânio-safira, assim como a descrição de cada elemento ótico dentro dela e sua atuação para determinar o regime de oscilação do laser.

\subsection{Cavidade de Fabry-Perot}

A cavidade linear mais simples é a chamada Fabry-Perot, que consiste em dois espelhos paralelos, como na figura 2.1.

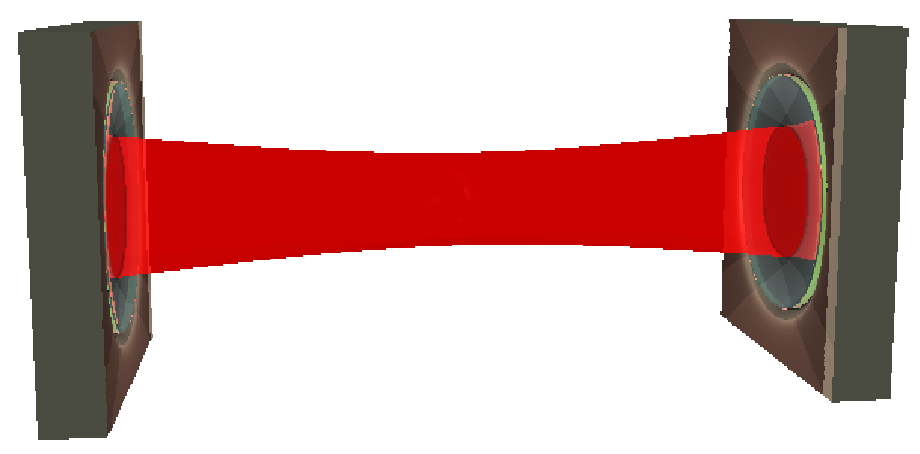

Figura 3.1. Exemplo de uma cavidade de Fabry-Perot

Uma cavidade de Fabry-Perot ainda mais simples consiste em apenas uma lâmina de vidro ou outro material qualquer, transparente para a faixa de frequência do feixe incidente, cujas superfícies façam o papel dos espelhos. 
Ao atravessar a cavidade uma vez, o campo ganha uma fase proporcional à distância percorrida pelo feixe. Parte do campo é transmitida e parte é refletida. A parte do refletida percorre novamente a cavidade, ganha novamente uma fase e pode ser mais uma vez transmitida ou refletida pelo outro espelho.

O campo que atravessa a cavidade é a soma de todos os campos transmitidos, e o campo refletido, a soma de todos os campos refletidos.

Além da diferença de fase devido ao caminho percorrido dentro da cavidade, existe um atraso de fase entre os feixes ao sair do material, que pode ser visto na figura 3.2 , onde $d=\frac{l}{\cos \theta}$ e $l_{0}=2 l \operatorname{tg} \theta \operatorname{sen} \theta_{0}$.

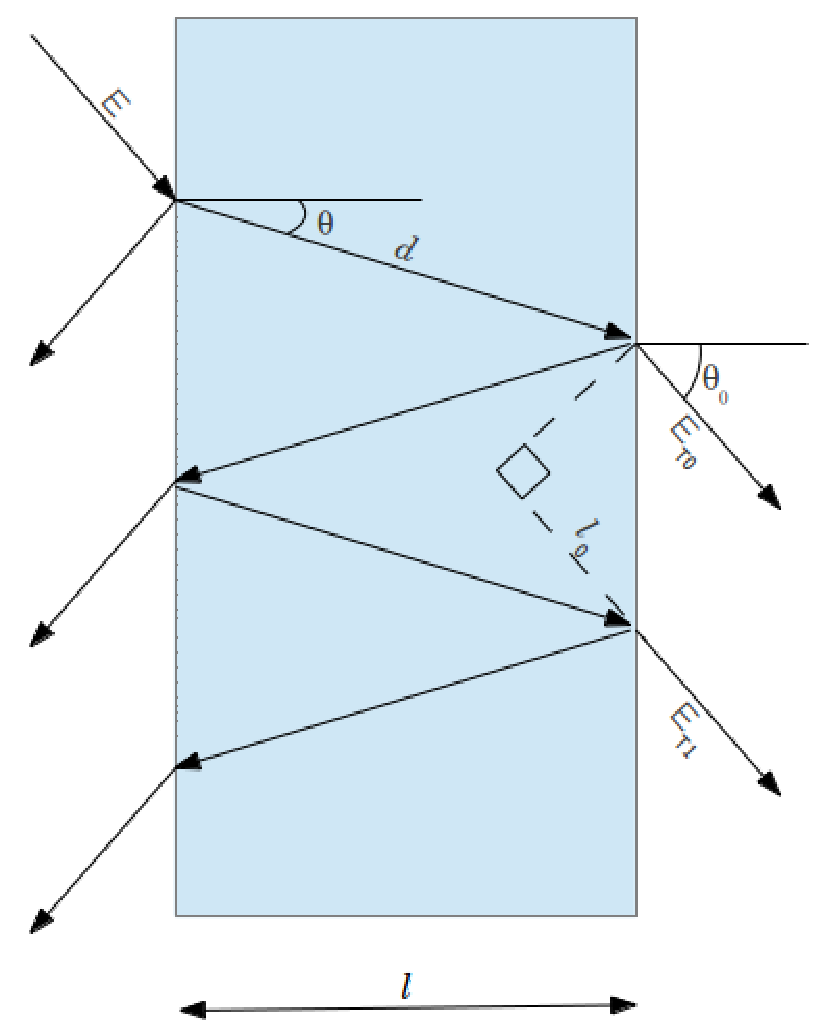

Figura 3.2. Reflexões do feixe na cavidade de Fabry-Perot

Para uma onda incidente plana, descrita como $E=E_{0} e^{i k x}$, podemos escrever o primeiro campo transmitido como

$$
E_{T 0}=E_{0} t_{1} e^{i k d_{2}} t_{2}
$$

onde $t_{1}$ é o coeficiente de transmissão do espelho de entrada, $t_{2}$ o coeficiente de transmissão do espellho de saída e $k$ é o número de onda dentro da cavidade.

O próximo campo transmitido será

$$
E_{T 1}=E_{0} t_{1} e^{i k d} r_{2} e^{i k d} r_{1} e^{i k d} t_{2} e^{-i k l_{0}}=E_{\mathrm{To}_{\mathrm{o}}} r_{2} r_{1} e^{i \delta},
$$

onde $r_{1}$ é o coeficiente de reflexão na superfície ou espelho de entrada, $r_{2}$ é o coeficiente de reflexão na superfície ou espellho de saída, $k_{0}$ é o número de onda fora da cavidade e $\delta$ é a diferença de fase entre cada feixe transmitido e vale

$$
\delta=2 k d-k_{0} l_{0}=\frac{2 k l}{\cos \theta}-2 l \operatorname{tg} \theta k_{0} \operatorname{sen} \theta_{0} .
$$


Como $k_{0} \operatorname{sen} \theta_{0}=k \operatorname{sen} \theta$ :

$$
\delta=2 k l \cos \theta
$$

Após uma nova reflexão o feixe ganha outra vez a mesma fase e por isso cada campo transmitido pode ser escrito em função do primeiro campo transmidito:

$$
E_{T j}=E_{T o}\left(r_{2} r_{1} e^{i \delta}\right)^{j},
$$

e, portanto, o campo transmitido total vale:

$$
E_{T}=\sum_{j} E_{T j}=E_{T o} \sum_{j}\left(r_{2} r_{1} e^{i \delta}\right)^{j}=E_{o} \frac{t_{1} t_{2} e^{i k d}}{1-r_{2} r_{1} e^{i \delta}} .
$$

Como a intensidade é proporcional ao quadrado do campo temos:

$$
T_{\text {ef }}=\left|\frac{E_{T}}{E_{0}}\right|^{2}=\frac{T_{1} T_{2}}{1+R_{1} R_{2}-2 \sqrt{R_{1} R_{2}} \cos \delta},
$$

onde $T_{\text {ef }}$ é a transmissão efetiva da cavidade e $R_{i}=r_{i} r_{i}^{*}$ e $T_{i}=t_{i} t_{i}^{*}=1-R_{i}$ são a reflexão e a transmissão de cada superfície ou espelho.

No caso mais simples, em que as reflexões pelas superfícies de entrada e saída são iguais, a transmissão efetiva vale

$$
T_{\mathrm{ef}}=\frac{T^{2}}{1+R^{2}-2 R \cos \delta}=\frac{1}{1+F \operatorname{sen}^{2}\left(\frac{\delta}{2}\right)},
$$

onde

$$
F=\frac{4 R}{(1-R)^{2}}
$$

é chamado coeficiente de finesse.

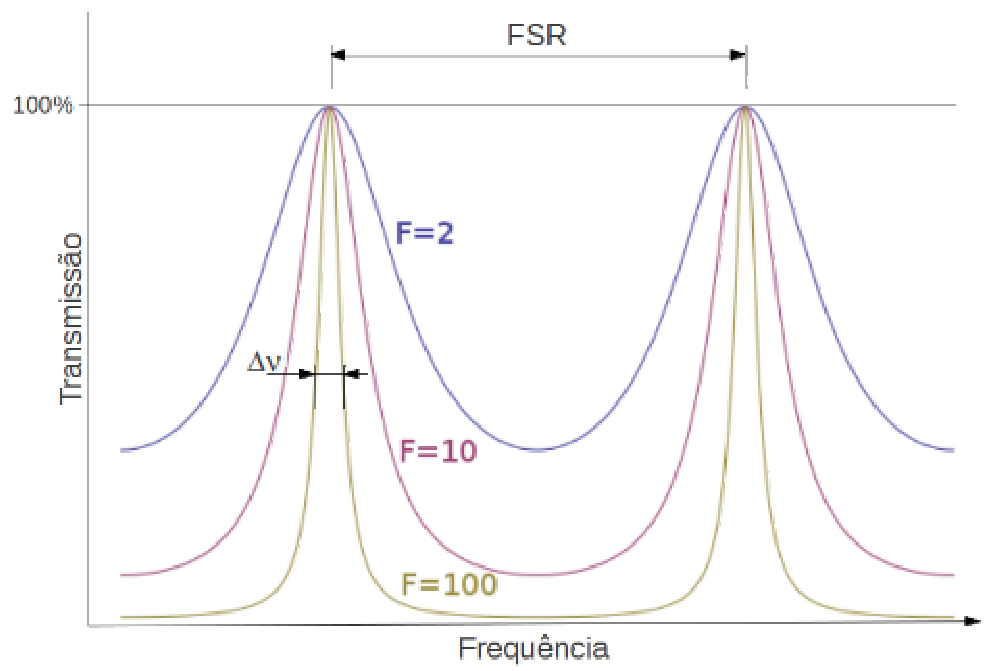

Figura 3.3. Transmissão de uma cavidade de Fabry-Perot com alta (linha vermelha) e baixa (linha azul) Finesse. 
Os picos de transmissão da cavidade ocorrem quando $\delta=2 n \pi$. A distância entre dois picos é chamada de Free Spectral Range (FSR); a largura a meia altura do pico de transmissão $\Delta \nu$ é chamada de largura de banda da cavidade; e a resolução da cavidade, dada pela razão entre o free spectral range e a largura de banda é chamada de finesse:

$$
\mathcal{F}=\frac{F S R}{\Delta \nu}
$$

Para a cavidade de Fabry-Perot a transmissão cai pela metade quando $F_{\operatorname{sen}^{2}}\left(\frac{\delta}{2}\right)=1$, que ocorre para $\delta= \pm 2 \operatorname{arcsen}\left(\frac{1}{\sqrt{F}}\right)$ e, portanto, $\Delta \nu=4 \operatorname{arcsen}\left(\frac{1}{\sqrt{F}}\right)$ e a finesse vale:

$$
\mathcal{F}=\frac{2 \pi}{4 \operatorname{arcsen}\left(\frac{1}{\sqrt{F}}\right)} \approx \frac{\pi \sqrt{R}}{1-R}=\frac{\pi \sqrt{F}}{2} .
$$

Outra maneira de medir a qualidade de uma cavidade é através do fator de qualidade $Q_{c}$ da cavidade, que é a razão entre a energia do campo aprisionado e a potência dissipada pela cavidade:

$$
Q_{c}=\omega \frac{U_{\mathrm{ic}}}{P_{d}}=\frac{2 \pi c}{\lambda} \frac{U_{\mathrm{ic}}}{P_{d}}
$$

onde $\omega$ é a frequência do campo, $\lambda$ é o comprimento de onda do campo, $c$ é a velocidade da luz, $U_{\text {ic }}$ é a energia do campo intra cavidade e $P_{d}$ é a potência dissipada.

No caso da cavidade de Fabry-Perot sem nenhum meio de ganho, a potência dissipada sobre a energia do campo é equivalente à transmissão por tempo pelas superfícies ou espelhos da cavidade.

Iremos definir a perda a cada reflexão em um espelho $\delta_{i}$ a partir de uma notação exponencial para a reflexão [12]:

$$
R_{i}=r_{i}^{2}=e^{-\delta_{i}} .
$$

A perda total que um feixe sofre em uma cavidade pode ser escrita como uma somatória de todas as perdas por reflexão:

$$
\delta_{c}=\sum_{i=1}^{N} \delta i
$$

Na cavidade de Fabry-Perot, a perda causada pela transmissão dos espelhos, em um intervalo de um segundo, é igual a perda a cada reflexão do campo, multiplicada pelo número de voltas que a luz dá na cavidade por segundo:

$$
\frac{P_{d}}{U_{\mathrm{ic}}}=\delta_{c} \frac{n_{\mathrm{voltas}}}{\text { segundo }}=\delta_{c} \frac{c}{L},
$$

onde $L$ é o comprimento da cavidade e $c$ a velocidade da luz.

Assim, podemos escrever o fator de qualidade $Q_{c}$ em função das perdas da cavidade

$$
Q_{c}=\frac{2 \pi L}{\lambda} \frac{1}{\delta_{c}} .
$$


Voltando para a equação (3.6), podemos reescrever a finesse em função das perdas da cavidade substituindo $R$ por $e^{-\delta_{c} \text { : }}$

$$
\mathcal{F}=\frac{\pi e^{-\delta_{c} / 2}}{1-e^{-\delta c}},
$$

que no limite em que as perdas são muito pequenas pode ser aproximado por

$$
\mathcal{F} \approx \frac{\pi\left(1-\frac{\delta_{c}}{2}\right)}{\delta_{c}} \approx \frac{\pi}{\delta_{c}},
$$

de forma que para cavidades macroscópicas de alta finesse o fator de qualidade e a finesse podem ser relacionadas:

$$
Q_{c}=\frac{2 L}{\lambda} \mathcal{F}=\frac{2 L \nu}{c} \mathcal{F}=\frac{\nu}{\mathrm{FSR}} \mathcal{F}
$$

onde se considerou que para uma cavidade linear, o comprimento espectral livre é a distância entre duas frequências ressonantes $\left(\nu=n \frac{c}{2 L}\right)$ e portanto vale $\mathrm{FSR}=\frac{c}{2 L}$.

Embora exista uma relação direta entre o fator de qualidade e a finesse, vale ressaltar que o fator de qualidade diz respeito à energia perdida por tempo, e, portanto, se alongarmos o comprimento da cavidade, para a mesma qualidade de reflexão dos espelhos, o número de reflexões por segundo diminuirá e o fator de qualidade aumentará, embora a finesse seja exatamente a mesma.

Para generalizar mais a expressão da finesse devemos considerar que as perdas da cavidade não acontecem pela transmissão dos espelhos, mas durante todo o percurso do feixe. Assim definimos uma perda por caminho percorrido de forma que

$$
\mathcal{F}=\frac{\pi e^{-L \delta_{c} / 2}}{1-e^{-L \delta c}}
$$

cuja expansão em Taylor não pode mais ser truncada em primeira ordem para micro-cavidades. Neste caso a relação dada por (3.7) entre poder de resolução e de armazenamento de energia da cavidade, deixa de valer.

As cavidades descritas nesta monografia são todas macroscópicas e de alta finesse (de modo prático uma finesse $\mathcal{F} \approx 100$ para uma cavidade passiva, no espectro visível, é considerada alta [12]), de forma que em nenhum momento será discutido seu fator de qualidade.

\subsection{Oscilação intracavidade}

Em regime de oscilação, dentro de uma cavidade, o campo oscilante é amplificado cada vez que passa pelo meio de ganho, mas sofre perdas também, a maioria delas devido às transmissões que ocorrem em cada espelho e às reflexões indesejadas que ocorrem nos outros elementos óticos da cavidade.

Mesmo em uma cavidade laser ideal é desejado que haja perdas em um dos espelhos, que permitem que parte do campo intracavidade possa sair. As "perdas" pelo espelho de saída é que formam de fato o feixe laser que observamos. 
Para um regime de oscilação estável é necessário que ao fim de uma volta completa dentro da cavidade o campo intracavidade tenha a mesma intensidade e fase do que no começo da volta. Para estudarmos esse regime é necessário considerarmos tanto o ganho de fase e intensidade que o campo tem ao atravessar o dopante, descritas em (2.27), como as perdas e a variação da fase do campo ao atravessar todo o espaço livre da cavidade.

O campo que atravessa um meio de ganho de comprimento $L$, uma única vez, pode ser descrito por:

$$
E(L)=E(0) e^{\left(\alpha_{m}-\alpha_{0}\right) L} e^{i(k+\Delta k) L}=E(0) \tilde{g}(\omega) .
$$

Ao percorrer toda a cavidade e voltar ao ponto inicial o campo passa a ser

$$
E(z)=E(0) \tilde{g}(\omega) e^{-i \varphi} r_{c},
$$

onde $\varphi$ é a fase ganha ao percorrer o espaço livre da cavidade e $r_{c}$ é o produto dos coeficientes de reflexão de cada um dos $\mathrm{N}$ espelhos da cavidade:

$$
r_{c}=\prod_{i=1}^{N} r_{i} .
$$

O regime de estabilidade de oscilação impõem duas condições: que o ganho iguale as perdas e que a fase total seja um múltiplo de $2 \pi$ :

$$
\begin{gathered}
e^{\left(\alpha_{m}-\alpha_{0}\right) L} r_{c}=1 \\
\varphi+k L+\Delta k L=2 \pi q, \quad q=\text { int. }
\end{gathered}
$$

\subsubsection{Limiar de oscilação}

Utilizando a notação exponencial para a reflexão dos espelhos:

$$
R_{i}=r_{i}^{2}=e^{-\delta_{i}}
$$

e definindo $\delta_{c}=\sum_{i=0}^{N} \delta i$, sendo que $\delta_{0}=2 \alpha_{0} L$, a condição de oscilação (3.8) fica:

$$
2 \alpha_{m} L=\delta_{c},
$$

que pode ser relacionada à intensidade do laser intracavidade pela equação (2.35), de forma que:

$$
\frac{I}{I_{\mathrm{sat}}}=\frac{2 \alpha_{m 0} L}{\delta_{c}}-1
$$

Se essa condição não é satisfeita, significa que as perdas de cada volta superam o ganho e o campo é atenuado ao invés de amplificado, não havendo portanto oscilação intracavidade. Nessa situação vale a equação (2.6) e $\alpha_{m 0} \propto \frac{R_{p}}{\gamma_{3}}$.

Aumentando a taxa de bombeio, o ganho também irá aumentar, até atinjir a condição (3.8) quando a potência intracavidade estabiliza, obedecendo a equação (2.4) e $\alpha_{m 0} \propto \frac{\gamma_{2}-\gamma_{32}}{\gamma_{3} \gamma_{2}} R_{p}$. Assim podemos definir uma taxa mínima de bombeio necessário para que o ganho iguale as perdas:

$$
2 \alpha_{m 0} L=\delta_{c} \Leftrightarrow R_{p}=R_{p \mathrm{th}} \Rightarrow \frac{R_{p}}{R_{p \mathrm{th}}}=\frac{2 \alpha_{m 0} L}{\delta_{c}},
$$


onde $R_{p \text { th }}$ é a taxa de bombeio no limiar de oscilação e vale:

$$
R_{p \mathrm{th}}=\frac{\delta_{c}}{L}\left(\frac{e r_{12} \Omega}{2 \varepsilon E_{0}} \frac{\gamma}{\frac{|\Omega|^{2}}{2}+\left(\frac{\gamma}{2}\right)^{2}+\delta^{2}} \frac{\gamma_{2}-\gamma_{32}}{\gamma_{3} \gamma_{2}}\right)^{-1} .
$$

A primeira condição de oscilação da cavidade fica sendo então:

$$
\frac{I}{I_{\mathrm{sat}}}=\frac{W}{W_{\mathrm{sat}}}=\frac{R_{p}}{R_{p \mathrm{th}}}-1=\frac{W_{p}}{W_{\mathrm{th}}}-1=\frac{P_{p}}{P_{\mathrm{th}}}-1
$$

onde $P_{p}$ é a potência de bombeio, proporcional à taxa de bombeamento $W_{p}$, que é proporcional à $R_{p}$, e $P_{\text {th }}$ é a potência de bombeio no limiar de oscilação, proporcional à $W_{\text {th }}$.

Como a potência de saída $P_{s}$ do laser é uma fração da potência intracavidade, dada pela transmissão do espelho de saída da cavidade, chega-se em

$$
P_{s}=T P=T P_{\text {sat }}\left(\frac{P_{p}}{P_{\text {th }}}-1\right)
$$

\subsubsection{Modos longitudinais}

A condição de fase para a oscilação do campo dentro cavidade, dada pela equação (3.9), leva a uma condição de dependência da frequência para a oscilação:

$$
\frac{\omega}{c_{0}}(Z-L)+\frac{\omega n}{c_{0}} L\left(1+\frac{\chi^{\prime}}{2}\right)=2 \pi q \Rightarrow Z+n L\left(-\frac{1}{n}+1+\frac{\chi^{\prime}}{2}\right)=\frac{2 \pi q c_{o}}{\omega},
$$

onde $Z$ é o comprimento total da cavidade, $L$ é o comprimento do meio de ganho, $\lambda_{0}$ é o comprimento de onda do campo oscilante, $c_{0}$ é a velocidade da luz no vácuo e $n$ é o índice de refração do meio dopante.

O termo $\chi^{\prime}$ pode ser desconsiderado porque, próximo da ressonância $\left(\omega-\omega_{a} \approx 0\right)$ $\chi^{\prime} \ll 1$ (ver figura 2.8). Além disso, não nos interessa saber exatamente qual é a frequência de cada modo da cavidade, mas sim a separação entre dois modos distintos, para podermos estimar quantos modos existem dentro de uma dada largura de linha.

A condição de fase é portanto:

$$
\omega_{q}=\frac{2 \pi q c_{0}}{Z+L(n-1)}
$$

o que significa que a distância entre um modo de frequência $\omega_{q}$ e um de frequência $\omega_{q+1}$ para uma cavidade laser é

$$
\Delta \omega_{\mathrm{cav}}=\frac{2 \pi c_{0}}{Z+L(n-1)} .
$$

Ainda no intuito de conhecer a separação entre dois modos, podemos considerar, normalmente, que o comprimento de $L$ do meio de ganho, comparado com o tamanho da cavidade $Z$, é desprezível e, portanto, o FSR da cavidade laser pode ser aproximada por:

$$
\mathrm{FSR}=\Delta \nu_{\mathrm{cav}} \approx \frac{c_{0}}{Z}
$$


ou em termos do comprimento de onda:

$$
\Delta \lambda_{\mathrm{cav}}=\frac{\lambda_{0}^{2}}{Z}
$$

Para cavidades lasers macroscópicas, a separação entre dois modos é pequena comparada à largura de linha de um meio ótico, o que faz com que existam muitos modos possíveis de oscilação. Uma cavidade de $1 \mathrm{~m}$, por exemplo, tem um intervalo espectral livre $\Delta \nu \simeq 0.3 \mathrm{GHz}$, enquanto a largura de linha do ganho de um laser de rubi é da ordem de 30Ghz. Isso significa que existem em torno de 100 modos longitudinais capazes de oscilar.

Apesar de existirem múltiplos modos possíveis para a oscilação, cada modo precisa atingir uma condição em que os ganhos superem as perdas. O ganho que o meio amplificador pode proporcionar, porém, é limitado pela inversão de população, o que leva a uma competição entre os modos dentro da cavidade. Um modo que tenha maior ganho irá ser amplificado mais rapidamente e o número de fótons nesse modo será maior do que o número de fótons em outros modos. Evidentemente, em uma volta seguinte pelo meio de ganho, o modo com o maior número de fótons tem maior propabilidade de ser amplificado, de forma que este modo satura rapidamente o cristal, impedindo outros modos de oscilarem.

Quando dois modos têm praticamente o mesmo ganho, pequenas flutuações da cavidade, provocando mais perdas em um ou em outro, fazem com que o laser salte de modo constantemente. Dentro de uma competição entre modos, mesmo perdas pequenas são capaz de determinar qual prevalecerá.

Para construir um laser monomodo é preciso, portanto, jogar com perdas capazes de distinguir entre frequências. Como fazer isso será o tema do final deste capítulo.

\subsection{Propagação do campo intracavidade}

Enquanto a condição 3.8 é uma condição de realimentação do amplificador, a condição 3.9 é consequência da propagação longitudinal do campo dentro da cavidade. Existe ainda outra condição de oscilação da cavidade que diz respeito à difração, ou seja, à variação do perfil transverso do campo.

Se a difração dentro de uma cavidade não é controlada, em pouco tempo o campo se expande até que não possa mais ser contido, provocando perdas que poderiam ser eliminadas através do uso de lentes e espelhos que mantivessem o laser colimado.

Não é qualquer cavidade que mantém o campo colimado em seu interior, e construir uma que o faça não é sempre trivial. É necessário, primeiro, saber como o perfil transverso do campo varia conforme o campo se propaga.

\subsubsection{Onda não plana}

O campo eletromagnética que oscila dentro da cavidade precisa, obrigatoriamente, obedecer à equação de onda derivada das equações de Maxwell [33], [34]:

$$
\nabla^{2} E-\frac{1}{c} \frac{\partial^{2} E}{\partial t^{2}}=0
$$


Uma solução bastante simples para esta equação é a solução da onda plana que se propaga em uma única direção, do tipo $E=E_{0} e^{i(k z-\omega t)}$. Entretanto, ondas planas não podem existir em um espaço confinado, pois suas condições de fronteira não respeitam a lei de conservação de energia.

A respeito de uma prova da não existência de certas soluções de Maxwell feita por Hillion ${ }^{3.1}$, Henning F. Harmuth escreveu:

"As conservações das leis da física são construídas pela equação de Maxwell, modificadas ou não, através das chamadas simetrias. Em particular, a lei de conservação de energia é garantida por uma invariância a deslocamentos temporais. Essa é, entretanto, apenas uma condição necessária. Se nós definirmos uma função de excitação com energia infinita, nós excitamos uma onda com energia infinita e mesmo assim estamos fora da lei de conservação de energia. Isso significa, em termos da matemática, que a condição de fronteira precisa ser quadrado integrável. Para uma onda esférica excitada em um ponto, o termo "quadrado integrável" pode se referir apenas à variável temporal. Se a excitação é por uma superfície finita, "quadrado integrável" refere-se tanto à variável temporal quanto às variáveis espaciais.

Existe um problema se uma onda plana é excitada, por exemplo, por uma condição de fronteira em $x=0$. Ainda que a condição de fronteira com respeito ao tempo seja quadrado integrável, a função de excitação tem energia infinita uma vez que a superfície $x=0$ é infinita. Experiências mostram que é possível obter resultados "razoáveis" nesse caso, mas é prudente checar resultados fundamentais para ondas planas contra os resultados mais físicos para ondas esféricas. Em qualquer caso, condições de fronteira quadrado integráveis com respeito ao tempo precisam satisfazer obrigatoriamente a conservação de energia." 3.2

Uma solução não plana genérica para uma onda que se propaga na direção $\hat{z}$ (a direção de propagação é imposta pela geometria da cavidade) é do tipo

$$
E=u(x, y, z) e^{i(k z-\omega t)},
$$

onde $u(x, y, z)$ é o perfil transverso da onda e precisa obedecer à equação 3.13 . Portanto:

$$
\left[\left(\frac{\partial^{2} u}{\partial x^{2}}+\frac{\partial^{2} u}{\partial y^{2}}+\frac{\partial^{2} u}{\partial z^{2}}\right)+2 i k \frac{\partial u}{\partial z}-k^{2} u+\frac{\omega^{2}}{c^{2}} u\right] e^{i(k z-\omega t)}=0,
$$

sendo que $k^{2}=\frac{\omega^{2}}{c^{2}}$.

3.1. P. Hillion, "Remarks on Harmuth's 'Correction of Maxwell's equations for signals I.' ". IEEE Trans. Electromagn. Compat., vol. 33, no. 1, p. 144, May 1991.335]

3.2. Harmuth, H.F. "Hillion's proof of the nonexistence of certain solutions of Maxwell's equations". IEEE Trans. Electromagn. Compat., vol. 33, no. 4, p. 371, Nov 1991. 
É coerente supormos que a variação da amplitude no perfil transverso do feixe seja muito maior do que a variação da amplitude na direção de propagação, ou seja, que o feixe tem um perfil que varia lentamente conforme se propaga. Essa aproximação é chamada de Slowly Varying Envelope Approximation (SVEA) [32], e significa dizer que:

$$
\left|\frac{\partial^{2} u}{\partial z^{2}}\right| \ll\left|\frac{\partial^{2} u}{\partial x^{2}}\right|,\left|\frac{\partial^{2} u}{\partial y^{2}}\right| .
$$

Sendo assim, a equação (3.14) pode ser aproximada por:

$$
\left(\frac{\partial^{2} u}{\partial x^{2}}+\frac{\partial^{2} u}{\partial y^{2}}\right)+2 i k \frac{\partial u}{\partial z}=0 .
$$

Essa é uma equação conhecida, exatamente igual à aproximação paraxial da equação de Helmholtz, e sua solução para cada componente transversa é um polinômio de Hermite de ordem $n$. A solução geral é, portanto, o produto de dois polinômios de ordens $n$ e $m$ para as componentes $x$ e $y$ respectivamente.

A necessidade de que $u(x, y, z)$ seja quadrado integrável implica que as soluções sejam multiplicadas por funções de distribuições gaussianas, que também devem obedecer às equações de onda, dando origem a novas soluções, conhecidas como polinômios de Hermite-Gauss:

$$
u_{\mathrm{mn}}(x, y, z)=u_{n}(x, z) u_{m}(y, x),
$$

onde

$$
u_{n}(x, z)=K_{0} A(x, z) H_{n}\left(\frac{\sqrt{2 x}}{w(z)}\right) e^{-i \frac{k x^{2}}{2 q(z)}}
$$

sendo $H_{n}$ o polinômio de Hermite de ordem $n ; A(x, z)$ a distribuição gaussiana que será discutida em detalhe na subseção seguinte; $K_{0}=\left(\frac{2}{\pi}\right)^{1 / 4}\left(\frac{1}{2^{n} n ! w_{0}}\right)$ um fator de normalização de $u(x, z)$; e $q(z)$ e $w(z)$ funções que aparecem no tratamento da onda gaussiana que será discutido a seguir.

\subsubsection{Feixes gaussianos}

A solução de ordem $n=0, m=0$ para a onda não plana leva a um perfil de onda gaussiano, simétrico no plano transverso, o que nos permite reescrever a equação (3.14) para o perfil gaussiano em coordenadas cilíndricas desprezando a variação em $\theta$ :

$$
\frac{1}{r} \frac{\partial A(r, z)}{\partial r}+\frac{\partial^{2} A(r, z)}{\partial r^{2}}+2 i k \frac{\partial A(r, z)}{\partial z}=0,
$$

onde $A(r, z)$ é a distribuição de amplitude do modo $n=0, m=0$.

A solução para esta equação é:

$$
A(r, z)=\frac{1}{q(z)} e^{i\left(\frac{k}{2 q(z)} r^{2}\right)}
$$

onde $q(z)$ pode ser comparado ao raio de uma onda esférica, que é também uma solução da equação 3.13 :

$$
E_{\mathrm{esf}}=\frac{1}{\rho} e^{-i k \rho},
$$


onde:

$$
\rho=\sqrt{x^{2}+y^{2}+z^{2}}=z \sqrt{1+\frac{x^{2}+y^{2}}{z^{2}}},
$$

que, para $z \gg x, y$ (aproximação paraxial), pode ser aproximado por:

e, portanto:

$$
\rho \simeq z\left(1+\frac{r^{2}}{2 z^{2}}\right)
$$

$$
E_{\mathrm{esf}} \simeq \frac{1}{z} e^{-i k z} e^{-i k \frac{r^{2}}{2 z}}
$$

semelhante à (3.18). A onda esférica, porém, não é quadrado integrável no espaço e, por isso, não é uma solução real. Para que a equação (3.18) represente uma solução real, é necessário que o raio $q(z)$ seja complexo.

Aplicando a solução de (3.18) em (3.17) temos:

$$
\frac{\partial}{\partial z} q(z)=1
$$

que implica em $q(z)=q_{0}+z \operatorname{com} q(0)=i z_{0}$ e, portanto,

$$
q(z)=z+i z_{0}
$$

Assim a equação (3.18) pode ser reescrita como:

$$
A(r, z)=\frac{1}{q(z)} e^{-i \frac{k r^{2}}{2}\left(\frac{z}{z^{2}+z_{0}^{2}}\right)} e^{-i r^{2}\left(\frac{1}{2} \frac{k z_{0}}{z^{2}+z_{0}^{2}}\right)} \equiv \frac{1}{q(z)} e^{-i \frac{k r^{2}}{2 R(z)}} e^{-\frac{r^{2}}{w^{2}(z)}} .
$$

O módulo ao quadrado de $A(r, z)$ descreve um perfil gaussiano em $r$ para o qual $86.5 \%$ da intensidade do feixe está contido em um raio $r=\frac{w(z)}{2}$ :

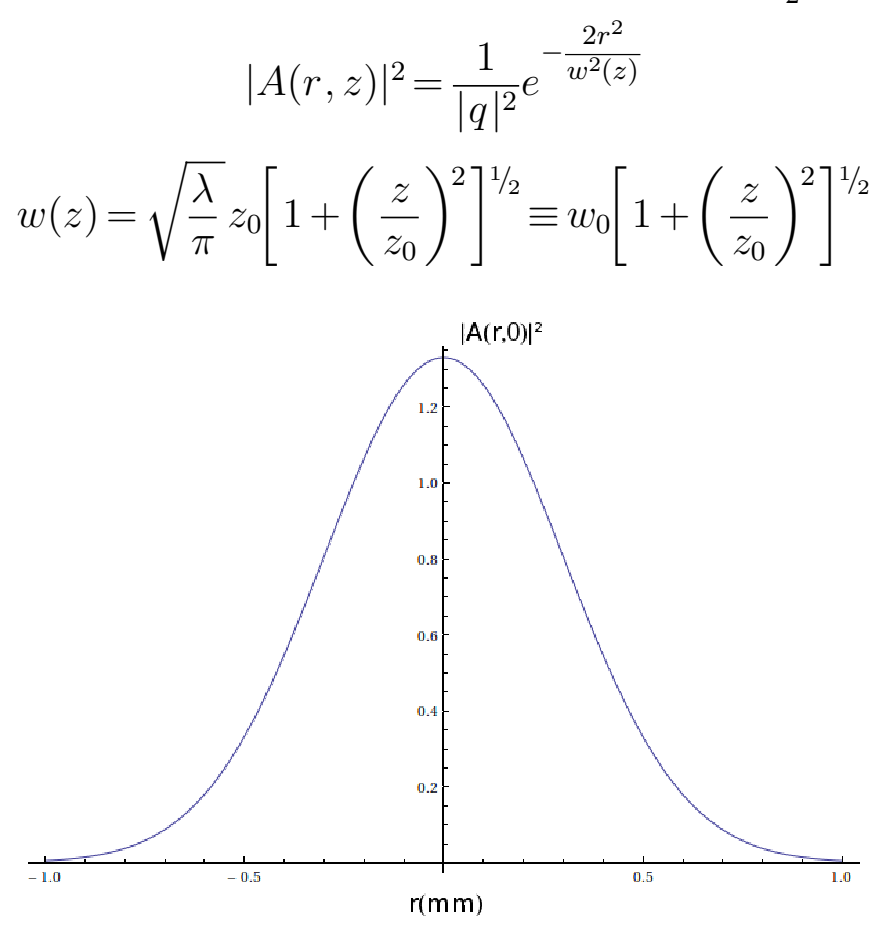

Figura 3.4. Perfil gaussiano de um feixe na posição $z=0$ com cintura $w_{0}=0.3 \mathrm{~mm}$. 
A menor largura que o feixe pode ter, chamada de cintura do feixe, ocorre para a posição $z=0$ e vale $w(0)=w_{0}=\sqrt{\frac{\lambda}{\pi}} z_{0}$. Quando o feixe atinge a distância $z=z_{0}$, a área do feixe $\frac{\pi w^{2}(z)}{4}$ dobra. A distância $z_{0}$ é conhecida como comprimento de Rayleigh.

Comparando agora a equação (3.20) com a aproximação paraxial da onda esférica em 3.19, percebe-se que $R(z)$ é a curvatura da onda [32].

$$
R(z)=z\left[1+\left(\frac{z_{0}}{z}\right)^{2}\right]
$$

Próximo ao plano $z=0$, a curvatura tende a infinito, e a onda se aproxima de uma onda plana. Conforme a onda se afasta da origem, a frente de onda passa a se tornar parabólica, até que, para $z^{2} \gg z_{0}^{2}$, região para a qual vale a aproximação paraxial, a curvatura tende a $z$, o que significa que a frente de onda se assemelha a uma frente de onda esférica.

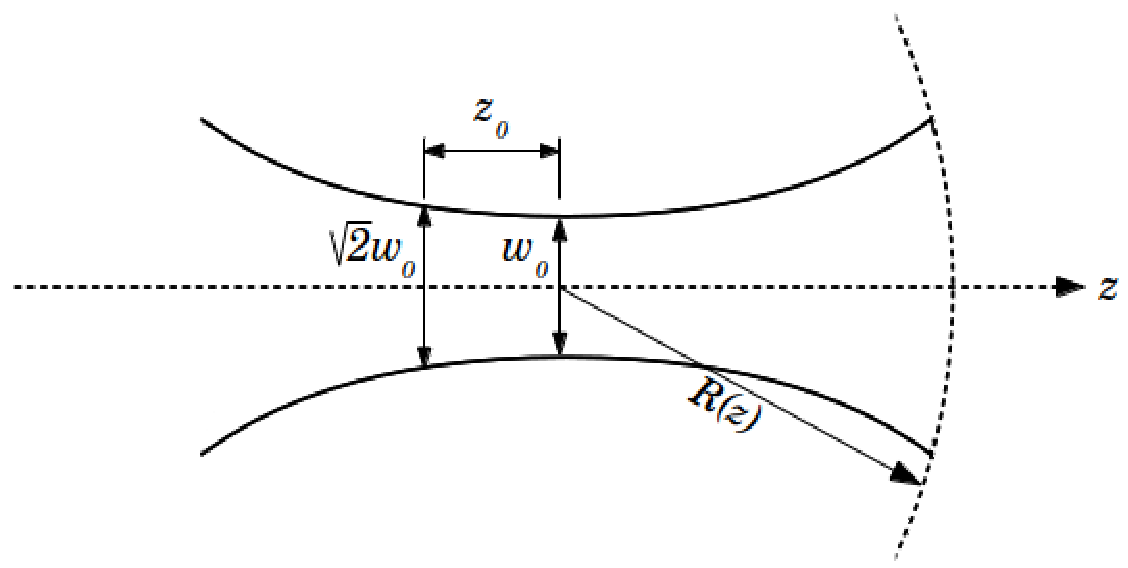

Figura 3.5. Largura $w$ do feixe em função de $z$.

O raio complexo $q(z)$ pode ser escrito em função do raio de curvatura $R(z)$ e da cintura do feixe $w(z)$ :

$$
\frac{1}{q(z)}=\frac{1}{R(z)}-i \frac{\lambda}{\pi w^{2}(z)}
$$

\subsubsection{Outros modos transversos}

Além do modo gaussiano, existe uma infinidade de modos derivados da equação de onda paraxial. Em coordenadas cartesianas esses modos representam os diferentes

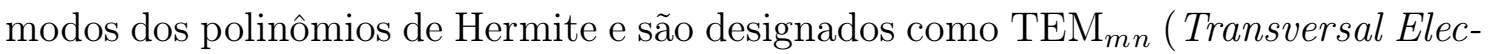
tromagnetic Mode), sendo $\mathrm{TEM}_{00}$ o modo gaussiano fundamental. 
Em coordenadas cilíndricas, o perfil transverso do campo tem os modos derivados dos polinômios de Laguerre [36], e designados como como $\mathrm{TEM}_{p l}$, onde o índice $p$ define o modo radial e o índice $l$ define o modo angular.

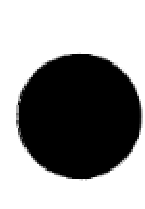

00

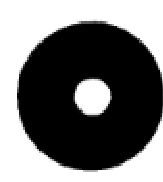

$01^{*}$

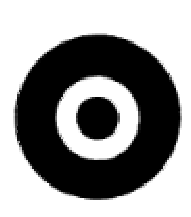

10

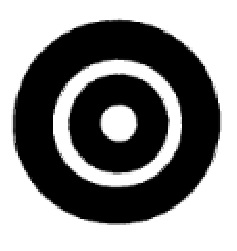

$11^{*}$

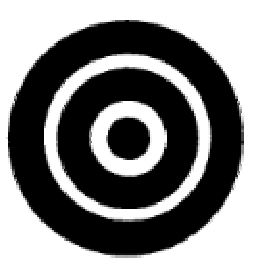

20

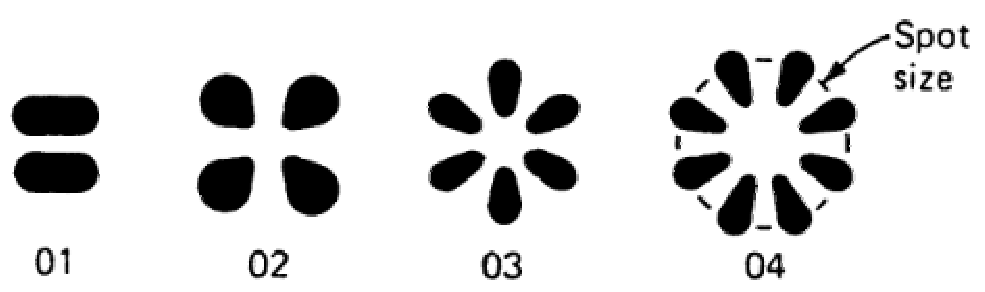

Cylindrical

(a)

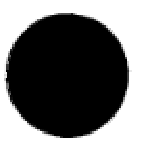

00

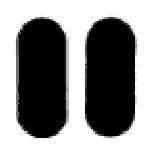

10

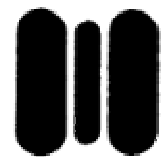

20

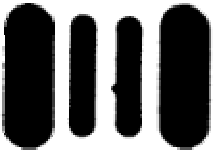

30

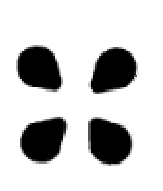

11

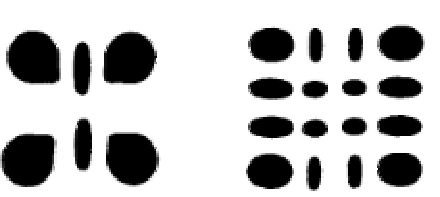

21
33

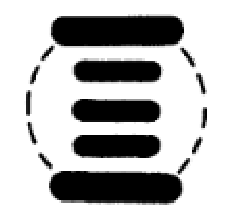

04

Rectangular

(b)

Figura 3.6. Imagem esquemática de alguns perfis transversos de modos cilíndricos (a) e retangulares (b).

Retirado de [27, Koechner, p.212].

Tanto os polinômios de Hermite como os de Laguerre, formam uma base que nos permite escrever qualquer solução para a equação de onda, e, como consequência, é possível escrever qualquer modo $\mathrm{TEM}_{p l}$ na base dos modos $\mathrm{TEM}_{m n}$ e vice-versa.

Todos os modos são descritos pelo raio complexo $q(z)$ definido pela equação 3.21, mas $w(z)$ não representa, sempre, a metade da largura do feixe para modos de ordem maior que zero. Mesmo assim, a transformação após a propagação através 
de elementos óticos, para qualquer modo, pode ser calculada através das matrizes ABCD que serão apresentadas na subseção seguinte.

A figura 3.7 mostra a distribuição de intensidade de alguns modos em coordenadas cilíndricas. O modo $\mathrm{TEM}_{00}$ é o que concentra a maior intensidade no seu centro, e portanto é o que tem maior probabilidade de oscilar em uma cavidade com meio de ganho cilindricamente simétrica.

É possível, etretanto, privilegiar a oscilação de outros modos, aplicando perdas locais que não afetam aqueles que têm intensidade nula no ponto.

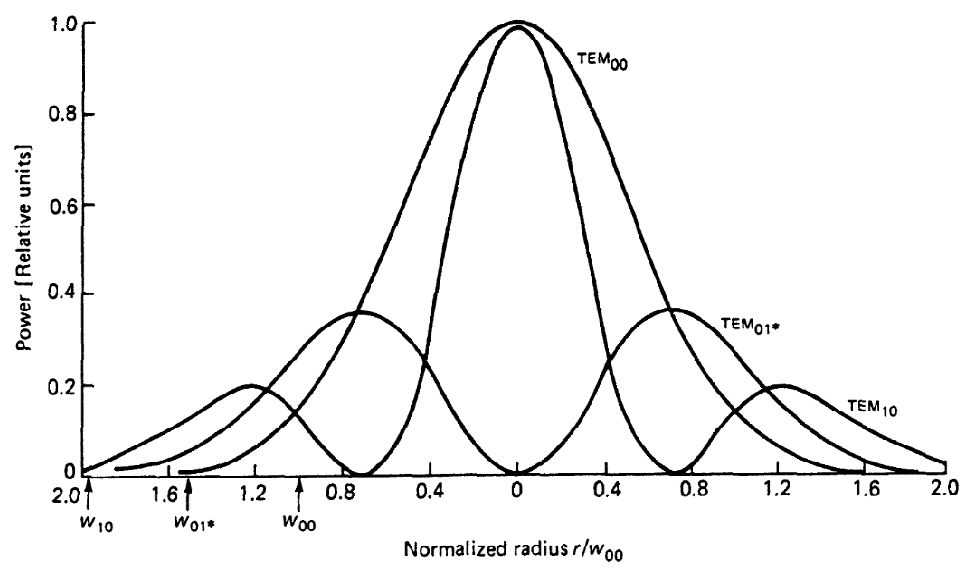

Figura 3.7. Distribuição de intensidade radial para os modos $\mathrm{TEM}_{00}, \mathrm{TEM}_{01} *$ e $\mathrm{TEM}_{10}$. Retirado de [27, Koechner, p.213].

\subsubsection{Matrizes ABCD}

As matrizes ABCD são uma ferramenta desenvolvida para ótica geométrica, que permitem descrever a propagação de um feixe por elementos óticos paraxiais como lentes, espelhos, etc, de um ponto até outro, através da transformação de um vetor coluna descrito pela distância $r$ e pelo ângulo $\theta \approx \frac{\partial r}{\partial z}$ do feixe em relação ao eixo ótico [37].

A importância das matrizes ABCD é que, considerando ao invés de $r$ e $\theta$, a largura da seção transversa da onda gaussiana $w(z)$ e o raio complexo $q(z)$, pode-se descrever a propagação do feixe gaussiano dentro da cavidade que se deseja construir.

A validade da matriz ABCD para descrever a propagação de feixes gaussianos será demonstrada no final desta subseção. Primeiramente será demonstrado como se dá a utilização e construção das matrizes ABCD para feixes.

A matriz $\mathrm{ABCD}$ que descreve a propagação livre de um feixe da posição $z=z_{1}$ até a posição $z=z_{2}=z_{1}+d$, tem que ser a matriz de transformação linear do vetor $f(z)=\left(\begin{array}{c}r(z) \\ r^{\prime}(z)\end{array}\right)$ que obedece a relação

$$
M_{\mathrm{pl}} f\left(z_{1}\right)=f\left(z_{2}\right)=\left(\begin{array}{c}
r_{1}+d r_{1}^{\prime} \\
r_{1}^{\prime}
\end{array}\right),
$$


pois, como evidenciado pela figura 3.8 , o raio que parte de $z_{1}$ mantém o seu ângulo $\theta$ com relação ao eixo ótico ao se propagar até $z_{2}$, mas se afasta uma distância equivalente a $d r_{1}^{\prime}$.

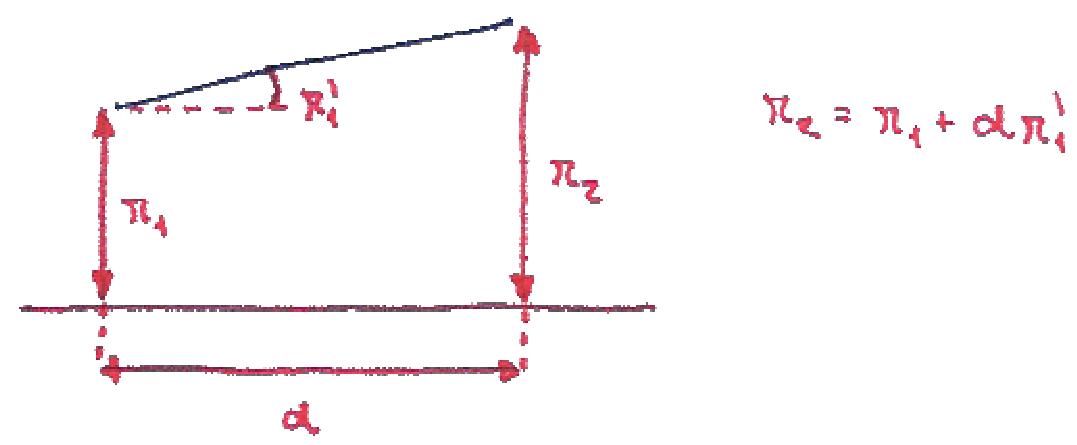

Figura 3.8. Propagação livre de um feixe.

Sendo assim, a matriz para a propagação livre por uma distância $d$ é

$$
M_{\mathrm{pl}}=\left(\begin{array}{cc}
1 & d \\
0 & 1
\end{array}\right)
$$

A matriz $\mathrm{ABCD}$ que descreve um feixe atravessando a interface entre um meio diéletrico com índice de refração $n_{1}$, e outro com índice de refração $n_{2}$, deve ser tal que altere o ângulo de propagação do feixe de acordo com a lei de Snell na aproximação paraxial: $n_{1} r_{1}^{\prime}=n_{2} r_{2}^{\prime}$.

Portanto, a matriz ABCD para a mudança de meio é

$$
M_{\mathrm{mm}}=\left(\begin{array}{cc}
1 & 0 \\
0 & \frac{n_{1}}{n_{2}}
\end{array}\right) .
$$

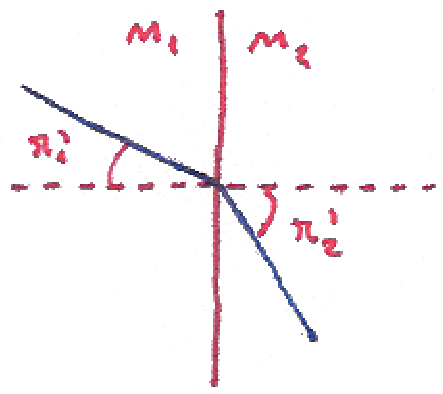

Figura 3.9. feixe mudando de um meio de índice de refração $n_{1}$ para um com índice de refração $n_{2}$

Já a matriz que descreve o feixe que atravessa uma lente esférica de distância focal $f$ deve obedecer a relação

$$
\frac{1}{p}+\frac{1}{q}=\frac{1}{f}
$$




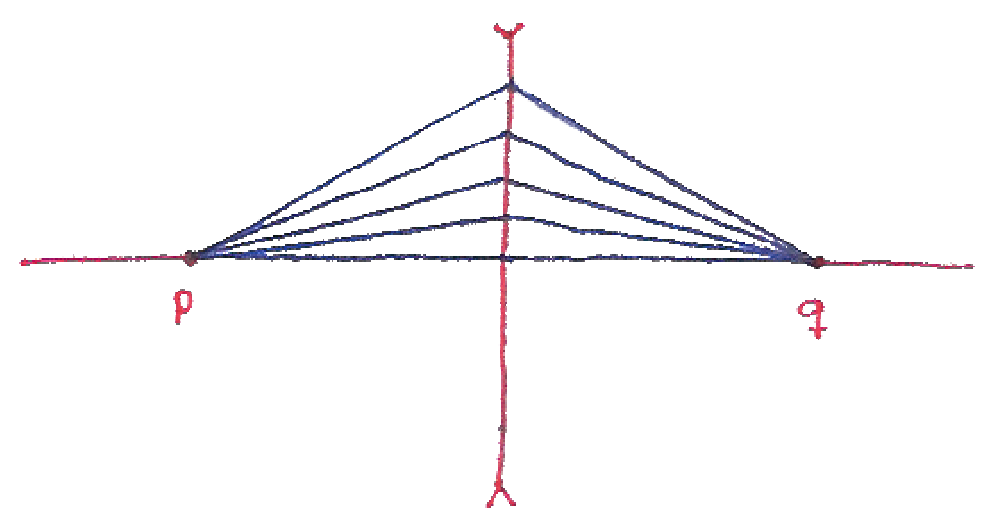

Figura 3.10. Diversos feixes atravessando uma lente partindo de um ponto p e sendo focados em um ponto q.

Na superfície da lente o ângulo do feixe incidente é $r_{1}^{\prime}=\frac{r_{1}}{p}$ e passa a ser $r_{2}^{\prime}=$ $-\frac{r_{2}}{q}=-\frac{r_{1}}{q}$, pois $r_{1}=r_{2}$. Portanto $r_{1}^{\prime}-r_{2}^{\prime}=\frac{r_{1}}{p}+\frac{r_{1}}{q}=\frac{r_{1}}{f} \Rightarrow r_{2}^{\prime}=r_{1}^{\prime}-\frac{r_{1}}{f}$. Assim a matriz para a lente esférica delgada é:

$$
M_{l}=\left(\begin{array}{cc}
1 & 0 \\
-\frac{1}{f} & 1
\end{array}\right) .
$$

Uma grande vantagem do uso de matrizes ABCD é que uma série de elementos óticos paraxiais, dispostos em sequência, pode ser descrita por uma única matriz resultante do produto da matriz de cada elemento, pois se um elemento transforma um vetor coluna $f\left(z_{1}\right)$ em $f\left(z_{2}\right)=M_{1} f\left(z_{1}\right)$ e o elemento seguinte modifica o vetor resultante através de uma transformação $f\left(z_{3}\right)=M_{2} f\left(z_{2}\right)$, então o vetor resultante do segundo elemento pode ser descrito como $f\left(z_{3}\right)=M_{2} M_{1} f\left(z_{1}\right)=M_{21} f\left(z_{1}\right)$, onde $M_{21}=M_{2} M_{1}$.

Dessa forma, qualqer sequência de elementos alinhados com relação a um mesmo eixo ótico pode ser descrita por uma única matriz de transformação ABCD.

Supondo agora que um feixe que atravesse os elementos tenha origem também no eixo ótico, como uma frente de onda esférica paraxial, então o raio de curvatura dessa onda esférica, que pode ser descrito como $R=\frac{r}{r^{\prime}}$, pode ser transformado também pela matriz ABCD da seguinte maneira:

$$
R_{2}=\frac{r_{2}}{r_{2}^{\prime}}=\frac{A r_{1}+B r_{1}^{\prime}}{C r_{1}+D r_{1}^{\prime}}=\frac{A R_{1}+B}{C R_{1}+D}
$$

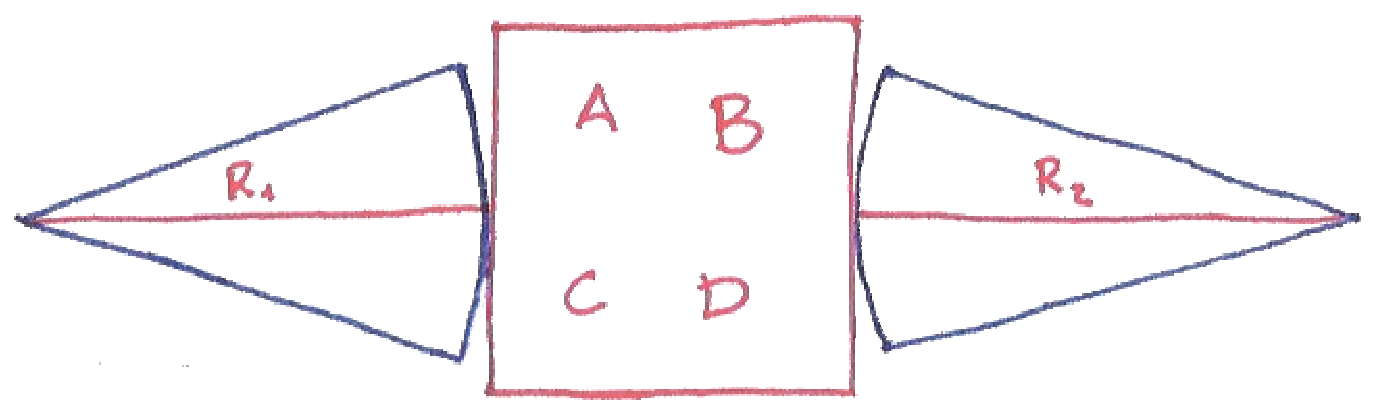

Figura 3.11. Onda esférica, distante $R_{1}$ de um elemento descrito por uma matriz ABCD, sendo focado em outro ponto, distante $R_{2}$ do elemento. 
Para a propagação de feixes gaussianos o raio $R$ é substituido pelo raio complexo $q$, e todas as propriedades das matrizes $\mathrm{ABCD}$ permanecem válidas, de forma que as mesmas matrizes utilizadas para ótica geométrica, para qualquer elemento ótico, podem ser utilizadas para os feixes gaussianos.

A validade da matriz de propagação livre para feixes gaussianos, por exemplo, pode ser facilmente verificada pela equação abaixo:

$$
q\left(z_{2}\right)=q\left(z_{1}\right)+d=z_{1}+i z_{0}+d=q\left(z_{1}+d\right) .
$$

Já a demonstração para a mudança de meio é um pouco mais complicada:

$$
q\left(z_{2}\right)=\frac{n_{2}}{n_{1}} q\left(z_{1}\right) \Rightarrow z_{2}+i z_{0_{2}}=\frac{n_{2}}{n_{1}}\left(z_{1}+i z_{0_{1}}\right) .
$$

Exatamente entre os meios dielétricos, pode-se considerar, sem perda de generalidade, $z_{1}=z_{2}=0$. Assim, percebemos que a cintura do feixe é a mesma para o feixe incidente e o transmitido $w_{0_{1}}=w_{0_{2}}$, mas, o comprimento de Rayleigh para o qual a largura do feixe dobra é outro

$$
z_{0_{2}}=\frac{n_{2}}{n_{1}} z_{0_{1}}
$$

Como, na distância de Rayleigh, a cintura do feixe tem raio $\sqrt{2} w_{0}$, podemos considerar que o ângulo de propagação de um feixe gaussiano em $z=0$ vale aproximadamente $\theta \simeq \frac{\sqrt{2} w_{0}}{z_{0}}$. Portanto:

$$
\theta_{2} \simeq \frac{\sqrt{2} w_{0}}{z_{0_{2}}}=\frac{n_{1}}{n_{2}} \frac{\sqrt{2} w_{0}}{z_{0_{1}}}=\frac{n_{1}}{n_{2}} \theta_{1}
$$

que é a lei de Snell, provando que a matriz de mudança de meio se aplica ao feixe gaussiano.

A matriz da lente esférica implica em:

$$
q\left(z_{2}\right)=\frac{q\left(z_{1}\right)}{-\frac{1}{f} q\left(z_{1}\right)+1} \Rightarrow \frac{1}{q\left(z_{1}\right)}-\frac{1}{q\left(z_{2}\right)}=\frac{1}{f},
$$

que é exatamente a equação da lente de Gauss.

Assim como demonstrada para estas três matrizes, a validade da aplicação das matrizes ABCD para feixes gaussianos pode ser demonstrada para qualquer outra matriz ABCD utilizada em ótica geométrica.

\subsubsection{Sistemas periódicos de foco}

O caminho de um feixe dentro de uma cavidade fechada pode ser descrito como um loop infinito de matrizes ABCD. No caso de dois espelhos côncavos, paralelos, de raios de curvatura $R_{1}$ e $R_{2}$, por exemplo, pode-se considerar como eixo ótico, o versor de propagação da onda $\hat{k}=\frac{\vec{k}}{|k|}$, o que permite desprezarmos a inversão no sentido de propagação provocada pelos espelhos, de forma que os espelhos podem ser tratados como lentes convergentes de foco $f=-\frac{R}{2}$. 

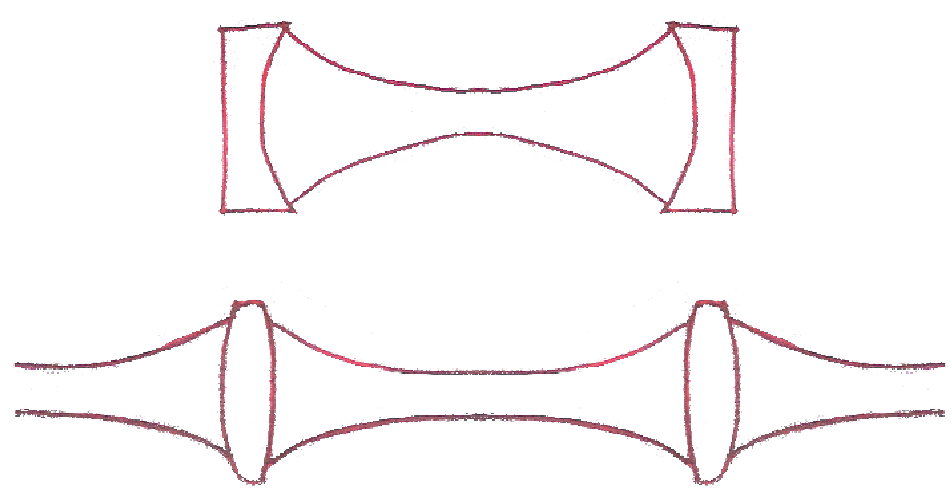

Figura 3.12. Acima uma cavidade tipo Fabry-Perot, com um espelho de raio $R_{1}$ e outro de raio $R_{2}$. Abaixo um pedaço de um sistema equivalente formado por uma série infinita de lentes de focos $f_{1}=-\frac{2}{R_{1}}$ e $f_{2}=-\frac{2}{R_{2}}$ dispostas em sequência.

O desdobramento dos espelhos permite considerar o sistema como uma sequência infinita de lentes, como mostra a figura 3.12, que podem, por sua vez, ser descritas por uma sequência infinita de matrizes ABCD's. Entretanto, se o sistema é estável, faz-se necessária uma condição de auto consistência que imponha que o feixe, após uma volta completa na cavidade, seja exatamente o mesmo que no início. Em termos matemáticos isso significa que

$$
q_{1}=q_{2}=\frac{A q_{1}+B}{C q_{1}+D}
$$

onde a matriz $\mathrm{ABCD}$ corresponde à matriz de transformação da cavidade após uma única volta.

A condição de auto consistência implica que

$$
q=\frac{-(D-A) \pm \sqrt{(D-A)^{2}+4 C B}}{2 C}=z+i z_{0}
$$

Como $z_{0}=\frac{\pi w_{0}^{2}}{\lambda}$ é uma grandeza necessariamente positiva, para que uma cavidade seja estável, é preciso que a matriz $\mathrm{ABCD}$, que representa uma volta da cavidade, tenha:

$(D-A)^{2}+4 C B<0$.

Como é propriedade das matrizes $\mathrm{ABCD}$ que, para um feixe que não muda de meio, seu determinante seja unitário, portanto $A D-B C=1$, a condição de estabilidade se torna:

$$
\frac{|D+A|}{2}<1
$$

com

$$
q=\frac{A-D}{2 C} \pm i \frac{\sqrt{4-(D+A)^{2}}}{2 C}
$$


No caso da cavidade específica da figura 3.12, a matriz ABCD vale:

$$
\begin{aligned}
& M_{\text {cavidade }}=M_{l}\left(\frac{R_{2}}{2}\right) M_{\mathrm{pl}}(d) M_{l}\left(\frac{R_{1}}{2}\right) M_{\mathrm{pl}}(d)= \\
& =\left(\begin{array}{cc}
1-\frac{2 d}{R_{2}} & 2 d\left(1-\frac{d}{R_{2}}\right) \\
-\frac{2}{R_{1}}-\frac{2}{R_{2}}+\frac{4 d}{R_{1} R_{2}} & -\frac{4 d}{R_{1}}-\frac{2 d}{R_{2}}+\frac{4 d}{R_{1} R_{2}}+1
\end{array}\right) .
\end{aligned}
$$

A condição de estabilidade é:

$$
\begin{gathered}
\frac{1}{2}\left|-\frac{4 d}{R_{1}}-\frac{4 d}{R_{2}}+\frac{4 d^{2}}{R_{1} R_{2}}+2\right|=\left|2\left(1-\frac{d}{R_{1}}\right)\left(1-\frac{d}{R_{2}}\right)-1\right|<1 \\
\Rightarrow 0<\left(1-\frac{d}{R_{1}}\right)\left(1-\frac{d}{R_{2}}\right)<1 .
\end{gathered}
$$

Essa expressão pode ser convenientemente representada pelo gráfico de $g_{1}=1-\frac{d}{R_{1}}$ por $g_{2}=1-\frac{d}{R_{2}}$ mostrado na figura 3.13 .

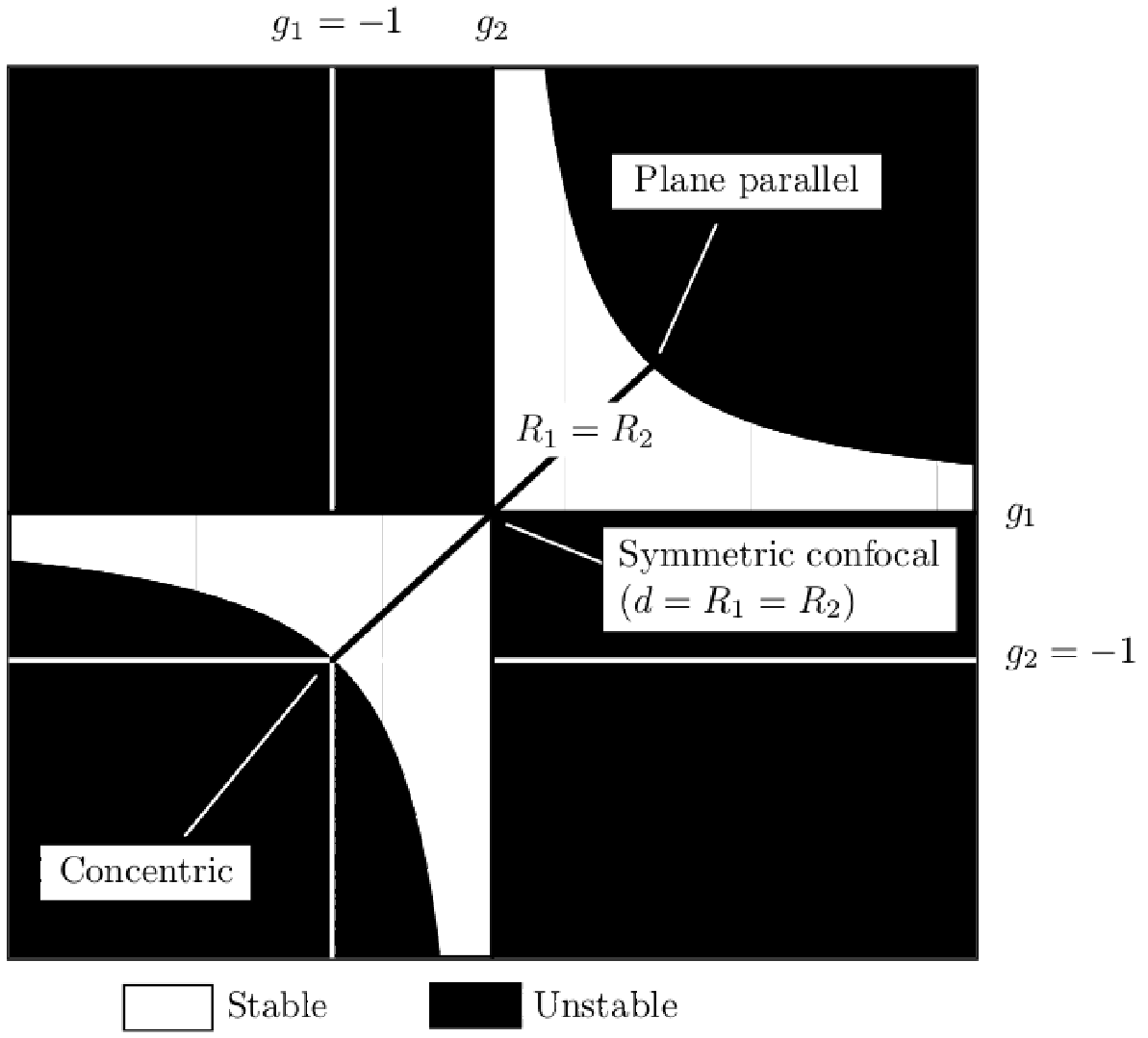

Figura 3.13. Diagrama de estabilidade da cavidade de FP. Retirado de [19, Nagourney, p.17]. 


\subsection{Cavidade do Titânio Safira}

Entre as cavidades linear e de onda propagante, a mais conveniente para o laser contínuo de titânio safira é a cavidade de onda propagante, porque nela se evitam os nós das ondas estacionárias que ocorrem em cavidades lineares, onde o campo é sempre nulo e, portanto, não é amplificado. Além disso, é importante que o feixe de bombeio seja introduzido na mesma direção do campo intracavidade, de forma que ele atravesse o cristal em todo o seu comprimento, maximizando sua eficiência. Em uma cavidade linear, seria imprudente alinhar o bombeio dessa maneira sem a utilização de um isolador ótico, o que produziria muitas perdas, pois parte do feixe seria refletido no espelho de entrada, podendo danificar o laser de bombeio.

O feixe de bombeio se propagando na mesma direção do feixe ressonante da cavidade também facilita o alinhamento dos espelhos, pois ele é intenso e visível.

Outro fator importante é que o titânio-safira tem uma intensidade de saturação bastante alta, de forma que podemos bombeá-lo com muita intensidade. Por isso, é desejável que a cavidade seja desenhada de maneira que haja um foco intracavidade sobre o cristal de titânio-safira, onde o campo seja extremamente concentrado, tipicamente da ordem de $10 \mu m$ de diâmetro. Além disso, é desejado que a cavidade seja longa (da ordem de $1 \mathrm{~m}$ ), de forma que seu comprimento espectral livre seja pequeno o bastante para que se possa sintonizar a frequência do laser com bastante precisão [38].

Cavidades que satisfazem essas condições, entretanto, requerem espelhos côncavos posicionados com um ângulo oblíquo de incidência, que provocam distorções astigmáticas no feixe, comprometendo a performance do laser. Assim é importante que o astigmatismo provocado pelos espelhos possa ser compensado de alguma maneira pelos elementos intracavidade, o que será o assunto da subseção seguinte.

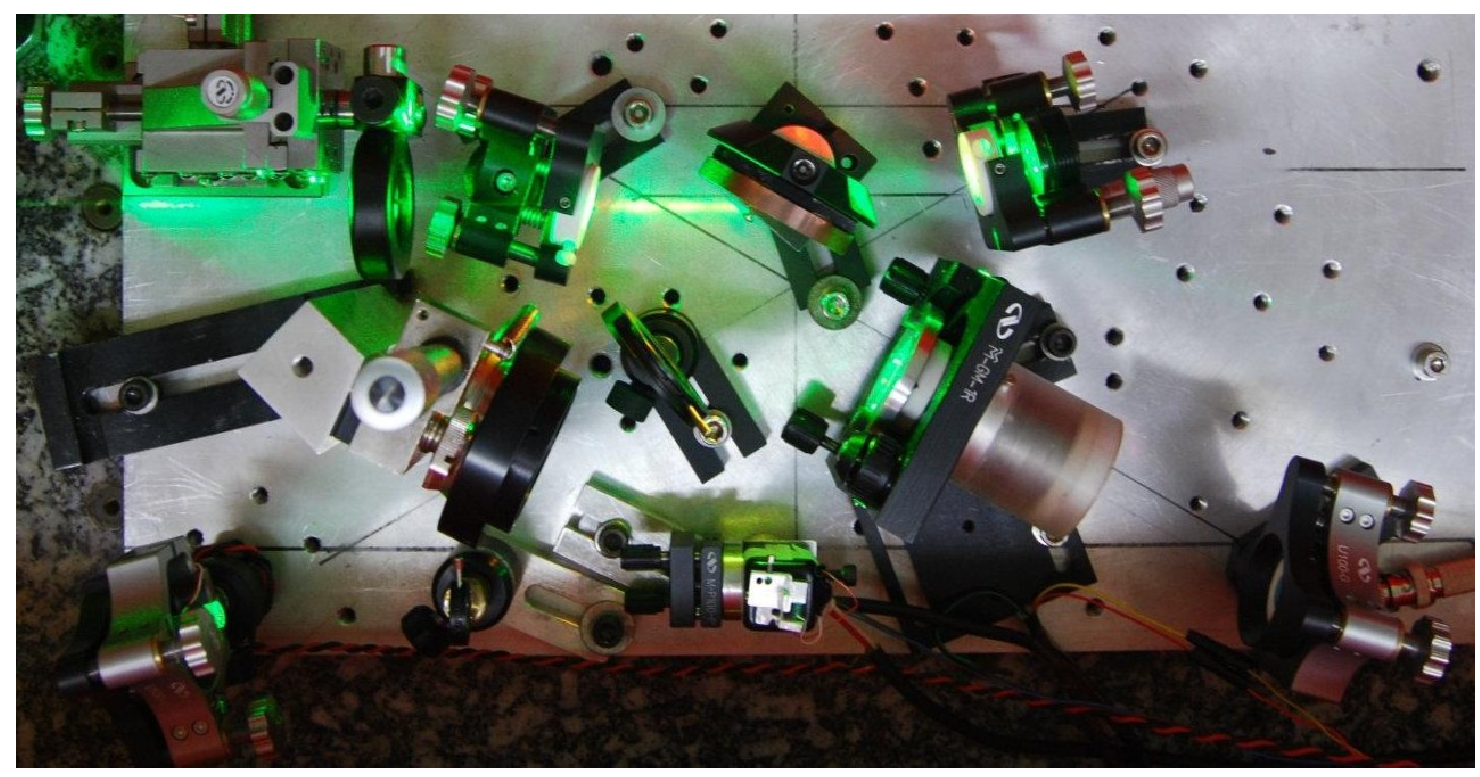

Figura 3.14. Cavidade do laser CW de titânio-safira. 
O cristal e outros elementos óticos no interior da cavidade, devem ter suas faces cortadas em ângulo de Brewster a fim de reduzir a reflexão e, consequentemente, as perdas intracavidade. O corte em ângulo de Brewster é feito apenas para a componente horizontal da polarização, pois assim, o campo com polarização vertical sofrerá perdas por reflexão e consequentemente não oscilará de forma a garantir que o laser saia da cavidade com polarização linear horizontal.

As perdas para as componentes de polarização vertical permitem, além disso, garantir a circulação do campo em um único sentido quando utilizado um diodo ótico.

O diodo ótico age de manira diferente nas ondas que o atravessam em cada sentido, e causam um giro de polarização em apenas uma delas. Assim, somente a outra terá sempre polarização horizontal dentro da cavidade.

Da mesma maneira, é possível selecionar uma faixa de frequências de oscilação do laser através de um filtro de frequência, conhecido como filtro de Lyot, que produz giros de polarização para frequências indesejadas.

O funcionamento do diodo ótico e do filtro de frequência serão apresentados em mais detalhe nas seções 3.5.2 e 3.6.1.

\subsubsection{Astigmatismo da cavidade}

A quebra da simetria cilíndrica da cavidade pelos espelhos curvos fora do eixo, provoca aberrações no laser conhecidas como astigmatismo.

Em princípio, o campo intracavidade tem um perfil simétrico no plano transverso $(x y)$. A deformação astigmática significa uma quebra dessa simetria, uma vez que as componentes do perfil do campo, nos eixos $x$ e $y$, focam em pontos diferentes. Essa quebra de simetria faz com que nenhum modo com simetria cilíndrica possa oscilar.

Para estudar a aberração astigmática, é útil definir dois planos que contenham cada uma das componentes do perfil do campo: o plano sagital $(x z)$ que contém o eixo ótico e a componente horizontal (paralela ao plano da mesa), e o plano trangencial $(y z)$, que contém o eixo ótico e a polarização vertical.

O cristal de titânio-safira é posicionado em ângulo de Brewster apenas para a componente da polarização no plano sagital, o que, convenientemente, provoca também uma aberração astigmática no campo. Escolhendo o ângulo certo para os espelhos fora do eixo ótico é possível fazer com que as duas aberrações se anulem, e haja apenas um único foco para o campo em ambas as componentes, nos eixos $x$ e $y$, mantendo o feixe intracavidade simétrico [39].

\subsubsection{Astigmatismo provocado pelo cristal em ângulo de Brewster}

O astigmatismo provocado pelo cristal de titânio-safira, cortado em ângulo de Brewster, se dá pelo fato de que as duas componentes do perfil do feixe experimentam caminhos óticos diferentes. Para calcular essa diferença é conveniente utilizar as matrizes ABCD para as propagações do feixe nos planos tangencial e sagital. 


\section{Plano tangencial:}

Consdera-se como eixo ótico para a definição das matrizes ABCD, um feixe de referência, que se propaga linearmente, sem difratar, no centro de simetria do perfil transverso do campo e que incide no centro do cirstal, com ângulo de Brewster $\theta_{B}$ em relação à reta normal ao plano do cristal, como ilustrado na figura 3.15.

Um outro feixe de referência, contido no plano tangencial, incide a uma distância $w_{i}$ em $y$, com relação ao feixe que representa o eixo ótico, e um ângulo $\alpha$, dentro da aproximação paraxial, também em relação ao eixo ótico.

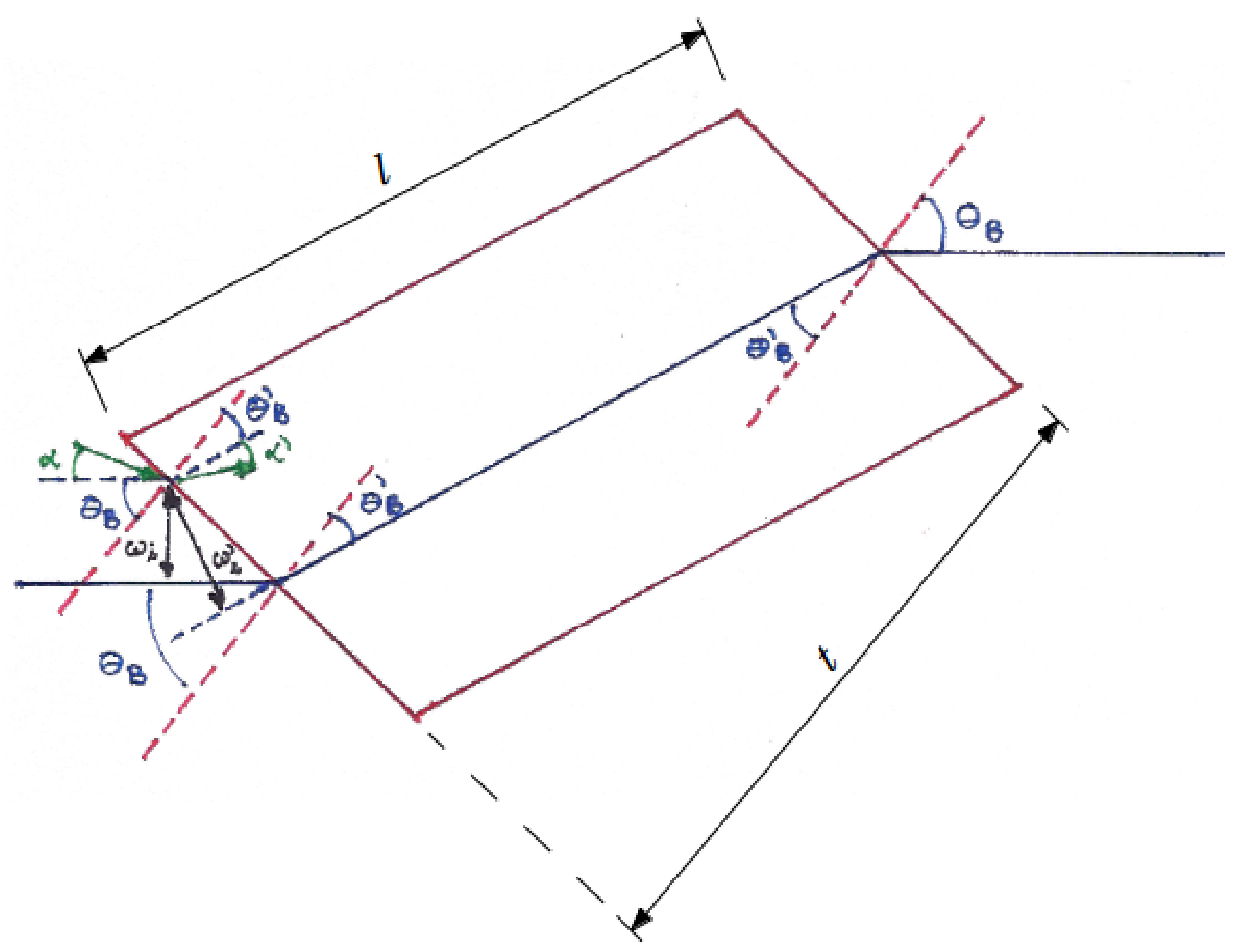

Figura 3.15. O feixe em azul, incidente no centro do cristal em ângulo de Brewster $\theta_{B}$, é o eixo ótico utilizado para calcular a propagação do feixe verde, que incide no cristal com ângulo $\theta_{B}+\alpha$, sendo $\alpha$ o ângulo do feixe com relação ao eixo ótico, a uma distância $w_{i}$ do feixe azul. Após entrarem no cristal, a distância do feixe verde com relação ao feixe azul passa a ser considerada $w_{i}^{\prime}$ e o seu ângulo é $\alpha^{\prime}$.

Embora o angulo $\alpha$ seja pequeno, o ângulo de incidência do segundo feixe com o cristal, $\theta_{B}+\alpha$, é grande o bastante para não permitir o uso de aproximações paraxiais para a transformação do feixe. Assim é preciso considerar a seguinte mudança para o ângulo $\alpha$ :

$$
\begin{aligned}
n_{1} \operatorname{sen}\left(\theta_{B}+\alpha\right) & =n_{2} \operatorname{sen}\left(\theta_{B}^{\prime}+\alpha^{\prime}\right) \\
n_{1}\left[\operatorname{sen}\left(\theta_{B}\right) \cos (\alpha)+\cos \left(\theta_{B}\right) \operatorname{sen}(\alpha)\right] & =n_{2}\left[\operatorname{sen}\left(\theta_{B}^{\prime}\right) \cos \left(\alpha^{\prime}\right)+\cos \left(\theta_{B}^{\prime}\right) \operatorname{sen}\left(\alpha^{\prime}\right)\right] .
\end{aligned}
$$


A aproximação paraxial para $\alpha$, entretanto, é válida e, portanto,

$$
n_{1}\left[\operatorname{sen}\left(\theta_{B}\right)+\alpha \cos \left(\theta_{B}\right)\right]=n_{2}\left[\operatorname{sen}\left(\theta_{B}^{\prime}\right)+\alpha^{\prime} \cos \left(\theta_{B}^{\prime}\right)\right]
$$

onde $n_{1}$ é o índice de refração do ar, $n_{2}$ o índice de refração do cristal, $\theta_{B}^{\prime}$ o ângulo do feixe central com relação à normal dentro do cristal e $\alpha^{\prime}$ o ângulo do segundo feixe com relação ao eixo central dentro do cristal, como indicado na figura 3.15.

Sabemos que para o feixe central

$$
n_{1} \operatorname{sen} \theta_{B}=n_{2} \operatorname{sen} \theta_{B}^{\prime}
$$

e que para o ângulo de Brewster

$$
\operatorname{tg} \theta_{B}=\frac{n_{2}}{n_{1}} \Rightarrow \cos \theta_{B}=\frac{1}{\sec \theta_{B}}=\frac{1}{\sqrt{1-\operatorname{tg}^{2} \theta_{b}}}=\frac{n_{1}}{\sqrt{n_{1}^{2}+n_{2}^{2}}} .
$$

Substituindo ambas em (3.23) temos:

$$
n_{1} \alpha \cos \left(\theta_{B}\right)=n_{2} \alpha^{\prime} \cos \left(\theta_{B}^{\prime}\right) \Rightarrow n_{1}^{2} \alpha=n_{2}^{2} \alpha^{\prime} .
$$

Além da variação no ângulo, o segundo feixe sofre uma alteração na distância em $y$, com relação ao eixo ótico, ao penetrar no cristal, como se pode ver também na figura 3.15 , onde a projeção de $w_{i}$ no plano do cristal vale

e

$$
p=\frac{w_{i}}{\cos \theta_{B}}
$$

$$
w_{i}^{\prime}=p \cos \theta_{B}^{\prime}=\frac{w_{i}}{\cos \theta_{B}} \cos \theta_{B}^{\prime}
$$

Porém, para o ângulo de Brewster vale:

e, portanto,

$$
\cos \theta_{B}^{\prime}=\frac{n_{2}}{\sqrt{n_{2}^{2}+n_{1}^{2}}}=\sqrt{1-\frac{n_{1}^{2}}{n_{2}^{2}+n_{1}^{2}}}=1-\cos ^{2} \theta_{B}=\operatorname{sen} \theta_{B}
$$

$$
w_{i}^{\prime}=w_{i} \operatorname{tg} \theta_{B}=w_{i} \frac{n_{2}}{n_{1}}
$$

Assim, podemos finalmente escrever a matriz ABCD de mudança de meio, para o cristal em ângulo de Brewster, no plano tangencial:

$$
M_{\mathrm{mm}_{t}}=\left(\begin{array}{cc}
\frac{n_{2}}{n_{1}} & 0 \\
0 & \frac{n_{1}^{2}}{n_{2}^{2}}
\end{array}\right)
$$

Uma vez dentro do cristal, o feixe percorre um caminho de comprimento $l$ ao lado do eixo ótico, onde $l$ é o caminho ótico do feixe central que vale em relação à espessura $t$ do cristal

$$
l=\frac{t}{\cos \theta_{B}^{\prime}}=t \frac{\sqrt{n_{2}^{2}+n_{1}^{2}}}{n_{2}}
$$


A matriz $\mathrm{ABCD}$ para a propagação dentro do cristal vale

$$
M_{\mathrm{pl}}=\left(\begin{array}{ll}
1 & l \\
0 & 1
\end{array}\right)
$$

e, portanto, a matriz de transformação do feixe no plano tangencial que atravessa o cristal é:

$$
M_{c_{t}}=\left(\begin{array}{cc}
\frac{n_{1}}{n_{2}} & 0 \\
0 & \frac{n_{2}^{2}}{n_{1}^{2}}
\end{array}\right)\left(\begin{array}{cc}
1 & l \\
0 & 1
\end{array}\right)\left(\begin{array}{cc}
\frac{n_{2}}{n_{1}} & 0 \\
0 & \frac{n_{1}^{2}}{n_{2}^{2}}
\end{array}\right)=\left(\begin{array}{cc}
1 & \frac{n_{1}^{3}}{n_{2}^{3}} l \\
0 & 1
\end{array}\right) \text {, }
$$

ou, em função da espessura do cristal:

$$
M_{c_{t}}=\left(\begin{array}{cc}
1 & \frac{n_{1}^{3} \sqrt{n_{2}^{2}+n_{1}^{2}}}{n_{2}^{4}} t \\
0 & 1
\end{array}\right)
$$

\section{Plano sagital:}

Para o plano sagital, o eixo ótico é o mesmo que para o plano tangencial, entretanto, considera-se o segundo feixe, um feixe de referência que incide no cristal a uma distância $w_{i}$ em $x$, do feixe central, e com ângulo $\alpha$. No plano $x z$, entretanto, a superfície do cristal é perpendicular ao eixo ótico e o ângulo de incidência do segundo feixe com o cristal é o próprio ângulo $\alpha$.

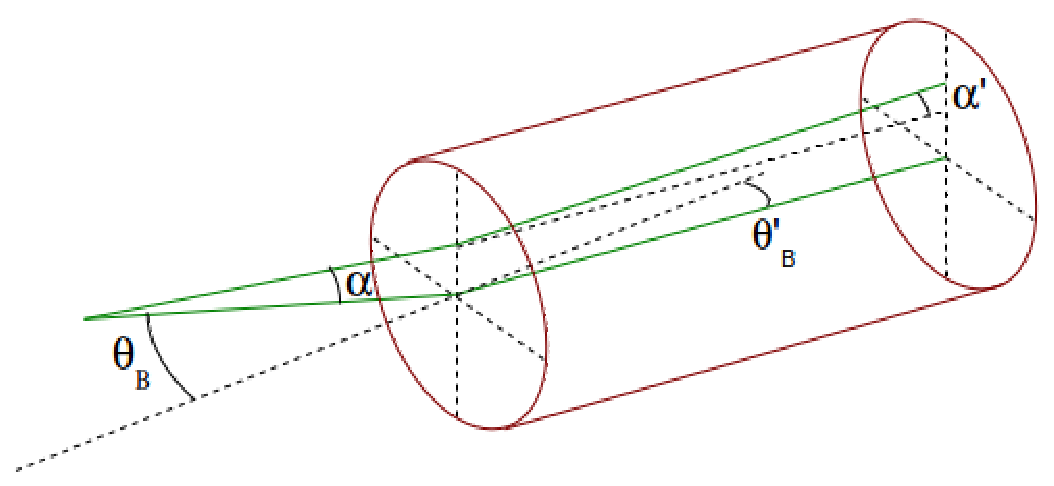

Figura 3.16. Um feixe incidente no centro do cristal serve como eixo ótico para um segundo feixe que incide a um ângulo $\alpha$ em relação ao feixe de referência, dentro do plano sagital.

Além disso, não existe alteração da distância $w_{i}$ no momento em que o feixe penetra o cristal, e portanto a matriz ABCD para a mudança de meio é simplesmente

$$
M_{\mathrm{mm}_{s}}=\left(\begin{array}{cc}
1 & 0 \\
0 & \frac{n_{1}}{n_{2}}
\end{array}\right) \text {. }
$$

A propagação dentro do cristal também se dá pela distância $l$, que representa justamente o caminho ótico do feixe central. 
Assim, a matriz ABCD total para a transformação do feixe que atravessa o cristal, no plano sagital, é:

$$
M_{c_{s}}=\left(\begin{array}{cc}
1 & 0 \\
0 & \frac{n_{2}}{n_{1}}
\end{array}\right)\left(\begin{array}{cc}
1 & l \\
0 & 1
\end{array}\right)\left(\begin{array}{cc}
1 & 0 \\
0 & \frac{n_{1}}{n_{2}}
\end{array}\right)=\left(\begin{array}{cc}
1 & \frac{n_{1}}{n_{2}} l \\
0 & 1
\end{array}\right) .
$$

\subsubsection{Astigmatismo provocado pelo espelho curvo fora do eixo ótico}

Também para o espelho fora do eixo ótico, o ângulo $\theta$ entre o eixo ótico e o eixo do espelho está contido no plano tangencial yz, sendo que o eixo ótico é novamente o eixo $z$ de propagação do feixe gaussiano.

É mais fácil, afim de calcular o astigmatismo provocado pelo espelho, tratar o espelho como uma lente convergente.

\section{Plano tangencial:}

Para o plano tangencial, um objeto sobre o eixo ótico, a uma distância $p^{\prime}$ do centro da lente, forma uma imagem, também sobre o eixo ótico, a uma distância $q^{\prime}$ do centro da lente.

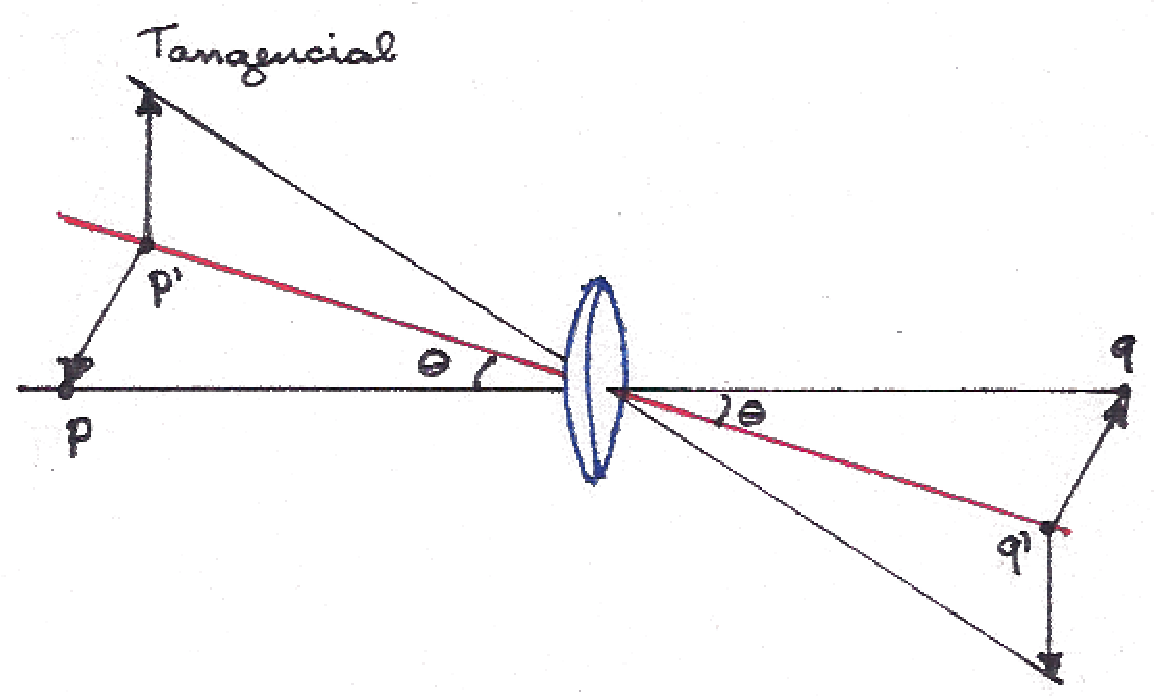

Figura 3.17. Lente inclinada para um objeto no plano tangencial.

Podemos imaginar um plano que contém o objeto e cruza o eixo da lente a uma distância $p$ do seu centro, e um que contém a imagem e cruza o eixo da lente a uma distância $q$.

Sabemos que, para uma lente convergente de foco $f$, um objeto em um plano distante $p$ do centro da lente forma uma imagem em um plano paralelo, distante $q$ do centro da lente, de forma que

$$
\frac{1}{p}+\frac{1}{q}=\frac{1}{f}
$$


Pela figura 3.17, ficam claras as relações entre $p$ e $p^{\prime}$ e $q$ e $q^{\prime}$ :

$$
\begin{aligned}
p^{\prime} & =p \cos \theta \\
q^{\prime} & =q \cos \theta,
\end{aligned}
$$

de forma que, com relação ao eixo ótico, o foco equivalente da lente para o objeto contido no plano tangencial é tal que:

$$
\frac{1}{f_{t}^{\prime}}=\frac{1}{p^{\prime}}+\frac{1}{q^{\prime}}=\frac{1}{p \cos \theta}+\frac{1}{q \cos \theta}=\frac{1}{f \cos \theta}
$$

Portanto, a matriz ABCD para a lente inclinada no plano tangencial deve ser igual à matriz de transformação da lente normal, entretanto para o foco equivalente $f^{\prime}=$ $f \cos \theta$ :

$$
M_{l_{t}}=\left(\begin{array}{cc}
1 & 0 \\
-\frac{1}{f \cos \theta} & 1
\end{array}\right) \text {, }
$$

lembrando que o foco de um espelho curvo é a metade do raio de curvatura do espelho.

\section{Plano sagital:}

Para o plano sagital, o ângulo $\theta$ não influencia sobre o plano no qual será formada a imagem, que é sempre perpendicular à superfície da lente. Portanto, a distância entre a lente e o plano que contém a imagem, é simplesmente a projeção da distância em que a imagem é formada no eixo de simetria da lente.

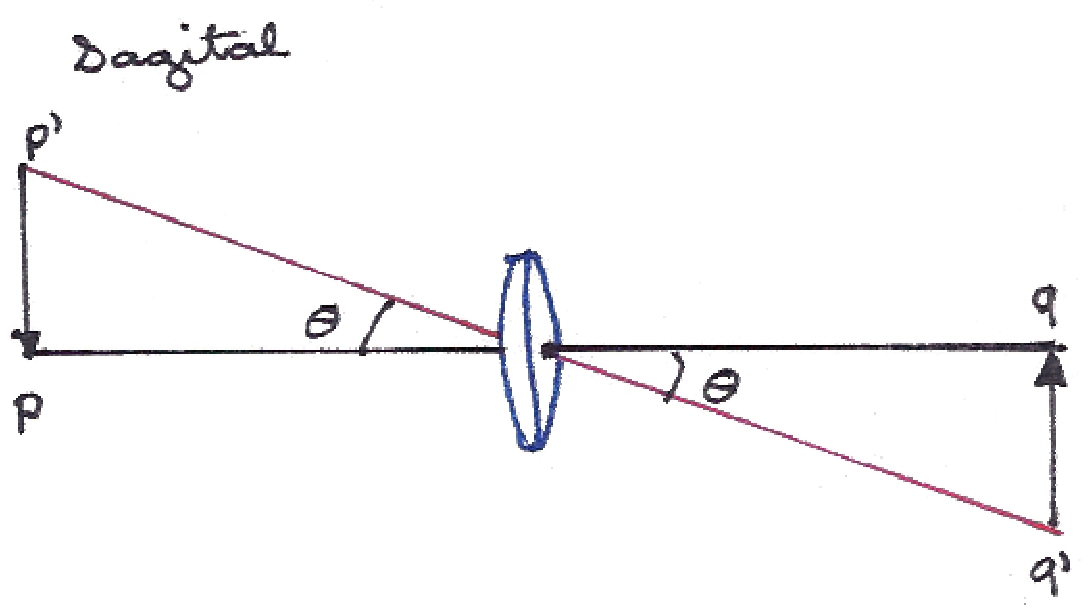

Figura 3.18. Lente inclinada para um objeto no plano tangencial.

Assim sendo, se o objeto está a uma distância $p^{\prime}$ do centro da lente, contido em um plano paralelo a lente, que dista $p$ do seu centro, então, para o plano sagital,

$$
p /=\frac{p}{\cos \theta}
$$


da mesma forma que

$$
q^{\prime}=\frac{q}{\cos \theta}
$$

Portanto, o foco equivalente da lente para um objeto contido no plano tangencial é tal que:

$$
\frac{1}{f_{s}^{\prime}}=\frac{1}{p^{\prime}}+\frac{1}{q^{\prime}}=\frac{\cos \theta}{p}+\frac{\cos \theta}{q}=\frac{\cos \theta}{f}
$$

e a matriz $A B C D$ para a lente inclinada no plano sagital é:

$$
M_{l_{s}}=\left(\begin{array}{cc}
1 & 0 \\
-\frac{\cos \theta}{f} & 1
\end{array}\right) \text {. }
$$

\subsubsection{Geometria e cálculo da cavidade}

Uma vez que conhecemos a matriz ABCD para cada elemento da cavidade do titânio-safira, podemos linearizar a cavidade e calcular a matriz para uma volta completa do campo, assim como foi feito para a cavidade linear na seção 3.3.5.

A cavidade do titânio safira é composta por dois espelhos curvos, dois espelhos planos e um cristal. As cavidades real e aberta, tendo o centro do feixe como eixo ótico, estão representadas na figura 3.19.
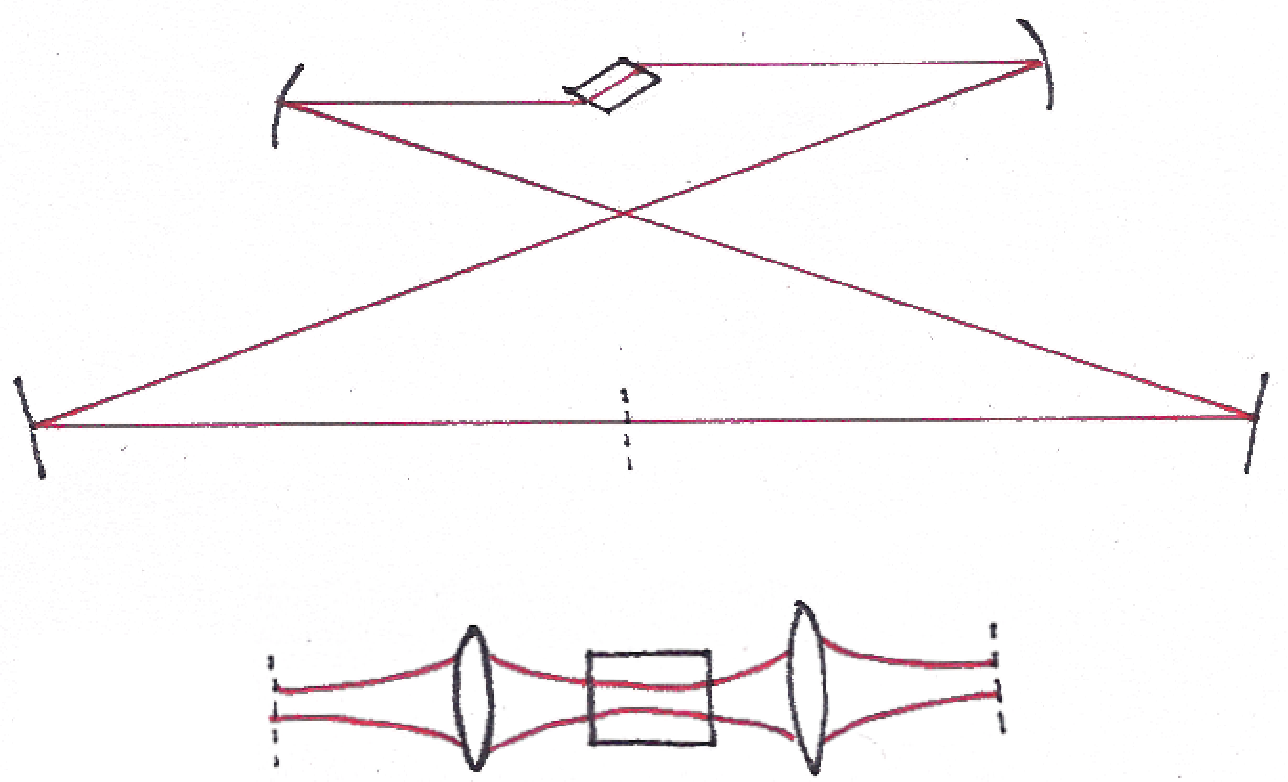

Figura 3.19. Esquema da cavidade do laser de titânio-safira somente com o cristal, e esquema da linearização da mesma cavidade. 
Essa configuração permite eliminar completamente o astigmatismo, tanto dentro como fora da cavidade [39].

O foco da lente que representa o espelho, e a matriz de propagação através do cristal, são diferentes para o plano tangencial e para o plano sagital, de forma que existem duas matrizes que representam a propagação do feixe em ambos os planos.

Fixando alguns parâmetros, podemos traçar um gráfico da cintura do feixe entre os espelhos planos, para cada matriz $\mathrm{ABCD}$, em função do ângulo de incidência do feixe com os espelhos curvos e da distância entre os espelhos e o cristal de titâniosafira.

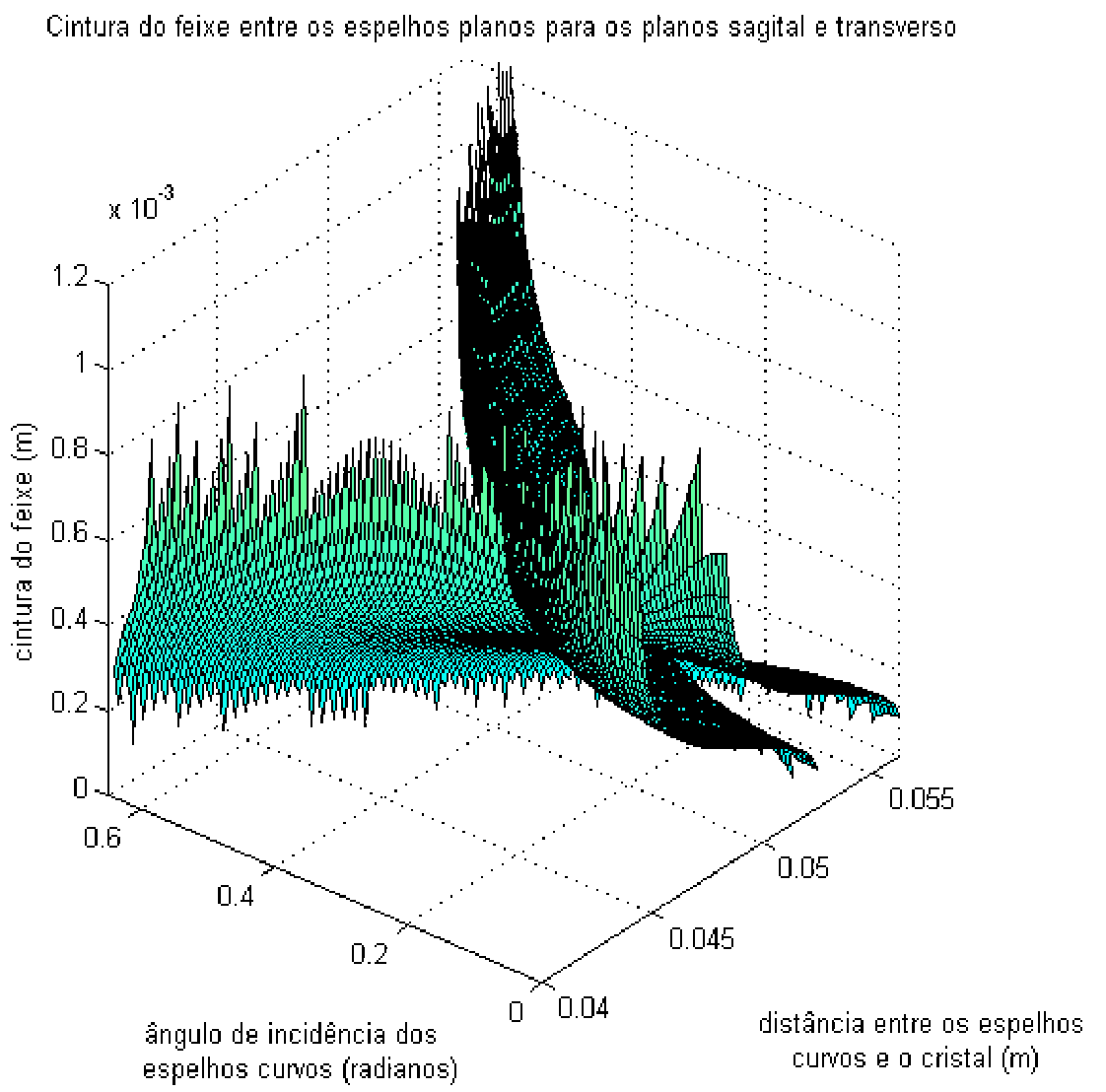

Figura 3.20. Curvas das cinturas estáveis do feixe nos planos transverso e sagital para os parâmetros da cavidade laser construída, em função do ângulo dos espelhos com relação ao eixo ótico e da distância entre os espelhos curvos.

A intersecção entre as curvas da cintura dos feixes indica os valores dos ângulos e distância para o posicionamento dos espelhos curvos, para os quais o astigmatismo é completamente corrigido. Esse valores são melhores vizualizados na figura 3.21, na qual foi feita a projeção da intersecção em um plano. 


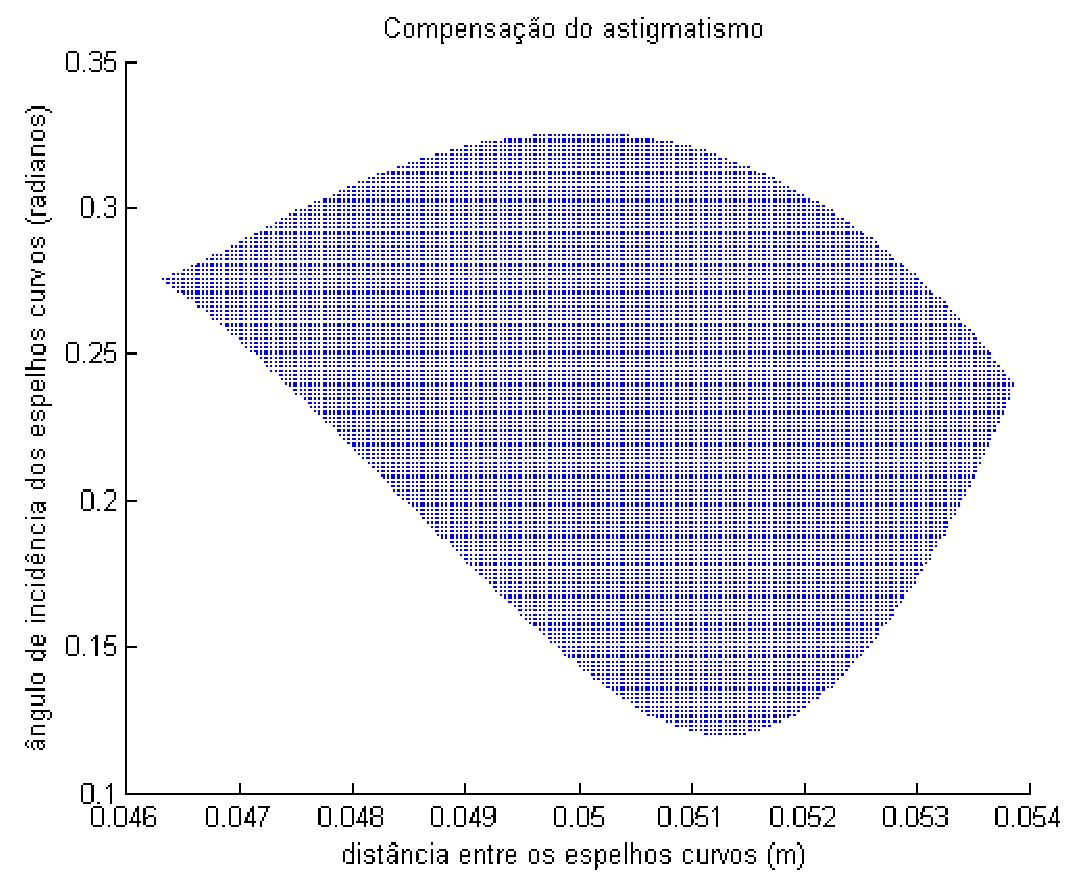

Figura 3.21. Gráfico da intersecção das curvas das cinturas dos planos sagital e transverso $w_{0 s}-w_{0 t}=0$ em função do ângulo e da distância entre os espelhos curvos e o cristal de titânio-safira, para os parâmetros da cavidade construida.

A partir de então podemos escolher um valor para o ângulo dos espelhos curvos e verificar as restrições dadas pela condição de estabilidade da equação (3.22), que podem ser visualizadas através de um gráfico de $\frac{|D+A|}{2}$ em função da distância entre os espelhos e o cristal (figura 3.22).

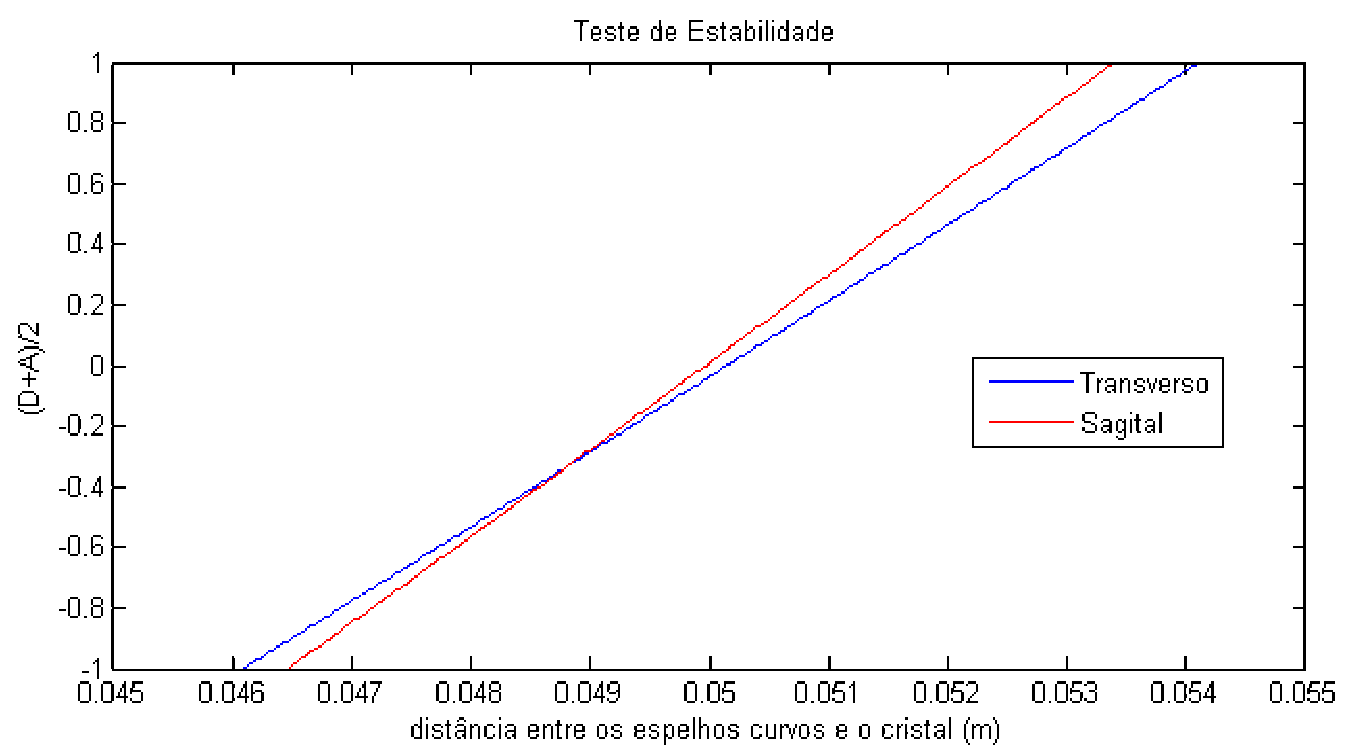

Figura 3.22. Teste de estabilidade da cavidade para um ângulo de incidência do feixe com os espelhos de $15^{\circ}$.

A cintura do feixe coincide para os dois eixos do plano transverso para o ângulo de $15^{\circ}$ de incidência do feixe com os espelhos e uma distância de $4,9 \mathrm{~cm}$ entre o 
espelho curvo e o cristal, como pode ser visto pela figura 3.23.

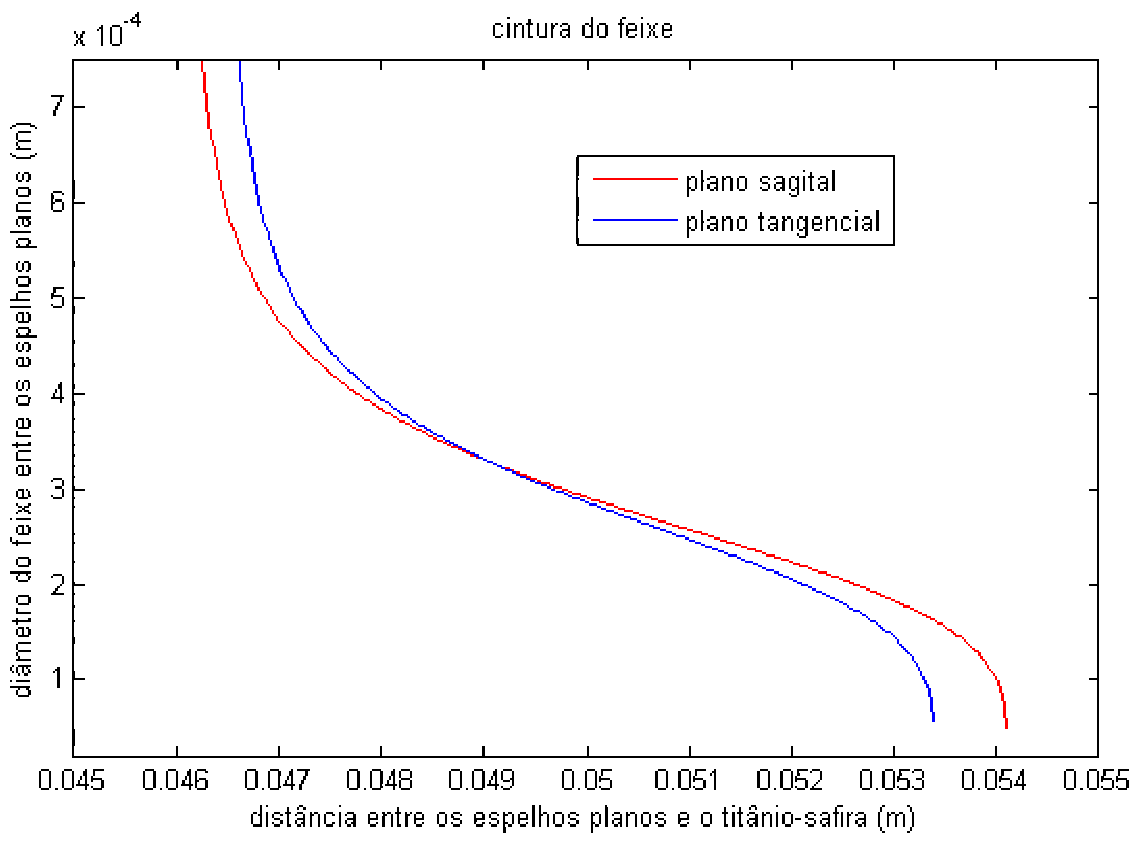

Figura 3.23. Cintura do feixe em relação à distância entre o cistal de titânio-safira e os espelhos curvos, para um ângulo de incidência do feixe com os espelhos de $15^{\circ}$.

\subsection{Birrefringência e Efeito Faraday}

Além do cristal de titânio-safira, existem também outros elementos presentes no interior da cavidade, que têm a função de manter o feixe circulando em um único sentido e de controlar a frequência do laser. Tais elementos funcionam com base na propriedade de birrefringência de alguns materiais e no efeito Faraday.

Na seção 2.7 mostramos como a susceptibilidade de um meio atômico altera o vetor de onda $\vec{k}$ do campo que se propaga pelo meio, e como essa alteração depende da estrutura atômica do meio, bem como da dessintonia entre a frequência do campo e a frequência de ressonância atômica.

Se os dipolos elétricos de um meio, formados pela polarização provocada por um campo elétrico, não têm nenhuma direção preferencial de alinhamento, o meio é dito isotrópico. Neste caso, o campo que se propaga através dele sofre a mesma alteração do vetor de onda, qualquer que seja a direção de sua polarização.

Em contraposição ao meio isotrópico, um meio, como por exemplo, um cristal uniaxial, no qual os átomos estão estruturados em camadas, absorve com probabilidades diferentes campos com polarização contida no plano das camadas atômicas, ou no plano perpendicular a elas. Isso implica em uma diferença de velocidade de propagação para ondas com polarizações em cada um dos planos. Tais meios são chamados de birrefringentes. 
Existem ainda cristais com simetria tridimensional, para os quais a velocidade de propagação de uma onda depende das três possíveis componentes de polarização. Estes cristais são chamados de biaxiais.

Cristais birrefringentes têm susceptibilidade distinta para apenas dois eixos. O eixo de simetria do cristal é chamado de eixo extraordinário e os eixos perpendiculares a ele são chamados de eixos ordinários.

Alguns cristais birrefringentes, como o açúcar e o quartzo, por exemplo, podem possuir ainda uma estrutura helicoidal, que pode ser destra ou sinistra. Tal estrutura provoca o que se chama de birrefringência circular. Neste caso, as polarizações com velocidades de propagação distintas dentro do meio serão as polarizações circulares $\sigma_{+}$e $\sigma_{-}$.

A birrefringência circular também pode ser induzida, quando um campo se propaga através de um meio, com uma frequência próxima a da ressonância de uma transição atômica em que $\Delta m_{l}= \pm 1$. O átomo irá absorver luz com polarização circular $\sigma_{+}$quando $\Delta m_{l}=1$ e $\sigma_{-}$quando $\Delta m_{l}=-1$, como indicado na figura 3.24.

B

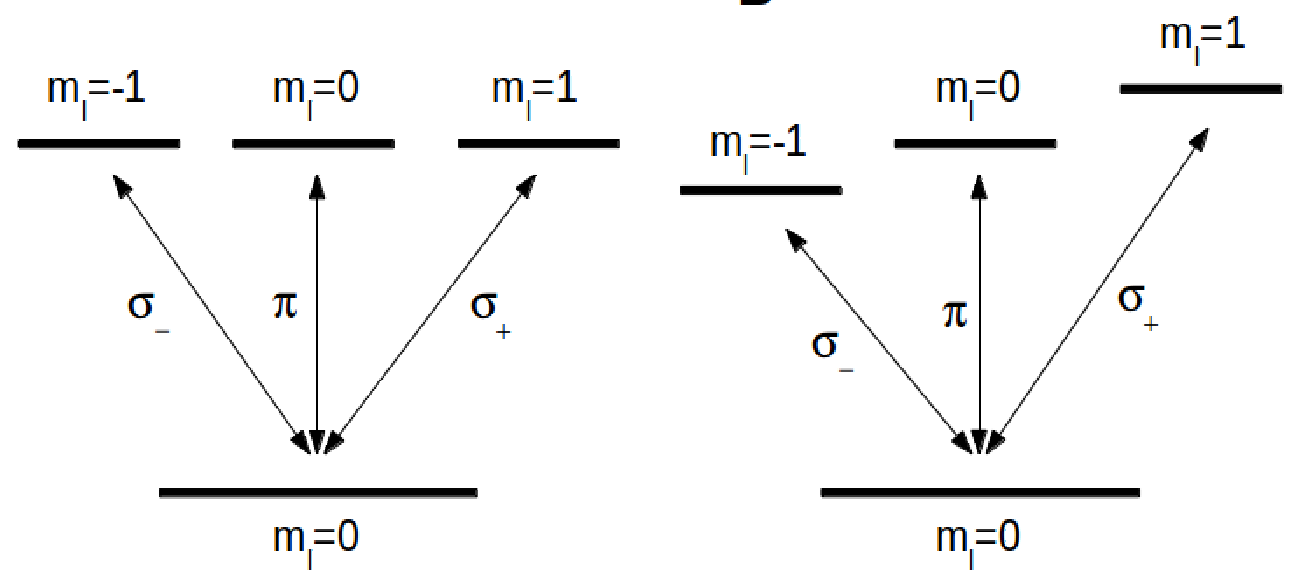

Figura 3.24. Níveis energéticos de uma transição de birrefringência circular induzida

Aplicando-se um campo magnético, é possível abrir os níveis de energia com valores distintos de $m_{l}$ devido ao efeito Zeeman. Essa diferença de energia faz com que, dependendo da frequência do campo propagante, uma das polarizações circulares seja acelerada com relação à outra. Este efeito é chamado de efeito Faraday.

A principal diferença entre a birrefringência circular e a birrefringência circular induzida, ou efeito Faraday, é que, enquanto para o efeito Faraday a polarização rápida depende da frequência do campo propagante e da direção do campo magnético, para a birrefringência circular a polarização que se propaga mais rápido depende apenas da simetria do meio atômico. Por esse motivo, um campo que atravessa um meio de birreffringência circular induzida, irá sentir um atraso para uma determinada polarização, digamos $\sigma_{-}$, independente do sentido de propagação. Já um campo, que atravessa um material de birrefringência comum, sentirá um atraso para uma polarização, dependendo do seu sentido de propagação. 
Exemplo 3.1. Um campo que atravessa um material de birrefringência circular e se propaga na direção $z$, com polarização linear no plano $y z$, pode ser decomposto em dois campos de polarização circular $\sigma_{+}$e $\sigma_{-}$

$$
E_{i}=E_{0} \cos (k z) \hat{y}=\frac{E_{0}}{2}(\cos (k z) \hat{y}+\operatorname{sen}(k z) \hat{x})+\frac{E_{0}}{2}(\cos (k z) \hat{y}-\operatorname{sen}(k z) \hat{x})
$$

Se, após atravessar o material, o atraso entre as duas polarizações é de uma fase $\varphi$, então o campo de saída é

$$
E_{f}=\frac{E_{0}}{2}\left(\cos \left(k z+\frac{\varphi}{2}\right) \hat{y}+\operatorname{sen}\left(k z+\frac{\varphi}{2}\right) \hat{x}\right)+\frac{E_{0}}{2}\left(\cos \left(k z-\frac{\varphi}{2}\right) \hat{y}-\operatorname{sen}\left(k z-\frac{\varphi}{2}\right) \hat{x}\right),
$$

que pode ser expandido como:

$$
\begin{aligned}
& E_{f}=\frac{E_{0}}{2}\left\{\left[\cos (k z) \cos \left(\frac{\varphi}{2}\right)-\operatorname{sen}(k z) \operatorname{sen}\left(\frac{\varphi}{2}\right)\right] \hat{y}+\left[\operatorname{sen}(k z) \cos \left(\frac{\varphi}{2}\right)+\right.\right. \\
& \left.\left.\cos (k z) \operatorname{sen}\left(\frac{\varphi}{2}\right)\right] \hat{x}\right\}+\frac{E_{0}}{2}\left\{\left[\cos (k z) \cos \left(\frac{\varphi}{2}\right)+\operatorname{sen}(k z) \operatorname{sen}\left(\frac{\varphi}{2}\right)\right] \hat{y}+\right. \\
& \left.\left[\operatorname{sen}(k z) \cos \left(\frac{\varphi}{2}\right)-\cos (k z) \operatorname{sen}\left(\frac{\varphi}{2}\right)\right] \hat{x}\right\} \\
& E_{f}=E_{0}\left[\cos (k z) \cos \left(\frac{\varphi}{2}\right) \hat{y}+\cos (k z) \operatorname{sen}\left(\frac{\varphi}{2}\right) \hat{x}\right]=E_{0} \cos (k z)\left[\cos \left(\frac{\varphi}{2}\right) \hat{y}+\operatorname{sen}\left(\frac{\varphi}{2}\right) \hat{x}\right] .
\end{aligned}
$$

Portanto, o campo que atravessa o material sofre um giro de $\frac{\varphi}{2}$ na polarização.

Note que, pela figura 3.25, no caso em que o material tem uma estrutura helicoidal, se o campo é refletido e passa outra vez pelo material, o giro na polarização é cancelado. Entretando, no caso da birrefringência circular induzida (figura 3.26), se o campo é refletido e atravessa novamente o material, ele sofre novamente um giro de $\frac{\varphi}{2}$.
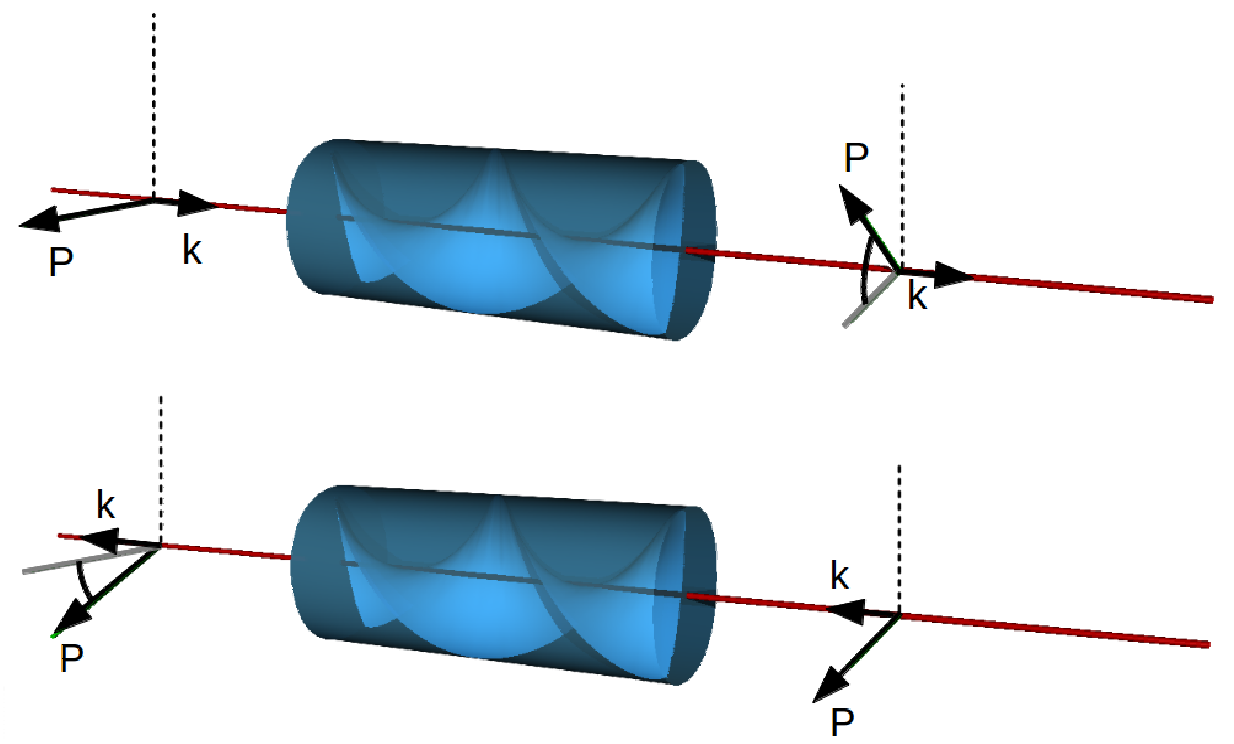

Figura 3.25. Acima um campo de polarização $P$ atravessa um material com estrutura helicoidal e sofre um giro na polarização. Abaixo um campo atravessa o mesmo material no sentido contrário e sofre um giro contrátrio na polarização. 

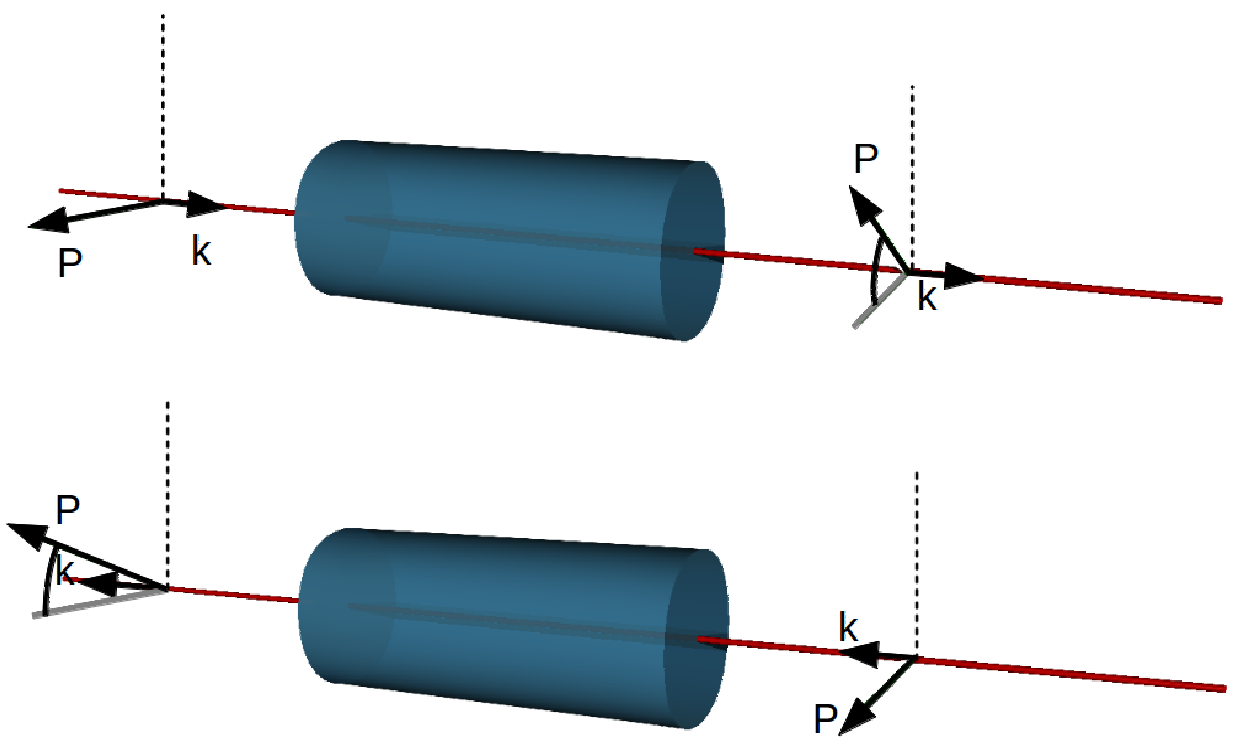

Figura 3.26. Acima um campo de polarização $P$ atravessa um material sujeito a um campo magnético e sofre um giro na polarização devido ao efeito Faraday. Abaixo um campo atravessa o mesmo material no sentido contrário e sofre um giro igual na polarização.

O giro da polarizaçào devido ao efeito Faraday é proporcional ao campo aplicado, ao comprimento do cristal e a uma constante de proporcionalidade referente às propriedades do material, chamada de constante de Verdet:

$\theta=\frac{\varphi}{2}=V B l$.

Normalmente os cristais utilizados para rotação de elipse são cristais de TGG (Terbium-Gallium Garnet), que tem constante de Verdet em torno de 60rad(T.m $)^{-1}$, pois podem ser aplicados para um pente de frequência de $400-1100 \mathrm{~nm}$, com exceçào de $470-500 \mathrm{~nm}$.

\subsubsection{Lâminas de onda}

Lâminas de onda são lâminas de espessura controlada, feitas de um material birrefringente (normalmente um cristal uniaxial de quartzo) cortado de forma que o eixo extraordinário seja paralelo à superfície da lâmina.

A espessura da lâmina determina o atraso de fase entre as componentes das polarizações. Se, para um determinado comprimento de onda $\lambda$, este atraso é proporcional a $\frac{\lambda}{2}$, então a lâmina é dita de meia onda. Existem, também, lâminas comerciais de quarto de onda.

Exemplo 3.2. Um campo de polarização linear que se propaga na direção $z$, atravessa uma lâmina de meia onda cujo eixo lento coincide com o eixo $y$ 


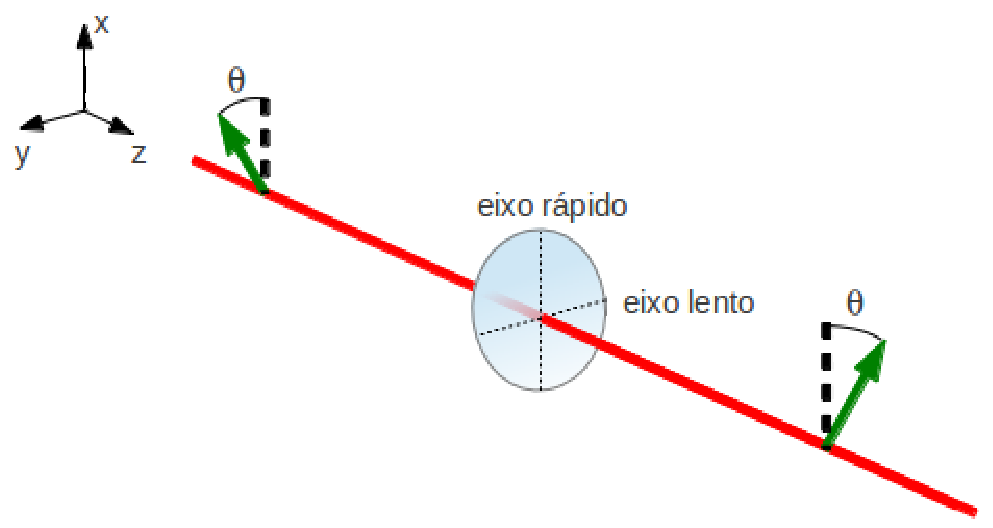

Figura 3.27. Campo de polarização linear atravessa uma lâmina de meia onda cujo eixo lento coince com o eixo $x$.

$$
E_{i}=E_{0} \cos (k z)(\cos \theta \hat{x}+\operatorname{sen} \theta \hat{y})
$$

Então o campo, após atravessar a lâmina, será:

$$
E_{f}=E_{0} \cos (k z) \cos \theta \hat{x}+E_{0} \cos \left(k z+\frac{\lambda}{2}\right) \operatorname{sen} \theta \hat{y}
$$

Como $k=\frac{2 \pi}{\lambda}$ :

$$
E_{f}=E_{0} \cos (k z) \cos \theta \hat{x}-E_{0} \cos (k z) \operatorname{sen} \theta \hat{y}=E_{0} \cos (k z)(\cos \theta \hat{x}-\operatorname{sen} \theta \hat{y}) .
$$

Ao atravessar uma lâmina de meia onda, a componente da polarização do campo sobre o eixo mais lento da lâmina é invertida, de forma que o campo sofre um giro de $2 \theta$ sobre o eixo rápido, onde $\theta$ é o ângulo entre a polarização do campo e o eixo rápido da lâmina de onda.

Exemplo 3.3. Um campo de polarização linear que se propaga na direção $z$ atravessa uma lâmina de quarto de onda cujo eixo lento coincide com o eixo $x$.

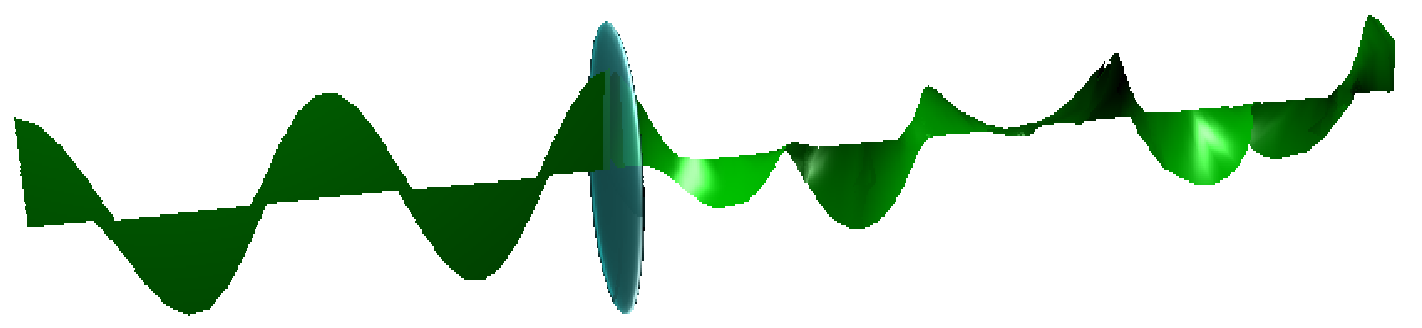

Figura 3.28. Campo de polarização linear atravessa uma lâmina de quarto de onda cujo eixo lento coince com o eixo $x$. 
$E_{i}=E_{x} \cos (k z) \hat{x}+E_{y} \cos (k z) \hat{y}$.

Após atravessar a lâmina o campo será:

$E_{f}=E_{x} \cos \left(k z+\frac{\pi}{2}\right) \hat{x}+E_{y} \cos (k z) \hat{y}=E_{x} \operatorname{sen}(k z) \hat{x}+E_{y} \cos (k z) \hat{y}$.

Assim, para esse caso, o campo de polarização linear que atravessa uma lâmina de quarto de onda sai com polarização elíptica.

\subsubsection{Diodo ótico}

O diodo ótico é responsável por fazer com que o campo se propague apenas em um sentido dentro de uma cavidade linear. Ele consiste de uma lâmina de meia onda e um cristal de birrefringência circular induzida.

O cristal é colocado em ângulo de Brewster no plano yz (plano horizontal), minimizando as perdas para a componente da polarização nesse plano. A lâmina de onda, também em ângulo de Brewster, é ajustada de forma a provocar uma rotação na polarização horizontal igual e contrária à rotação provocada pelo cristal. Assim, para um determinado sentido de propagação do feixe, ambas as rotações se cancelam e o feixe permanece com polarização horizontal.
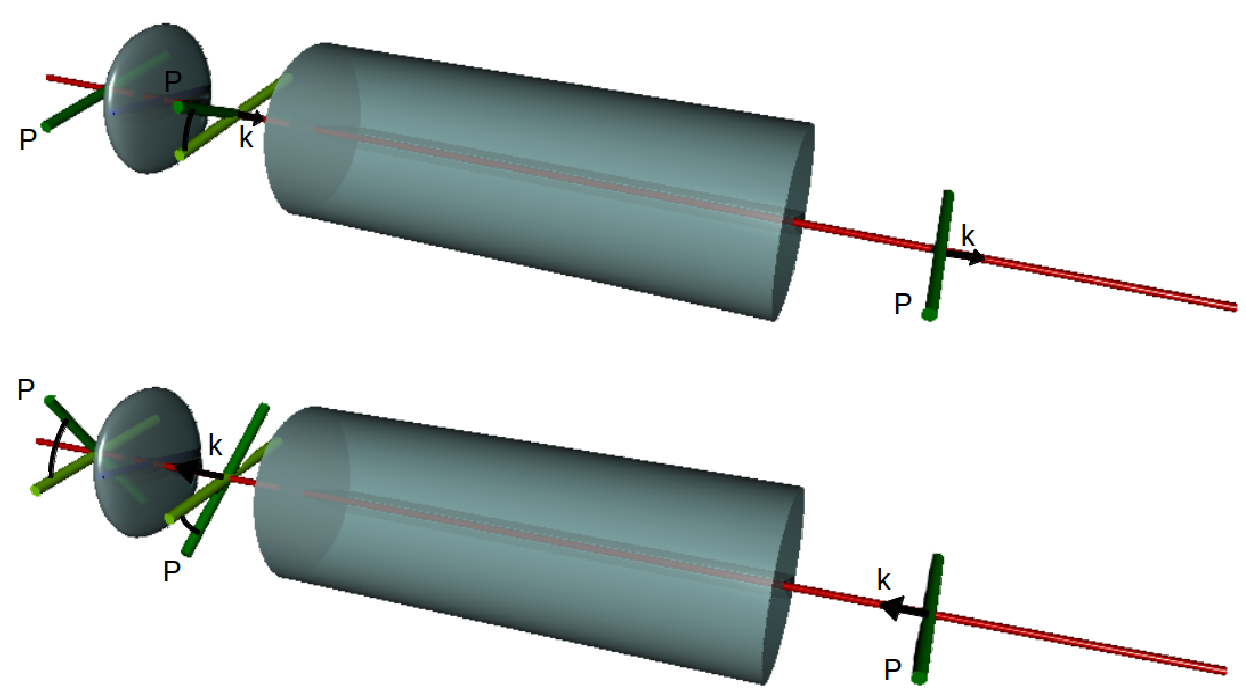

Figura 3.29. Acima um feixe com polarização $P$ horizontal atravessa uma lâmina de onda e sofre um giro na polarização, em seguida o feixe atravessa um material sujeito a um campo magnético e sofre um giro na polarização no sentido oposto, devido ao efeito Faraday, terminando com polarização horizontal.

Abaixo o feixe atravessa primeiramente um material sujeito a um campo magnético, sofrendo um giro por efeito Faraday. Em seguida o feixe atravessa uma lâmina de onda e sofre mais um giro na polarização.

Entretanto, para o feixe que se propaga no sentido oposto, as rotações se somam, e o feixe sai com uma componente da polarização no plano vertical. 
Normalmente, os cristais de birrefringência circular induzida utilizados em ressoadores laser são bastante finos e as rotações provocadas por eles são muito pequenas mas, como na cavidade, praticamente todos os elementos são colocados em ângulo de Brewster para a componente horizontal da polarização, as perdas por reflexão nas componentes verticais são suficientes para fazer com que o feixe que é girado não seja capaz de competir com o feixe que se mantém com polarização horizontal, garantindo assim que o laser oscile em um único sentido.

\subsubsection{Isolador ótico}

Embora o isolador ótico não seja introduzido dentro da cavidade de um laser, ele é frequentemente utilizado logo após a saída da cavidade, para evitar que uma possível reflexão do laser volte para dentro da cavidade e desestabilize o sistema. Seu funcionamento é semelhante ao do diodo ótico, porém é normalmente construído com cubos polarizadores antes e depois do diodo.

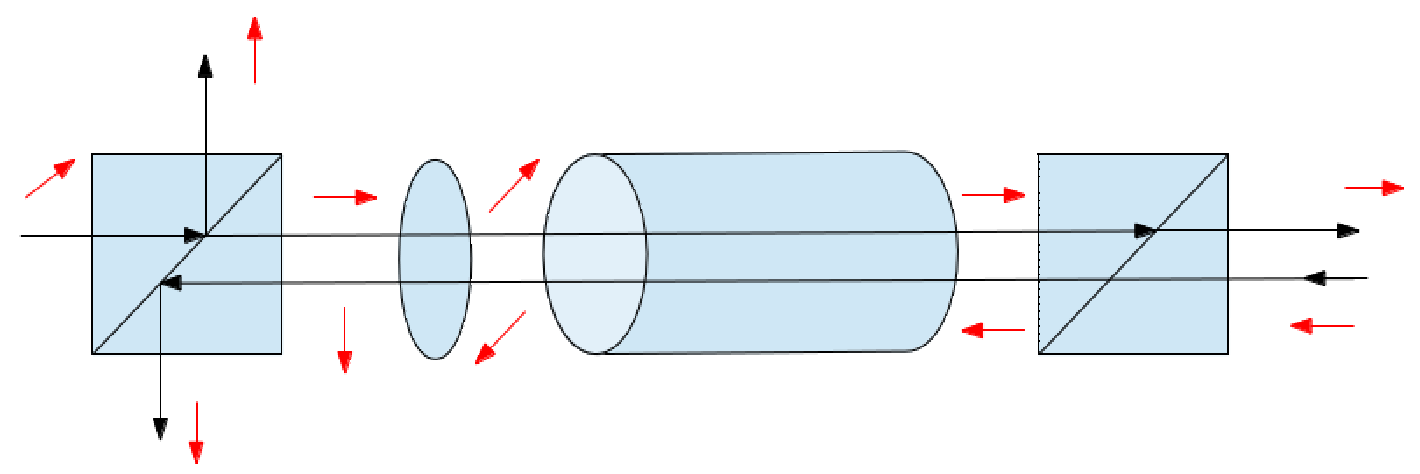

Figura 3.30. Esquema de um isolador ótico ideal, no qual as flechas pretas indicam o sentido de propagação do feixe enquanto as setas vermelhas indicam a direção de polarização do feixe. Um feixe que se propaga da esquerda para a direita tem a polarização dividida entre horizontal e vertical por um cubo polarizador. A polarização horizontal que atravessa o cubo sofre um giro de $45^{\circ}$ no sentido anti-horário ao atravessar uma lâmina de onda e outro giro de $45^{\circ}$ no sentido horário devido ao efeito faraday ao atravessar um cristal sujeito a um campo magnético. O feixe sai do isolador ótico com polarização horizontal.

O feixe que se propaga da direita para a esquerda atravessa um cubo polarizador com polarização horizontal e sofre dois giros de $45^{\circ}$, ambos no sentido horário, de forma que termina com polarização vertical e é completamente refletido pelo cubo polarizador.

O cubo polarizador tem uma superfície dielétrica interna que reflete a polarização vertical e transmite a polarização horizontal.

A lâmina de onda do isolador se torna desnecessária quando podemos girar o cubo polarizador. Ajustando o primeiro cubo, é possível fazer com que o feixe que atravessa o isolador, ao ser refletido e voltar no sentido contrário sofra um giro tal que sua polarização seja completamente refletida pelo cubo de entrada.

No caso ideal (figura 3.30), o diodo ótico produz, no feixe refletido, um giro de exatamente $90^{\circ}$. Entretanto, na realidade, cristais que geram uma rotação grande 
por intensidade do campo magnético são normalmente opacos, enquanto materiais transparentes produzem pouca rotação. Assim isoladores reais causam uma perda de cerca de $10 \%$ no campo transmitido, quando bloqueiam completamente o feixe refletido (figura 3.31).

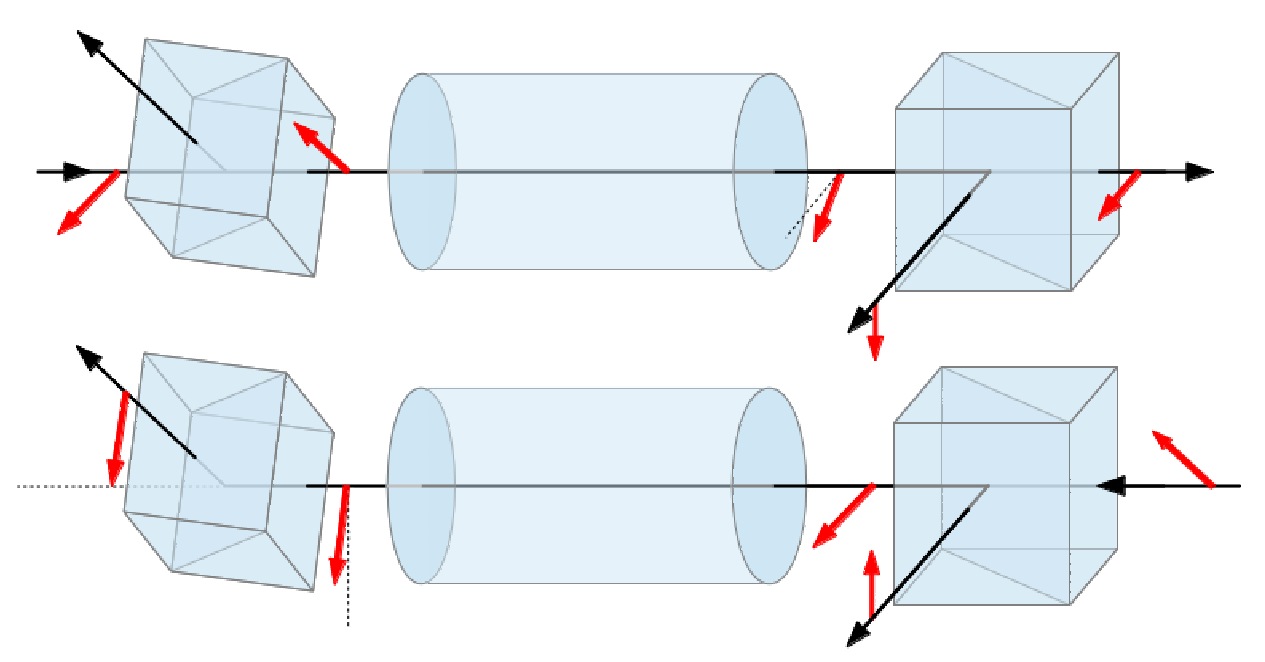

Figura 3.31. Esquema de isolador real. A cima, a polarização do feixe que atravessa o isolador da esquerda para a direita, que sofre uma perda ao atravessar o primeiro cubo, e sai do isolador com polarização horizontal. A baixo, a direção de polarização do feixe que atravessa o isolador da direita para a esquera, que é totalmente refletido pelo cubo da esquerda.

\subsection{Seleção e travamento de frequência}

Em princípio, o laser de titânio safira deve ser intrinsecamente monomodo, e a frequência ressonante com a cavidade, que tiver maior ganho e menor perda, oscilará. Entretanto, existe uma tendência do laser de saltar entre modos de ganho alto devido a perturbações mecânicas ou térmicas na cavidade.

Sem nenhum seletor de frequência, o laser de titânio-safira normalmente varia entre cerca de 10 a $70 \mathrm{~nm}$ ao redor de $\lambda=775-800 \mathrm{~nm}$ [23], o que representa uma variação de frequência de cerca de $30 \mathrm{THz}$. Isso significa que, dentro de uma cavidade de $1 \mathrm{~m}$, cujo comprimento espectral livre é aproximadamente $\mathrm{FSR} \simeq 0,3 \mathrm{GHz}$, podem oscilar cerca de cem mil modos longitudinais distintos, o que é extremamente vantajoso para a construção de lasers pulsados. O que limita a oscilação de mais modos é, em geral, a ótica utilizada no laser.

Para atingir um sistema monomodo estável, o primeiro passo é reduzir o número de modos através de um filtro de frequência. Em lasers de corante ou lasers vibrônicos, como o de titânio-safira, que têm um pente de frequência muito grande, é 
comum o uso de um filtro de Lyot, ou filtro birrefringente, descrito em maior detalhe na subseção seguinte, que permite sintonizar a frequência do laser de saída com precisão de milésimo de nanometros, introduzindo pequenas perdas nas frequências indesejadas.

A largura de banda do filtro de Lyot utilizado foi estimada como sendo menor do que $0.5 \mathrm{GHz}$ e seu comprimento espectral livre é grande o bastante para que haja apenas um pico de transmissão dentro da região de maior ganho do cristal de titâniosafira.

Com o filtro de frequência, o número de possíveis modos oscilantes é reduzido para no máximo três, mas ainda é necessário outro elemento para garantir a operação monomodo. Para tanto utilizamos um etalon.

O etalon é uma lâmina de vidro, ou outro cristal, que funciona como uma cavidade de Fabry-Perot, para a qual as frequências dos picos de transmissão dependem do ângulo de incidência do campo, como demonstrado na seção 3.1.

Girando o etalon é possível selecionar um modo de frequência que não sofra perdas por reflexão ao atravessar a cavidade, e impor perdas aos outros.

Muitos lasers, ao invés de utilizarem filtros de frequência, utilizam dois etalons de tamanhos diferentes, mas, para o titânio-safira, que tem uma banda de emissão extremamente larga, é preferível a utilização do filtro de Lyot.

Outra característica do etalon é que, para não introduzir muitas perdas no feixe intracavidade, é desejado que a reflexão, em suas superfícies, seja pequena, o que faz com que ele tenha uma banda de transmissão larga. Mesmo assim, as pequenas perdas introduzidas por ele são suficientes para discriminar entre um dos três modos que oscilam na cavidade laser com o filtro de Lyot.

Um último controle fino da frequêcia é feito variando-se micrometricamente o tamanho da cavidade, de forma a alterar as frequências dos modos longituinais, permitindo que se escolha uma frequência com precisão maior do que o FSR da cavidade. Esse controle é feito eletronicamente e, junto com um controle eletrônico do ângulo de etalon, é possível compensar flutuações na frequência do laser de saída, através do que se chama de sistema de travamento de frequência.

Um bom sistema de travamento de frequência é o que garante uma largura de linha estreita para o feixe de saída. Entretanto esta largura é limitada pelo produto das larguras de linha do filtro de Lyot, do etalon e dos modos longitudinais da cavidade.

\subsubsection{Filtro de Lyot}

A idéia do filtro de Lyot é utilizar uma lâmina de um material birrefringente, normalmente o quartzo, para provocar um giro na polarização do feixe. Como o índice de refração dos eixos ordinários e extraordinários depende da frequência do campo que o atravessa, o giro da polarização também dependerá. 
Se após o cristal birrefringente houver um filtro polarizador, apenas a componente do campo cuja polarização tiver a direção do filtro não será atenuada.

Se um campo tiver uma frequência tal que, após ser girado pelo cristal birrefringente, sua polarização esteja exatamente na direção do filtro polarizador, este campo não sofrerá nenhuma atenuação. Evidentemente, um outro campo que gira $90^{\circ}$ a mais do que ele também não sofrerá atenuações.

A polarização do feixe é mantida inalterada se a defasagem entre as componentes sobre o eixo rápido e sobre o eixo lento é múltipla de $2 \pi$ :

$$
\varphi=k\left(n_{e}-n_{o}\right) l=2 \pi m,
$$

$\operatorname{com} m=1,2,3, \ldots$

onde $l$ é o caminho ótico do feixe dentro do material birrefringente e $n_{e}$ e $n_{o}$ são os índices de refração dos eixos extraordinário e ordinário.

O campo que atravessa o material é

$$
\vec{E}=E_{e} \cos \left(\omega t-k_{e} l\right) \hat{e}+E_{o} \cos \left(\omega t-k_{o} l\right) \hat{o}
$$

e tem módulo

$E=E_{e} \cos \left(\omega t-k_{e} l\right) \operatorname{sen} \alpha+E_{o} \cos \left(\omega t-k_{o} l\right) \cos \alpha=E_{0}\left(\cos \left(\omega t-k_{e} l\right) \operatorname{sen}^{2} \alpha+\right.$ $\left.\cos \left(\omega t-k_{o} l\right) \cos ^{2} \alpha\right)$,

onde $\alpha$ é o ângulo entre a polarização da onda incidente e eixo ordinário do cristal.

A intensidade transmitida é, portanto,

$$
\begin{gathered}
I=|E|^{2}=I_{0}\left(\operatorname{sen}^{4} \alpha+\cos ^{4} \alpha+2 \operatorname{sen}^{2} \alpha \cos ^{2} \alpha \cos \varphi\right)= \\
=I_{0}\left(\operatorname{sen}^{4} \alpha+\cos ^{4} \alpha+2 \operatorname{sen}^{2} \alpha \cos ^{2}\left(1-\operatorname{sen}^{2} \frac{\varphi}{2}\right)\right)= \\
I_{0}\left(\left(\operatorname{sen}^{2} \alpha+\cos ^{2} \alpha\right)^{2}-2 \operatorname{sen}^{2} \alpha \operatorname{sen}^{2} \frac{\varphi}{2}\right)= \\
=I_{0}\left(1-2 \operatorname{sen}^{2} \alpha \operatorname{sen}^{2} \frac{\varphi}{2}\right) .
\end{gathered}
$$

Especificamente para $\alpha=45^{\circ}$, a transmissão do filtro de Lyot vale:

$$
\frac{I}{I_{o}}=\cos ^{2}\left(\frac{k \Delta n}{2} l\right)
$$

Quanto maior for o comprimento do filtro, maior será o intervalo espectral livre entre os campos que atravessam o polarizador sem sofrer nenhuma perda, porém mais estreitos serão os picos de transmissão. 


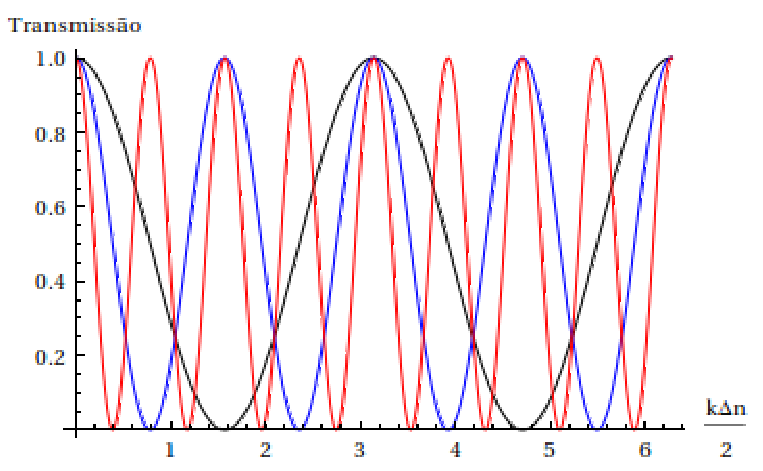

Figura 3.32. Transmissão de um Filtro de Lyot simples para três de cristais tamanhos diferentes $l, 2 l$ e $4 l$.

Se o filtro de Lyot for composto por uma sequência de filtros birrefringentes ao invés de um só, sendo o comprimento de cada um deles um múltiplo de um mesmo valor, a transmissão do filtro composto será o produto da transmissão de cada filtro:

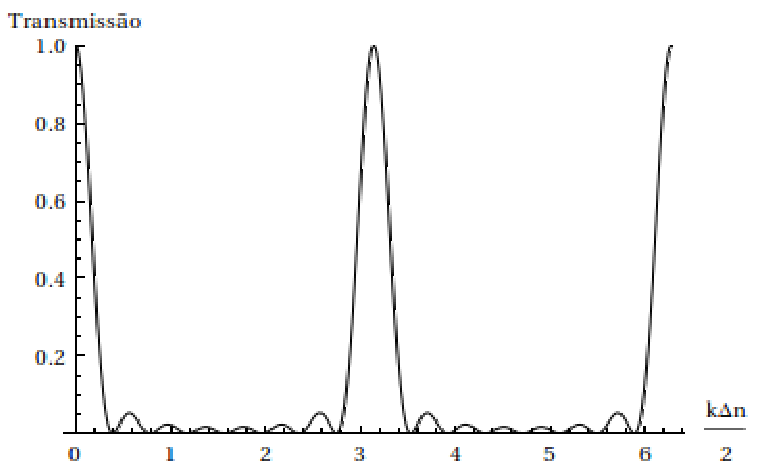

Figura 3.33. Transmissão de um filtro de Lyot composto por três cristais de comprimentos $l, 2 l$ e $4 l$.

No caso da cavidade laser, não é necessário a utilização de filtros polarizadores. Se os cristais são colocados em ângulo de Brewster, as pequenas perdas sofridas pelos campos que não tiverem polarização horizontal bastam para evitar sua oscilação.

Os campos de uma frequência específica que sofrerem um giro tal que sua polarização permaneça horizontal após atravessar o filtro de Lyot, oscilarão. A quantidade e o comprimento dos cristais de quartzo determinará a quantidade de modos da cavidade que atravessam o filtro. Normalmente os filtros de Lyot são compostos por apenas três cristais de quartzo.

Outro fator importante com relação à incidência em ângulo de Brewster é que, para qualquer incidência diferente de $0^{\circ}$, o tamanho do caminho ótico do feixe dentro do cristal dependerá da posição dos eixos ordinários e extraordinários do cristal, de forma que, girando o cristal ao redor do seu eixo de simetria, é possível controlar o giro da polarização de um determinado modo de frequência.

A demonstração de que um filtro de Lyot inclinado pode servir como um seletor de frequência para lasers foi feita pela primeira vez por Yarborough e Hobart[40] e está detalhada em [41] e [42]. A transmissão máxima ocorre para comprimentos de 
onda que obedecem a relação:

$$
\lambda=\frac{\Delta n \cdot l}{m \operatorname{sen} \theta} \operatorname{sen}^{2} \beta,
$$

onde $\theta$ é o ângulo de incidência (ângulo de Brewster no caso do laser) e $\beta$ é o ângulo que o feixe refratado que viaja dentro do cristal faz com o eixo ótico.

\subsubsection{Sistema de travamento do etalon}

A função do sistema de travamento do etalon é controlar eletronicamente o ângulo do etalon dentro da cavidade, de forma que uma determinada frequência, correspondente a um modo longitudinal da cavidade, tenha o mínimo de perdas.

Quando a cavidade sofre alguma alteração de tamanho, ou por uma oscilação de seus componentes óticos, ou por uma variação térmica qualquer, a frequência do modo oscilante na cavidade varia. Nesse caso o etalon precisa girar, de forma que a nova frequência do modo continue sofrendo o mínimo de perdas.

Assim, o etalon não mantém a cavidade fixa em uma única frequência, mas garante que apenas um modo oscile dentro da cavidade laser, e a intensidade do campo de saída irá depender justamente do casamento entre a frequência desse modo e a frequência de máxima transmissão do etalon, que, por sua vez, depende do ângulo $\theta$ de incidência do campo intracavidade, como indicado pela equação 3.3. Portanto $I_{s}=I(\theta)$, e travar o laser em um modo significa variar $\theta$ de forma que $I$ seja máximo, ou seja, $\frac{d I}{d \theta}=0$.

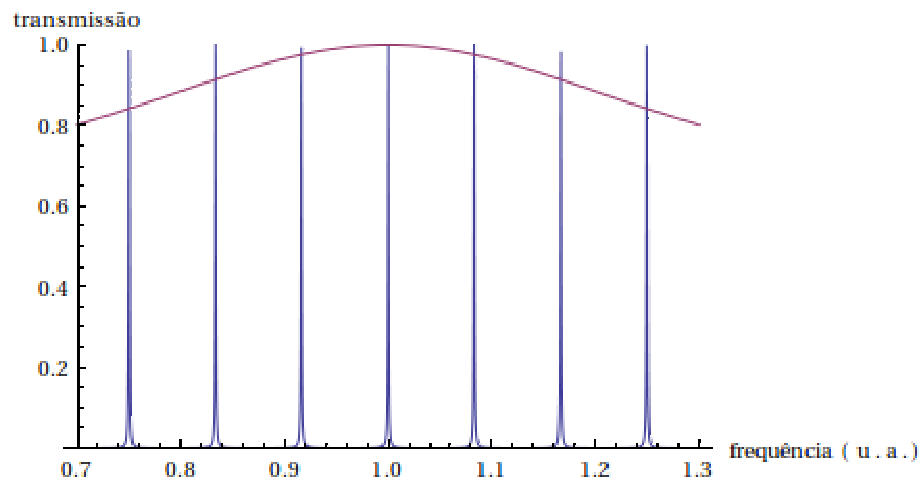

Figura 3.34. Em azul o esquema de uma curva de transmissão de um etalon sobreposta aos modos longitudinais de uma cavidade em lilas. O modo no centro da figura é o único que não sofre perdas ao atravessar o etalon.

Fisicamente, para se obter a derivada da intensidade e função de $\theta$ em um ponto $\theta_{0}$ qualquer, é preciso explorar os valores de $I(\theta)$ na vizinhança de $\theta_{0}$. O que significa que é preciso aplicar uma pequena perturbação rápida no ângulo do etalon.

Na prática, um controle lento do ângulo é feito através de um galvo, que gira quando se aplica sobre ele uma tensão, enquanto a perturbação rápida no ângulo é feita através de um piezo elétrico, ou pzt, enconstado no suporte do etalon, como pode ser visto na figura 3.35, que oscila com alta frequência (cerca de $30 \mathrm{kHz}$ ). 


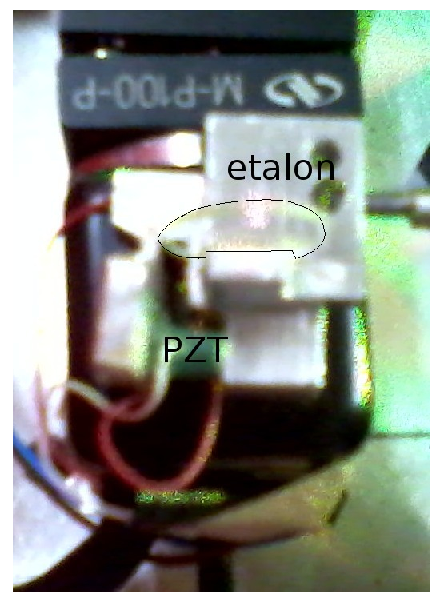

Figura 3.35. Foto do etalon sobre o galvo, que pode girá-lo sobre o seu centro, e do pzt que pode provocar uma pequena variação no ângulo do etalon.

O pzt recebe um sinal senoidal de frequência $\omega$, fazendo com que o angulo $\theta$ varie como:

$$
\theta=\theta_{0}+A \cos (\omega t)
$$

onde $A$ é a amplitude de oscilação do pzt.

Consequentemente:

$$
I(\theta)=I\left(\theta_{0}+\cos \omega t\right),
$$

que pode ser expandido em uma série de Taylor em torno de $\theta_{0}$.

$$
I(\theta)=I\left(\theta_{0}\right)+\frac{d I}{d \theta}\left(\theta_{0}\right) A \cos \omega t+\frac{d^{2} I}{d \theta^{2}}\left(\theta_{0}\right) A^{2} \cos ^{2} \omega t+\ldots
$$

Como a amplitude de oscilação é muito pequena podemos truncar a série até o termo de segunda ordem.

O sinal da intensidade de saída do laser é medido por um fotodetector e eletronicamente multiplicado por um sinal senoidal com a mesma frequência $\omega$ que o pzt. O sinal resultante é:

$$
\begin{gathered}
I(\theta) \cos (\omega t+\varphi) \simeq \\
\simeq I\left(\theta_{0}\right) \cos (\omega t+\varphi)+\frac{d I}{d \theta}\left(\theta_{0}\right) A \cos \omega t \cos (\omega t+\varphi)+\frac{d^{2} I}{d \theta^{2}}\left(\theta_{0}\right) A^{2} \cos ^{2} \omega t \cos (\omega t+\varphi)= \\
=I\left(\theta_{0}\right) \cos (\omega t+\varphi)+\left(A \frac{d I}{d \theta}\left(\theta_{0}\right)+\frac{d^{2} I}{d \theta^{2}}\left(\theta_{0}\right) A^{2} \cos \omega t\right)\left(\cos ^{2} \omega t \cdot \cos \varphi-\frac{1}{2} \operatorname{sen} 2 \omega t \operatorname{sen} \varphi\right)
\end{gathered}
$$

Por fim, o sinal passa por um filtro passa-baixa que desaparece com a oscilação de frequência $\omega$, devolvendo uma média temporal do sinal. A resultante é simplesmente a derivada da intensidade, multiplicada por um termo dependente de $\varphi$ :

$$
\langle I(\theta) \cos (\omega t+\varphi)\rangle=\frac{A}{2} \cos \varphi \frac{d I}{d \theta}\left(\theta_{0}\right)
$$

O sinal resultante é chamado sinal de erro. Se o sinal de erro for positivo ou negativo, o galvo rodará em um sentido ou em outro, a fim de levar o sinal de erro para zero. O sentido correto que o galvo deve rodar para manter o laser travado é determinado pela fase $\varphi$ que deve ser 0 ou $\pi$ para que o sinal de erro seja maximizado. 


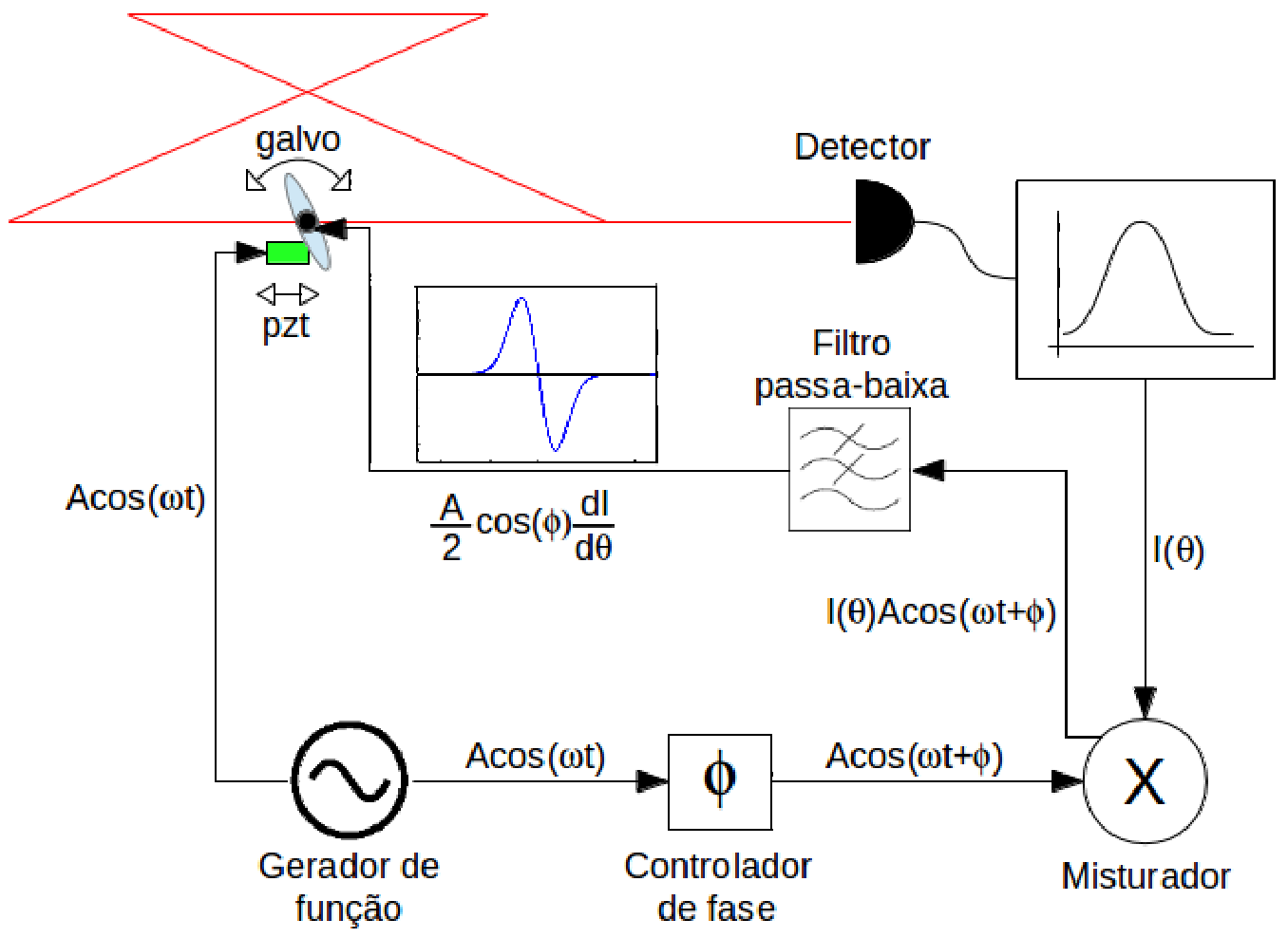

Figura 3.36. Esquema do sistema de travamento do etalon.

A amplitude de oscilação $A$ pode também ser controlada para aumentar ou diminuir o sinal de erro. Entretanto se $A$ for muito alto, significa que se está provocando uma perturbação grande na cavidade, o que prejudicará o sistema de travamento. Assim, a amplitude da perturbação deve ser a mínima suficiente para travar o laser.

\subsubsection{Sistema de travamento da cavidade}

O travamento do etalon garante o regime monomodo estável, entretanto não garante que a frequência do modo oscilante seja sempre a mesma. Variações no tamanho da cavidade alteram as frequências dos modos da cavidade e, para manter a frequência do feixe de saída fixa, é preciso duas coisas: ter uma referência de frequência que não varie com o tempo e poder alterar o tamanho da cavidade para ajustar a frequência do laser com relação à frequência de referência.

O controle do tamanho da cavidade laser é feito colocando um pzt atrás de um dos espelhos planos e a referência de frequência pode ser obtida de diversas maneiras.

Em geral átomos são uma excelente referência de frequência quando seus níveis de energia podem ser resolvidos com precisão. Para o travamento de lasers de titâniosafira é comum a utilização dos níveis de energia de vapor de rubídio como referência, pois as frequências de máximo ganho do laser coincidem com faixas de absorção do rubídio. A resolução dos níveis finos dos átomos costuma ser feita através da espectroscopia de absorção saturada, descrita na seção 4.3.3, que elimina o alargamento Doppler. O resultado é um pico estreito ao redor de uma frequência bem determinada e que não varia com o tempo. 
Apesar da altíssima precisão, referências atômicas são inconvenientes quando desejamos variar a frequência do laser. Embora seja possível variar as frequências de referência de átomos através do efeito Zeeman, para variar significativamente a frequência do laser de saída seria necessário um campo magnético intenso. Por esse motivo optamos por não utilizar referências atômicas, mas sim o sinal de transmissão de uma cavidade de Fabry-Perot estável.

A cavidade de referência é uma cavidade de Fabry-Perot rígida, o que significa que os espelhos de entrada e saída não são fixados de maneira independente, mas de forma que exista um vínculo entre eles e que a peça que os une seja de um material que sofra pouca dilatação térmica.

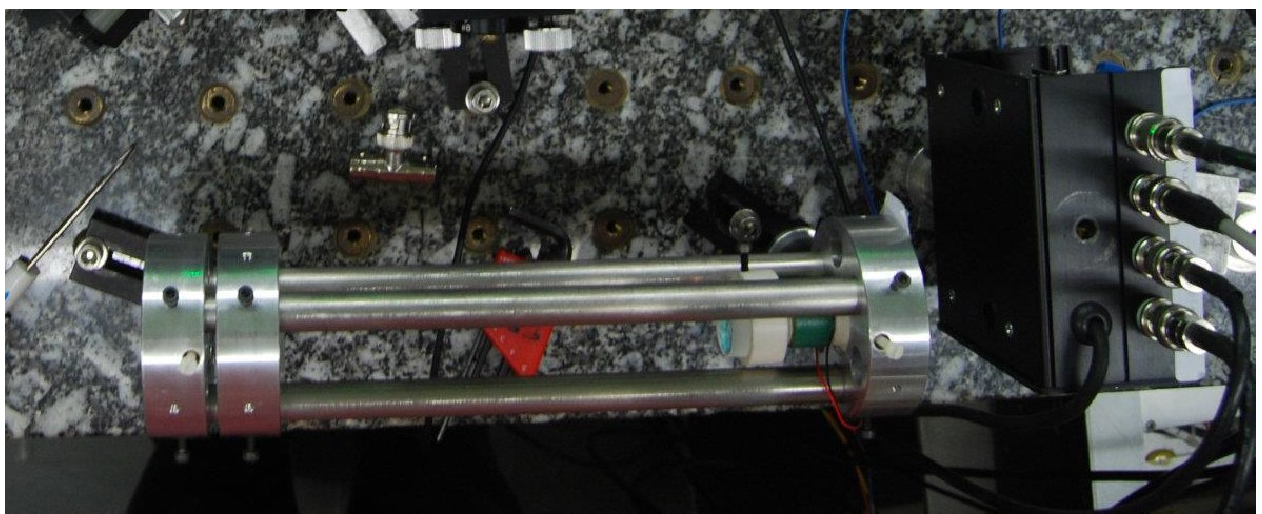

Figura 3.37. Cavidade de referência feita com barras de invar. As duas pontas das barras estão fixadas em um suporte sobre a mesa. Um dos espelhos fica preso a uma das extremidades, em cima de um pzt cilíndrico (espelho da direita), enquanto o outro fica em um suporte cuja distância com relação ao espelho da direita pode ser ajustada.

Para a cavidade de referência construída, a distância entre os espelhos é controlada através de um pzt e, para eliminar flutuações de intensidade do feixe de saída causadas por flutuações de intensidade do laser, fez-se uma montagem na qual medimos tanto a intensidade do feixe de saída da cavidade de referência como a intensidade de um feixe que não passa por ela, e depois subtraímos uma da outra. Uma flutuação de intensidade do laser estará presente em ambos os feixes medidos e portanto será cancelada pela subtração dos dois.
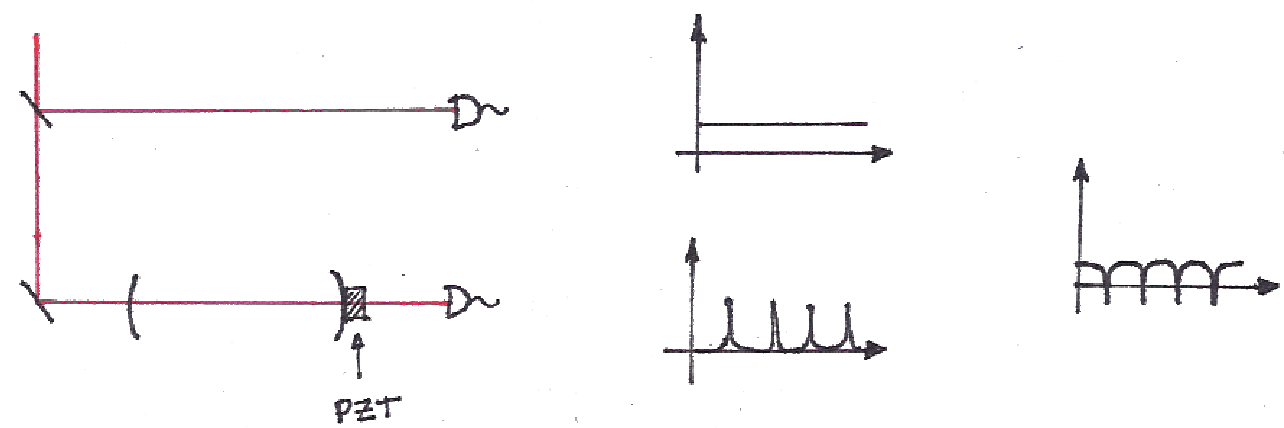

Figura 3.38. À esquerda, esquema da montagem do travamento da cavidade; ao centro, os sinais detectados por cada detector; À direita, o sinal resultante da subtração de um dos sinais pelo outro. 
O sinal resultante é o sinal de erro do travamento da cavidade. Quando ele é positivo a tensão no pzt da cavidade do laser aumenta, variando a frequência do laser até que o sinal de erro seja nulo. Se ele for negativo a tensão no pzt diminui, deslocando a frequência do laser para o lado contrário.

O travamento falha quando a perturbação na frequência é tanta que leva o laser a travar em outro modo da cavidade de referência. Como a região para a qual o sinal de erro é positivo é sempre mais larga do que a região do sinal negativo, o travamento fica mais estável se a região negativa for maximizada, o que acontece se a intensidade dos picos de transmissão da cavidade de referência for, também, maximizada e se o ponto de travamento for o mais afastado possível desses picos, como indicado na figura 3.39. Portanto, a intensidade medida do feixe que não passa pela cavidade deve ser a menor possível e a finesse da cavidade a maior possível.
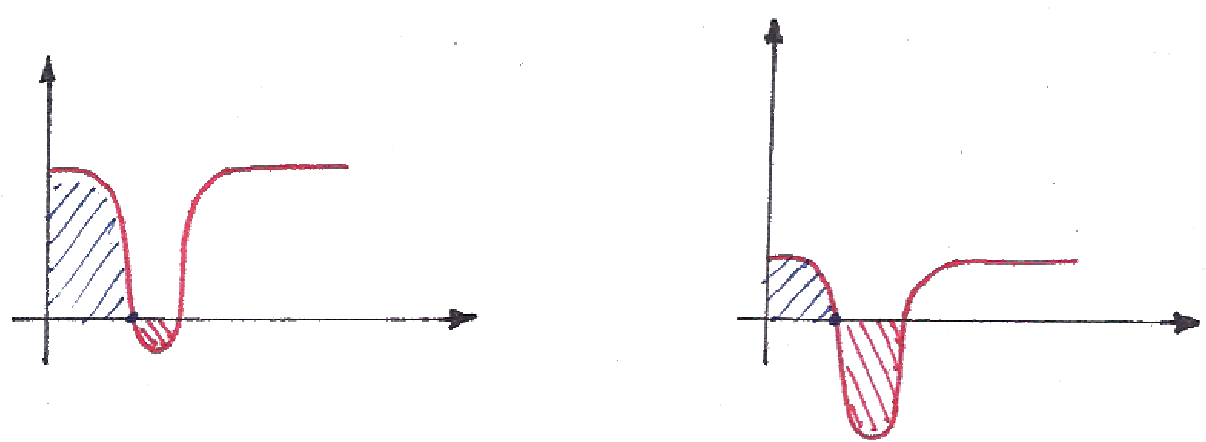

Figura 3.39. Ilustração de dois possíveis pontos de travamento: um perto do pico de transmissão da cavidade de referência, com a região do sinal de erro negativo pequena, e outro mais afastado do pico de transmissão, com a região do sinal negativo maior, e que se mostra mais eficiente para o travamento.

Entretanto vale lembrar que, quanto menor a intensidade do feixe que não passa pela cavidade, menos eficiente será a correção das oscilações de intensidade do laser, fazendo com que o travamento fique sujeito a perturbações.

A frequência do travamento é alterada ao variarmos o comprimento da cavidade de referência, pois o sistema de travamento faz com que o tamanho da cavidade do laser também se altere, de forma que o sinal de erro permaneça nulo e a frequência do laser varie. 



\section{Capítulo 4}

\section{Caracterização e Medidas}

A última etapa da construção de um laser é a análise de suas características com a finalidade de determinarmos se o laser construído possui as especificações desejadas, necessárias para cumprir com seus propósitos.

As demandas para um laser contínuo estão normalmente relacionadas à sua potência de saída, ao seu perfil transverso, à sua largura de linha e estabilidade de frequência, a flutuações de potência e a ruídos quânticos de fase e amplitude.

Neste capítulo serão apresentados os métodos de caracterização das propriedades clássicas utilizados e os resultados obtidos para o laser construído.

\subsection{Potência de Saída}

Como visto anteriormente na seção 3.2.1, existe uma relação direta entre a potência 
de saída do laser e a potência de bombeio, dada pela equação (3.12):

$$
P_{s}=T \frac{P_{\mathrm{sat}}}{P_{\mathrm{th}}} P_{p}-T P_{\mathrm{sat}}=a P_{p}+b
$$

para $P_{p} \geqslant P_{\text {th }}$

Nesta condição em que existe oscilação intracavidade, os ganhos e perdas por reflexões ou absorção do feixe estão em equilíbrio. O que determina a relação entre a potência de saída do laser e a potência do bombeio é, além das características do meio de ganho, a capacidade da cavidade de armazenar energia. Quanto menos perdas houver na cavidade, menor será a potência de limiar de bombeio necessária para a oscilação e maior será a potência de saída do laser para uma determinada potência de bombeio.

Assim a qualidade da cavidade pode ser determinada através do grafíco $W_{p} \times W_{s}$.

Devemos medir potência do laser de bombeio imediatamente antes da cavidade laser para garantir que não há perdas significativas entre a potência no ponto medido e no cristal. Da mesma forma a potência do laser deve ser medida na saída da cavidade. Durante as medidas precisamos tomar cuidado com as variações de temperatura que ocorrem devido a um aquecimento da cavidade pelo feixe de bombeio e pelo feixe intracavidade.

O desalinhamento do laser devido ao aquecimento da cavidade é significativo e pode ser caracterizado através de um gráfico da potência de saída do laser pelo tempo.

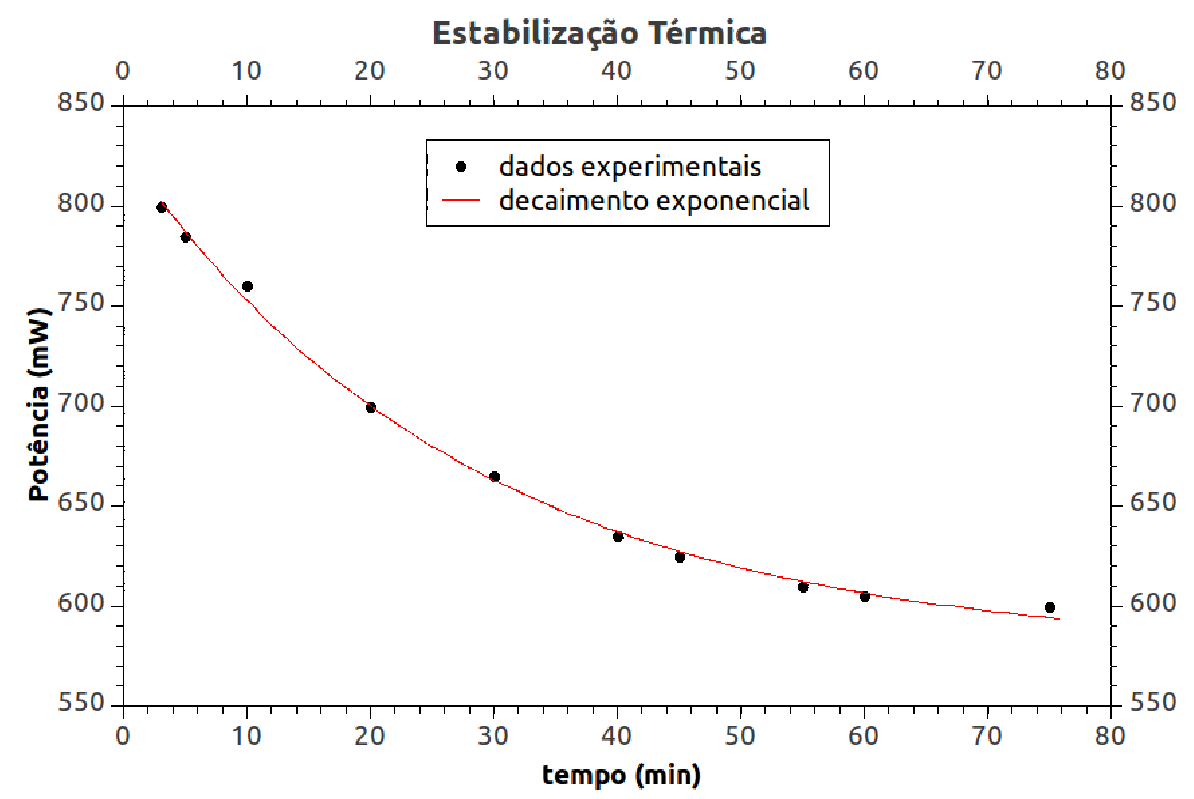

Figura 4.1. Medida experimental da queda de potência de um laser de Titânio Safira com o tempo devido ao aquecimento da cavidade. 
No gráfico da figura 4.1 pode se ver a queda de aproximadamente $25 \%$ da potência do laser ao longo de uma hora, revelando o quão relevante é a estabilização térmica para medidas longas. A potência caiu exponencialmente de cerca de $810 \mathrm{~mW}$ até cerca de $580 \mathrm{~mW}$ após $75 \mathrm{~min}$, quando se estabilizou.

Após esta estabilização é possível realinhar o laser e observar que não há mais queda de potência com o tempo. Entretanto o realinhamento da cavidade não permite que se obtenha a mesma potência inicial. Possíveis causas são efeitos de perda de coerência dentro do cristal, que ocorrem devido a decaimentos não radioativos, como a emissão de fônons, e que são maiores para temperaturas mais elevadas. Outra possível causa são efeitos de lentes térmicas, que alteram o índice de refração dos cristais devido ao aquecimento provocado pelo feixe, modificando o tamanho da cavidade. Variações de temperatura também afetam o tempo de decaimento do nível ${ }^{2} \mathrm{E}$, como demonstrado por [22, Albers et al. (1986)].

Para o laser construído durante este trabalho, a potência final após a estabilização é de cerca de $90 \%$ da potência inicial.

Para contornar o problema do aquecimento da cavidade durante a realização de medidas podemos esperar um tempo após ligar o bombeio, até que a temperatura da cavidade se estabilize, ou então tomar cada medida rapidamente bloqueando o bombeio em seguida de forma que o cristal não chegue a esquentar significativamente.

Ambas as alternativas foram experimentadas na realização da medida de $W_{p} \times$ $W_{s}$ e estão representadas no gráfico da figura 4.2 .

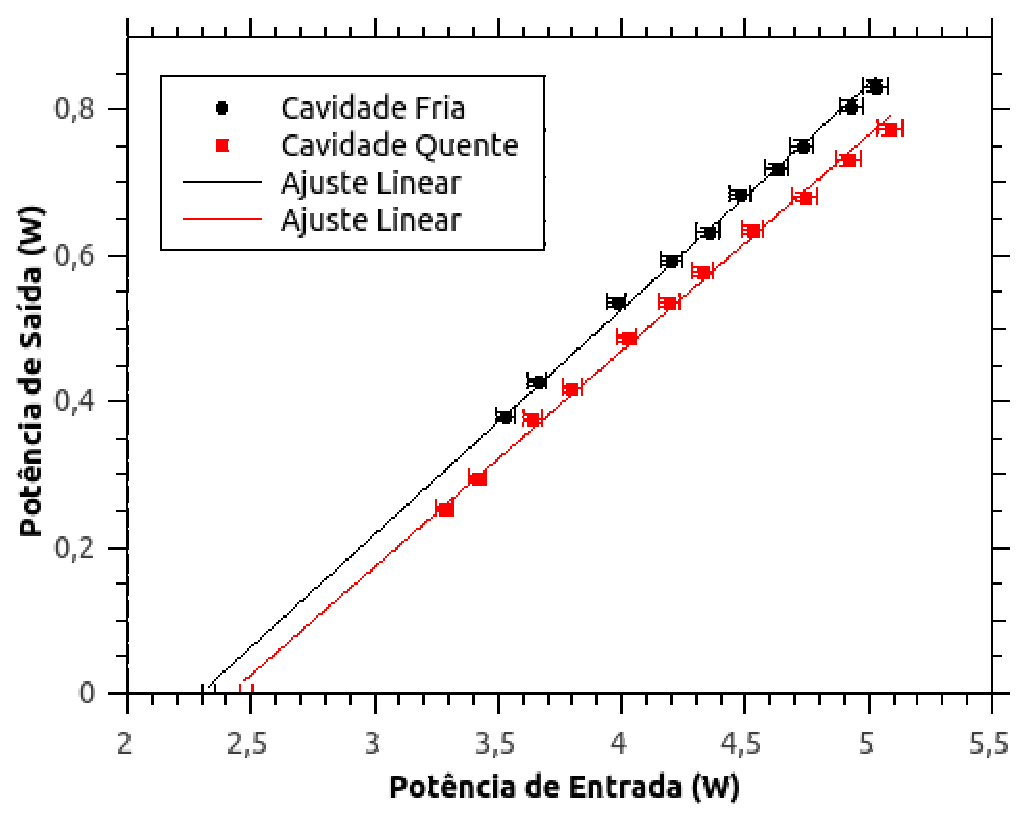

Figura 4.2. Potência de saída do laser em relação à potência de bombeio para duas condições de medidas. Na primeira (em preto) as medidas são feitas rapidamente sem permitir o aquecimento da cavidade. Na segunda (em vermelho) esperou-se a cavidade se estabilizar termicamente para depois alinhá-la e realizar as medidas. 
Os coeficientes lineares dos gráficos das duas medidas são compatíveis entre si, demonstrando que os efeitos de variação do tempo de decaimento devido ao aumento de temperatura não são significativos dentro da faixa de variação de temperatura do laser em operação contínua. O coeficiente linear é diretamente proporcional à potência de saturação do laser, que está relacionada apenas aos tempos de decaimento dos níveis do cristal de titânio safira (2.5).

Já o coeficiente angular varia, pois é inversamente proporcional à potência de limiar da cavidade, que por sua vez depende diretamente das perdas intracavidade. Isso significa que, após a estabilização de térmica da cavidade, mesmo com um realinhamento dos espelhos, as perdas são maiores do que com a cavidade "fria".

Entretanto essa diferença não é preocupante a ponto de que seja necessário introduzir um controle de temperatura da cavidade. Pois a potência de saída obtida para $5 \mathrm{~W}$ de bombeio, após a estabilização térmica, foi de $0,77 \mathrm{~W}$, o que é mais do que o suficiente para os fins a que se destinará o laser construido.

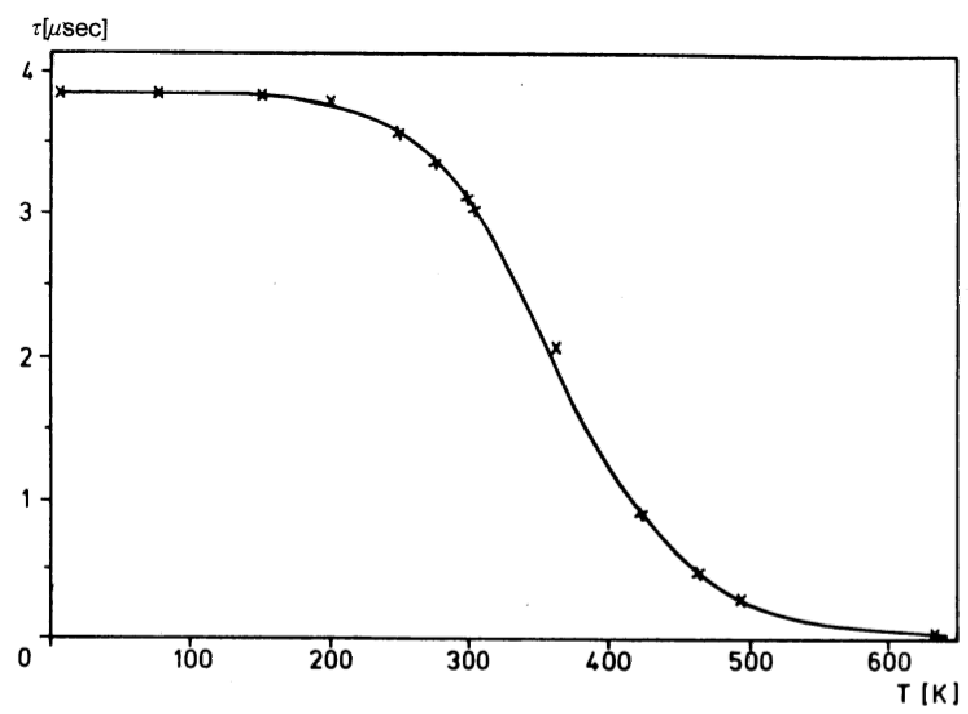

Figura 4.3. Dependência do tempo de vida do Estado ${ }^{2} \mathrm{E}$ com a temperatura. Retirado de [22, Albers et al., 1986].

As perdas intracavidade são estipuladas através da eficiência quântica do laser que pode ser escrita em função da relação entre as potências de bombeio e de saída:

$$
\eta_{Q}=\eta \frac{\lambda_{s}}{A \lambda_{p}}
$$


onde $\eta=a$ é o coeficiente angular do gráfico $W_{p} \times W_{s}$ e $A$ é a fração da potência de bombeio que é absorvida pelo cristal.

A eficiência quântica do laser pode ser relacionada com as perdas $L$ da cavidade se comparada com a eficiência quântica interna $\eta_{Q_{i}}$ :

$$
\eta_{Q}=\eta_{Q_{i}} \frac{T}{T+L}
$$

onde $T$ é a transmissão do espelho de saída da cavidade e a eficiência quântica interna é dada pela razão entre as taxas de decaimento radioativo e decaimento total e pode ser escrita em função da potência irradiada e a potência disponível:

$$
\eta_{Q_{i}}=\frac{\gamma_{r}}{\gamma}=\frac{P_{r} \lambda_{r}}{P_{\mathrm{abs}} \lambda_{p}}=\frac{P_{r} \lambda_{r}}{A P_{p} \lambda_{p}}
$$

Como verificamos que as taxas de decaimento não variam significativamente para a diferença de temperatura entre as medidas que geraram duas retas da figura 4.2, podemos assumir que o valor de $\eta_{Q_{i}}$ não varia e seu valor pode ser estimado utilizando o tempo do decaimento radioativo $\tau_{r}=\gamma_{r}^{-1}=3,85 \mu \mathrm{s}$ e o tempo de decaimento do estado excitado que pode ser obtido a partir da curva da figura 4.3. Esses valores levam a uma eficiência quântica interna $\eta_{Q_{i}}=87,0(3) \%$ para temperatura ambiente.

Também seria possível determinarmos o valor de $\eta_{Q_{i}}$ experimentalmente através das equações (4.1) e (4.2) levantando duas curvas de $P_{p} \times P_{s}$ para acopladores de saída diferentes, contanto que as perdas internas e a eficiência quântica se mantivessem as mesmas.

Para o laser construído, a fração do bombeio absorvida pelo cristal vale $A=0.9$ e as eficiências de inclinação medidas valem $\eta^{f}=31,3(4) \%$ para a cavidade "fria", que resulta em uma eficiência quântica $\eta_{Q}^{f}=51,0(7) \%$, e $\eta^{q}=30,3(4) \%$ para a cavidade "quente", que resulta em uma eficiência quântica $\eta_{Q}^{q}=49,3(7) \%$. Assim as perdas internas da cavidade podem ser determinadas como sendo $L^{f}=2,12(7) \%$ para a cavidade "fria" e $L^{q}=2,29(8) \%$ para a cavidade "quente"; as potências de limiar são $P_{\mathrm{th}}^{f}=2,32(7) W$ e $P_{\mathrm{th}}^{q}=2,45(6) W$ respectivamente e a potência de saturação é $P_{\text {sat }}=24,7(4) W$.

Uma vez medidas as perdas espúrias de uma cavidade, é possível calcularmos qual seria o melhor espelho de saída para maximizar a potência do laser para um certo bombeio.

Para isso precisamos primeiramente calcular qual a constante de proporção entre a potência de limiar e as perdas da cavidade:

$$
K=\frac{P_{\mathrm{th}}}{(T+L)}
$$


Então, da equação (3.12) temos:

$$
P_{s}=T P_{\text {sat }}\left(\frac{P_{p}}{K(T+L)}-1\right)
$$

A derivada em função de $T$ leva ao seguinte critério de maximização da potência de saída:

$$
T=\sqrt{\frac{L P_{p}}{K}}-L
$$

Portanto na condição da cavidade "quente", para um bombeio de $5 W$, o espelho de saída ideal seria um de $T=2,78(10) \%$, e a potência do laser obtida nesta condição seria $791 \mathrm{~mW}$. Para a cavidade fria, também para um bombeio de $5 W$, o ideal seria um espelho de $T=2,65(9) \%$ e a potência de saída seria $845 \mathrm{~mW}$. Para o espelho utilizado e as perdas calculadas, a potência máxima prevista não é muito inferior a este resultado e vale $772 \mathrm{~mW}$ para a cavidade "quente" e $840 \mathrm{~mW}$ para a cavidade "fria". A potência máxima medida está compatível com esses resultados e foi de $773(8) \mathrm{mW}$ e $832(8) \mathrm{mW}$ respectivamente.

\subsection{Perfil transverso do laser}

Como discutido no capítulo anterior, cavidades comuns oscilam preferencialmente no modo gaussiano. Mesmo assim, perdas devido a alinhamento ou sujeiras podem fazer com que outros modos oscilem e, portanto, é importante verificarmos o perfil transverso do laser.

A medida do perfil transverso possibilita, além de tudo, verificarmos a cintura do feixe dentro da cavidade, pois a propagação do modo gaussiano é conhecida e sabendo a cintura do feixe podemos determinar a largura dele em qualquer ponto e vice-versa.

A medida experimental do perfil transverso do feixe serve, portanto, para validar as contas feitas para a cavidade e garantir que não há um fator externo relevante que tenha sido desprezado nos cálculos.

Existem equipamentos capazes de levantar bidimensionalmente o perfil transverso de um feixe qualquer. Estes equipamentos são chamados de perfilômetros e funcionam bloqueando parte do feixe e calculando a variação da potência resultante desta ação. Assim é possível determinar a potência de cada parte do perfil transverso do feixe.

Na falta deste tipo de equipamento é possível levantar o perfil transverso do feixe utilizando, para bloquear parcialmente o feixe, alguma superfície reta e bastante regular, como, por exemplo, uma lâmina de barbear.

Deslocando a lâmina de forma a bloquear cada vez mais o feixe, enquanto obser- 
vamos a variação da potência do feixe que a atravessa, como indicado na figura 4.4, é possível determinarmos o perfil em uma dimensão do feixe.

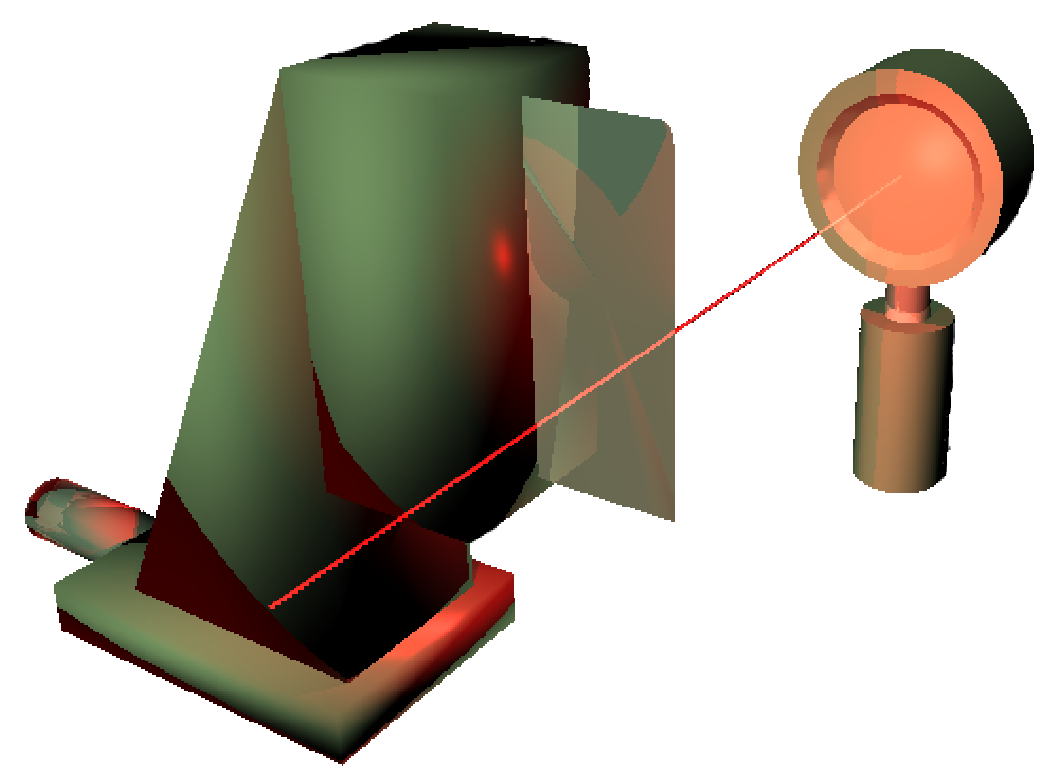

Figura 4.4. Feixe parcialmente bloqueado por uma lâmina tem sua potência medida. A lâmina pode ser deslocada micrometricamente por um transladador linear, de forma a se controlar a fração bloqueada do feixe.

A diferença de potência medida para duas posições distintas da lâmina corresponde à potência do pedaço do feixe contido entre estas duas posições, que é proporcional à área do perfil transverso do feixe entre estes dois pontos, de forma que a curva levantada é a integral do perfil transverso do feixe.

A figura 4.5 é uma curva do perfil horizontal do feixe levantada para um ponto arbitrário fora da cavidade.

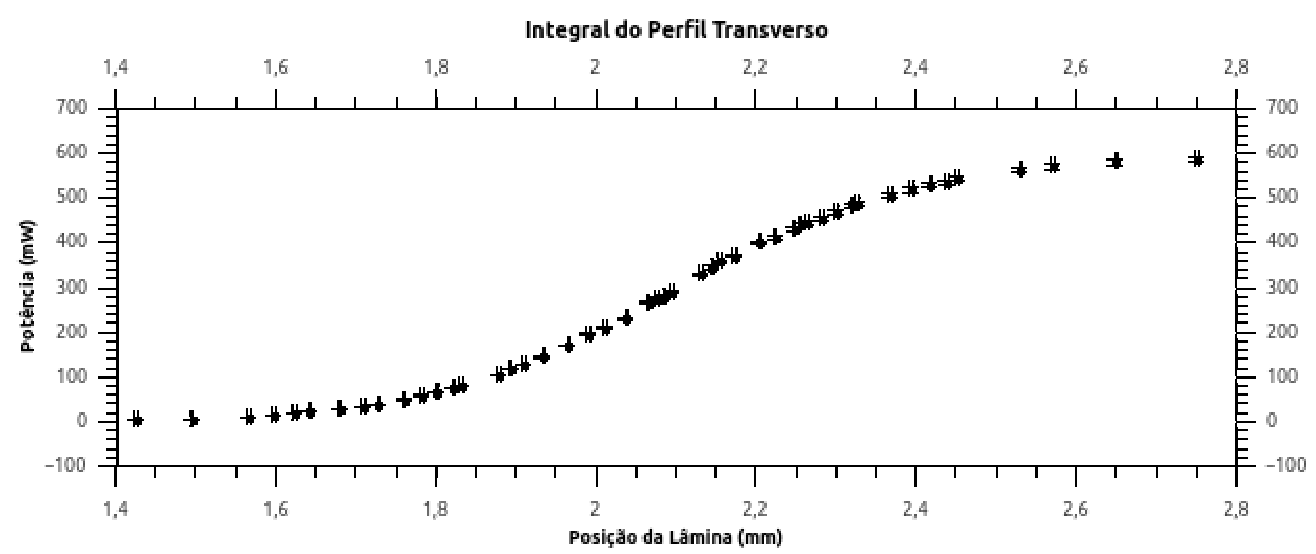

Figura 4.5. Potência do feixe que atravessa um lâmina de barbear que é aos poucos deslocada, até que o feixe passe livremente. 
A curva da figura 4.5 foi derivada numericamente, dando origem a outra curva (figura 4.6) que foi ajustada por uma gaussiana de largura 0,46(5)mm.

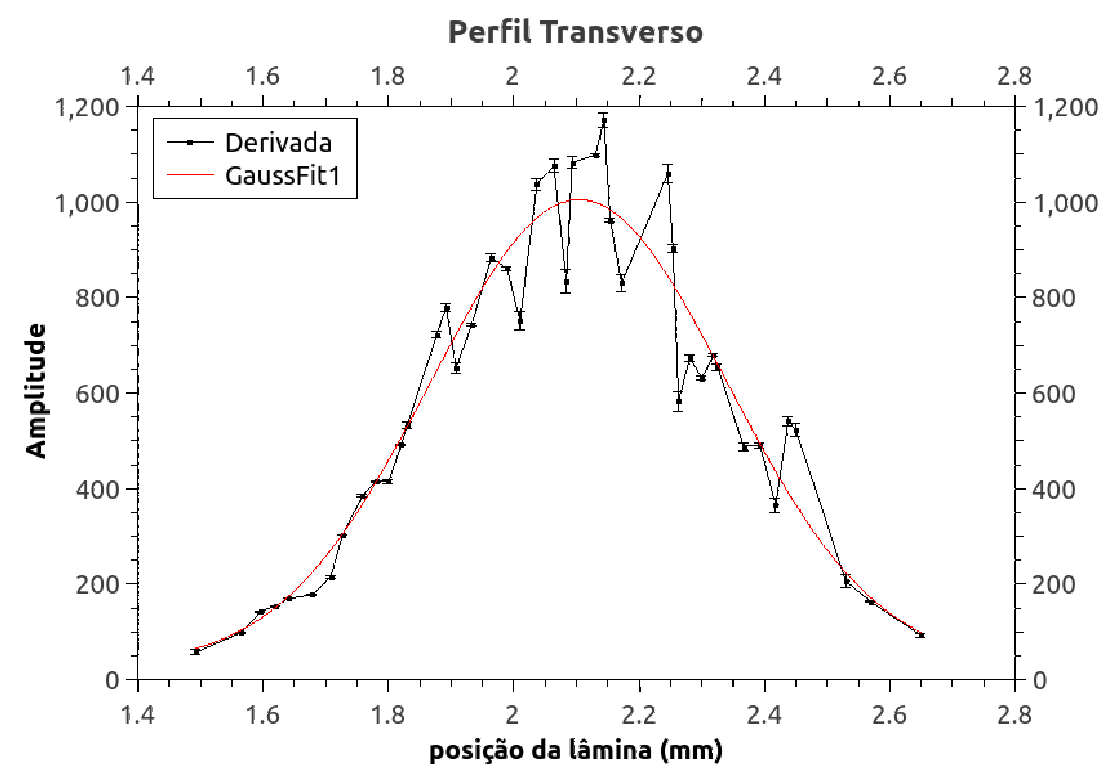

Figura 4.6. Derivada numérica dos pontos experimentais da figura 4.5.

O mesmo procedimento foi feito para o perfil vertical do feixe e o resultado para o ajuste gaussiano foi uma curva de largura $0,43(8) \mathrm{mm}$, de forma que não há indícios de astigmatismo.

O valor teórico para a largura do feixe no ponto, calculado através dos parâmetros da cavidade é de $0,43 \mathrm{~mm}$ e está de acordo com os resultados obtidos experimentalmente.

\subsection{Estabilidade de Frequência}

A estabilidade em frequência do laser é uma de suas características mais importantes e está diretamente relacionada à qualidade do sistema de travamento. Ela é determinada pelo tempo de resposta e a amplitude de perturbação que os sistemas de travamento são capazes de corrigir e pela estabilidade térmica da cavidade de referência.

No caso do titânio safira construído, em que o etalon é responsável por evitar saltos de modos enquanto o travamento na cavidade de referência é responsável por controlar variações mais sutis de frequência, é importante saber analisar e caracterizar cada um dos sistemas independentemente.

Além das limitações dos sistemas de travamento, a estabilidade da cavidade de referência será um fator determinante para a estabilidade em frequência de todo o laser. Assim, também é importante o estudo dos efeitos de flutuação de frequência por perturbações da cavidade de referência isolados do sistema de travamento da cavidade.

Nas subseções seguintes será apresentado um método de estudo e caracterização de cada sistema de travamento individualmente bem como o levantamento das perturbações térmicas às quais está sujeita a cavidade de referência, e como elas perturbam o laser como um todo. 


\subsubsection{Resposta e limitações do travamento do etalon}

O sistema de travamento do etalon deve ser capaz de corrigir tanto flutuações aleatórias, causadas por perturbações mecânicas ou térmicas, quanto perturbações controladas, aplicadas no PZT sob um espelho da cavidade (tweeter), no intuito de variar sua frequência.

Entretanto, o tempo que o sistema leva para corrigir uma perturbação na cavidade é limitado pela velocidade de rotação do galvo, que é, em geral, menor do que a velocidade máxima de um PZT. Por esse motivo, se a perturbação causada pelo tweeter for mais rápida do que o galvo é capaz de corrigir, o laser fica sujeito a saltos de modo.

Para testar o limite do sistema de travamento, aplicamos um sinal senoidal no tweeter enquanto observamos, em um osciloscópio, a intensidade do laser transmitida por uma cavidade de análise, como mostra a figura 4.7.

A velocidade da perturbação que o galvo precisa corrigir diz respeito ao quanto o laser varia em frequência em um intervalo de tempo e, para um sinal senoidal, ela é proporcional ao produto entre a frequência e a amplitude do sinal.

Conhecendo o tamanho da cavidade de análise e, consequentemente, o seu comprimento espectral livre, podemos relacionar a amplitude do sinal aplicado no tweeter com uma perturbação em frequência. Especificamente no caso da figura 4.7, a distância entre dois picos de transmissão é de aproximadamente $500 \mathrm{MHz}$ e a variação da tensão aplicada no tweeter neste intervalo corresponde a cerca de $1,56 \mathrm{~V}$, de forma que a variação de frequência por tensão é aproximadamente $320 \mathrm{MHz} / \mathrm{V}$.

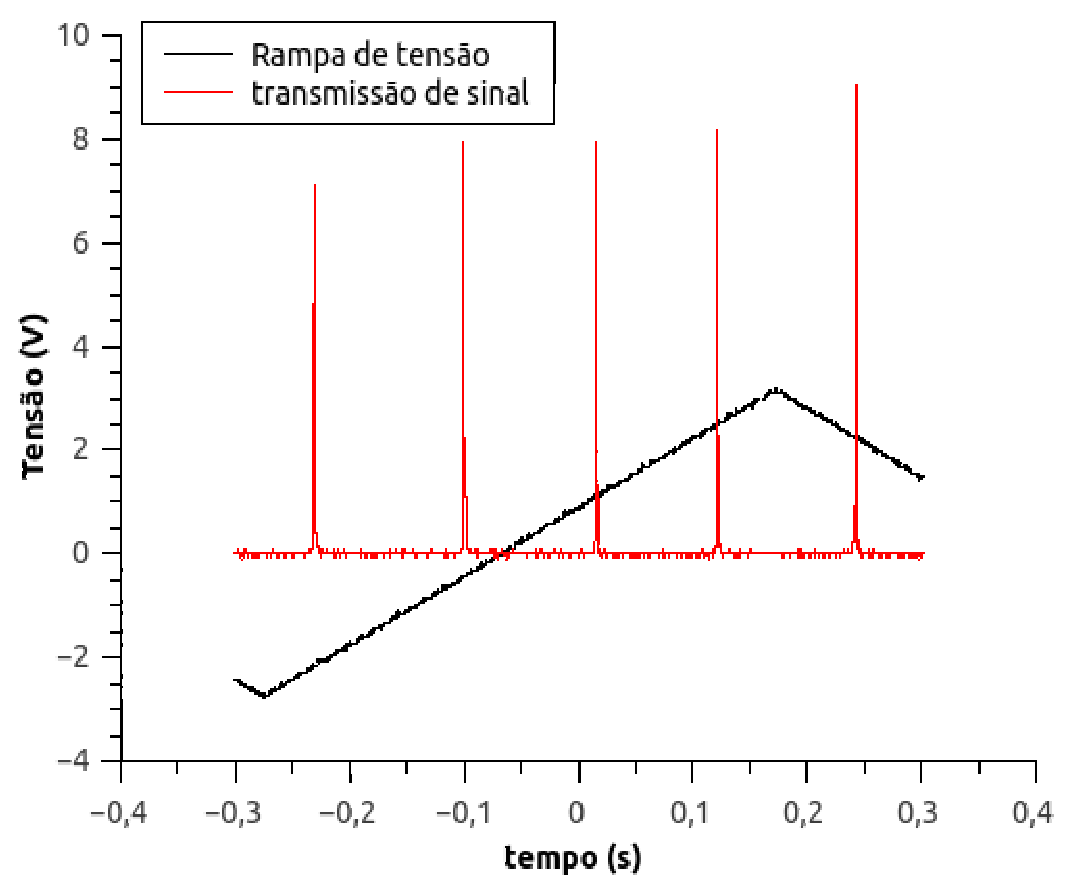

Figura 4.7. Picos de transmissão de uma cavidade de Fabry-Perot distantes uns dos outros cerca de $500 \mathrm{MHz}$. A imagem foi obtida variando a frequência do laser através da aplicação de uma rampa de tensão em um PZT. 
No caso específico, a rampa de tensão não era diretamente aplicada ao PZT, ela passava por um amplificador. A contante de amplificação, entretanto, não é relevante, mas pode ser inferida somente com base no fato de que a varição de comprimento do PZT corresponde a $1 \mu \mathrm{m} / V$ e que a varição de frequência de um comprimento espectral livre da cavidade laser se deve a uma variação de $\lambda$ do caminho ótico e, portanto,

$$
\frac{\Delta \lambda}{\mathrm{FSR}_{\text {laser }}}=\frac{L \Delta \lambda}{c}=\frac{\Delta L}{\lambda},
$$

onde $L$ é o tamanho da cavidade laser e $\lambda$ é o comprimento de onda médio, $\Delta L$ é a variação do tamanho da cavidade e $\Delta \lambda$ a variação correspondente de comprimento de onda.

Para testarmos a velocidade da perturbação que o galvo é capaz de corrigir, diminuímos a amplitude do sinal aplicado ao tweeter conforme aumentávamos sua frequências de forma a permanecermos sempre no limite em que começavam a ocorrer os saltos de modo. As medidas realizadas estão ilustradas na figura 4.8.

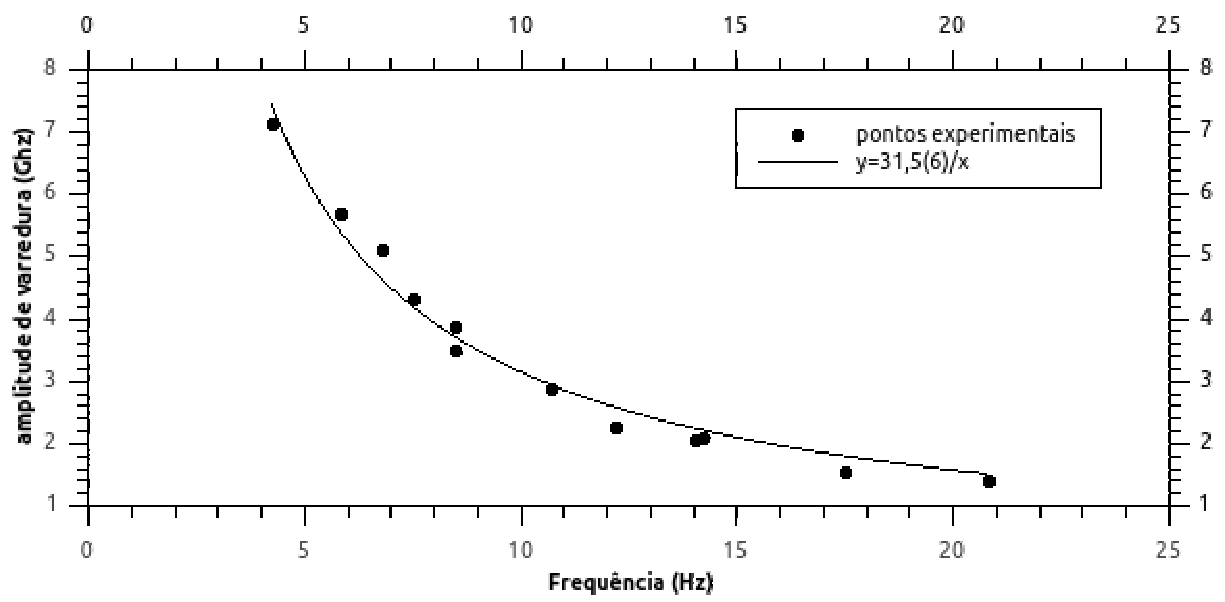

Figura 4.8. Gráfico experimental da amplitude máxima de perturbação em GHz, suportada pelo sistema de travamento do etalon, para diferentes valores de frequência de perturbação, sendo a perturbação um sinal senoidal.

É possível observar uma queda linear que indica a velocidade máxima de resposta do sistema, proporcional ao produto entre a amplitude e a frequência da perturbação, $v_{\text {travamento }}=31,5(6) \mathrm{GHz} / \mathrm{s}$. Perturbações mais rápidas do que isso não são corrigidas pelo sistema de travamento do etalon, mas não necessariamente provocam um salto de modo do laser.

\subsubsection{Sinal de Erro do Travamento da Cavidade de Referência}

Diferentemente do travamento do etalon, o travamento na cavidade de referência é feito através do PZT do tweeter, que tem uma resposta muito mais rápida do que o galvo que controla o etalon. Por esse motivo e pelo fato de que o FSR da cavidade de referência é usualmente maior do que o FSR do laser, este sistema, se bem calibrado, deverá ser limitado apenas pelo sistema de travamento do etalon.

Se uma perturbação no laser fizer com que o travamento do etalon falhe e o laser salte para um modo diferente da cavidade laser, o sistema de travamento da cavidade rapidamente fará uma correção induzindo o laser a variar em frequência para travar 
no modo mais próximo da cavidade de referência. Como o tempo de resposta do galvo é lento comparado ao do PZT, qualquer correção do sistema de travamento da cavidade é, para o travamento do etalon, uma perturbação demasiado rápida para ser corrigida, e portanto o sistema salta de modo novamente, dando origem a uma sucessão de reações que não permitem que o laser atinja um equilíbrio.

Como foi ilustrado no capítulo 3.36, o sinal de erro do sistema de travamento da cavidade é assimétrico, de forma que a posição do espelho tende a ser corrigida sempre para o mesmo lado. Por isso as reações em cadeia de saltos de modo tem fim quando o pzt da cavidade laser atinge o seu limite de extensão e o sistema de travamento falha por completo sem conseguir minimizar o sinal de erro.

Assim, enquanto o sinal de erro do sistema de travamento da cavidade oscila em torno de zero, é seguro supor que não ocorreram saltos de modo e que as variações do sinal de erro representam as variações de frequência do laser. Portanto a amplitude do sinal de erro é um bom indício da largura de linha do laser construído.

A intensidade do feixe transmitido pela cavidade de referência varia de acordo com a frequência do laser (3.3):

onde

$$
I_{t}=\frac{I_{o}}{1+F \operatorname{sen}^{2}\left(\frac{\delta}{2}\right)},
$$

$$
\delta=\frac{4 \pi l}{c} \nu
$$

Como ilustrado na figura 4.9, para uma flutuação pequena de intesidade transmitida devido a uma variação da frequência, vale a aproximação:

$$
\Delta I_{t}=\left|\left(\frac{\partial I_{t}}{\partial \nu}\right)_{I_{t 0}}\right| \Delta \nu
$$

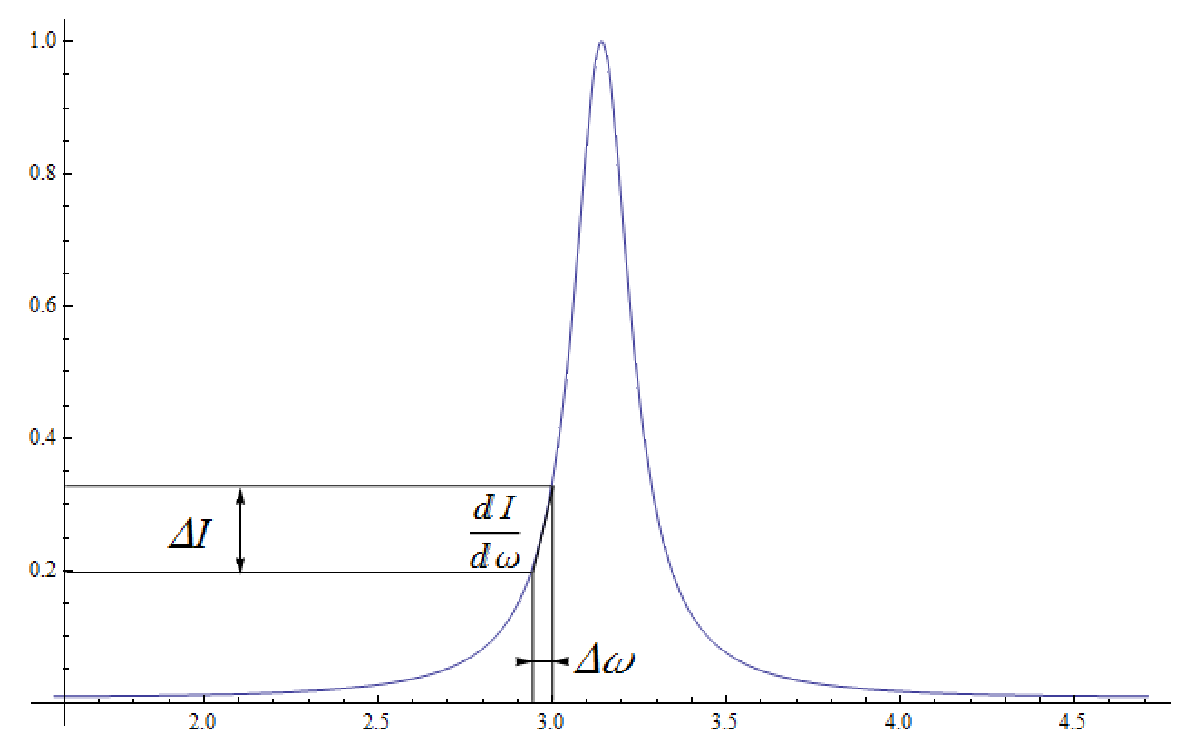

Figura 4.9. Intensidade da transmissão de uma cavidade de análise em função da frequência do feixe transmitido. 
Derivando (3.3) e utilizando

obtemos que:

$$
\operatorname{sen}\left(\frac{\delta}{2}\right)=\sqrt{\frac{1}{F}\left(\frac{I_{0}}{I_{t}}-1\right)}
$$

$$
\frac{\partial I_{t}}{\partial \nu}=-\frac{I_{t}^{2}}{I_{0}} F \operatorname{sen}\left(\frac{\delta}{2}\right) \cos \left(\frac{\delta}{2}\right) \frac{\partial \delta}{\partial \nu}=-\frac{I_{t}^{2}}{I_{0}} \sqrt{\left(\frac{I_{0}}{I_{t}}-1\right)\left(F-\frac{I_{0}}{I_{t}}+1\right)} \frac{4 \pi l}{c}
$$

e, portanto,

$$
\Delta \nu=\frac{c}{4 \pi l} \frac{1}{\sqrt{\left(\frac{I_{0}}{I_{t}}-1\right)\left(F-\frac{I_{0}}{I_{t}}+1\right)}} \frac{I_{0}}{I_{t}} \frac{\Delta I_{t}}{I_{t}} .
$$

Reescrevendo a equação acima em função da finesse da cavidade, através de (3.6), chegamos finalmente a:

$$
\Delta \nu=\frac{c}{4 \pi l} \frac{1}{\sqrt{\left(\frac{I_{0}}{I_{t}}-1\right)\left(\frac{4 \mathcal{F}}{\pi^{2}}-\frac{I_{0}}{I_{t}}+1\right)}} \frac{I_{0}}{I_{t}} \frac{\Delta I_{t}}{I_{t}} .
$$

Aqui, $\Delta I_{t}$ é a largura de linha da amplitude de oscilação do sinal de erro, $I_{t}$ é a intensidade do ponto no qual se faz o travamento, e $I_{0}$ é a intensidade máxima do sinal transmitido.

Para determinar $\Delta I_{t}$, devemos observar a flutuação do sinal de erro do travamento da cavidade ao redor do zero. Essa flutuação, entretanto, depende do intervalo de tempo entre duas medidas.

Os diagramas da figura 4.10 indicam a distribuição de pontos do sinal de erro medidos em intervalos de $4.10^{-5} s$, durante uma janela de $0,4 s$ (esquerda) e intervalos de $4 \cdot 10^{-7} s$, durante uma janela de $4 \cdot 10^{-3} s$ (direita). A diferença da largura à meia altura da gaussiana ajustada em cada caso é vizível.
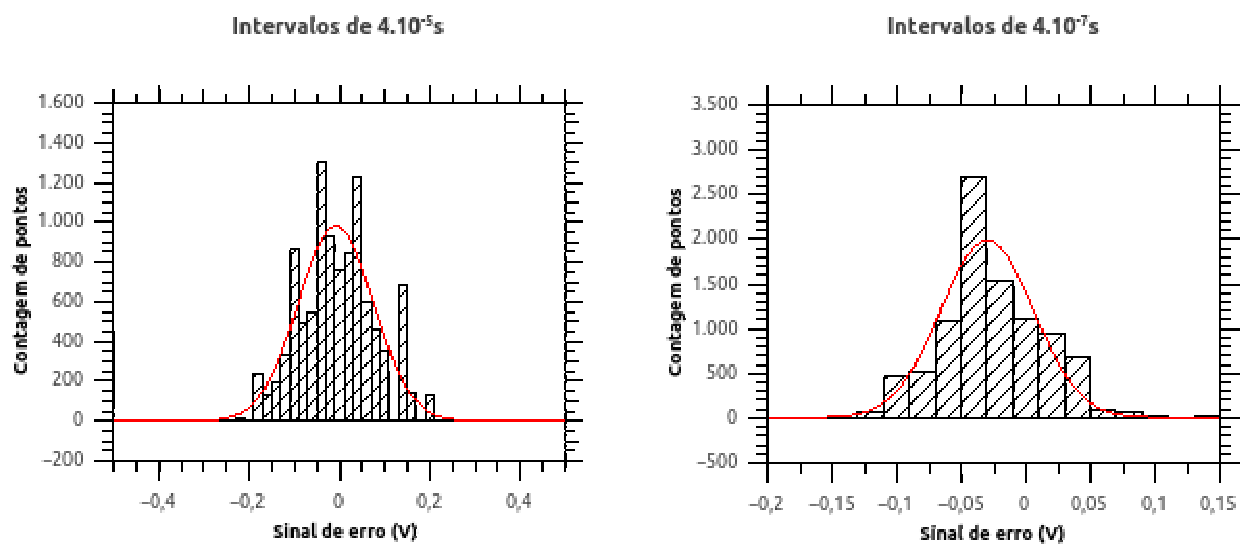

Figura 4.10. Histogramas das medidas do sinal de erro realizadas com 10000 pontos em intervalos de tempo de $4.10^{-5} s$ (esquerda) e $4.10^{-7} s$ (direita), ajustados por curvas gaussianas de largura à meia altura de $1,66(9) \cdot 10^{-1} V$ e $7,2(3) \cdot 10^{-2} V$, respectivamente. $\mathrm{O}$ deslocamento do valor médio das gaussianas com relação ao 0 é consequência de um offset na medição do sinal de erro. Em ambos os casos o ponto de travamento valia $I_{t}=540 \mathrm{mV}$ e o valor máximo da transmissão valia $I_{0}=-11,6 \mathrm{~V}$. A unidade em Volts é consequência de uma conversão da potência medida em um sinal elétrico enviado para um osciloscópio. 
No primeiro caso, o laser está sujeito a uma série de flutuações que ocorrem em intervalos longos de tempo. No segundo caso são relevantes apenas flutuações mais rápidas. A maior perturbação visível e que limita a largura da distribuição é a provocada pela perturbação do etalon, com uma frequência de aproximadamente $30 \mathrm{kHz}$. As medidas de largura de linha do laser, porém, costumam ser mais rápidas do que isso, e, portanto, devemos considerar a largura estimada por esse método como um limite superior para a largura de linha real do laser.

Para o laser construído, utilizando $\frac{\Delta I_{t}}{I_{t}}=0,133$, medimos $\mathcal{F}=400$, o que nos levou a um limite superior para a largura de linha de $\Delta \nu=8.5 \mathrm{MHz}$.

\subsubsection{Espectroscopia de Absorção Saturada}

As flutuações de frequência do laser, que limitam a sua largura de linha, são em parte devido a perturbações na cavidade laser e em parte devido a perturbações na cavidade de referência na qual o laser está travado. Para poder discriminar o papel da perturbação de cada cavidade na variação de frequência do laser, é preciso utilizar uma referência absoluta de frequência.

A fim de comparar a variação de frequência do laser com níveis de transições atômicas utilizamos um processo de espectroscopia de absorção saturada.

A espectroscopia de absorção saturada é um método simples de espectroscopia atômica que permite resolver os níveis da estrutura fina dos átomos.

Em um processo simples de absorção, passamos um feixe laser através de um meio atômico. O feixe é absorvido se sua frequência coincidir com uma frequência de absorção do átomo, mas, devido ao movimento dos átomos, ocorre o efeito Doppler, que provoca alargamento das linhas de absorção, nos impedindo de distinguir entre dois níveis de energia muito próximos.

No processo de absorção saturada, o meio atômico é atravessado por dois feixes contrapropagantes de mesma frequência. Um deles é chamado de feixe de bombeio e o outro de prova.

Devido ao efeito Doppler, quando os feixes estão ajustados abaixo da frequência de absorção atômica, os átomos que se moverem contrários ao sentido de propagação dos feixes irão absorvê-los, ou seja, os átomos que se moverem com o mesmo sentido em que o feixe de bombeio se propaga, irão absorver o feixe de prova, que se propaga no sentido oposto, e vice-versa.

Já no caso em que os lasers estão acima da frequência de absorção, eles serão absorvidos pelos átomos que se moverem no mesmo sentido em que se propagam.

A saturação da absorção ocorre quando os feixes estão em ressonância com a frequência de absorção atômica. Nessa situação, os feixes serão absorvidos apenas pelos átomos que não se locomovem na direção de propagação dos feixes. Esses átomos poderão absorver tanto o feixe de bombeio quanto o feixe de prova, mas como o número de átomos nesta condição é limitado, ocorre saturação da amostra que se torna parcialmente transparente aos feixes. 
Dessa forma, ao observarmos a transmissão do feixe de prova em função de sua frequência, vemos um espectro de absorção com picos estreitos nas frequências de absorção atômica.

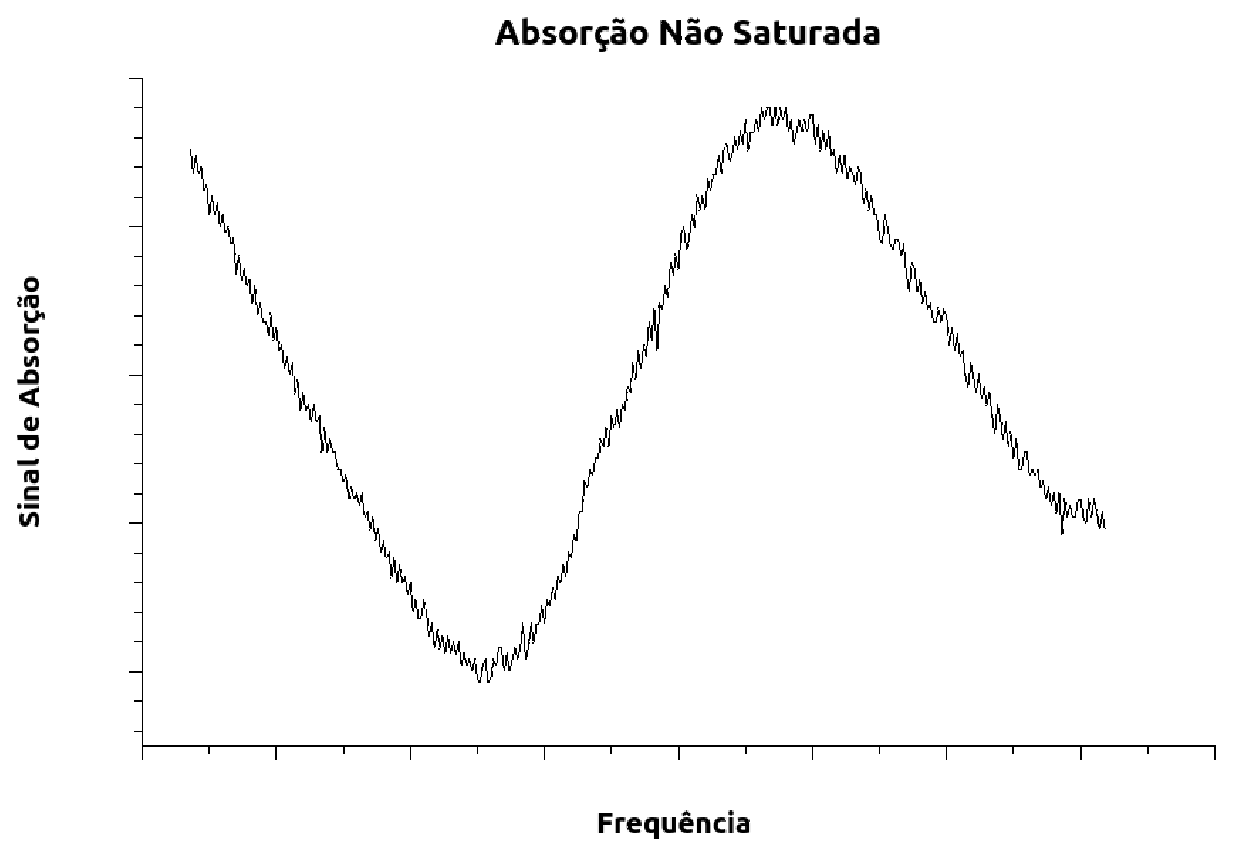

Figura 4.11. Espectroscopia de absorção de um átomo de rubídio para uma varredura de $1,5 \mathrm{GHz}$, na região da linha espectral $F_{g}=3,{ }^{85} \mathrm{Rb}$.

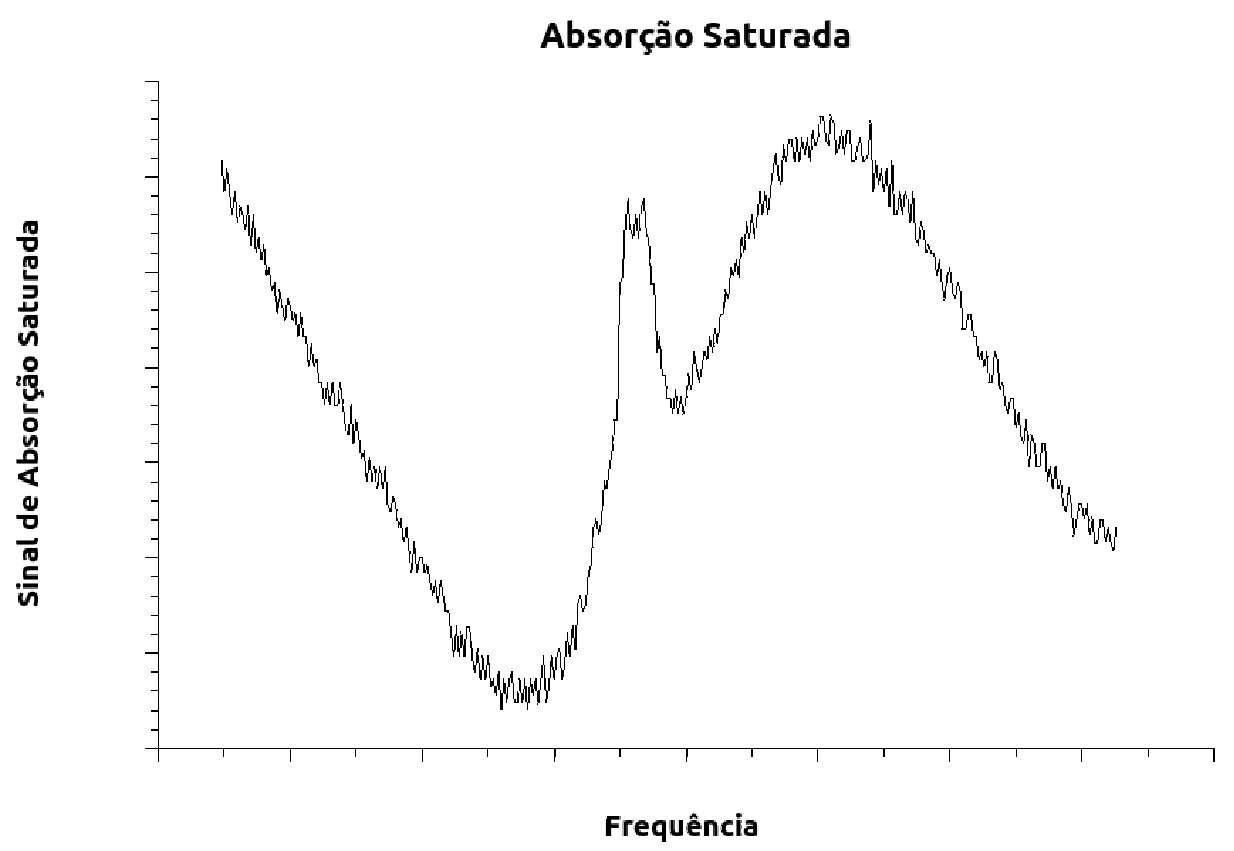

Figura 4.12. Espectroscopia de absorção saturada de um átomo de rubídio para uma varredura de $1,5 \mathrm{GHz}$, na região da linha espectral $F_{g}=3,{ }^{85} \mathrm{Rb}$. 
Além dos picos de transmissão nas frequências de ressonância atômica, existem também picos chamados de cross-over, que acontecem quando os feixes estão em sintonizados entre duas frequências de absorção atômica muito próximas. Nesse caso, os átomos podem absorver ou o feixe de bombeio ou o feixe de prova, dependendo do seu sentido de propagação, pois estarão ressonantes com uma das frequências de absorção. Existe, portanto, a saturação da amostra que se torna parcialmente transparente.

O processo de absorção saturada permite, entre outras coisas, que se tenha uma idéia da largura de linha do laser utilizado na espectroscopia pois, se a largura de linha do laser for maior do que a separação entre dois picos da absorção saturada, então é impossível resolvê-los.

Para o estudo da largura de linha do laser, realizamos a espectroscopia de átomos de rubídio na transição $5 S_{1 / 2} \rightarrow 5 P_{3 / 2}$, conhecida como linha $D_{2}$. Analisamos especificamente o isótopo ${ }^{85} \mathrm{Rb}$, que tem spin nuclear $I=5 / 2$, e portanto o momento angular total para o estado fundamental da transição pode ser $F_{g}=2 \mathrm{ou} 3$, enquanto para o estado excitado as opções são $F_{e}=1,2,3$ ou 4.

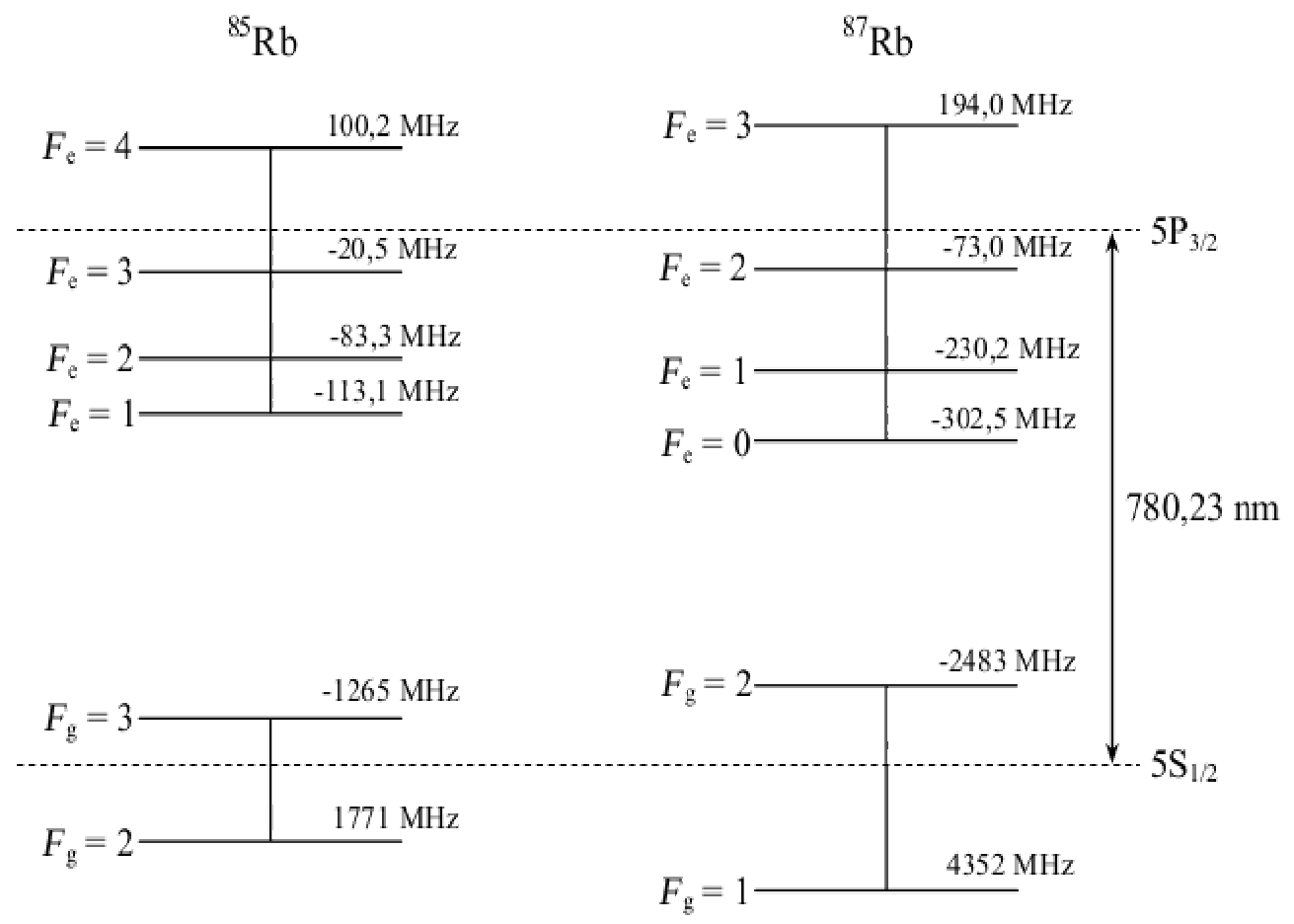

Figura 4.13. Níveis hiperfinos da linha $D_{2}$ dos isótopos ${ }^{85} \mathrm{Rb}$ e ${ }^{87} \mathrm{Rb}$ do Rubídio, fora de escala. 
A figura 4.14 mostra a espectroscopia de absorção saturada levantada em torno da linha $D_{2}$, a partir de $F_{g}=3$ do ${ }^{85} \mathrm{Rb}$. Os dois picos mais intensos são picos de cross-over $F_{e}=3 / 4$ e $F_{e}=2 / 4$ e sabemos que a separação entre eles é de $31,4 \mathrm{MHz}$. Assim domos capazes de converter a escala temporal (tempo de varredura do laser) em uma escala de frequência, podendo determinar, então, a largura à meia altura do pico mais estreitos (no caso o da transição para $F_{e}=4$ ), que é de $6,6 \mathrm{MHz}$.

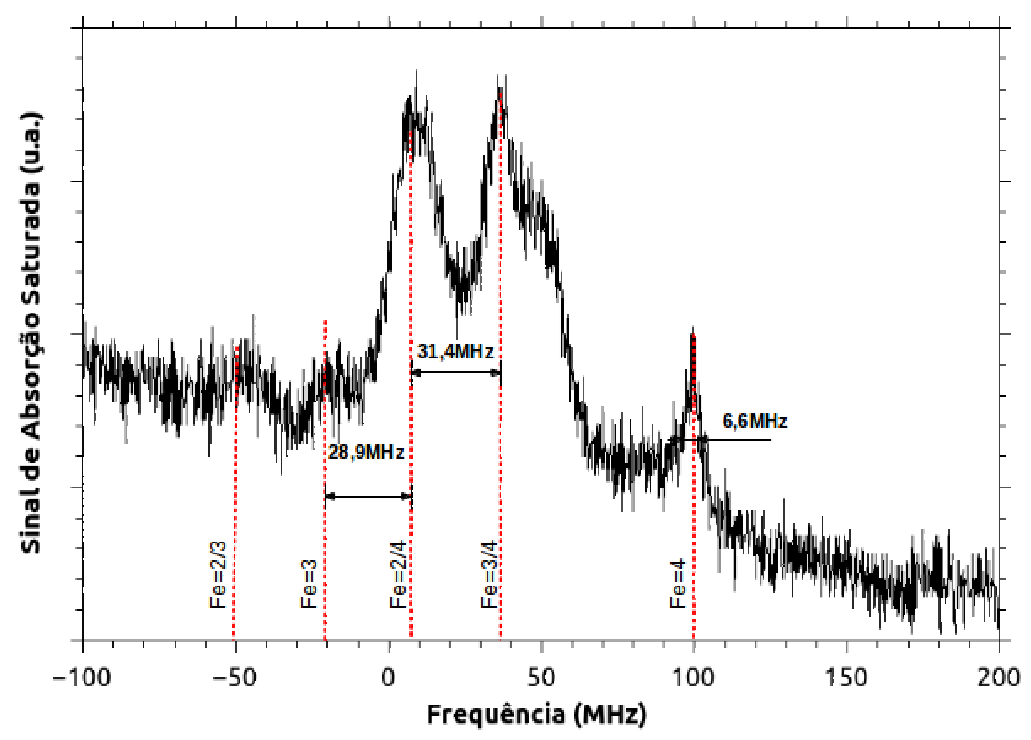

Figura 4.14. Sinal de espectroscopia de absorção saturada de vapor de rubídio, a partir da linha $F_{g}=3$ do ${ }^{85} \mathrm{Rb}$ para as linhas indicadas na imagem.

Sabemos, também, que a largura natural dos átomos é de cerca de $6 \mathrm{MHz}$, e que a largura obtida na espectroscopia é uma convolução entre a largura do laser e a largura natural. Portanto, concluímos que a largura do laser deve ser, no máximo $0,6 \mathrm{MHz}$.

\subsection{Flutuação de Frequência}

Uma vez montado o esquema de absorção saturada, é possível observar os efeitos da flutuação térmica da cavidade. Para isso, mantemos apenas o travamento do etalon ativo e, varrendo a cavidade laser, observamos os picos de transmissão do laser pela cavidade de referência, bem como o espectro de absorção saturada. 


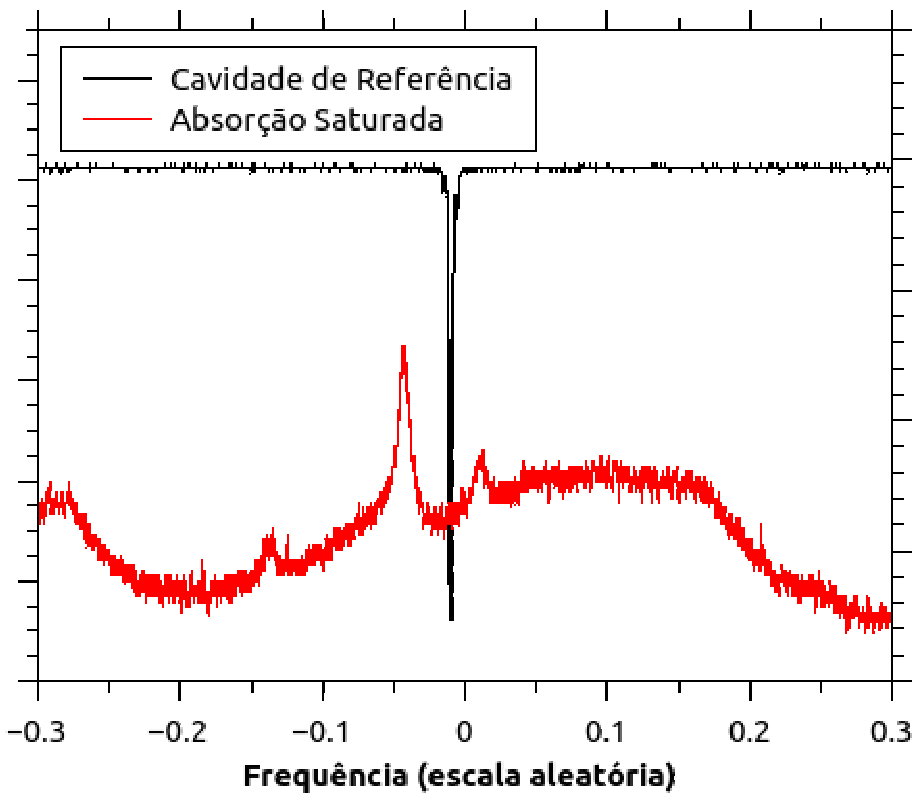

Figura 4.15. Imagem da espectroscopia de absorção saturada e do sinal de travamento na cavidade de referência. Uma flutuação comum das imagens indica uma variação da frequência do laser, enquanto uma flutuação do pico de transmissão em relação ao pico da absorção saturada indica a variação do comprimento da cavidade de referência.

A variação da posição dos picos de absorção saturada corresponde a uma variação da frequência do laser, enquanto a variação da posição dos picos de transmissão da cavidade de referência corresponde tanto a variações de frequência do laser como a variações do tamanho da cavidade de referência. Subtraindo a primeira da segunda, podemos determinar a variação do tamanho da cavidade e estimar qual a variação térmica correspondente.

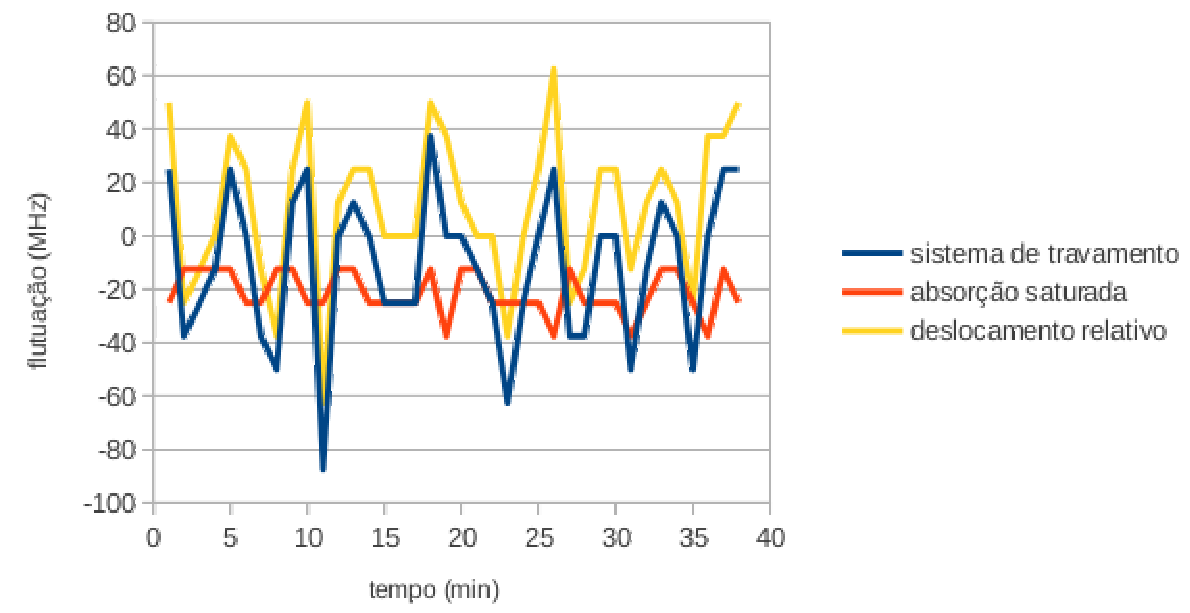

Figura 4.16. Representação da flutuação em frequência dos picos de absorção saturada e transmissão da cavidade de referência em intervalos de um minuto. 
Na figura 4.16, está representado o deslocamento em frequência dos picos observados em intervalos de um minuto. Como pode ser visto, o deslocamento da absorção saturada é praticamente constante e sua variação tem média de $-21,4 \mathrm{MHz} / \mathrm{min}$, que indica uma variação constante da cavidade, provavelmente por efeitos térmicos.

Muito embora a potência do laser já estivesse estabilizada, uma flutuação em frequência de dezenas de $\mathrm{MHz}$ equivale a flutuações de temperatura da ordem de $10^{-3}$ Kelvin.

O deslocamento relativo entre o sinal de absorção saturada e os picos de transmissão da cavidade de referência, após 38 minutos, foi de $400(30) \mathrm{MHz}$, que leva a uma variação média de 10,35(81) MHz/minuto. Esse deslocamento de frequência equivale a uma variação de tamanho da cavidade de $1,64(13) \cdot 10^{-8} \mathrm{~m}$. Como a cavidade é feita de pyrex, cujo coeficiente de dilatação térmica é $3,3.10^{-6}$, é possível estimar a variação de temperatura que provocou esse deslocamento como sendo de aproximadamente $0,033 \mathrm{~K}$.

Como depois foi constatado, o deslocamento positivo do sinal da cavidade de referência com relação ao sinal de absorção saturada indica um aumento da temperatura da cavidade.

\subsection{Flutuações de Potência}

Flutuações do sinal de saída são inevitáveis em um laser e podem ocorrer devido a diversos motivos. Caracterizar as flutuações permite identificar suas fontes e minimizá-las.

Em lasers de estado sólido, a flutuação predominante costuma ser devido à oscilação da população atômica dos átomos ao redor do estado de equilíbrio. Em lasers contínuos esta flutuação aparece na forma de uma oscilação senoidal. Em lasers pulsados essa oscilação faz com que os pulsos tenham um formato mais pontiagudo ao invés de uma curva suave e com que as potências de pico de dois pulsos distintos sejam diferentes [27].

No caso do laser construído, Existe também uma flutuação senoidal da potência com frequência de aproximadamente $30 \mathrm{KHz}$, devido à modulação do etalon.

Outras oscilações de baixa frequência podem ser associadas à vibrações mecânicas ou perturbações sonoras.

Durante a espectroscopia de absorção saturada, pudemos observar uma outra oscilação senoidal que, após alguns testes, concluímos ser consequência de uma oscilação do laser de bombeio: um Verdi V-18 da Coherent. Também observamos que a frequência da oscilação crescia com a potência média do laser de bombeio, enquanto a amplitude máxima da oscilação, normalizada pela potência média, caía. 
Outra característica desta oscilação é que ela não está presente todo o tempo, mas aparece e desaparece, às vezes mais e às vezes menos intensa. Porém, quando o laser de bombeio opera com maior potência, a frequência com que a oscilação aparece diminui.

Assim, para minimizar as oscilações é recomendado trabalhar com o bombeio em sua potência máxima $(18 \mathrm{~W})$.

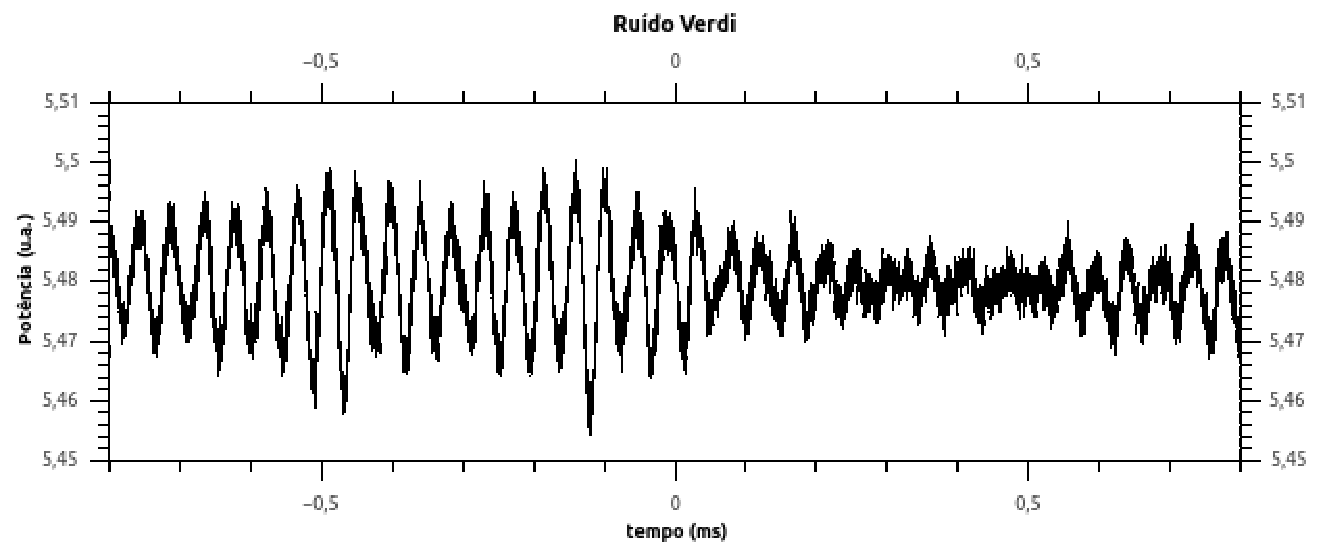

Figura 4.17. Flutuação da intensidade do laser de bombeio.

Para medir a flutuação da potência do laser de bombeio, eliminamos outras fontes de luz e medimos a luz espalhada do bombeio, amplificada por um fotodetector, durante um longo intervalo de tempo. Depois, normalizamos a amplitude máxima da oscilação pelo valor médio da potência.

A variação da amplitude máxima e da frequência das oscilações estão expressas nas figuras 4.18 e 4.19 .

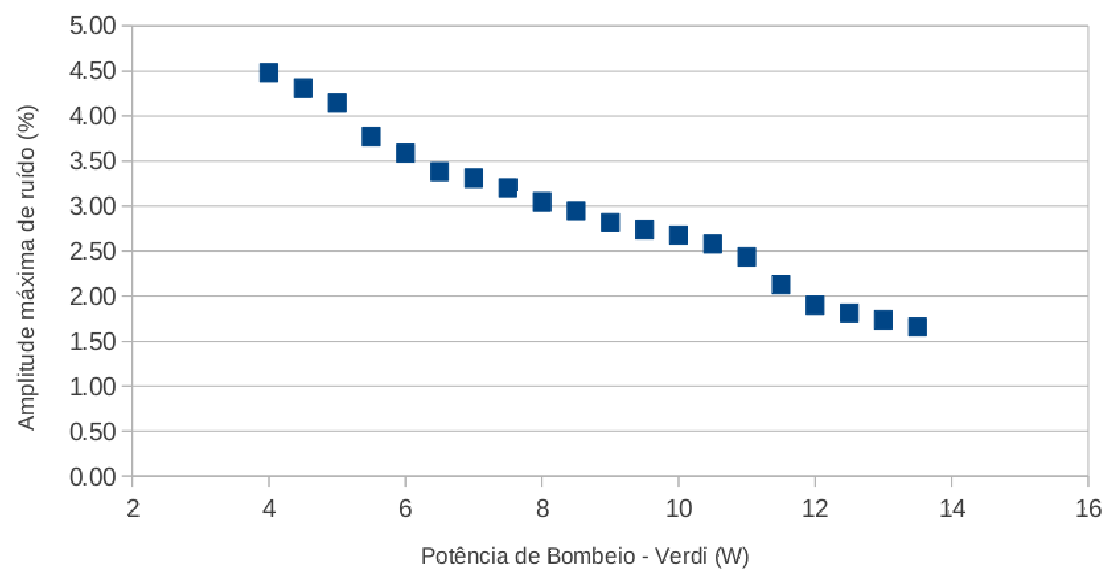

Figura 4.18. Amplitude máxima da oscilação da intensidade do laser de bombeio, normalizada pelo valor médio, em função da potência do bombeio. 


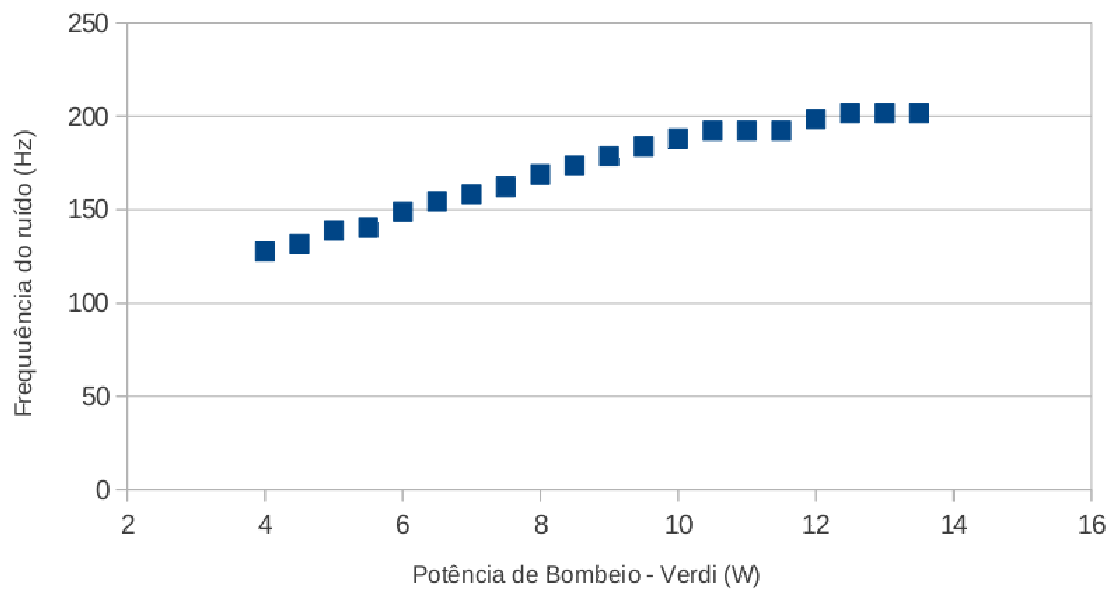

Figura 4.19. Variação da frequência do sinal de ruído do laser de bombeio em função da potência do bombeio.

Com estas medidas concluímos a caracterização das propriedades clássicas do laser construído. Determinamos a intensidade e as causas de suas flutuações de potência e frequência, além de sua largura de linha. Para concluirmos o trabalho, entretanto, ainda é necessário o estudo de suas flutuações quânticas de amplitude e fase. 


\section{Capítulo 5 Ruídos Quânticos}

Nos capítulos anteriores, a largura de linha e as flutuações de frequência e intensidade, foram apresentadas como as características principais para se definir as limitações de um laser CW. Além disso, o fluxo de fótons emitidos pelo laser foi tratado como contínuo e em nenhum momento falou-se sobre sua distribuição estatística ou sobre as propriedades quânticas do campo.

Entretanto, quando temos a intenção de utilizar um campo em experimentos que envolvem as propriedades quânticas da luz, as características das distribuições dos fótons desse campo são extremamente importantes.

Evidentemente, fótons podem ser distribuídos de diferentes maneiras e o estado de um campo está relacionada à sua origem, de forma que, ao escolhermos a fonte de fótons que utilizaremos em uma experiência, estamos selecionando o estado do campo com o qual trabalharemos. Portanto é importante conhecermos qual distribuição têm os fótons emitidos pelo laser que contruímos.

O que diferencia o laser de outras fontes de luz é que o estado do campo gerado por um laser monocromático, operando acima do limiar, pode ser descrito, em algumas condições, como um estado coerente.

Neste capítulo será apresentada, sucintamente, a teoria que envolve a distribuição de fótons e as condições para as quais o laser contruído pode ser considerado uma fonte de campo em estado coerente. Uma descrição mais detalhada sobre a quantização do campo pode ser encontrada em livros-texto como [43], [44], [45]. O espectro de ruído do laser e métodos experimentais para sua caracterização estão descritos em [31] e [46]. As descrições sobre as técnicas utilizadas neste trabalho também podem ser encontradas com uma abordagem diferente em outras dissertações do grupo [4], [2], [3] e [47].

\subsection{Estado Coerente}

Formalmente, cada modo de um campo eletromagnético pode ser descrito como um oscilador harmônico e cada estado desse oscilador corresponde a um estado diferente do campo.

Um campo monomodo, com o número de fótons bem definido, é descrito por um estado de Fock, ou estado número, e representado por $|n\rangle$, onde $n$ diz respeito ao número de fótons que compõem tal estado. Na ausência de fótons, o campo é descrito pelo estado de vácuo $|0\rangle$. 
Com base nos estados número, definimos os operadores de contrução e aniquilação $\hat{a}^{\dagger}$ e $\hat{a}$ de forma que

$$
\begin{gathered}
\hat{a}^{\dagger}|n\rangle=\sqrt{n+1}|n+1\rangle \\
\hat{a}|n\rangle=\sqrt{n}|n-1\rangle,
\end{gathered}
$$

sendo a comutação entre $\hat{a}$ e $\hat{a}^{\dagger}$

$$
\left[\hat{a}, \hat{a}^{\dagger}\right]=\hat{a} \hat{a}^{\dagger}-\hat{a}^{\dagger} \hat{a}=\hat{1}
$$

A partir dessa definição, e assumindo que o estado de vácuo é normalizado, podemos garantir que todos os estados de Fock sejam também normalizados escrevendo um estado $|n\rangle$ qualquer a partir da aplicação sucessiva do operador de criação $\hat{a}^{\dagger}$ no estado de vácuo:

$$
|n\rangle=\frac{\left(a^{\dagger}\right)^{n}}{\sqrt{n !}}|0\rangle
$$

Como os estados de Fock são ortogonais entre si, ou seja, $\langle m \mid n\rangle=0$ para $m \neq n$, eles formam uma base ortonormal que nos permite definir outros estados.

O estado no qual estamos interessados e que deve corresponder, dentro de um determinado limite, ao estado de saída do laser é chamado de estado coerente $|\alpha\rangle$, e é autoestado do operador de aniquilação $\hat{a}$ :

$$
\hat{a}|\alpha\rangle=\alpha|\alpha\rangle \text {. }
$$

Uma consequência importante disso é que, em um caso ideal, para um campo no estado coerente, com um número de fótons elevado, ao retirarmos um fóton, as propriedades estatísticas do campo não se alteram.

Para que possamos escrever os estados número no espaço de Fock, precisamos determinar os coeficientes $c_{n}$ tais que:

Para isso fazemos

$$
|\alpha\rangle=\sum_{n} c_{n}|n\rangle
$$

que leva a:

$$
\langle n \mid \alpha\rangle=c_{n}=\left\langle 0\left|\frac{a^{n}}{\sqrt{n !}}\right| \alpha\right\rangle=\frac{\alpha^{n}}{\sqrt{n !}} c_{0}
$$

$$
c_{n}=\frac{a^{n}}{\sqrt{n !}} c_{0} \text {. }
$$

A normalização do estado coerente exige, entretanto, que

$$
\sum\left|c_{n}\right|^{2}=1=\sum \frac{|\alpha|^{2 n}}{n !}\left|c_{0}\right|^{2}=\left|c_{0}\right|^{2} e^{|\alpha|^{2}}
$$

e, portanto, $\left|c_{0}\right|^{2}=e^{-\alpha^{2}}$.

Como existe liberdade de escolha para a fase global, podemos tomar o coeficiente $c_{0}$ como sendo real, de forma que

$$
c_{n}=\frac{\alpha^{n}}{\sqrt{n !}} e^{-\frac{|\alpha|^{2}}{2}}
$$


e, assim, o estado coerente normalizado pode ser escrito como

$$
|\alpha\rangle=e^{-\frac{1}{2}|\alpha|^{2}} \sum_{n} \frac{\alpha^{n}}{\sqrt{n !}}|n\rangle .
$$

O fato do estado coerente ser uma superposição de estados de Fock faz com que o seu número de fótons não seja bem definido. Ao invés disso, a probabilidade de se medir $n$ fótons, dada pela equação

$$
P(n)=|\langle n \mid \alpha\rangle|^{2}=\frac{|\alpha|^{2 n}}{n !} e^{-|\alpha|^{2}}
$$

obedece a uma distribuição poissoniana com relação a $n$, e, como tal, tem a variância igual à média

$$
\Delta^{2} n=\langle n\rangle=|\alpha|^{2}
$$

e, para $n \gg 1$, tende a uma gaussiana.

Uma propriedade de estados com distribuição gaussiana é que sua estatística pode ser totalmente descrita apenas por sua média e sua variância. Por esse motivo, iremos considerar o campo como sendo representado por um campo médio somado de uma flutuação de média nula e iremos definir como ruído quântico, a variância da flutuação.

Especificamente para o estado coerente, o ruído quântico é proporcional à intensidade do campo.

Verificar se o ruído quântico é proporcional à intensidade de um campo campo é, então, um primeiro teste simples para determinarmos se o campo está em um estado coerente. Essa medida de ruído do estado coerente é chamada medida de shot-noise.

Para outros estados quânticos, ainda que o ruído não tenha uma dependência linear com a intensidade, é importante que possamos saber qual será o ruído quântico dada uma determinada intensidade do feixe. Porém, não podemos comparar uma medida de ruído diretamente com a intensidade do campo pois o seu valor dependerá do sistema de medição. Esse obstáculo pode ser contornado comparando o ruído com o ruído de shot-noitse, que depende da intensidade e também do sistema de medição.

A medida de shot-noise é, portanto, extremamente importante por servir como escala para qualquer medida de ruído.

\subsection{Ruído Quântico de um Laser}

Como dito anteriormente, o campo eletromagnético gerado por um laser monocromático se assemelha a um estado coerente. Porém, todo laser tem uma largura de linha, descrita aproximadamente por uma Lorentziana.

Felizmente, a experiência nos mostra que podemos tratar independentemente os diferentes modos do laser que existem dentro da largura de linha, descrevendo cada um por um estado quântico coerente, cuja variância é proporcional à sua intensidade.

Fora da largura de linha, espera-se que os estados do laser sejam estados de vácuo, com incerteza de fase e amplitude limitadas apenas pelas relações de incerteza, e uniformes para qualquer frequência. 
Assim, o espectro de ruído do laser pode ser visto, a princípio, como uma combinação de uma lorentziana, chamada de portadora e que tem máximo na frequência de oscilação do laser, com uma distribuição regular de ruído dos estados de vácuo. Mas existe uma outra questão que deve ser abordada, no que diz respeito ao ruído quântico, que é a difusão da fase do laser ao longo do tempo.

Dentro de uma cavidade, o meio de ganho do laser gera luz em fase com o campo amplificado. Entretanto, como a cavidade não impõem nenhuma condição restritiva sobre a fase do campo oscilante, eventualmente ela pode variar.

Considerando um caso simples em que a fase do laser varia constantemente com o tempo, o campo pode ser descrito como

$$
E(t)=E_{0}(t) \cos (\Omega t)=E_{0}(t) \frac{e^{i \Omega t}+e^{-i \Omega t}}{2} .
$$

A transformada de Fourier desse campo é, pela propriedade de modulação da transformada de Fourier:

$$
\mathfrak{F}[E(t)](\omega)=\mathfrak{F}\left[E_{0}(t) \frac{e^{i \Omega t}+e^{-i \Omega t}}{2}\right](\omega)=\frac{\mathfrak{F}\left[E_{0}(t)\right](\omega+\Omega)+\mathfrak{F}\left[E_{0}(t)\right](\omega-\Omega)}{2}
$$

e o ruído passa a ter, também, duas componentes, chamadas de bandas laterais, com frequência $\pm \Omega$ com relação à frequência média do laser.

Na prática, a variação da fase do laser não é constante, mas pode ser interpretada como uma soma infinita de variações, e o efeito resultante é o de uma série contínua de bandas laterais ao redor da portadora.

O ruído das bandas que correspondem a flutuações rápidas, comparadas com o tempo de difusão de fase, deve ser igual ao shot-noise, enquanto que, próximo da frequência de análise, o ruído quântico deve se tornar cada vez maior, divergindo para $\Omega=0$.

A quantidade de fóton nas bandas laterais é muito menor do que na portadora, onde está concentrada a maior parte dos fótons. Porém, como o estado que descreve o campo é uma somatória de estados que representam cada modo do campo, em uma média quadrática existem, tanto termos referentes ao produto entre os modos das bandas laterais por eles mesmos, e que representam a intensidade das bandas laterais, sendo muito inferiores à intensidade da portadora (intensidade do campo), como termos correspondentes ao produto dos modos das bandas pelo modos da portadora. Para estes termos, a portadora amplifica as bandas laterais, que crescem com a raiz da intensidade do campo.

Resumindo, podemos dizer que, no espaço das frequências, as bandas laterais carregam a informação do ruído de fase que é proporcional a raiz da intensidade, e que deve ser igual ao ruído de vácuo (shot-noise) para altas frequências de análise, e divergir para baixas frequências.

Como a flutuação de um estado coerente sempre é proporcional à sua intensidade, para os casos em que o ruído do laser excede o shot-noise, dizemos que o campo tem excesso de ruído. Como veremos mais adiante, existem também estados para os quais o ruído pode ser inferior ao shot-noise. Esses estados são chamados de estados comprimidos. 
As medidas de caracterização de ruído têm como objetivo determinar para quais frequências de análise o laser pode ser considerado um estado coerente e a partir de quando ele passa a ter excesso de ruído.

\subsection{Excesso de Ruído}

Como foi dito anteriormente, o estado do campo pode ser escrito como um estado médio, somado de uma flutuação de média nula. Podemos considerar que essas flutuações do campo não estão contidas propriamente no estado do campo, mas nos operadores de criação e aniquilação que o descrevem, de forma que $\hat{a}=\langle\hat{a}\rangle+\delta \hat{a}$, $\operatorname{com}\langle\delta \hat{a}\rangle=0$.

Esses operadores, entretanto, não são hermitianos, mas podemos definir com base neles os operadores quadratura de amplitude e fase, $\hat{Q}^{\prime}$ e $\hat{P}^{\prime}$ que também podem ser descritos em termos de uma média e uma flutuação:

$$
\begin{gathered}
\hat{Q}^{\prime}=\hat{a}^{\dagger}+\hat{a} \\
\hat{P}^{\prime}=i\left(\hat{a}^{\dagger}-\hat{a}\right) .
\end{gathered}
$$

A partir da regra de comutação dos operadores de criação e aniquilação temos a relação de comutação entre $\hat{Q}^{\prime}$ e $\hat{P}^{\prime}$ :

$$
\left[\hat{Q}^{\prime}, \hat{P}^{\prime}\right]=2 i
$$

e, portanto, $\hat{Q}^{\prime}$ e $\hat{P}^{\prime}$ se comportam como conjugados canônicos adimensionais e obedecem à relação de incerteza:

$$
\sqrt{\delta Q^{\prime 2}} \sqrt{\delta P^{\prime 2}} \geqslant \frac{1}{2 i}\left\langle\left[\hat{Q}^{\prime}, \hat{P}^{\prime}\right]\right\rangle=1
$$

onde vamos considerar apenas estados gaussianos para os quais

$$
\delta Q^{2}=\Delta Q^{\prime 2}=\left\langle\hat{Q}^{\prime 2}\right\rangle-\left\langle\hat{Q}^{\prime}\right\rangle^{2}
$$

Os estados coerentes, incluindo o estado de vácuo, são estados para os quais o produto das incertezas é mínimo e a relação de incerteza corresponde à igualdade. Neste estado não existe diferença entre os ruídos de amplitude e fase e

$$
\Delta Q^{\prime 2}=\Delta P^{\prime 2}=1
$$

Para estados com excesso de ruído, a incerteza de pelo menos uma das quadraturas é maior do que unitária e $\sqrt{\Delta Q^{\prime 2}} \sqrt{\Delta P^{\prime 2}}>1$, menos para os estados comprimidos, para os quais a incerteza da quadratura conjugada é menor do que o ruído do estado coerente, de forma que $\sqrt{\Delta Q^{\prime 2}} \sqrt{\Delta P^{\prime 2}}=1$. 
O excesso de ruído, entretanto, não precisa ser máximo necessariamente para $\hat{Q}^{\prime}$ ou $\hat{P}^{\prime}$, mas pode ser para uma combinação dos dois. Por isso, é conveniente definirmos observáveis mais genéricos, para uma fase qualquer $\beta$, através das relações

$$
\begin{gathered}
\hat{Q}=\hat{a}^{\dagger} e^{i \beta}+\hat{a} e^{-i \beta}=\hat{Q}^{\prime} \cos \beta+\hat{P}^{\prime} \operatorname{sen} \beta \\
\hat{P}=\hat{a}^{\dagger} e^{i\left(\beta+\frac{\pi}{2}\right)}+\hat{a} e^{-i\left(\beta+\frac{\pi}{2}\right)}=-\hat{Q}^{\prime} \operatorname{sen} \beta+\hat{P}^{\prime} \cos \beta
\end{gathered}
$$

que obedecem à mesma relação de comutação e, portanto, à mesma relação de incerteza que $\hat{Q}^{\prime}$ e $\hat{P}^{\prime}$.

Através destes operadores um estado comprimido pode ser definido como sendo um estado para o qual exista um valor de $\beta$ tal que

$\Delta Q^{2}(\beta)<1$.

\subsection{Estatística de Fótons}

Um campo qualquer, descrito por um estado $|\alpha\rangle$ tem um número médio de fótons $\bar{n}$ que pode ser obtido pela média do operador número $\hat{n}$.

Estados de Fock são autoestados do operador número

$$
\hat{n}|n\rangle=n|n\rangle
$$

e como consequência, têm um número de fótons bem determinado:

$$
\langle\hat{n}\rangle=n \text {. }
$$

A variância do número de fótons de um estado é dada por

$$
\Delta n^{2} \equiv\left\langle\hat{n}^{2}\right\rangle-\langle\hat{n}\rangle^{2}
$$

Evidentemente, para o estado número $\left\langle\hat{n}^{2}\right\rangle=n^{2}$ e, portanto, $\Delta n^{2}=0$.

Devido às propriedades dos operadores de criação e aniquilação

$$
\begin{gathered}
\hat{a}|n\rangle=\sqrt{n}|n-1\rangle \\
\hat{a}^{\dagger}|n\rangle=\sqrt{n+1}|n+1\rangle,
\end{gathered}
$$

na base dos estados de Fock, o operador número pode ser escrito como

$$
\hat{n}=\hat{a}^{\dagger} \hat{a}
$$

pois

$$
\hat{a}^{\dagger} \hat{a}|n\rangle=\sqrt{n} \hat{a}^{\dagger}|n-1\rangle=n|n\rangle=\hat{n}|n\rangle
$$

Como vimos anteriormente, estados coerentes, diferentemente dos estados de Fock, não possuem um número de fótons bem definidos. Ao invés disso:

$$
\langle\alpha|\hat{n}| \alpha\rangle=\sum_{n, m} c_{m}^{*} c_{n}\langle m|\hat{n}| n\rangle=\sum_{n}\left|c_{n}\right|^{2} n
$$

Como o estado coerente é autoestado do operador de aniquilação:

$$
\begin{gathered}
\hat{a}|\alpha\rangle=\alpha|\alpha\rangle \\
\langle\alpha| \hat{a}^{\dagger}=\langle\alpha| \alpha^{*},
\end{gathered}
$$


o valor desta média é $|\alpha|^{2}$ :

$$
\langle\alpha|\hat{n}| \alpha\rangle=\left\langle\alpha\left|\hat{a}^{\dagger} \hat{a}\right| \alpha\right\rangle=\left\langle\alpha\left|\alpha^{*} \alpha\right| \alpha\right\rangle=|\alpha|^{2} .
$$

Para o cálculo da variância do estado coerente, é necessário utilizarmos as regras de comutação dos operadores de criação e aniquilação a fim de ordenarmos os operadores de forma conveniente:

$$
\left[\hat{a}, \hat{a}^{\dagger}\right]=1 \Rightarrow \hat{a} \hat{a}^{\dagger}=1+\hat{a}^{\dagger} \hat{a} .
$$

Assim,

$$
\left\langle\alpha\left|\hat{n}^{2}\right| \alpha\right\rangle=\left\langle\alpha\left|\hat{a}^{\dagger} \hat{a} \hat{a}^{\dagger} \hat{a}\right| \alpha\right\rangle=\left\langle\alpha\left|\hat{a}^{\dagger}\left(1+\hat{a}^{\dagger} \hat{a}\right) \hat{a}\right| \alpha\right\rangle=|\alpha|^{2}\left(1+|\alpha|^{2}\right)
$$

e, como já era esperado do estado coerente:

$$
\Delta n^{2}=|\alpha|^{2}
$$

\subsection{Ruído de Amplitude}

A medida de ruído de amplitude do laser pode ser feita através de uma montagem simples em que se mede o campo de um laser combinado ao campo do vácuo por um divisor de feixes $50 \% / 50 \%$, como ilustrado na figura 5.1.

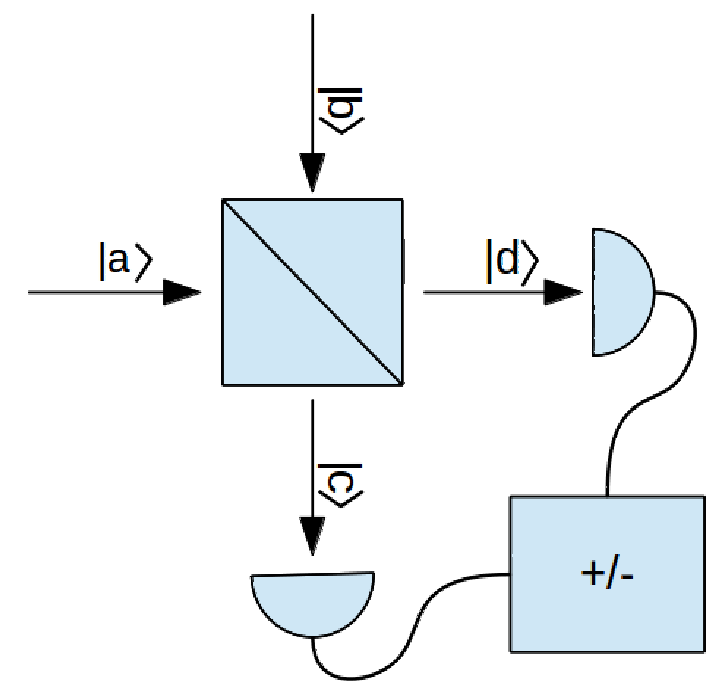

Figura 5.1. Esquema de método para medição de ruído de amplitude.

O campo do laser, ao ser refletido pelo divisor de feixes, ganha uma fase de $\pi / 2$ com relação ao campo do vácuo transmitido. Já a diferença de fase entre o campo do laser transmitido e o campo do vácuo refletido é de $-\pi / 2$. Como a fase relativa entre os campos é arbitrária, podemos escrever os operadores para os campos transmitidos e refletidos como:

$$
\begin{gathered}
\hat{c}=\frac{1}{\sqrt{2}}(\hat{a}+\hat{b}) \\
\hat{d}=\frac{1}{\sqrt{2}}(\hat{a}-\hat{b}),
\end{gathered}
$$


onde fizemos, mais uma vez, uso da equivalência entre as notações de Heisenberg e Schrödinger para escrever a relação entre os campo como uma relação entre os operadores, sendo que o operador $\hat{a}$ age somente sobre o estado $|a\rangle, \hat{b}$ age somente sobre o estado $|b\rangle$ e os estados sobre o qual os operadores $\hat{c}$ e $\hat{d}$ atuam são $|c\rangle=$ $|d\rangle=|a\rangle \otimes|b\rangle$.

Se $\hat{c}$ é o operador de aniquilação para o estado $|c\rangle$, então $\hat{a}$ e $\hat{b}$ são, consequentemente, os operadores de aniquilação para os estados $|a\rangle$ e $|b\rangle$, respectivamente, e os operadores número, que dão a intensidade do campo no estado $|c\rangle$ e $|d\rangle$, são

$$
\begin{aligned}
& \hat{I}_{c}=\hat{c}^{\dagger} \hat{c}=\frac{1}{2}\left(\hat{a}^{\dagger} \hat{a}+\hat{b}^{\dagger} \hat{b}+\hat{a}^{\dagger} \hat{b}+\hat{b}^{\dagger} \hat{a}\right) \\
& \hat{I}_{d}=\hat{d}^{\dagger} \hat{d}=\frac{1}{2}\left(\hat{a}^{\dagger} \hat{a}+\hat{b}^{\dagger} \hat{b}-\hat{a}^{\dagger} \hat{b}-\hat{b}^{\dagger} \hat{a}\right) .
\end{aligned}
$$

Vale ressaltar que, quando realizamos uma medida de intensidade, normalmente não somos capazes de contar números de fótons, e o que medimos, efetivamente, é a variação do fluxo de energia no tempo.

Voltando aos estados $|c\rangle$ e $|d\rangle$, alterando a fase entre eles podemos somá-los ou subtrai-los, dando origem aos sinais de soma e subtração cujos operadores de intensidade são

$$
\begin{aligned}
& \hat{I}_{+}=\hat{I}_{c}+\hat{I}_{d}=\hat{a}^{\dagger} \hat{a}+\hat{b}^{\dagger} \hat{b} \\
& \hat{I}_{-}=\hat{I}_{c}-\hat{I}_{d}=\hat{a}^{\dagger} \hat{b}+\hat{b}^{\dagger} \hat{a},
\end{aligned}
$$

que têm média

$$
\begin{gathered}
\left\langle\hat{I}_{+}\right\rangle=\left\langle\hat{a}^{\dagger} \hat{a}\right\rangle_{a}+\left\langle\hat{b}^{\dagger} \hat{b}\right\rangle_{b}=\left\langle\hat{n}_{a}\right\rangle_{a}+\left\langle\hat{n}_{b}\right\rangle_{b} \\
\left\langle\hat{I}_{-}\right\rangle=\left\langle\hat{a}^{\dagger}\right\rangle_{a}\langle\hat{b}\rangle_{b}+\langle\hat{a}\rangle_{a}\left\langle\hat{b}^{\dagger}\right\rangle_{b} .
\end{gathered}
$$

Para o cálculo da flutuação dos sinais é necessário escrevermos

$$
\begin{gathered}
\hat{I}_{+}^{2}=\hat{a}^{\dagger} \hat{a} \hat{a}^{\dagger} \hat{a}+2 \hat{a}^{\dagger} \hat{a} \hat{b}^{\dagger} \hat{b}+\hat{b}^{\dagger} \hat{b} \hat{b}^{\dagger} \hat{b}=\hat{a}^{\dagger} \hat{a}^{\dagger} \hat{a} \hat{a}+\hat{a}^{\dagger} \hat{a}+2 \hat{a}^{\dagger} \hat{a} \hat{b}^{\dagger} \hat{b}+\hat{b}^{\dagger} \hat{b}^{\dagger} \hat{b} \hat{b}+\hat{b}^{\dagger} \hat{b} \\
\hat{I}_{-}^{2}=\hat{a}^{\dagger} \hat{a}^{\dagger} b b+\hat{a}^{\dagger} \hat{a} \hat{b} \hat{b}^{\dagger}+\hat{a} \hat{a}^{\dagger} \hat{b}^{\dagger} \hat{b}+\hat{b}^{\dagger} \hat{b}^{\dagger} \hat{a} \hat{a}= \\
=\hat{a}^{\dagger} \hat{a}^{\dagger} b b+\hat{a}^{\dagger} \hat{a}\left(\hat{b}^{\dagger} \hat{b}\right)+1+\left(\hat{a}^{\dagger} \hat{a}+1\right) \hat{b}^{\dagger} \hat{b}+\hat{b}^{\dagger} \hat{b}^{\dagger} \hat{a} \hat{a}
\end{gathered}
$$

que nos permitem deduzir:

$$
\begin{gathered}
\left\langle\hat{I}_{+}^{2}\right\rangle=\left\langle\hat{a}^{\dagger} \hat{a}^{\dagger} \hat{a} \hat{a}\right\rangle_{a}+\left\langle\hat{n}_{a}\right\rangle_{a}+2\left\langle\hat{n}_{a}\right\rangle_{a}\left\langle\hat{n}_{b}\right\rangle_{b}+\left\langle\hat{b}^{\dagger} \hat{b}^{\dagger} \hat{b} \hat{b}\right\rangle_{b}+\left\langle\hat{n}_{b}\right\rangle_{b} \\
\left\langle\hat{I}_{-}^{2}\right\rangle=\left\langle\hat{a}^{\dagger}\right\rangle\left\langle\hat{b}^{2}\right\rangle+\left\langle\hat{b}^{\dagger 2}\right\rangle\left\langle\hat{a}^{2}\right\rangle+2\left\langle\hat{n}_{a}\right\rangle\left\langle\hat{n}_{b}\right\rangle+\left\langle\hat{n}_{a}\right\rangle+\left\langle\hat{n}_{b}\right\rangle .
\end{gathered}
$$

Como

$$
\begin{gathered}
\left\langle\hat{I}_{+}\right\rangle^{2}=\left\langle\hat{n}_{a}\right\rangle_{a}^{2}+\left\langle\hat{n}_{b}\right\rangle_{b}^{2}+2\left\langle\hat{n}_{a}\right\rangle_{a}\left\langle\hat{n}_{b}\right\rangle_{b} \\
\left\langle\hat{I}_{-}\right\rangle^{2}=\left\langle\hat{a}^{\dagger}\right\rangle_{a}^{2}\langle\hat{b}\rangle_{b}^{2}+\langle\hat{a}\rangle_{a}^{2}\left\langle\hat{b}^{\dagger}\right\rangle_{b}^{2}+2\left\langle\hat{a}^{\dagger}\right\rangle_{a}\langle\hat{a}\rangle_{a}\langle\hat{b}\rangle_{b}\left\langle\hat{b}^{\dagger}\right\rangle_{b},
\end{gathered}
$$

podemos finalmente calcular as variâncias $\Delta \hat{I}_{ \pm}^{2}=\left\langle\hat{I}_{ \pm}^{2}\right\rangle-\left\langle\hat{I}_{ \pm}\right\rangle^{2}$ :

$$
\Delta \hat{I}_{+}^{2}=\left\langle\hat{n}_{a}^{2}\right\rangle_{a}-\left\langle\hat{n}_{a}\right\rangle_{a}^{2}+\left\langle\hat{n}_{b}^{2}\right\rangle_{b}-\left\langle\hat{n}_{b}\right\rangle_{b}^{2}=\Delta n_{a}^{2}+\Delta n_{b}^{2}
$$


e, assumindo que $|b\rangle$ é um estado de vácuo e que portanto $b|b\rangle=0$,

$$
\Delta \hat{I}_{-}^{2}=\left\langle\hat{n}_{a}\right\rangle=I_{a}
$$

O objetivo dessa medida é obter o ruído de amplitude $\Delta n_{a}^{2}$ do campo $|a\rangle$. Em princípio, esse ruído poderia ser medido simplesmente com a medição de $\Delta \hat{I}_{+}^{2}$, subtraindo-se o ruído do vácuo. Entretanto, como já foi ressaltado, para que o valor obtido faça sentido é preciso compará-lo com o shot-noise que é dado diretamente pelo sinal de subtração.

Além disso, os detectores reais não são perfeitos e não detectam todos os fótons que nele incidem, mas apenas uma fração deles. Por isso, podemos assumir que, com relação ao estado de vácuo, existe um coeficiente $\eta$ que multiplica a intensidade do campo do laser e, portanto, temos que fazer a substituição $|a\rangle \rightarrow \sqrt{\eta}|a\rangle$, que leva a $\hat{a} \rightarrow \sqrt{\eta} \hat{a}$ e consequentemente:

$$
\begin{gathered}
\Delta \hat{I}_{+}^{2}=\eta \Delta n_{a}^{2}+\Delta n_{b}^{2} \\
\Delta \hat{I}_{-}^{2}=\eta I_{a},
\end{gathered}
$$

de forma que o sinal de subtração nos permite normalizar o sinal de soma, sendo

$$
R \equiv \frac{\Delta \hat{I}_{+}^{2}-\Delta n_{b}^{2}}{\Delta \hat{I}_{-}^{2}}=\frac{\Delta n_{a}^{2}}{I_{a}}
$$

o ruído normalizado em escala de shot-noise.

Quando o campo é representado por um estado coerente, sua variância é igual à sua intensidade de forma que $R=1$. Se o campo tem excesso de ruído, então $\Delta n_{a}^{2}$ deixa de ser mínimo e $R \neq 1$, podendo ser menor que unitário para determinadas quadraturas de estados comprimidos.

Dessa forma, concluímos que é possível determinar o excesso de ruído através da medida de $R$.

\subsection{Ruído de Fase}

Da maneira como foi montado, o método descrito na seção anterior permite a medida do ruído apenas da quadratura de amplitude mas não dá acesso a informações sobre o ruído da quadratura de fase.

Para que fosse possível inferir sobre o ruído de fase utilizamos um método que nos permitiu girar a elipse de ruído no espaço de fase.

Para entender melhor o método vamos considerar o campo no domínio da frequência, onde, como explicitado na seção 5.1, o espectro do ruído de um laser é composto por uma portadora e um contínuo de bandas laterais ao seu redor.

As bandas laterais são, sobretudo, consequência da difusão da fase ao longo do tempo, que fazem com que a transformada de Fourier do campo seja quebrada em duas componentes de frequência $\pm \Omega$ em relação à portadora.

Da mesma forma, iremos aplicar a transformada de Fourier sobre o operador de aniquilação de um modo:

$$
\hat{a}(\Omega)=\mathfrak{F}[\hat{a}(t)](\omega)=\mathfrak{F}\left[\hat{a}(t) \frac{e^{i \Omega t}+e^{-i \Omega t}}{2}\right](\omega)=\frac{\mathfrak{F}[\hat{a}(t)](\omega+\Omega)+\mathfrak{F}[\hat{a}(t)](\omega-\Omega)}{2}
$$


e, portanto,

$$
\hat{a}(\Omega)=\frac{1}{2}[\hat{a}(\omega+\Omega)+\hat{a}(\omega-\Omega)] .
$$

Para o operador de criação utiliza-se a propriedade de conjugação da transformada de Fourier que garante que se

$$
F(\Omega)=\mathfrak{F}[f(t)] \Rightarrow \mathfrak{F}\left[f^{*}(t)\right]=F^{*}(-\Omega) .
$$

Sendo assim:

$$
\hat{a}^{\dagger}(\Omega)=\frac{1}{2}\left[\hat{a}^{\dagger}(\omega-\Omega)+\hat{a}^{\dagger}(\omega+\Omega)\right]
$$

Vale chamar atenção para o fato de que os novos operadores obtidos, $\hat{a}(\Omega)$ e $\hat{a}^{\dagger}(\Omega)$, não são exatamente operadores de criação e aniquilação no espaço da frequência, mas são construídos a partir dos operadores $\hat{a}(\omega+\Omega), \hat{a}(\omega-\Omega)$ e $\hat{a}^{\dagger}(\omega+\Omega), \hat{a}^{\dagger}(\omega-\Omega)$, que podem ser interpretados como operadores de criação e aniquilação e das bandas laterais.

Operadores de criação e aniquilação podem ser escritos de maneira mais genérica se considerarmos uma fase global $\beta$. Além disso, por consequência da transformada de Fourier, se um operador de criação da portadora tem uma fase global, então os operadores de criação das bandas laterais terão, a princípio, a mesma fase. Assim escreveremos

$$
\begin{gathered}
\hat{a}(\Omega) \rightarrow \hat{a}(\Omega) e^{i \beta}, \\
\hat{a}^{\dagger}(\Omega) \rightarrow \hat{a}^{\dagger}(\Omega) e^{-i \beta} .
\end{gathered}
$$

O efeito desta fase é o mesmo que nas equações (5.1) e (5.2). Ela faz com que o ruído de amplitude do laser se converta, aos poucos, em ruído de fase, sem que haja nenhum efeito nas medidas de intensidade:

$$
\hat{I}=\hat{a}^{\dagger} \hat{a}=\frac{1}{4}\left[\hat{a}^{\dagger}(-\Omega) \hat{a}(+\Omega)+\hat{a}^{\dagger}(-\Omega) \hat{a}(-\Omega)+\hat{a}^{\dagger}(+\Omega) \hat{a}(+\Omega)+\hat{a}^{\dagger}(+\Omega) \hat{a}(-\Omega)\right] .
$$

Quando esta fase vale 0 ou $\pi, P= \pm P^{\prime}$ e $Q= \pm Q^{\prime}$ são as quadraturas de fase e amplitude respectivamente. Quando a fase passa a ser $\frac{\pi}{2}$ ou $\frac{3 \pi}{2}, P= \pm Q^{\prime}$ e $Q=\mp P^{\prime}$ são as quadraturas de amplitude e fase respectivamente. Sendo assim, variar a fase da portadora permite converter totalmente ruído de fase em ruído de amplitude.

Outra alternativa para medirmos o ruído de fase é aplicar um atraso de fase $\varphi$ em apenas uma das bandas laterais:

$$
\begin{gathered}
\hat{a}(+\Omega) \rightarrow \hat{a}(+\Omega) e^{i \varphi} \\
\hat{a}^{\dagger}(+\Omega) \rightarrow \hat{a}^{\dagger}(+\Omega) e^{-i \varphi} .
\end{gathered}
$$

Para todos os efeitos, isso equivale a aplicar uma fase de $\varphi / 2$ no campo todo, pois tais operadores são resultantes da tranformada de Fourier de

$$
\hat{a}(t) \frac{e^{i \Omega t} e^{i \varphi}+e^{-i \Omega t}}{2}=\hat{a}(t) e^{i \frac{\varphi}{2}} \frac{e^{i\left(\Omega t+\frac{\varphi}{2}\right)}+e^{-i\left(\Omega t+\frac{\varphi}{2}\right)}}{2}=\hat{a}(t) e^{i \frac{\varphi}{2}} \cos \left(\Omega t+\frac{\varphi}{2}\right) .
$$

Como aplicar uma fase na modulação é irrelevante, o efeito do atraso de fase entre as bandas laterais é também um giro da elipse de ruído. 
Foi dito anteriormente que, na prática, não existem apenas duas bandas laterais, mas uma infinidade delas e, para cada uma delas, ou seja, para cada valor de $\Omega$, existem operadores de criação e aniquilação, cujas variâncias estamos interessados em medir.

Para selecionar uma única frequência de análise $\Omega$ utilizamos um demodulador Para a aplicação da fase em uma única banda lateral, ou diretamente na portadora, utilizamos uma cavidade de Fabry-Perot.

O campo refletido pela cavidade de Frabry-Perot é

$$
E_{R}=E_{o} \frac{r_{1}-r_{2} e^{i k l}}{1-r_{2} r_{1} e^{i 2 k l}}
$$

A figura 5.2 mostra a reflexão do sinal e a fase que o feixe refletido ganha, em função da frequência, para uma cavidade específica:

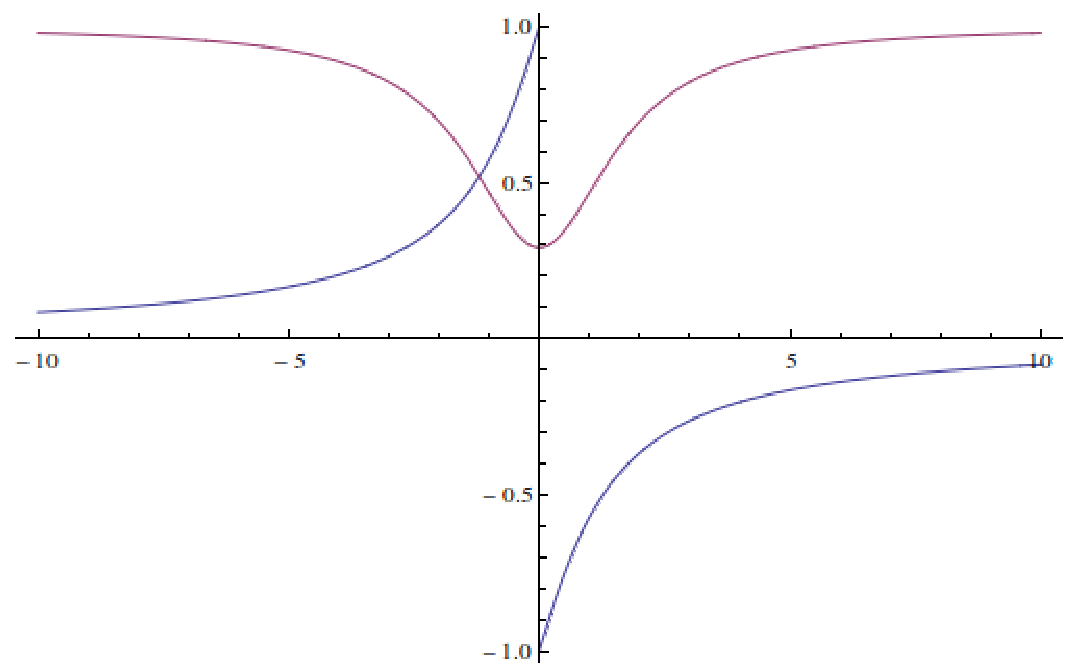

Figura 5.2. Módulo ao quadrado (azul) e argumento (roxo) do campo refletido por uma cavidade de $\mathrm{FSR}=1,67 \mathrm{GHz}$, e espelhos de entrada com $R=0,99$ e saída com $R=0,997$.

Como se pode ver, ao passar pela frequência de ressonância, a fase do campo sofre um giro que chega a $180^{\circ}$ quando a Finesse da cavidade é alta.

Esse processo através do qual o campo refletido ganha uma fase é seletivo em frequência e, por isso, variando-se a frequência de ressonância da cavidade, é possível proporcionar um giro de fase em uma banda lateral apenas, ou na portadora.

Quando a frequência da portadora está um pouco abaixo da frequência de ressonância, a fase ganha por ela é de $-\frac{\pi}{2}$ e a elipse de ruído sofre um giro, convertendo o ruído de fase em ruído amplitude. À medida que a frequência de ressonância se aproxima da frequência da portadora, a fase ganha pela portadora deixa de existir, bem como o giro da elipse de ruído. Quando a frequência da portadora é maior que a frequência da ressonância da cavidade, a fase inverte para $\frac{\pi}{2}$ e novamente ruído de amplitude e fase se invertem.

Quando uma das bandas laterais se aproxima da frequência de ressonância, banda lateral e portadora ficam com uma diferença de fase de $\pi$, e a elipse de ruído dá um giro, convertendo novamente ruído de fase em ruído de amplitude. 
Devido ao fato de que a cavidade tem uma largura de linha de transmissão, existem casos para os quais tanto a portadora como uma das bandas laterais ganham uma fase, de forma que ambos os processos de rotação da elipse de ruído se misturam, e os ruídos de fase não chega a ser completamente convertido em ruído de amplitude, ou não chega a ser convertido mais de uma vez. Para que se possa distinguir entre a rotação devido à fase da portadora ou à fase das bandas laterais, é preciso que a razão entre $\Omega$ e a largura de banda da cavidade seja maior ou igual a $\sqrt{2}$ [3].

\subsection{Medidas de Ruído}

As primeiras medidas realizadas visavam verificar se o ruído de amplitude do laser variava proporcionalmente à sua amplitude, como seria esperado para estados coerentes, e a partir de qual frequência de análise o ruído de soma e subtração eram iguais.

Essas medidas foram realizadas através de um analisador de espectro, que realiza a modulação do feixe para toda uma faixa de frequência. Os detectores utilizados foram construídos no próprio laboratório e a soma e subtração dos sinais foi feita utilizando-se três equipamentos passivos de subtração, cada um deles atenuando o sinal por um fator de $3 \mathrm{dBm}$, dispostos como no diagrama da figura 5.3.

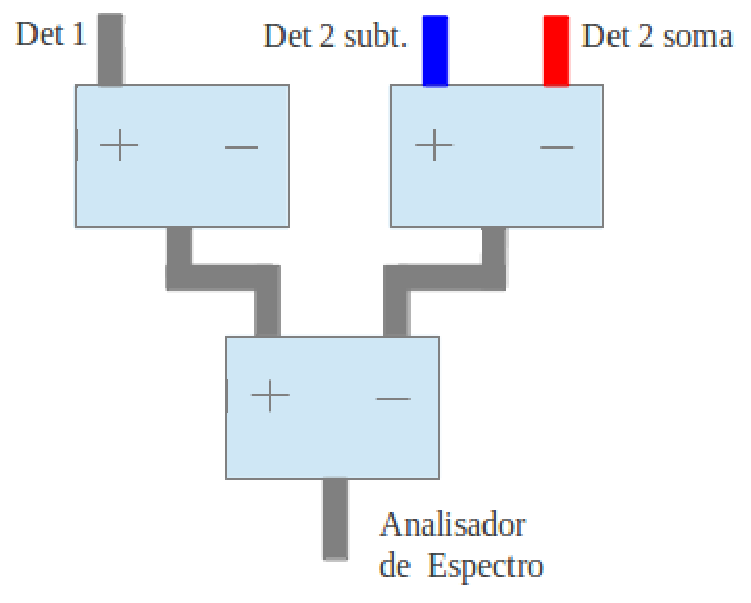

Figura 5.3. Esquema de montagem utilizada para realizar a soma e subtração dos sinais com elementos passivos que fazem apenas a subtração. Um dos sinais passa por duas caixas de subtração sem sofrer nenhum giro na fase, enquanto o outro sofre um ou dois giros de $180^{\circ}$, dependendo se é conectado na entrada positiva ou negativa da primeira caixa. A montagem foi feita desta maneira para que os sinais vindo de ambos os detectores sofram a mesma atenuação.

A medida para frequências de análise de até 40MHz (figura 5.4), para três valores de intensidade, mostra que para altas frequências o ruído decai proporcionalmente com a intensidade, como esperado de um estado coerente (o ruído diminui aproximadamente $3 \mathrm{dBm}$ quando a intensidade é reduzida pela metade). Além disso, é possível verificar que o ruído dos detectores é bastante menor do que o ruído de amplitude medido, quando o laser tem intensidade de $4,75 \mathrm{~mW}$ (cerca de $2,38 \mathrm{~mW}$ em cada detector). 


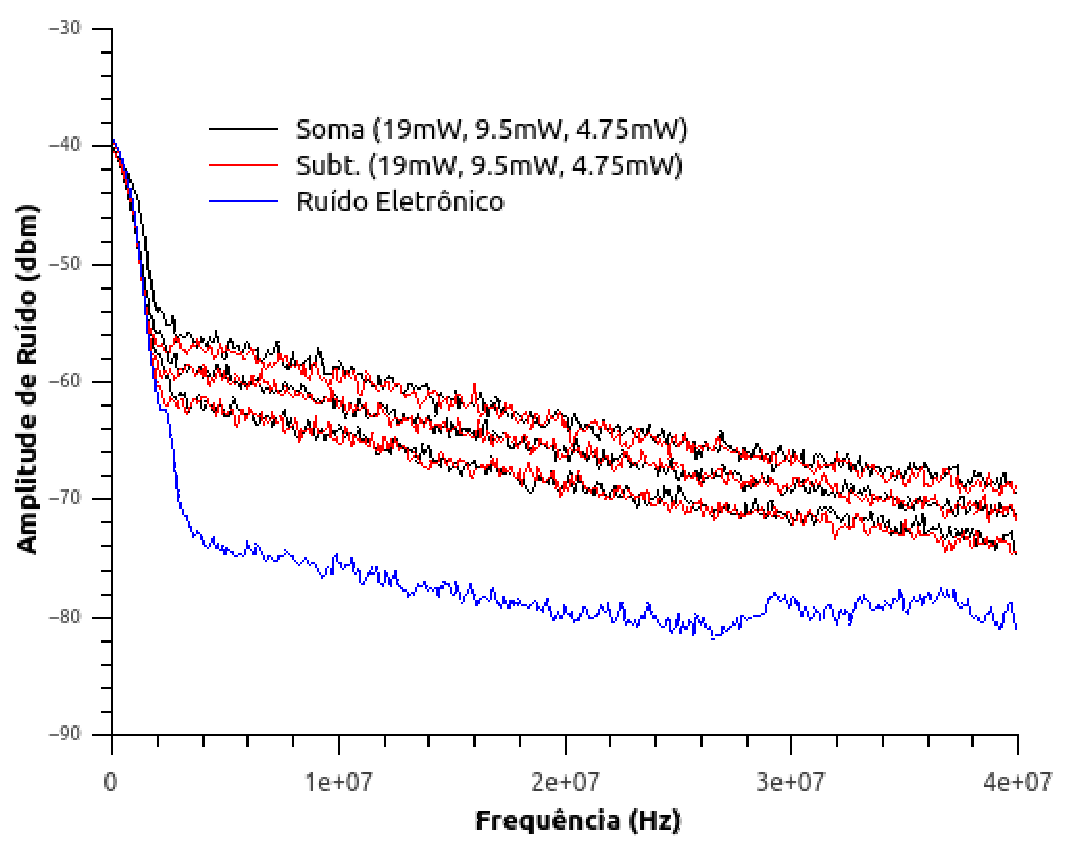

Figura 5.4. Sinais de soma (preto) e subtração (vermelho) para a intensidade do laser antes do divisor de feixes igual a $19 \mathrm{~mW}, 9,5 \mathrm{~mW}$ e $4,75 \mathrm{~mW}$ e o sinal de soma dos ruídos (azul).

Na figura 5.5, é possível ver com mais detalhe a diferença entre os sinais de soma e subtração dos ruídos, para frequências abaixo de $5 \mathrm{MHz}$. Até um pouco mais do que $4 \mathrm{MHz}$, o ruído de soma é maior do que o ruído de subtração (shot-noise), e portanto o laser não corresponde a um estado coerente.

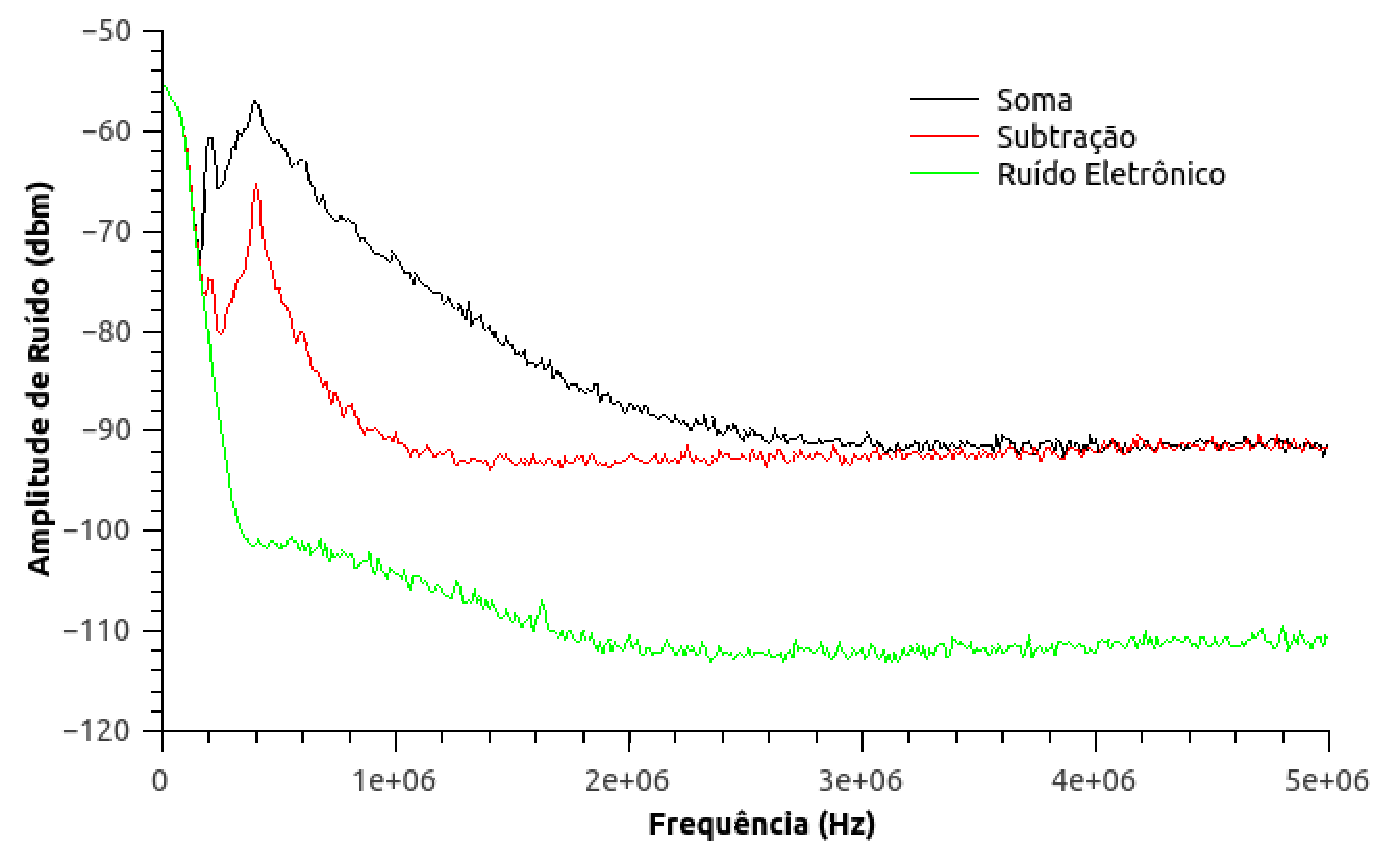

Figura 5.5. Sinais de soma (preto) e subtração (vermelho) para a intensidade do laser igual a $17,5 \mathrm{~mW}$ em cada detector, e sinal de soma dos ruídos (verde). 
Dentro da região para a qual ruído de soma e subtração pareciam compatíveis, escolhemos uma frequência fixa qualquer e realizamos medidas da intensidade do ruído de soma e subtração conforme variávamos a intensidade do laser (figura 5.6).

\section{ruído de amplitude}

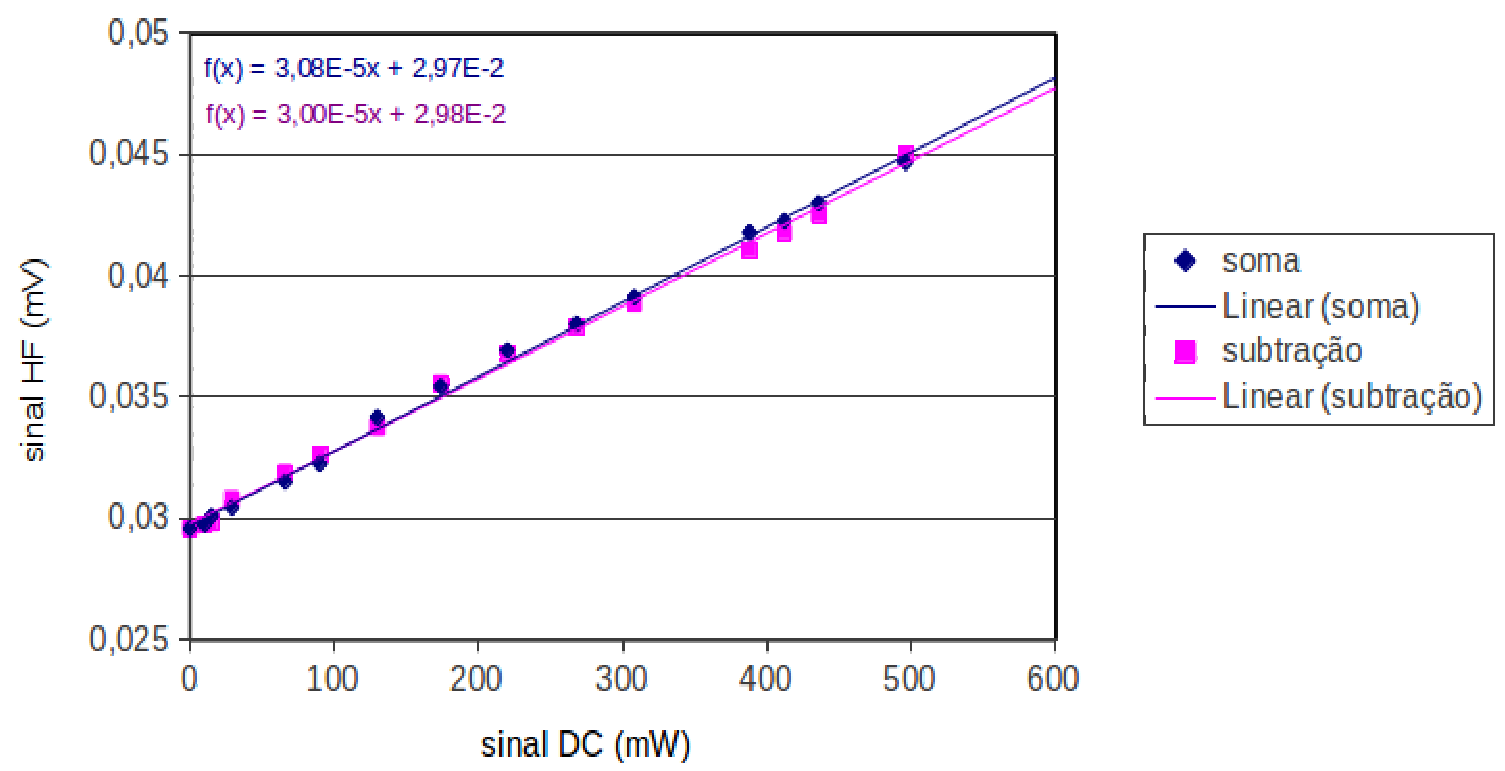

Figura 5.6. Intensidade do ruído de amplitude em função da intensidade do laser, para a frequência de análise de 18,4MHz.

Vemos um comportamento linear do ruído com relação à intensidade do laser, tanto para a soma quanto para a subtração dos sinais, e ambas as curvas têm aproximadamente a mesma inclinação, como é esperado de um estado coerente. O coeficiente linear é o ruído eletrônico do sistema de medição.

Para as medidas de ruído de fase, construímos uma cavidade de análise em anel, de Finesse $\mathcal{F}=465$ e comprimento espectral livre $\mathrm{FSR}=1,67 \mathrm{GHz}$, portanto com largura de banda de $3,4 \mathrm{MHz}$. Escolhemos uma cavidade em anel, porque nela é mais fácil separar o feixe refletido, que não sai sobreposto ao feixe incidente.

A cavidade foi construída com $18 \mathrm{~cm}$ de comprimento, um espelho de entrada plano de reflexão $r=99,9 \% \pm 5 \%$ (Layertec - A1004029), um outro espelho plano dielétrico fechado com $r>99,9 \%$ (Thorlabs - BB1-E03) e um espelho curvo de raio $R=15 \mathrm{~cm}$ e reflexão $r=99,97 \%$ (CVI - TLM2-800-0-1037-0.15CC). Para o feixe refletido, é possível considerar a cavidade como um Fabry-Perot simples, de apenas dois espelhos, onde o primeiro espelho é efetivamente o espelho de entrada, enquanto todas as outras perdas da cavidade são consideradas como a transmissão pelo espelho de saída.

O sinais HF de cada detector passaram por um demodulador construído no próprio laboratório e foram transferidos para o computador por uma placa de aquisição de dados, controlada por LabVIEW. 
A cada tomada de dados, variamos a frequência de transmissão da cavidade ao redor de um de seus picos, enquanto adquirimos 450 mil dados para o sinal HF e DC dos dois detectores.

Dividimos esses dados em grupos de 1000 dados, e, para cada um deles, através de um programa de computador, calculamos uma média para o sinal DC e a variância $\left\langle\delta^{2}\right\rangle$ do sinal HF para cada detector, além da média do produto dos sinais $\operatorname{HF}\left\langle\delta_{1} \delta_{2}\right\rangle$, para que se pudesse calcular a variância dos sinais de soma e subtração dos ruídos:

$\left\langle\left(\delta_{1} \pm \delta_{2}\right)^{2}\right\rangle=\left\langle\delta_{1}^{2}\right\rangle+\left\langle\delta_{2}^{2}\right\rangle \pm 2\left\langle\delta_{1} \delta_{2}\right\rangle$.

Para esse cálculo, entretanto, foi preciso antes extrair dos sinais medidos, os ruídos eletrônicos de todo o sistema de medida e garantir o balanceamento dos sinais HF dos detectores.

Durante as medidas verificou-se a existência de um offset nos ruídos eletrônicos dos dois detectores, gerado pela placa de aquisição de dados. Verificamos que a média do produto desses ruídos era igual ao produto de suas médias, indicando que não havia correlação entre eles

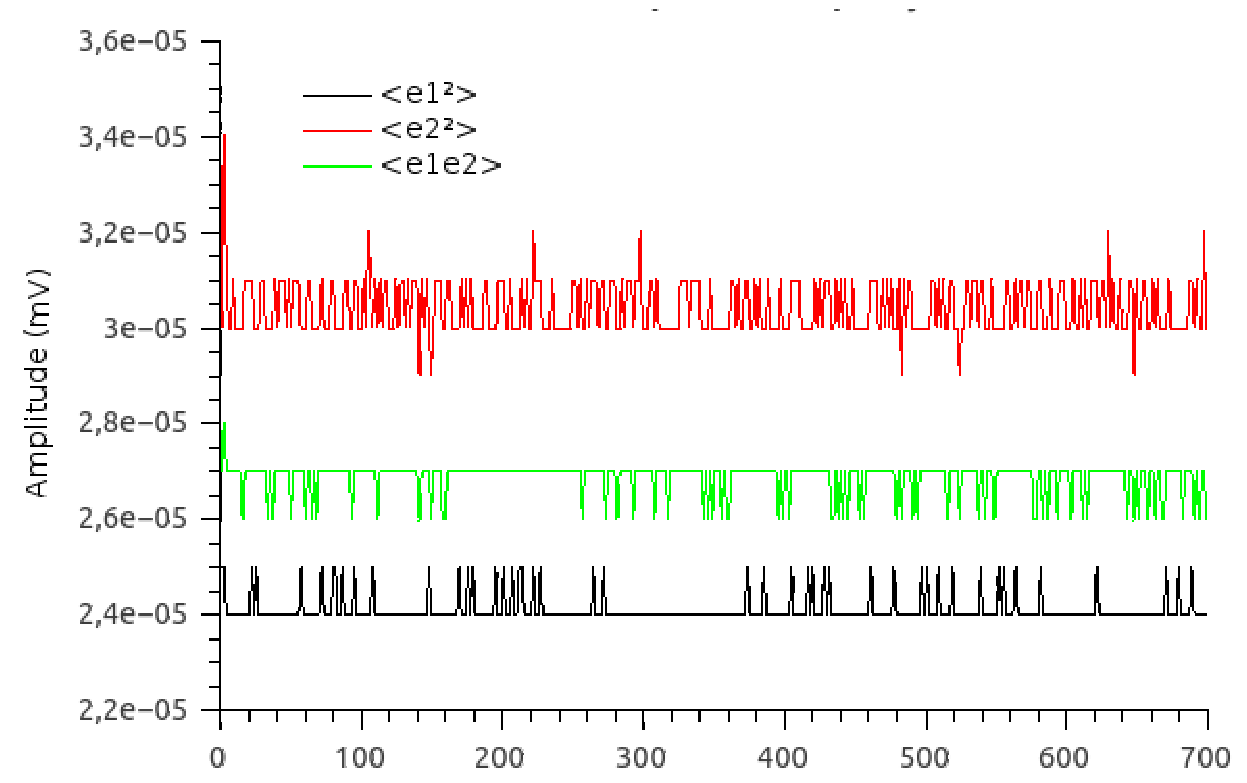

Figura 5.7. Medida da variância e da correlação dos ruídos eletrônicos de todo o sistema de medição (detectores, cabos, demodulador e placa de aquisição de dados), proveniente dos dois sinais medidos.

Como também não existe correlação entre o ruído eletrônico e o ruído do laser, a variância do sinal medido em relação à variância do laser e do ruído eletrônico é:

$\left\langle\mathrm{HF}^{2}\right\rangle=\left\langle(\delta+e)^{2}\right\rangle=\left\langle\delta^{2}\right\rangle+\left\langle e^{2}\right\rangle$,

onde $\left\langle\mathrm{HF}^{2}\right\rangle$ é a medida de variância realizada, $\left\langle\delta^{2}\right\rangle$ é a variância real do sinal e $\left\langle e^{2}\right\rangle$ é a variância do ruído eletrônico.

A calibração dos detectores foi feita para que a variância de ambos os sinais HF estivesse balanceada. Assim, depois de subtraído o ruído eletrônico, plotou- 
se um gráfico da variância de $\mathrm{HF}_{1}$ pela variância de $\mathrm{HF}_{2}$ para diversos valores de intensidade do laser, e ajustou-se sobre ele uma reta.

\section{Ajuste linear}

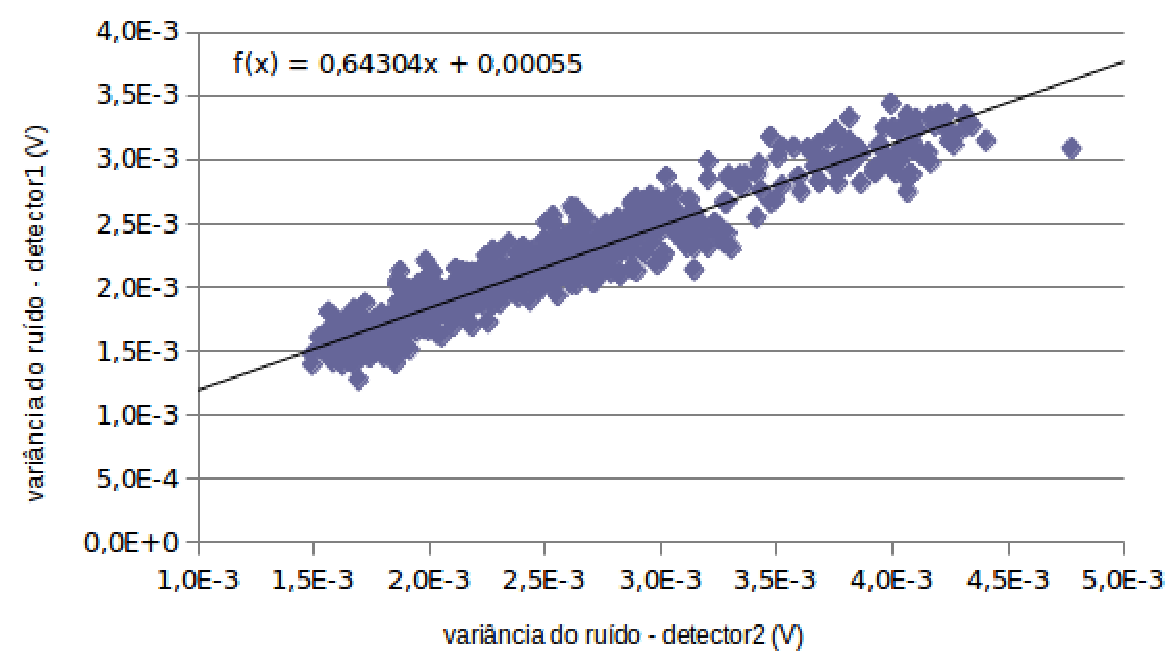

Figura 5.8. Relação da variância dos ruídos medidos por cada detector, utilizada para o balanceamento dos sinais. A medida em Volts é a intensidade do sinal proveniente da placa de aquisição.

Os coeficientes angular e linear $(a$ e $b$ ) obtidos foram utilizados para ajustar a variância do sinal de um dos detectores e as seguintes correções foram aplicadas:

$$
\begin{aligned}
& \left\langle\delta_{1}^{2}\right\rangle=a\left(\left\langle\mathrm{HF}_{1}^{2}\right\rangle-\left\langle e_{1}^{2}\right\rangle\right)-b \\
& \left\langle\delta_{1} \delta_{2}\right\rangle=\sqrt{a}\left(\left\langle\mathrm{HF}_{1} \mathrm{HF}_{2}\right\rangle-\left\langle e_{1} e_{2}\right\rangle\right) .
\end{aligned}
$$

A partir dessas correções, foi possível levantarmos as curvas de ruído do laser, e, para que pudéssemos ajustá-las, utilizamos o sinal DC como referência.

As curvas de reflexão utilizadas para o ajuste do sinal DC foram feitas considerando que, no limite em que as transmissões dos espelhos de uma cavidade de FabryPerot são muito pequenas $\left(T_{1}, T_{2} \ll 1\right)$, a finesse pode ser aproximada [31] por

$\mathcal{F}=\frac{2 \pi}{T_{1}+T_{2}}$,

e o valor mínimo $R_{\min }$ da reflexão $\frac{R}{R_{0}}$ do feixe pode ser escrito como

$R_{\text {min }}=\frac{T_{1}-T_{2}}{T_{1}+T_{2}}=\frac{\mathcal{F}}{2 \pi}\left(T_{1}-T_{2}\right)$. lhos.

Isso nos permite calcular um valor experimental para as transmissões dos espe-

A escala utilizada para o eixo das abscissas da curva de reflexão foi ajustada de forma que a distância entre dois vales de reflexão fosse de 1670, o que equivale ao comprimento espectral livre da cavidade de análise medido em $\mathrm{MHz}$. Finalmente, os dados experimentais foram ajustados à curva teórica fazendo com que suas larguras 
de linha coincidissem.

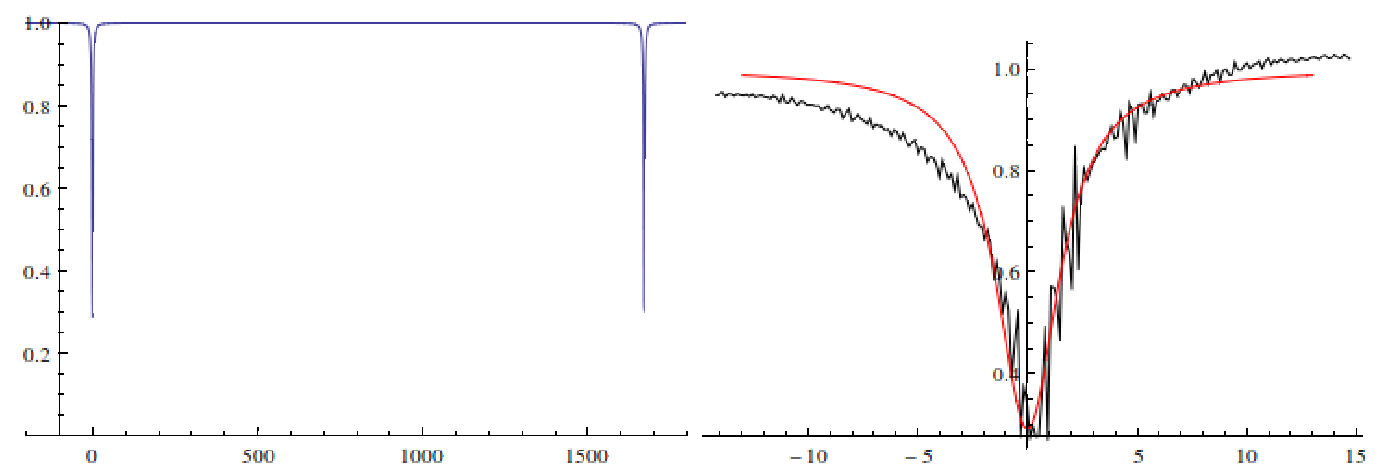

Figura 5.9. À esquerda, ajuste do comprimento espectral livre, em mega-hertz, da curva de reflexão. À direita, ajuste do sinal DC obtido experimentalmente à curva teórica.

Percebeu-se que as curvas de reflexão não possuíam uma forma simétrica, como pode ser observado na figura 5.10, sobre a qual foi ajustada de uma lorentziana.

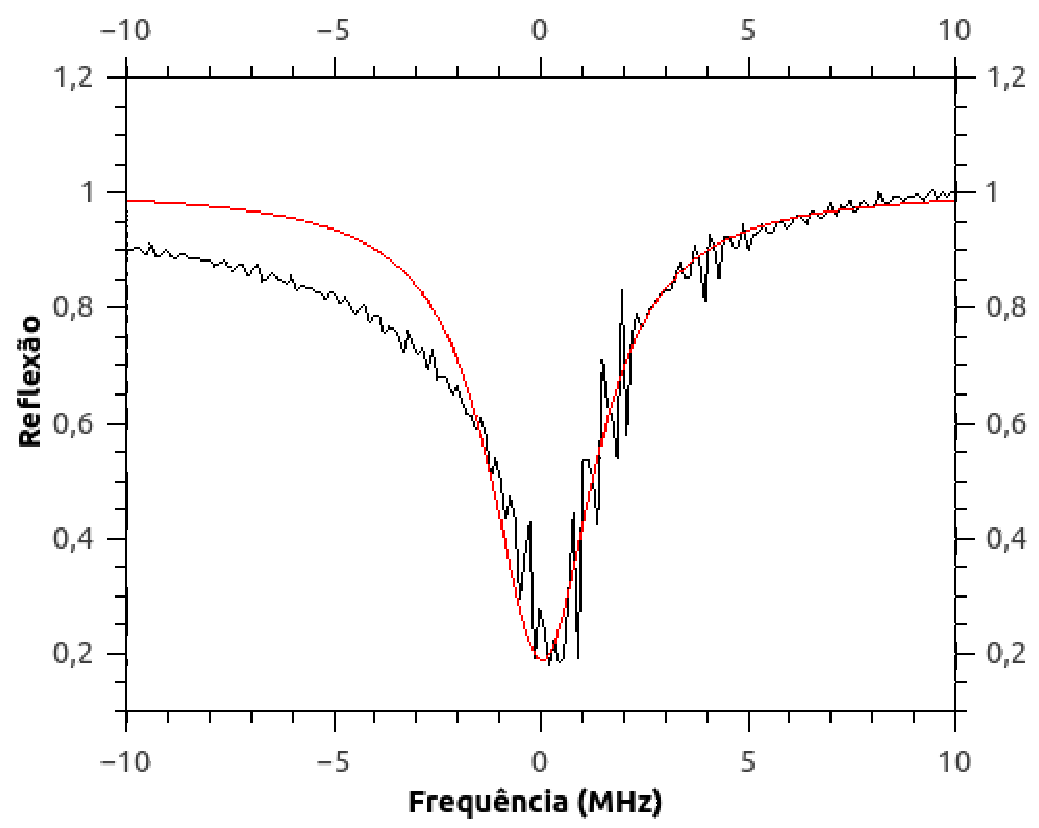

Figura 5.10. Reflexão do feixe pela cavidade de análise, com o lado direto ajustado por uma lorentziana (vermelho). A intensidade do feixe utilizado era $30 \mathrm{~mW}$.

Curvas semelhantes já haviam sido observadas em outras experiências do laboratório e acreditamos que sua assimetria seja causada por um efeito de aquecimento da cavidade. Fora da ressonância a cavidade não armazena luz e, portanto, ela está em um estado de menor temperatura. Ao passar pela ressonância, a cavidade esquenta, e efeitos de lente térmica podem alterar a reflexão da cavidade.

Algumas curvas feitas com o laser operando em mais baixa intensidade, mostram uma assimetria mais suave, como pode ser observado na figura 5.11. Entretanto, antes que se observasse tal efeito, a cavidade de análise precisou ser utilizada em 
outro experimento, de forma que todas as medidas de ruído realizadas foram feitas com $30 \mathrm{~mW}$ de potência ( $15 \mathrm{~mW}$ em cada detector).

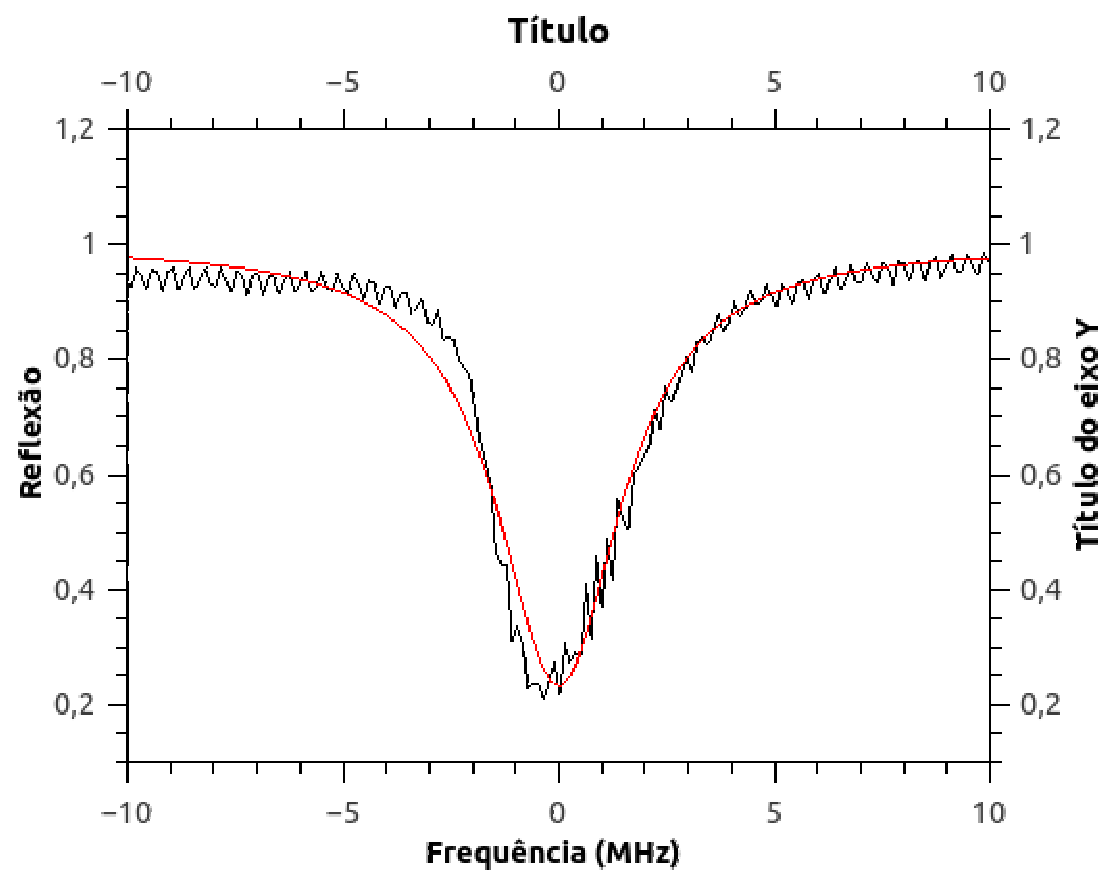

Figura 5.11. Reflexão do feixe pela cavidade de análise, com o lado direito ajustado por uma lorentziana (vermelho). A intensidade do feixe utilizado era $5 \mathrm{~mW}$.

Por esse motivo as curvas foram todas ajustadas para o lado em que a intensidade refletida chegava a ser maior (para as figuras apresentadas neste trabalho os ajustes foram feitos todos para o lado da frequência positiva).

O ajuste para as curvas de ruído foi feito com base na equação deduzida em outros trabalhos do grupo [3]:

$$
S_{R}(\omega, \Omega)=\left|g_{p}(\omega, \Omega)\right|^{2} S_{p}(\Omega)+\left|g_{q}(\omega, \Omega)\right|^{2} S_{q}(\Omega)+\left|g_{v p}(\omega, \Omega)\right|^{2}+\left|g_{v q}(\omega, \Omega)\right|^{2}
$$

onde $S_{q}(\Omega)$ e $S_{p}(\Omega)$ são os parâmetros a serem ajustados e representam os espectros de ruído das quadraturas de amplitude e fase, respectivamente; e

$$
\begin{aligned}
g_{q}(\omega, \Omega) & =\frac{1}{2}\left[e^{-i \theta_{R}(\omega)} E_{R}(\omega+\Omega)+e^{i \theta_{R}(\omega)} E_{R}^{*}(\omega-\Omega)\right] \\
g_{p}(\omega, \Omega) & =\frac{1}{2}\left[e^{-i \theta_{R}(\omega)} E_{R}(\omega+\Omega)-e^{i \theta_{R}(\omega)} E_{R}^{*}(\omega-\Omega)\right] \\
g_{v q}(\omega, \Omega) & =\frac{1}{2}\left[e^{-i \theta_{R}(\omega)} E_{T}(\omega+\Omega)+e^{i \theta_{R}(\omega)} E_{R}^{*}(\omega-\Omega)\right] \\
g_{v p}(\omega, \Omega) & =\frac{1}{2}\left[e^{-i \theta_{R}(\omega)} E_{T}(\omega+\Omega)-e^{i \theta_{R}(\omega)} E_{R}^{*}(\omega-\Omega)\right]
\end{aligned}
$$

sendo $\theta_{R}$ o argumento do campo refletido $E_{R}, E_{T}$ o campo transmitido, $\omega$ a frequência do feixe e $\Omega$ a frequência de análise. 


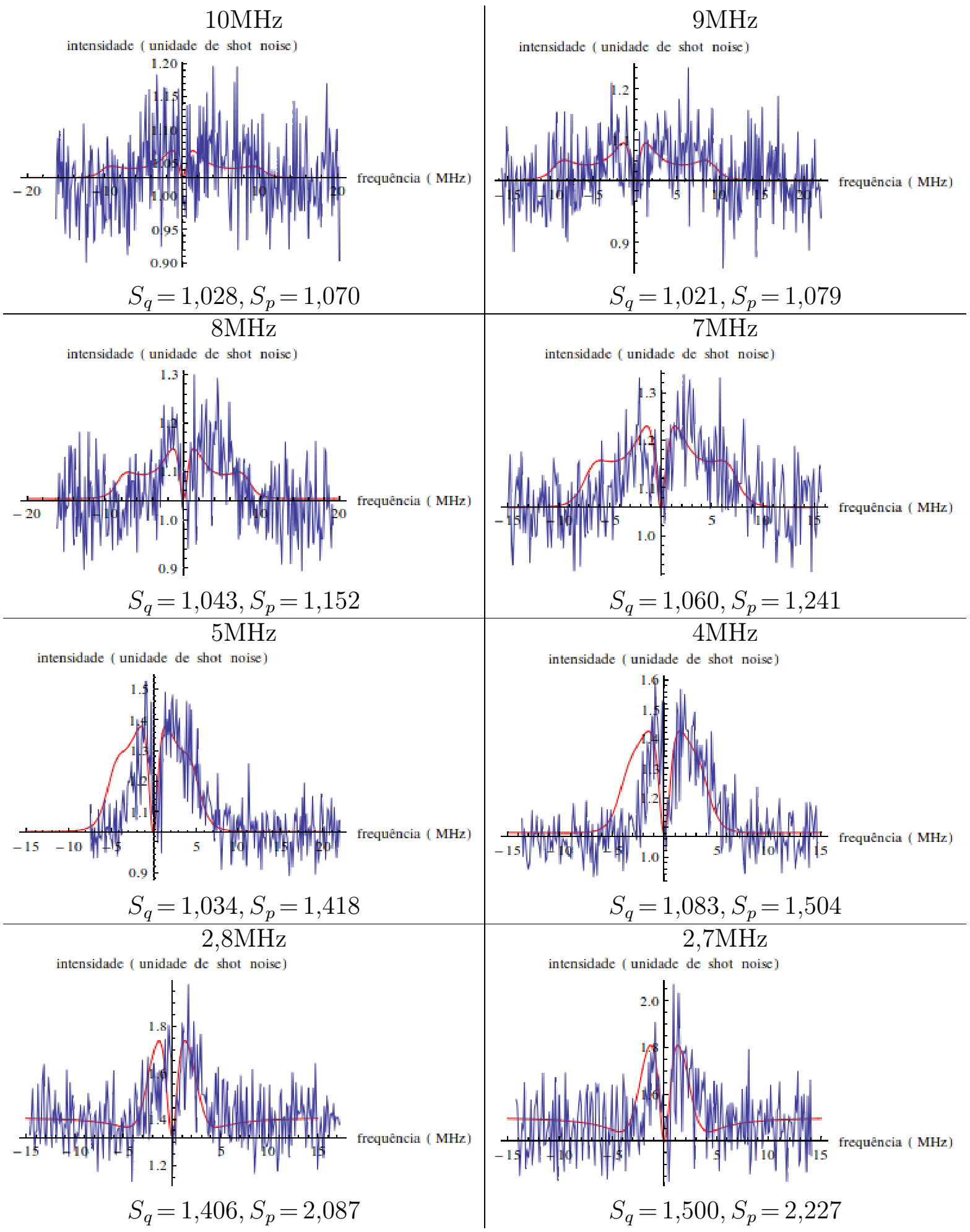

Figura 5.12. Curvas de ruído medidas para diversas frequências de modulação.

Como esperado, os valores de $S_{q}$ e $S_{p}$ diminuem conforme a frequência de modulação aumenta, tendendo a 1 , indicando um estado coerente.

Para a modulação de $10 \mathrm{MHz}$, as variâncias de ruído são da ordem do ruído eletrônico e portanto podemos considerar que o laser se comporta aproximadamente como um estado coerente. 
Dada a largura de banda da cavidade de análise $\Delta \delta=3,4 \mathrm{MHz}$, calculamos que os efeitos de rotação da elipse não deveriam ser disntinguíveis para frequências de modulação que obedeçam ao limite

$\frac{\Delta \delta}{\Omega} \geqslant \sqrt{2} \Rightarrow \Omega>\geqslant 4,8 \mathrm{MHz}$.

Esse valor é compatível com as figuras obtidas, uma vez que para $\Omega=5 \mathrm{MHz}$ já podemos perceber a existência de dois picos sobrepostos. Para as frequências de modulação maiores os picos passam a ser mais separados, embora não tão bem resolvidos.

Concluímos, com essa análise, que o ruído quântico do titânio-safira, como esperado, é muito inferior ao dos lasers de diodo que atualmente utilizamos nos OPO's e na armadilha de rubídio, que chegam a ser 2000 vezes o valor do shot-noise. 


\section{Capítulo 6}

\section{Conclusões e Perspectivas}

Durante este trabalho foi construído e caracterizado um laser de titânio-safira para ser utilizado como fonte de luz coerente em experimentos diversos.

Durante a caracterização do laser construído, com relação a sua potência de saída, observamos uma queda exponencial com o tempo, a partir do momento em que ele era ligado até cerca de 70 minutos depois, quando, ao realinhar a cavidade, conseguíamos por volta de $90 \%$ da potência inicial. Acreditamos que tal queda é consequência do aumento de temperatura do cristal devido à alta potência do laser intracavidade e que se estabiliza com o tempo.

Para os dois regimes da cavidade, antes e depois da potência estabilizar, levantamos um gráfico da potência de saída do titânio-safira em relação à potência de bombeio, através do qual pudemos medir a eficiência quântica do laser e a potência de limiar, tendo obtido $\eta_{Q}^{f}=51,0(7) \%$ e $W_{\mathrm{th}}^{f}=2,32(7) W$ para a cavidade "fria" e $\eta_{Q}^{q}=49,3(7) \%$ e $W_{\mathrm{th}}^{q}=2,45(6) W$ para a cavidade "quente". Com base nesses valores, estimamos as perdas espúrias da cavidade em cada caso como sendo $L^{f}=2,12(7) \%$ e $L^{q}=2,29(8) \%$, e, porfim, dadas tais perdas, qual seria a transmissão ideal para o espelho de saída do laser, operando com um bombeio de $5 W$, e chegamos a $T_{\text {ideal }}^{f}=$ $2,78(10) \%$ e $T_{\text {ideal }}^{q}=2,65(9) \%$, respectivamente.

Verificamos que o laser estava livre de astigmatismo e realizamos espectroscopia de absorção saturada em átomos de rubídio, que permitiu que estimássemos a largura de linha do laser como sendo inferior a $0,6 \mathrm{MHz}$, e a variação da frequência do laser com o tempo como sendo 10,35(81)MHz/minuto. Para diminuir esse drift estamos estudando a possibilidade de criarmos um sistema de controle de temperatura para a cavidade de análise.

Por último caracterizamos as propriedades quânticas do laser, observando que o mesmo produz luz no estado coerente para frequências de análise superiores a $10 \mathrm{MHz}$ e abaixo disso há excesso de ruído de fase.

O baixo ruído do titânio-safira permite que se prossiga com os estudos de emaranhamento e comunicação entre átomos de rubídio e outros sistemas. Para tanto está em andamento a construção de um oscilador paramétrico ótico bombeado pelo laser construído.

Outras perspectivas futuras são a utilização do titânio-safira em uma armadilha magneto-ótica e a tentativa de se gerar compressão de ruído no regime de mistura de quatro ondas. 



\section{Bibliografia}

[1] F. E. R. Campolim, Resfriamento e Aprisionamento Magneto-Ótico de Átomos de Rubídio. Dissertação de Mestrado, Universidade de São Paulo, 2001.

[2] A. S. Villar, Estudo de Enaranhamento no Oscilador Paramétrico Ótico Não-Degenerado Acima do Limiar. Dissertação de Mestrado, Universidade de São Paulo, 2004.

[3] A. S. Villar, Emaranhamento Multicolor entre Feixes Intensos de Luz. Dissertação de Doutorado, Universidade de São Paulo, 2007.

[4] J. E. S. César, Excesso de Ruído no Oscilador Paramétrico Ótico. Dissertação de Mestrado, Universidade de São Paulo, 2008.

[5] J. E. S. César, A. S. Coelho, K. N. Cassemiro, A. S. Villar, M. Lassen, P. Nussenzveig, and M. Martinelli, "Extra phase noise from thermal fluctuations in nonlinear optical crystals," Phys. Rev. A, vol. 79, 2009.

[6] A. S. Coelho, Emaranhamento Tripartite no Oscilador Paramétrico Ótico. Dissertação de Mestrado, Universidade de São Paulo, 2009.

[7] A. S. Coelho, F. A. S. Barbosa, K. N. Cassemiro, A. S. Villar, M. Martinelli, and P. Nussenzveig, "Three-color entanglement," Science, vol. 326, pp. 823-826, 2009.

[8] F. A. S. Barbosa, A. S. Coelho, A. J. De Faria, K. N. Cassemiro, A. S. Villar, P. Nussenzveig, and M. Martinelli, "Robustness of bipartite gaussian entangled beams propagating in lossy channels," Nature Photonics, vol. 4, pp. 858-861, 2010.

[9] F. A. S. Barbosa, A. J. De Faria, A. S. Coelho, K. N. Cassemiro, A. S. Villar, P. Nussenzveig, and M. Martinelli, "Disentanglement in bipartite continuous-variable systems," Phys. Rev. $A$, vol. 84, 2011.

[10] J. O. Haroldo, Projeto e Construção de um Laser de Ti:Safira Contínuo, Sintonizável, com Frequência Única e Estabilizada à uma Cavidade Externa de Referência. Dissertação de Mestrado, Universidade Estadual de Campinas, 2009.

[11] W. Feng, L. Lin, W. Wang, R. Li, and Z. Xu, "100-mhz multi-terawatt femtosecond ti: Sapphire laser with a regenerative amplifier," Chinese Optics Letters, vol. 5, no. 101, 2007.

[12] A. E. Siegman, Lasers. University Science Books, 5 ed., 1986.

[13] O. Svelto and D. C. Hanna, Principles Of Lasers. Springer, 5 ed., 2010.

[14] C. E. Webb and J. D. C. Jones, Principles, vol. 1 of Handbook of Laser Technology and Application. Institute of Physics, 1 ed., 2003.

[15] Lasers And Masers. Encyclopedia of Physical Science And Technology, CRC Press, 3 ed., 1982.

[16] H. J. Metcalf and P. V. D. Straten, Laser Cooling And Trapping. Springer, rev. ed., 1999.

[17] C. Cohen-Tannoudji, J. Dupont-Roc, and G. Grynberg, Atom-Photon Interactions: basic processes and applications. Wiley, 1992.

[18] C. Cohen-Tannoudji, J. Dupont-Roc, and G. Grynberg, Photons And Atoms: introduction to quantum electrodynamics. Wiley, 1989.

[19] W. G. Nagourney, Quantum Electronics For Atomic Physics. Oxford Graduate Texts, Oxford University Press, 2010. 
[20] P. F. Moulton, "Spectroscopic and laser characteristics of ti:al2o3," J. Opt. Soc. Am. B, vol. 3, no. 1, pp. 125-133, 1986.

[21] K. WALL and A. Sanchez, "Titanium sapphire lasers," The Lincoln Laboratory Journal, vol. 3, no. 3, pp. 447-462, 1990.

[22] P. Albers, E. Stark, and G. Huber, "Continuous-wave laser operation and quantum efficiency of titanium-doped sapphire," JOSA B, vol. 3, no. 1, pp. 134-139, 1986.

[23] G. S. Kruglik, G. A. Skripko, A. P. Shkadarevich, N. V. Kondratyuk, V. S. Urbanovich, and P. N. Nazarenko, "Output of al2o3:ti3+ crystal in the continuous and quasicontinuous regimes," J. App. Spectroscopy, vol. 45, no. 4, pp. 1031-1036, 1986.

[24] A. Sanchez, R. E. Fahey, A. J. Strauss, and R. L. Aggarwal, "Room-temperature continuouswave operation of a ti: Al2o3 laser," Optics Letters, vol. 11, no. 6, pp. 363-364, 1986.

[25] A. Einstein, "Strahlungs-emission und -absorption nach der quantentheorie," Verhandlungen der Deutschen Physikalischen Gesellschaft, vol. 18, pp. 318-323, 1916.

[26] A. F. R. D. T. Piza, Mecânica Quântica, vol. 51. EdUSP, 2003.

[27] W. Koechner, Solid-State Laser Engineering. Springer Series In Optical Sciences ; 1 , Springer, 6th rev. and updated ed., 2006.

[28] C. E. Webb, , and J. D. C. Jones, Laser Design and Systems, vol. 2 of Handbook of Laser Technology and Application. Institute of Physics, 1 ed., 2003.

[29] M. J. Webber, Handbook of Lasers. Handbook of Laser Technology and Application, CRC Press, 2001.

[30] A. Lipson and S. G. Lipson, Optical Physics. Cambridge University Press, 4 ed., 2010.

[31] G. Grynberg, A. Aspect, C. Fabre, and C. Cohen-Tannoudji, Introduction To Quantum Optics. Cambrige University Press, 2010.

[32] A. Yariv, Optical Electronics. The Holt, Rinehart, And Winston Series In Electrical Engineering, Saunders College Pub., 4 ed., 1991.

[33] D. J. Griffiths, Introduction To Electrodynamics. Pearson Education, 4, rev. ed., 2012.

[34] M. Born and E. Wolf, Principles Of Optics. Cambridge University Press, 7, exp. ed., 1999.

[35] P. Hillion and H. F. Harmuth, "Remark on harmuth's correction of maxwell's equations for signals. i'[and response]," Electromagnetic Compatibility, IEEE Transactions On, vol. 33, no. 2, pp. 144-145, 1991.

[36] Y. Senatsky, J. F. Bisson, J. Li, A. Shirakawa, M. Thirugnanasambandam, and K. Ueda, "Laguerre-gaussian modes selection in diode-pumped solid-state lasers," Optical Review, vol. 19, no. 4, pp. 201-221, 2012.

[37] E. Hecht, Optics. Addison-Wesley, 4 ed., 2002.

[38] H. Kogelnik, "Astigmatically compensated cavities for cw dye lasers," IEEE J. Quant. elect, vol. 8, no. 3, pp. 373-379, 1972.

[39] W. Johnston and P. Runge, "An improved astigmatically compensated resonator for cw dye lasers," IEEE J. Quant. elect, vol. 8, no. 8, pp. 724-725, 1972.

[40] J. M. Yarborough and J. Hobart., "Conference on laser engineering and applications," (Washington D.C.), IEEE/OSA Conference On Laser Engineering And Applications, 1973.

[41] S. Zhu, "Birefringent filter with tilted optic axis for tuning dye lasers: Theory and design," Applied Optics, vol. 29, no. 3, pp. 410-415, 1990.

[42] X. Wang and J. Yao, "Transmitted and tuning characteristics of birefringent filters," Applied Optics, vol. 31, no. 22, pp. 4505-4508, 1992.

[43] L. Mandel and E. Wolf, Optical Coherence And Quantum Optics. Cambridge University Press, 1995. 
[44] M. O. Scully and M. S. Zubairy, Quantum Optics. Cambridge University Press, 1997.

[45] D. F. Walls and G. J. Milburn, Quantum Optics. Springer-Verlag, 2 ed., 2008.

[46] H. A. Bachor and T. C. Ralph, Guide To Experiments In Quantum Optics, A. Physics Textbook, Wiley-VCH, 2nd, rev. and enl. ed., 2004.

[47] F. A. S. Barbosa, Flutuações do Campo Eletromagnético no Regime de Transparência Eletromagnética Induzida. Dissertação de Mestrado, Universidade de São Paulo, 2009. 